OCCUPATIONAL SEGREGATION BY SEX

by

DAVID DONALD SGHRECK

B.A., Grinnell College, 1969

A THESIS SUBMITTED IN PARTIAL FULFILLMENT OF THE REQUIREMENTS FOR THE DEGREE OF DOCTOR OF PHILOSOPHY

in

THE FACULTY OF GRADUATE STUDIES

(Department of Economics)

We accept this thesis as conforming to the required standard

THE UNIVERSITY OF BRITISH COLUMBIA

June, 1978

(C) David Donald Schreok, 1978 
In presenting this thesis in partial fulfilment of the requirements for an advanced degree at the University of British Columbia, I agree that the Library shall make it freely available for reference and study. I further agree that pemission for extensive copying of this thesis for scholarly purposes may be granted by the Head of my Department or by his representatives. It is understood that copying or publication of this thesis for financial gain shall not be allowed without my written permission.

Department of Economics

The University of British Columbia 2075 Wesbrook Place Vancouver, Canada V6T 1 W5

Date April 4, 1978 
This thesis is an attempt to describe and explain occupational segregation by sex as evidenced by 1961 Canadian census data.

Previous writers discussed the ethical question of whether men and women should be occupationally segregated or whether they should receive equal pay for equal work. This literature is reviewed. Irrespective of ethical issues, if men and women are equally productive but unequally paid, why should a profit maximizing firm hire any but the cheapest labour? This problem is known as Cassel's paradox. Previous attempts to resolve Cassel's paradox included the use of simple supply and demand models, barriers to competition, theories of monopsony, human capital theory and adjustments for quality differences. These approaches are criticized and alternative concepts of discrimination are reviewed. For the purpose of the thesis, statistical discrimination is defined as a situation in which employers draw inferences about productivity from unalterable attributes of individuals even though the attributes are not correlated with productivity.

A model of occupational segregation by sex is developed that permits analysis of statistical discrimination. Employers are assumed to hire labour under uncertainty as to its qualifications. Hiring is assumed to involve a cost. Each occupation is characterized by the traits required to perform in the occupation. The probability that a person is qualified for an occupation is assumed to depend on the traits required for the occupation and the person's sex. From 
these assumptions the derived demand for the male-female employment ratio by occupation is determined as a function of employer investment, male and female wages, and the required traits. Statistical discrimination is said to be indicated if a trait is significantly related to the male-female employment ratio and yet there is no significant difference in its distribution by sex.

A correlation coefficient of 0.78 is found in a relation between the logarithm of the male-female employment ratio and thirteen independent variables including a proxy for employer investment, the wage ratio, the male-female education ratio and ten traits. The education ratio, included in the regression analysis to adjust for quality differences, has the greatest impact of any variable. Its negative coefficient is opposite in sign to what was expected. It is possible that the negative education coefficient indicates discrimination. Data was not available for the actual distribution by sex for five of the ten traits. Three of the remaining traits, numerical aptitude, spatial aptitude and form aptitude, indicate the presence of statistical discrimination.

The need for further research on how stereotypes affect occupational segregation is suggested by this study. 
Table of Contents

page

Chapter 1: Introduction 1

Notes 4

Chapter 2: Review of the Literature 5

Normative Issues $\quad 5$

Supply and Demand 9

Cassel's Paradox $\quad 14$

Barriers to Competition $\quad 15$

$\begin{array}{ll}\text { Monopsony } & 16\end{array}$

$\begin{array}{ll}\text { Human Capital } & 19\end{array}$

Quality Adjustments 21

Qualified Discrimination 25

Discrimination Coefficients 28

Statistical Discrimination: Signalling 33

Statistical Discrimination: Employer Investment 39

Notes $\quad 44$

Chapter 3: A Model of Occupational Segregation by Sex $\quad 50$

Derived Demand 51

Supply $\quad 57$

Market Glearing $\quad 58$

$\begin{array}{ll}\text { Simplifying Assumptions } & 60\end{array}$

Notes 64

Chapter 4: Construction and Sources of Data 66

Census Data 66

Worker Traits 72 


$$
\text { Table of Contents (continued) }
$$

Chapter 4: Construction and Sources of Data

$\begin{array}{ll}\text { Sample Size } & 84 \\ \text { Notes } & 88\end{array}$

Chapter 5: Results 91

Data Description $\quad 91$

Regression 93

Education 96

Employer Investment 99

Aptitudes 100

Temperaments $\quad 102$

Interests 103

Working Conditions $\quad 104$

Elasticity 105

Discrimination $\quad 108$

Stereotypes 112

Conclusions $\quad 112$

Notes $\quad 114$

Selected Bibliography $\quad 116$

Appendix A: Job Content of Census Occupational Classes 120

Appendix B: Data Base 158

Appendix C: Occupational Code by Occupational Class Title 189 
I Midpoints used to calculate $\overline{W k}_{j i} \quad 69$

II Midpoints used to calculate $\mathrm{H}_{j i} \quad 70$

III Means used to calculate $\mathrm{E}_{j i} \quad 72$

IV Worker Traits 74

V Quantitative Indicators of GDD 76

VI Quantitative Indicators of SVP 77

VII Definitions of Aptitude Factors 77

VIII Quantitative Indicators of Aptitudes 79

IX Definitions of Temperament Factors 79

$X \quad$ Definitions of Interest Factors 81

XI Quantitative Indicators of Strength 82

XII Actual and Expected Number of Occupational Groups by 92 Occupational Division and by Interval of Male-Female Employment Ratio

XIII Estimates of Parameters 95

XIV Means, Standand Deviations and Impact of 96

XV Estimates of Parameters for Measuring Elasticity 107

XVI Median of Difference in Means for Paired Samples of 109 Boys and Girls of General Aptitude Test Battery Scores 
vii

Acknowledgements.

This thesis would not have been completed without the financial assistance I received from the University of British Columbia and from the Canada Council. I appreciate receiving a University of British Columbia Graduate Fellowship for the years 1969-70 and 1970-71. I appreciate receiving a Canada Council Doctoral Fellowship for the years $1971-72$ and $1972-73$. 
Chapter 1: Introduction

The purpose of this study is to describe and explain occupational segregation by sex as evidenced by 1961 Canadian census data.

Many highly emotional issues arise in discussions of women's role in the labour market. Chapter 2 begins by reviewing some of the normative issues that surround the question of whether men and women should be occupationally segregated. Normative issues may be irrelevant to profit maximizing firms. The usefulness for our problem of simple supply and demand models is examined and rejected. A central question in any examination of occupational segregation by sex, Cassel's paradox, is then reviewed. ${ }^{1}$ If the men and women who enter an occupation are equally qualified for employment but unequally paid, why would any profit maximizing firm hire any but the cheapest labour?

Chapter 2 examines a variety of approaches to Cassel's paradox. The possibility of restrictions upon perfect competition as the result of either union activity or cultural norms is discussed. Other approaches include models of monopsony and of differing investment in human capital as well as statistical adjustments that reduce apparent wage differences. None of the approaches is free from criticism. The alternative of discrimination is then examined.

If the profit motive is subordinate to other motivation, Cassel's paradox could be resolved by the presence of discrimination. Consideration of discrimination poses three problems. First, the use of the term discrimination carries with it a negative connotation. 
Opinions vary on whether discriminatory behaviour is in any sense "bad" even though the behaviour satisfied the definition given for discrimination. We must exercise extreme care so as not to allow normative issues to cloud our judgment on whether the criteria of any definition are satisfied by the data we observe. Second, opinions vary on what constitutes discrimination. Three alternative concepts are reviewed in chapter 2. Third, any weakening of the profit motive constitutes an extremely strong assumption. If any single firm is motivated only by profit it can be expected to eliminate its less profit conscious competitors. It is true that economists have considered other motivations for firms, but this has usually involved relaxing the assumption of perfect competition. ${ }^{2}$ An assumption is not necessarily wrong merely because it is strong. We have no trouble accepting that the profit motive is subordinate to statutes such as the criminal code. It is possible that some cultural basis of discrimination is more pervasive than the force of law.

The model that is developed in chapter 3 is based on a simple model of derived demand suggested by Kenneth Arrow's review of models of discrimination. 3 This approach employs a concept of statistical discrimination. In this context statistical discrimination refers to a situation in which employers draw inferences about productivity from unalterable attributes of individuals, e.g. race or sex, even though the attributes are not correlated with productivity in the population.

In chapter 3 Arrow's simple model is extended to consider many different occupations. Each occupation is identified by the quanti- 
tative indicators of factors considered necessary for effective job performance in the occupation, e.g. strength. The model developed in chapter 3 does not restrict the value of the elasticity of substitution between men and women. This is a direct result of the use of Joan Robinson's concept of efficiency labour as a means of aggregating labour inputs. 4 Efficiency labour is the aggregate or output of a process that has male and female labour as its inputs. Chapter 4 describes the data base used in this study and the prom blems presented by the data base. A major difficulty in any study of occupational segregation by sex is to find data on employment and wage rates broken down by sex and occupation. An additional difficulty for this study is to find data on the distribution by sex of quantitative indicators of factors considered necessary for effective job performance.

The model developed in chapter 3 provides the rationale for regressing the male-female employment ratio on the female-male wage ratio and a variety of quantitative indicators considered necessary for effective job performance. Chapter 5 presents the numerical results of this regression analysis. A correlation coefficient of 0.78 is found in the relation between the logarithm of the male-female employment ratio and nine quantitative indicators. We say that the evidence indicates the presence of statistical discrimination if a quantitative indicator is statistically significant in the regression and yet the available evidence shows no difference in the indicator's distribution by sex. No evidence is found on the distribution by sex of five of the indicators. The evidence on three of the remaining four indicators is consistent with the presence of statistical discrimination. 
Chapter 1: Notes

1. Gustav Cassel, The Theory of Social Economy (New York: Harcourt, Brace and Co., 1924), Joseph MacCabe (ed.), p. 315.

2. Joan Robinson, The Economics of Imperfect Competition (London: MacMillian \& Co., Ltd., 1965).

3. Kenneth Arrow, "Some Models of Racial Discrimination in the Labor Market," RAND Corporation research memorandum RM-6253-RC, multilith, Santa Monica, Feb. 1971.

4. Robinson, Op. Cit., p. 332 . 
Chapter 2: Review of the Literature

The forces that determine whether the labour force is occupationally segregated by sex may have little to do with the traditional realm of economic anlysis. The forces that determine interaction between the sexes may dwarf the "invisible hand" of the market. The attitudes that a woman's place is in the home and that a man must be his family's breadwinner may be more powerful. than the profit motive. In any event we begin our analysis of occupational segregation by examining the debate over whether men and women should be occupationally segregated. Normative Issues

The ethical debate pitted proponents of individual rights against pragmatists whose concern focused on the male's responsibility for family support. Positive economic analysis was rare in this debate. The principle of equating wage rates to the value of each sex's marginal product was recognized. However, emotions flared over differing assessments of these marginal products.

John Stuart Mill and Harriet Taylor Mill were among the first writers to argue for the rights of women. In his classic essay, "The Subjection of Women" (1869), J.S. Mill argued for a "principle of perfect equality" with, regard to access to jobs. Mill maintained that women are excluded from many occupations simply "because the generality of the male sex cannot yet tolerate the idea of living with an equal". 2

Later writers were much more pragmatic than Mill in their approach to women's rights. Sidney and Beatrice Webb feared that women 
"blacklegs" would undercut male wages. ${ }^{3}$ The Webbs argued for a policy of equal pay rates between the sexes so as to eliminate female competition. They indicated that, since women were inferior workers (sic), equal wages would lead to occupational segregation as the employers found the male workers more profitable. 4

The widespread employment of women during World War I in traditionally male occupations provided new evidence on women as workers, and reopened the debate on women's rights. Eleanor F. Rathbone argued that "if re-erected they (barriers to female employment) will have to be based frankly upon the desire of the male to protect himself from competition, and no longer upon the alleged incapacity of the female to compete". 5 Rathbone then addressed her arguments to the question of whether "fair competition" between the sexes is passible without "undercutting male standards of pay". 6 She argued that,

If the wages of men and women are really based upon fundamentally different conditions, and if these conditions cannot be changed, then it would seem that fair competition between then is impossible, and that women are the eternal blacklegs, doomed despite themselves to injure the prospects of men whenever they are brought into competition with them... If that were really so, then it would seem as if men were justified in treating women, as in practice they have treated them -- as a kind of industrial lepers, segregated in trades which men have agreed to abandon to them, permitted to occupy themselves in making clothing or in doing domestic service for each other, and in performing those subsidiary processes in the big staple trades, which are so monotonous or unskilled that men do not care to claim them. 7

In the above argument Rathbone maintained that men would not enter the lower paid occupations since they must seek a wage sufficient to support a family. Without the burden of supporting a 
family women would supposedly be able to accept the lower wages. A difference in the minimum wage acceptable to men and women can be interpreted as a difference in the supply curves of male and female labour.

Rathbone concluded her argument by recommending a government financed family support scheme. She maintained that with such a scheme the conditions facing men and women would be sufficiently similar so as to permit men and women to compete with each other. 8 In other words, Rathbone assumed that the male and female labour supply schedules would then become identical.

Like the Webbs Rathbone suggested that female workers may not be as efficient as male workers. Competition in her view would equalize efficiency wages but not absolute wages. She wrote ... any permanent recognized disadvantage that adheres to women workers as such should be allowed for as a pro rata rate reduction in their standard rates. The attempt to establish strict arithmetical equality between them goes further than is necessary to protect men against unfair competition and really weights the scales against the women. 9

In replying to Rathbone's article, Millicent G. Fawcett ignored the central thesis of the responsibility for family support and concentrated on Rathbone's suggestion that women are less efficient than men. Fawcett stated "In reading Miss Rathbone's article I cannot help feeling that she too much disregards the tremendously depressing effect on women's wages of the prewar trade union rules, combined with social use and wont which have kept women out of nearly all the skilled industries". 10 Fawcett went on to argue that "War experience ...has stiffened the conviction of many feminists that a large pro- 
portion of supposed feminine disadvantages exist more in imagination than in reality". 11 Fawcett concluded that "The one chance of women being received into industry by the men already employed as comrades and fellow-workers, not as enemies and blacklegs, is in their standing for the principle, equal pay for equal work, or as it is sometimes expressed, equal pay for equal results". 12

Fawcett's reply to Rathbone serves to illustrate the emotional nature of the debate on equal pay. There is no substantial disagreement between Fawcett and Rathbone. Both maintained that men and women should be paid equal efficiency wages, i.e. wages equal to the value of each sex's marginal product. However, the exchange was provoked by their differing subjective assessments of the relative efficiency of male and female workers.

During World War II women once again moved into traditionally male dominated occupations. Once again worried that female blacklegs would undercut male wages, the male dominated unions joined the feminists in the post war period in a call for legislation to enforce equal pay for equal work. 13 The Trades and Labor Congress of Canada recommended "that the receral and provinclal governments enact legislation to enforce a policy of equal pay for equal work and thus eliminate this competition....14

In 1951, Ontario was the first province in Canada to pass equal pay legislation. The federal government and eight provinces had passed equal pay acts by 1961.15 By 1963, twenty two states had passed equal pay laws in the United States. 16

Pragmatic definitions of equal pay for equal work were necessary 
for the new laws. Employers found that the spirit of the laws could easily be escaped by creating slight variations in the duties of male and female employees. In Canada, from the time the Federal Employees Equal Pay Act was passed in 1956 until December, 1971, only eighteen individuals registered complaints under the federal act. In none of the eighteen cases was the decision favorable to the employee. 17 The principle of equal treatment between the sexes had finally been accepted more than 100 years after the appeals of J.S. Mill, but this legalistic solution's success in establishing an ethical standard can be questioned.

Supply and Demand

Even if men have the additional responsibility of family support why should impersonal market forces respect this responsibility? With the publication of The Economics of Welfare in 1920, Pigou questioned the role of family support. According to Pigou,

In order to understand the matter rightly, analysis is necessary. The common idea is that women are normally paid less than men, because men's wages have, in general, to support a family, while women's wages have only to support the women themselves. This is very superficial. 18

Pigou argued that the employment and wage rates of men and women are determined by supply and demand. He suggested that two demand equations, one for each sex, could be expressed as functions of the wage rates of each sex. By setting supply equal to demand for each sex, wage rates and employment are determined in Pigou's model. He described the equilibrium situation as follows.

Men alone are employed in all occupations where the ratio of their efficiency to women's efficiency exceeds the ratio of their day wages to women's day wages; women alone in all 
occupations in the opposite case; and men and women indifferently in the marginal occupations in which their respective efficiencies bear to one another the same ratio as their respective day wages. In these marginal occupations, that is to say, the efficiency wages of the two sexes are equal. This equality of efficiency wages means, with certain allowances, equality of piece wages. The principal allowances are, first, a small extra for men because, since, at need, they can be put on night-work and can be sworn at more comfortably, it is rather more convenient to employ them; secondly; a small extra to the more skilful workers, whether men or women, because they occupy machinery for a shorter time than less skilful workers in accomplishing a given job. In equilibrium the piece wages paid to the members of the two sexes in the marginal occupations are, with these limitations, equal.19

Pigou noted that the number of "marginal occupations" in which both men and women are employed is small.

Pigou's supply and demand model can be criticized for having no predictive power. Valerie Oppenheimer used a model like this in her analysis of the increase in female labour force participation rates in the United States. 20 Oppenheimer argued that the demand for workers tends to be sex-specific. 21 Taking the occupational composition of each industry as constant, she argued that the changing composition of demand for final goods among industries, especially the increased demand for services relative to goods, resulted in an increased demand for specifically female labour. She then argued that since the traditional unmarried female labour force could not satisfy the demand, married women responded by entering the labour force.

Noah $M$. Meltz also used a model in which he assumed the existence of national labour markets with separate supply and demand schedules for each occupation for his work on occupational shifts in the Canadian labour force. ${ }^{22}$ He attempted to determine whether 
changes in an occupation's proportion of the labour force were primarily due to shifts in demand schedules or supply schedules by examining how the earnings in each occupation changed relative to the average of all occupations given the change in the occupation's share of the labour force. Meltz did not make the rather strong assertion of Oppenheimer that most jobs are sex-typed. Meltz was clearly aware, however, that some occupations have a large proportion of women. He paid particular attention to female labour force behaviour when he discussed changes in clerical and service occupations, the only census occupational groups containing more women than men. 23 When attempting to explain why a large proportion of the increase in the female labour force chose clerical occupations between 1931 and 1961, he argued that males and females are good substitutes in clerical work. Since women's wages were less than men's wages, he concluded that the demand for clerical workers was directed towards women. Meltz went on to argue that with the shift in demand from male to female clerical workers the male-female earnings differential in clerical occupations would be expected to narrow. When he found that the earnings differential did not narrow, the prediction's failure was attributed to the large increase in the supply of female clerical workers which acted to depress female wages. 24 The reason why women were attracted to clerical work, according to Meltz, was that female wage rate differentials between occupations were such as to shift new entrants to the labour force from service occupations to clerical occupations.25 
The supply and demand model was used as a filing system by both Oppenheimer and Meltz. Oppenheimer did not ask whether the increase in female labour force participation rates could be explained by the occupational supply and demand model. Rather she asked which force, supply or demand, played the greatest role in generating the increased female labour force participation. Similarly, Meltz accepted the supply and demand model and asked which force, supply or demand, was responsible for the change in each occupation's share of the labour force.

"Supply and demand" is not a very satisfactory answer to the question of what determines occupational segregation by sex and male-female wage differentials. At the very least this answer should be accompanied by a comparison of how supply and demand differ by sex. Unfortunately, there has been no successful empirical attempt to specify a complete model of labour markets along the lines outlined here. Given current data limitations, such a model is not likely to be estimated in the near future. Furthermore, the conceptual problems inherent in the supply and demand model are even more severe than the data Iinitations. The short run situations that are observed are disequilibrium situations in which unemployment exists and in which individuals search for jobs in several labour markets simultaneously. The usefulness of the traditional concept of labour supply for each market is questionable in this situation.

Pigou commented on male-female wage differentials when equilibrium in an occupational labour market is not attained. He dis- 
cussed the case where the efficiency wage paid to women is less than the efficiency wage paid to men but equal to the wage women could earn elsewhere. Pigou maintained that women's wages should not be increased in such cases since the disequilibrium provides an incentive for employers to break down traditions and hire women. 26 Furthermore, Pigou argued:

... since, ex hypothesi, they are more efficient, relatively to men, in these occupations than they are in marginal occupations common to both sexes, their entry would necessarily be beneficial to the national dividend. Hence, generally speaking, interference designed to enforce the payment to them of a 'fair' wage, as compared with the wages paid to men in circumstances when this means an unfairly high wage as compared with women's wages elsewhere, would injure the national dividend. 27

Pigou's argument seems to assume that an equilibrium will always be reached in which men and women are equally paid for equal work. Pigou argued that interference to enforce equal pay for equal work would remove the incentives to reach an equilibrium in which such interference would not be necessary.

Pigou's faith that markets will reach equilibrium may not be warranted. There is merit in the old platitude that the only thing that is constant is change. For growth theorists we might add that even change does not change at a constant rate. These commonplace observations are relevant to our problem of examining occupational segregation by sex as evidenced by 1961 census data. It is reasonable to assume that at any point in time we observe a state of disequilibrium.

While rejecting the usefulness of simple supply and demand models as described by Pigou we have not yet explained why we should 
consider anything other than some form of impersonal market forces. The inconsistency of assuming the existence of both a powerful profit motive and male-female wage differentials while observing anything other than complete occupational segregation by sex is known as Cassel's paradox. 28

\section{Cassel's Paradox}

With the publication of The Theory of Social Economy, Gustav Cassel appeared to argue that impersonal market forces would dominate any ethical debate. Cassel wrote,

But when it is said that it is unjust to pay female labour less than male, it is not clear why the employer who employs both kinds of labour together does not increasingly substitute the cheaper female labour for the dearer male labour. There you have the heart of the question. If the employer - and we must assume that he acts from a purely business point of view -- does not do this, we must conclude that he puts a higher value on the male labour for some reason or other, in spite of the supposed equal work. Practice does not recognize the equality of work that is affirmed by theorists. In the actual demand there is a very definite distinction between male and female labour, and that is the decisive factor. 29

Cassel did not refer to this statement as a paradox. In order to consider the statement to be a paradox it it necessary to accept four conditions as existing simultaneously. The four conditions are profit maximization, perfect competition, less than complete segregation, and unequal efficiency wages for the sexes. Cassel maintained "The rule is that men and women do different kinds of work in the same trade, and so get different wages. "30 The existence of complete segregation (doing "different kinds of work") would mean that there is no paradox. Cassel did go on to discuss the case of less than complete segregation when he wrote, 
Even when employment seems externally to be much the same, the demand turns for various reasons, to a certain extent, to male labour. There are certainly many solid reasons for this differentiation; though, objectively considered, they need not be reas onable. 31

While Cassel mentioned the possibility of demand turning to male labour for "unreasonable reasons" he went on to offer a warning. He warned that "Until we have examined and tested" all explanations "we must not jump at the theory that female labour is generally 'underpaid' relatively to male labour." 32 In the remainder of this chapter we will examine alternative explanations for occupational segregation and wage differentials. Barriers to Competition

In his 1922 Economic Journal article F.Y. Edgeworth questioned the condition of perfect competition. Edgeworth wrote "There is much force in Professor Cassel's argument; and his conclusion would be perfectly true if the implied premise, the existence of perfect competition, were true."33 Like Fawcett, ${ }^{34}$ Edgeworth argued that "The pressure of male trade unions appears to be largely responsible for that crowding of women into a comparatively few occupations, which is universally recognized as a main factor in the depression of their wages." 35

Edgeworth's argument can be termed the overcrowding hypothesis. 36 If labour supply were reduced by institutional restrictions for male dominated occupations while supply were increased for female occupations greater wage differences by sex would result. It is not so clear, however, why Edgeworth attributes these restrictions to unions. It is possible that other forces determine occupational segregation 
by sex and that the resulting male occupations are more easily organized by unions. The presence of unions might add to malefemale wage differences given segregation, but it does not follow that unions cause occupational segregation.

Cultural norms could provide barriers to competition with the same consequences as those attributed by Edgeworth to unions. In his 1954 study of the sociology of work. Theodore Caplow included a chapter on the occupational segregation of women in the United states. 37 Caplow argued that two specifically sociological factors are necessary to explain female occupational segregation.

Women are barred from four out of every five occupational functions not because of incapacity or technical unsuitability, but because the attitudes that govern interpersonal relationships in our culture sanction only a few working relationships between men and women, and prohibit all the others on grounds that have nothing to do with technology ...

There are two themes: (1) that it is disgraceful for a man to be directly subordinated to a woman, except in family or sexual relationships; (2) that intimate groups, except those based on family or sexual ties, should be composed of either sex but never of both. 38

Caplow concluded by arguing that the same forces which produce occupational segregation also act to prevent women from organizing so as to improve their status. 39 While we cannot dismiss the importance of cultural norms we must consider their conflict with the profit motive and the resulting paradox posed by Cassel. The book jacket to the paperback edition of Caplow's work refers to it as a sourcebook of hypotheses. Unfortunately, they are untested hypotheses.

Monopsony

P. Sargent Florence challenged Edgeworth's argument that the 
main reason why women's efficiency wages are lower than men's is that male trade unions crowd women into "comparatively few occupations". 40 Using 1921 census data for England and Wales, Florence attempted to estimate the number of women available for employment. He argued that the female labour supply schedule has a low flat portion and then rises steeply. Florence concluded as follows:

The fundamental factor is thus the women's supply-price curve, and this probably rises steeply after a certain amount of 'self-low-priced' labour has been absorbed. Taken in conjunction with elements of unilateral monopoly, indivisibility and immobility in the women's labour market, it is this peculiar supply-price curve that explains, in my view, Cassel's paradox of women's nonsubstitution for men in spite of their apparent better value for money. 41

Florence's argument was later expressed more clearly at a theoretical level by Joan Robinson. Robinson demonstrated that a monopsonistic firm that faces separate labour supply curves for men and women will minimize cost by hiring each sex to the point where the marginal cost of labour for each sex is equal to the value of the marginal product for each sex. Consequently, even if men and women are equally productive, male wages will exceed female wages in this model if the elasticity of supply for males exceeds the elasticity of supply for females. ${ }^{42}$ Recently Edmund S. Phelps 43 and Dale T. Mortensen ${ }^{44}$ have introduced a concept termed "dynamic monopsony power". An individual firm is said to have dynamic monopsony power when it must increase its offered wage rate in order to attract labour faster than other firms. Dynamic monopsony power does not depend on the properties of labour supply schedules as does monopsony power in the sense used by Robinson. In the long run the firms modeled by Phelps and Mortensen face perfectly elastic 
labour supply schedules. In the short run a firm must pay a higher price if it is in a hurry. While this is a useful concept for dynamic models it is not helpful for examining male-female wage differentials.

The traditional concept of monopsony power used by Florence and Robinson is not a persuasive explanation of male-female wage differentials for three reasons. First, it is difficult to believe that the model would apply to anything more than small isolated labour markets like company towns. It seems doubtful that monopsonistic conditions exist in the large urban areas where most people are employed. Florence took the existence of monopsonistic conditions for granted. Second, the theory calls for a clear concept of a labour supply schedule for each occupation. The usefulness of traditional concepts of labour supply schedules for each occupation may be questioned. Certainly, in the short run, what is actually observed is a disequilibrium situation with unemployment and with individuals searching for jobs in several occupational labour markets simultaneously. Florence did not attempt to quantify occupational labour supply schedules. He merely attempted to estimate the proportion of women in the total population that might be available as workers. Even if such schedules exist there is no reason for assuming that the elasticity for males will exceed the elasticity for females. Although the male breadwinner role may imply a greater elasticity the same role may encourage organization to limit the elasticity and increase wages. Third, in order for the theory to be empirically useful an operational definition of the concept of 
monopsony is needed. The search for such a definition may be subjected to all the criticisms that have been applied to operational definitions of monopoly. 45 In particular it is necessary to define the extent of the market. A particular job title may be unique to an individual firm. This does not mean that the firm is a monopsonist with respect to that job title. The appropriate labour supply schedule might pertain to an entire occupational class that includes the job title unique to one firm. Human Capital

Cassel's paradox might be explained by relaxing the assumption of equal productivity for the two sexes. Jacob Mincer has offered the following speculation on whether human capital investment decisions by the employee affect occupational segregation.

Some of the differences between earnings distributions of males and females are explainable by the effects of labour supply behavior on human capital investment decisions. Individuals who expect to spend only a part of their adult lives in the labour force have weaker incentives to invest in forms of human capital which primarly enhance market productivities than persons whose expected labor force attachment is permanent. Women are likely to invest less than men in vocational aspects of education and particularly in on-the-job training.

Interpretation of Mincer's speculation is dependent on what constitutes "weaker incentives to invest". The basis of his statement is that if a given investment in human capital increases hourly earnings by the same amount for men and women, it will increase life-time earnings of an average woman by a smaller absolute amount than the life-time earnings of an average man. Mincer might mean that this lower rate of return on a fixed investment is a weaker 
incentive for women to invest. Or he could mean that if the utility of a given absolute increase in life-time earnings is the same for both sexes, there will be a lower incentive to invest for women. However, our problem of labour supply behaviour is not simply the determination of how much education or training is purchased by men and women. It is, how do men and women choose between hundreds of different occupations. Therefore, Mincer's reference to incentives might refer to comparisons between occupations. In comparing occupations that require a high investment with occupations that require a lower investment, a man might have more incentive to invest than a woman. This does not indicate how a woman would behave relative to other women.

When determining their labour supply, women would compare the expected present value of the income streams of different occupations open to women. Mincer implies that women might be unwilling to forgo present earnings in order to invest in on-the-job training since they will not be in the labour force long enough to collect the greater but postponed earnings. By contrast, for the same investment, the present value of male earnings would be greater than female earnings since men expect to be in the labour force longer than women. However, the present value of male earnings is not relevant to a woman's decision to enter an occupation. What is relevant is the present value of the earning streams from other occupations that the woman would consider. For these alternative occupations, it might again be true that discounted female earnings are less than discounted male earnings. Let $M_{T}\left(F_{T}\right)$ be the present 
value for males (females) of the income stream from an occupation that requires on-the-job training. Let $M(F)$ be the present value for males (females) of the income stream from an occupation that does not require on-the-job training. Then, it is possible that $\mathrm{M}_{\mathrm{T}} / \mathrm{M}=\mathrm{F}_{\mathrm{T}} / \mathrm{F}$. In this case, it is possible that women are equally as Iikely as men to invest in on-the-job training. Mincer's conclusion that women are less likely to invest appears to depend on "incentive to invest" referring to a comparison of the rate of return or the utility of an income stream between the sexes rather than referring to a comparison of alternative occupations for each sex.

\section{Quality Adjustments}

If sex differences in education and training are not sufficient to resolve Cassel's paradox perhaps other sex differences might. Several studies have attempted to measure male-female wage differentials while adjusting for factors that might affect productivity. This approach takes occupational segregation as a given; however, Cassel's paradox would be resolved if it could be shown that wage differences by sex are due to differences in productivity.

In 1964, Henry Sanborn made an attempt to quantify male-female wage differentials while compensating for differences between the sexes that might affect productivity. Sanborn constructed indices of the ratio of female to male wage and salary income. A Paasche index of the form $\left(\Sigma Q_{f} Y_{f}\right) /\left(\Sigma Q_{f} Y_{m}\right)$ and a Laspeyres index of the form $\left(\Sigma Q_{m} Y_{f}\right) /\left(\Sigma Q_{m} Y_{m}\right)$ were constructed. 47 summation is over census occupations. $Q_{f}\left(Q_{m}\right)$ is the number of women (men) in an occupation. 
$Y_{f}\left(Y_{m}\right)$ is the median annual wage and salary income for women (men) in the occupation. Sanborn found, using 1950 U.S. census data, that the unadjusted ratio of median female to median male wage and salary income was 0.58 . Adjusting for occupational distribution through the construction of the indices, Sanborn found a ratio of 0.64 for the Paasche index and a ratio of 0.66 for the Laspeyres index. By taking the ratio of his indices to the aggregate ratio $(0.58)$ he argued that 10.3 to 13.8 per cent of the aggregate malefemale wage differential could be explained by observing that men occupy the higher paid occupations. Sanborn then adjusted his indices for differences between the sexes in hours worked, education, age, urbanness, and race. The adjustment consisted of multiplying the female wage in each occupation by an adjustment ratio for the occupation. For example, the adjustment ratio for hours worked consisted of the ratio of hours worked by men to hours worked by women. $^{48}$ After adjusting for the factors listed above, Sanborn found a female-male wage ratio for the Paasche index of 0.75 and for the Laspeyres index of 0.76 . The census data were based on 262 occupations. Using Bureau of Labor Statistics' data that provided more occupational classifications than those of the census for operatives and clerical workers, Sanborn further recalculated the ratios as 0.81 and $0.82 .^{49}$ Sanborn went on to argue that sex differences in terms of turnover, absenteeism and work experience further reduce the wage ratio so that "discrimination against women, if it exists at all, is under 10 percent". 50

Not only did Sanborn discount the importance of discrimination, 
but he also argued that discrimination must be on the part of consumers and fellow workers. Finding that his ratios, when calculated by broad occupation groups, were not all equal, he argued that employers could not be discriminating because they would discriminate equally across all occupations. 51 This assertion will be challenged in the theory that is developed below.

Sanborn accepted the occupational distribution of men and women as given. Throughout the literature on occupational segregation and male-female wage differentials, writers have recognized that the phenomena are determined by many of the same factors. Given the interrelatedness of occupational segregation and male-female wage differentials, Sanborn's procedure of adjustment for hours of work, education, age and other factors is questionable. An attempt should have been made to adjust the occupational distributions of men and women for these factors.

Sylvia Ostry calculated Sanborn's indices using 1961 Census of Canada data. 52 Ostry used mean rather than median incomes for the indices. The unadjusted ratios of female to male wage and salary income were 54.2 per cent for all wage earners and 59.3 per cent for full year wage earners. When both annual hours worked and occupational distribution were considered, the Paasche index was 67.2 per cent, and the Laspeyres index was 65.6 per cent. After also adjusting for age and education in a manner similar to Sanborn, the indices were 85.0 and 77.5. Unlike Sanborn, Ostry did not attempt any conjectures regarding her calculations.

An alternative method of measuring male-female wage differentials 
while adjusting for factors that might affect productivity was applied by Gideon Rosenbluth and R.A. Holmes in their study of academic salaries in Canada. 53 They postulated that academic salaries could be expressed as a linear function of a number of components including region, university size, control of the university (church, state), rank, field, highest degree obtained, and age. Separate regression equations were calculated for each sex using data for virtually all academic personnel in Canada for the academic years 1962/63 and 1965/66. Using the regression equations, male-female wage differentials were calculated while the independent variables in the regression had the same values for both sexes. They found that, When all other factors except rank are standardized the average female earned $\$ 2,100$ less than the average male. For corresponding ranks, the female differential was on the average $\$ 1,200^{n} .54$

The Rosenbluth-Holmes study was recently replicated by the Women's Action Group at the University of British Columbia. The Group used data pertaining to U.B.C. academic personnel for the academic year 1971/72. They found that when all factors other than rank are standardized the average female earned $\$ 3,071$ less than the average male. For corresponding ranks, the female differential was on the average $\$ 1,740.55$

Hartley Lewis has provided an attempt to isolate the influence of a factor, that was not considered in the studies mentioned above, on male-female wage differentials. Lewis estimated that for U.S. manufacturing in 1959, differences in labour turnover costs explain 
no more than ten per cent of the male-female wage differential. Lewis arrived at this estimate through a two-stage procedure. Using individual data for each of twenty two industries, he regressed wage rates on a host of demographic variables plus a dummy variable for sex. Lewis considered the regression coefficients on the dummy variable for sex to be a measure of the male-female wage differential in each industry. He then further used the twenty two sex coefficients by regressing them on the male-female labour turnover differential in each industry. The regression coefficient of this stage was interpreted as a measure of the proportion of the aggregate male-female wage differential due to the differential in turnover. 56 The studies reviewed above indicate that even when differences between men and women are taken into account women earn less than men. of course, it is possible that the researchers simply did not consider enough of the differences between men and women. An alternative conclusion is that women are paid less than men even when productivity differences are considered. If this conclusion is correct, we are left with Cassel's paradox. Why is it that omployers do not simply hire the cheaper but equally efficient female labour and thereby increase profits (reduce costs)? Qualified Discrimination

Kathleen Archibald conducted an empirical analysis of sex discrimination in hiring practices. Archibald recognized the problem of defining discrimination when she stated "Discrimination may be defined in a number of ways, but it always refers to impairing the opportunity of individuals solely on the basis of their nembership 
in a particular group". 57 We will refer to discrimination, in the sense used by Archibald, as qualified discrimination. When discussing Archibald's use of the term "discrimination" we must add the qualification "with respect to $x$ ", where $x$ is the attribute that defines the group. The normative issues mentioned above may pose a problem when we discuss discrimination with respect to sex. They might be more (or less) of a problem if we were to discuss discrimination with respect to height in the selection of basketball players.

As part of her study of women in the Canadian public service, Archibald conducted a selection experiment. In the experiment, 120 volunteer raters were asked to rank and rate five job candidates. The volunteer raters were participants in Public Service Commission training courses. Each rater was given the same five career resumes. Two of the resumes, say $A$ and $B$, were constructed so that they would be likely to rank first and second respectively. Male names were assigned to four of the resumes. A female name was always assigned to one of the best two resumes but not always the same one. In analyzing the results from the 117 raters who completed the experiment, Archibald reported "... it was found that when Male A competed against Female B, he was at the top of the eligibility list 86 per cent of the time, but when Female A competed against Male B, she was at the top only 58 per cent of the time". 58 These results are statistically significant at the level of 0.005 when a Chi-squared statistic is computed. 59 Kathleen Archibald drew the following conclusion from her experiment. 
In this experiment, a man had a considerably greatex chance of coming out on top of the eligibility list than did a woman of precisely equal ability and experience. Discrimination against women, whether conscious or unconscious, did affect the candidate evaluations made by this group of subjects. 60

Two similar experiments have been conducted in the United States in an attempt to analyze sex discrimination in academic hiring practices. I.S. Fidell asked the heads of psychology departments in the United States to respond to the desirability of each of ten candidates. Four of the ten hypothetical candidates were given female names. In analyzing the 155 forms that were returned (68 per cent of those sent), Fidell reported, "Clear sex differences were obtained in response to the question, at what level should this candidate be offered a position?"61 The possible levels ranged froll full professor to lecturer. In comparing the distributions of men and women among the ranks at which heads said they would be hired, Fidell reported that the probability that the two distributions were the same was less than 0.01 on the basis of the Komolgorov-Smirnov test of the similarity of two distributions. 62 Fidell reported that "... the modal level of offer for women was assistant professor, while for men it was associate professor". 63 Arie Y. Lewin and Linda Duchan conducted a similar experiment in their analysis of the hiring decision in departments of physical science in the United States. While their results were not statistically significant, they reported, "Comparison of responses to the varying quality resumes yielded results which showed a definite tendency for the chairman to prefer an average male over an average female, but to recognize a superior woman". 64 
The studies cited above clearly suggest that occupational segregation by sex be determined at least in part by discrimination with respect to sex. In order to apply Archibald's definition of discrimination in the above studies it was necessary to observe the qualifications of hypothetical individuals. Our problem is to describe and explain occupational segregation as evidenced by 1961 census data. A definition of discrimination and a methodology that depend on assessing individuals are not directly applicable to our problem. Alternative concepts of discrimination can be applied to census aggregates.

Discrimination Coefficients

The concept of a discrimination coefficient is the basis of Gary Becker's theory of discrimination. In the passage quoted below, Becker defined the concept as it applies to the types of discrimination that he considered.

By using the concept of a discrimination coefficient, it is possible to give a definition of a 'taste for discrimination' that is parallel for different factors of production, employers, and consumers. The money costs of a transaction do not always completely measure net costs, and a DC (discrimination coefficient) acts as a bridge between money and net costs. Suppose an employer were faced with the money wage rate $\pi$ of a particular factor; he is assumed to act as if $\pi\left(1+d_{i}\right)$ were the net wage rate, with $d_{i}$ as his $D C$ against this factor. An employee, offered the money wage rate $\pi_{j}$ for working with this factor, acts as if $\pi_{j}\left(1-d_{j}\right)$ were the net wage rate, with $d_{j}$ as his $D C$ against this factor. A consumer, faced with a unit money price of $p$ for the commodity 'produced' by this factor, acts as if the net price were $p\left(1+d_{k}\right)$, with $d_{k}$ as his $D C$ against this factor. In all three instances a DC gives the percentage by which either money costs or money returns are changed in going from money to net magnitudes: the employer uses it to estimate his net wage costs, the employee his net wage rate, and the consumer the net price of a commodity. 65 
In a trivial sense, Becker's concept of a discrimination coefficient can immediately "explain" Cassel's paradox. We need only to assume that discrimination coefficients exist such that employers do not consider the net cost of female labour to be less than male labour. Since the discrimination coefficients are not observable, this explanation is not testable unless additional assumptions are introduced regarding either the behaviour of firms or the determination of the discrimination coefficients.

Becker introduced assumptions regarding the behaviour of firms in his comparison of competitive and monopolistic industries. He argued that "... competitive industries discriminate less on the average than monopolistic ones ..." 66 Firms with small discrimination coefficients will have lower costs than other firms since they will hire the less expensive but equally efficient labour. These firms will be able to expand and drive out the higher cost, more discriminatory firms. Consequently, in the long run, the discrimination coefficient in competitive industries will be equal to the discrimination coefficient that is the smallest among competitive firms. In monopolistic industries, there are no pressures that lead to a reduction in the size of the discrimination coefficient. Consequently, he concluded that the discrimination coefficients of monopolistic firms will, on the average, be larger than those of competitive firms. This argument applies to the aggregate. There could be difference in economic rents, say on the advantage of location, that would permit some competitive firms to discriminate more than others even in the long run. In order to test this argument, Becker presented evidence 
that the number of nonwhites relative to the number of whites employed by competitive industries was larger than the number employed by monopolistic industries (the relative numbers pertained to Southern U.S. manufacturing industries in 1940). 67 This evidence was consistent with Becker's argument.

Becker introduced assumptions regarding the determination of the discrimination coefficients in his comparison of white and non-white income ratios. He analyzed the median incomes of white and Negro males in 1949 for all Southern Standard Metropolitan Areas as classified by the U.S. Census Bureau. He found a significant correlation between the proportional difference of these incomes and the percentage of non-whites in each area. He observed that "One interpretation of this result is that tastes for discrimination and thus market discrimination are positively associated with the percentage of non-whites in each SMA (Standard Metropolitan Area). Before accepting this interpretation, it is necessary to separate the income differentials caused by discrimination from those caused by differences in economic capacity." 68 Becker then found a significant correlation between the ratio of the median years of school of whites to non-whites and the percentage of nonwhites living in each area. He concluded The proportion of nonwhites in a SMA does not seem to have an important effect on tastes for discrimination that operate through the market." He went on to argue that "... since most education is publicly administered, this suggests that in the South political discrimination against nonwhites is positively associated with their relative number." 69 
The preceding argument illustrates a weakness in Becker's approach that is similar to the weakness in Sanborn's argument. 70 In both Becker's and Sanborn's arguments it was shown that the addition of previously unconsidered variables to the analysis of wage ratios tends to reduce any residual that might be defined as discrimination. It is more appropriate to say the addition of variables tends to reduce any residual that could be identified as a discrimination coefficient since Becker used this concept rather than a definition of discrimination.

This weakness is also illustrated in the recent work of Ronald L. Oaxaca. He argued that discrimination against females can be measured by the following equation. 7

$$
D=\left(\left(w_{m} / w_{f}\right)-\left(w_{m} / w_{f}\right)^{0}\right) /\left(w_{m} / w_{f}\right)^{0}
$$

Oaxaca's discrimination coefficient, $D$, is the proportionate difference between the actual male-female wage ratio, $w_{m} / W_{f}$, and the male-female wage ratio that would prevail in the absence of discrimination, $\left(w_{m} / w_{f}\right)^{\circ}$. Measurement of discrimination for Oaxaca then required determining the male-female wage ratio that would prevail in the absence of discrimination. Oaxaca obtained this ratio by first regressing logarithms of wage rates separately by race-sex groups on a wide range of variables including experience, education, industry, occupation, marital status, region, and size of urban area. His data were observations on approximately 60,000 individuals from the U.S. Survey of Economic Opportunity that was conducted for the Office of Economic Opportunity by the Bureau of the Census in February, 1967. He maintained that given the regressions, $\left(w_{m} / w_{f}\right)^{0}$ 
could be measured in two ways as given by equations 1 and $2 .^{72}$

$$
\begin{aligned}
& \text { (1) } \log \left(W_{m} / W_{f}\right)^{0}=b_{f}\left(\bar{M}^{\prime}-\bar{F}^{\prime}\right) \\
& \text { (2) } \log \left(W_{m} / W_{f}\right)^{0}=b_{m}\left(\overline{M^{\prime}}-\overline{F^{\prime}}\right)
\end{aligned}
$$

In the above equations, $b_{f}$ and $b_{m}$ are vectors of regression coefficients obtained from the regressions using female and male data respectively. Vectors of the mean values of the independent variables in the regressions for men and women are given by $\bar{M}^{\prime}$ and $\bar{F} \cdot$. Equations 1 and 2 are then supposed to represent what the male-female wage ratio would be if men and women faced the same wage structures, i.e. If the independent variables had the coefficients in both the male and female wage equations. Oaxaca maintained that the difference between equations $I$ and 2 is an index number problem. Using equation 1 , he estimated $D$ as 0.32 . The estimate was 0.21 using equation 2.73

Even if $\left(W_{m} / W_{f}\right)^{\circ}$ as measured by Oaxaca were an estimate of the wage ratio that would prevail in the absence of discrimination, his interpretation of $D$ could be criticized for being little more than a residual. More importantly this illustrates the problem of not clearly defining discrimination. As shown above, Becker defined the concept of discrimination coefficient. However, he did not define what he considered to be "political discrimination" or even "discrimination" when his context did not relate the term to his coefficients. Becker argued as follows:

In the sociopsychological literature on this subject one individual is said to discriminate against (or in favor of) another if his behavior towand the latter is not motivated by an 'objective' consideration of fact. It is difficult to use this definition in distinguishing a violation of objective facts from an expression of 
tastes or values. For example, discrimination and prejudice are not usually said to occur when someone prefers looking at a glamorous Hollywood actress rather than at some other woman; yet they are said to occur when he prefers living next to whites rather than next to Negros. At best calling just one of these actions 'discrimination' requires making subtle and rather secondary distinctions. $7^{4}$

Becker avoided these distinctions by introducing the concept of a discrimination coefficient. However, he failed to present an analysis of how discrimination coefficients are determined. They simply arise due to tastes.

Kathleen Archibald maintained that discrimination always refers to impairing the opportunity of individuals solely on the basis of their membership in a particular group. 75 Becker's example regarding Negros would be discrimination by Archibald's definition (assuming taste affects behaviour). However, Becker's example of a Hollywood actress would not be a case of discrimination according to Archibald. In this example the preference and behaviour of the observer results from observing a particular individual rather than characterizing that individual as one of a group of actresses.

Contrary to Becker's assertion it might be easier to use a concept of discrimination that isolates a disregard for "objective facts" than it is to use a concept that labels unexplained residuals. Statistical Discrimination: Signalling

Edmund S. Phelps, Kenneth Arrow and Michael Spence have developed models that involve a concept called "statistical discrimination".76 Phelps provided a brief general reference to this concept in his work on Modern Unemployment Theory and he later provided a mathematical extension of Arrow's model. 77 Although both Spence's and Arrow's 
models employ a concept of statistical discrimination, there are important and fundamental differences between the models.

Spence wrote that "The term 'statistical discrimination' refers to a situation in which employers draw inferences about productivity from indices, because those indices are correlated with productive capacity in the population. "78 Spence defined an "index" as an observable unalterable attribute of individuals, e.g. race or sex. He defined a signal as an observable alterable attribute of individuals, e.g. education. 79 spence emphasized that neither signals nor indices necessarily affect productivity. ${ }^{80}$ Spence's work focused on the individual's decision to invest in a signal. His analysis of statistical discrimination was secondary. For reasons developed below we will not use Spence's definition of "statistical discrimination".

When elaborating on his definition Spence wrote:

One suspects, although it would be difficult to prove, that when one mentions informational bases for discrimination, most people think in terms of statistical discrimination. How else could a productively irrelevant index be useful if it is not correlated with anything productively relevant? ... the statistical discriminatory mechanism is not a misconception, but it is a drastically incomplete view of how indices function in a market information system. And it may not be very important ...

If productivity is correlated with some index, for whatever reason, the result will be average wage differentials over groups defined by the index. But this has nothing or almost nothing to do with the informational structure of the market. It would be true in a world of perfect information, and it is true in the world where education by itself is a signal. 81

Spence emphasized that an index may not affect productivity; but may nevertheless be correlated with productivity. Due to this 
correlation he is able to conclude that average wage differentials between persons with different levels of an index would exist even without his version of "statistical discrimination". Recall the emotional exchanges during the normative debate between writers whose assessments of female productivity varied. 82 spence seems to have taken for granted that "statistical discrimination" is based on differences in productivity between the sexes (levels of an index).

Spence provided the following assumptions and definitions in the development of his model. 83

Let

$$
\begin{aligned}
& n=\quad \text { an unobservable unal terable personal character- } \\
& \text { istic which affects productivity, } \\
& y=\quad \text { an observable, alterable characteristic which } \\
& \text { may or may not affect productivity (a signal), } \\
& z=\quad \text { an observable unalterable attribute of indi- } \\
& \text { viduals (an index). } \\
& \text { s = individual productivity, } \\
& R(s \mid y, z)=\text { the employer's conditional distribution over } s \\
& \text { given } \mathrm{y} \text { and } \mathrm{z} \text {, } \\
& c(y, z, n)=\text { the costs of signalling } y \text { for a person of type } z, n \text {, } \\
& W_{R}(y)=\text { the employer's offered wage schedule to levels of } \\
& y \text {, given the conditional distribution } R(s \mid y, z) \text {, } \\
& A(n)=\text { the highest alternative net income outside this } \\
& \text { market for a person of type } n \text {. }
\end{aligned}
$$

Spence assumed that the employer adjusts his wages offered to

each level of $\mathrm{y}$ so that

$$
\text { (Spence: } 1)^{84} W_{R}(y)=\int s \operatorname{dR}(s \mid y, z)
$$

The individual is assumed to select $y$ to 
(Spence: 2) $\quad \max _{y}\left(w_{R}(y)-c(y, z, n)\right)$

There are several ambiguities in the above assumptions and definitions. Spence did not define "individual productivity". We may assume from his context that in his one-good world there is an underlying production function and that $s$ is the marginal productivity of this production function with respect to $\mathrm{n}$. By "conditional distribution" we may assume he means a cumulative frequency distribution.

Spence failed to motivate his assumption (1) regarding employer behaviour. His equation 1 means that the employers sets wages for each level of $y$ equal to the average marginal productivity for persons employed with level $y$ and supposedly varying levels of $n$. From his assumptions, however, he established a one-to-one relation between $y$ and $n$ for each level of $z$. We will further question this assumption after examining more of the model. Spence continued his assumptions and definitions as follows. 85

Let

$$
\varnothing_{R}(n)=\max _{y}\left(W_{R}(y)-c(y, z, n)\right)
$$

Define the set

$$
\varepsilon_{R}=\left\{n \mid \phi_{R}(n) \geqq A(n)\right\}
$$

The set $\varepsilon_{R}$ determines the set of people who stay in this market. Define:

$$
\left.Y_{R}(n)=\left\{\bar{y} \mid w_{R}(\bar{y})-c(\bar{y}, z, n) \geqq w_{R}(y)-c(y, z, n)\right\} \text { (Spence: } 5\right)
$$

Define:

$$
\Lambda_{R}=\left\{y \mid y \varepsilon Y_{R}(n) \text { for some } n\right\}
$$


Productivity is determined by $\mathrm{n}, \mathrm{y}$ and $\mathrm{z}$ according to

$$
s=s(n, y, z)
$$

(Spence: 7)

Spence's equation 7 can be substituted into his equation 1 so as to further examine his assumption regarding the behaviour of the employer.

$$
W_{R}(y)=\int S(n, y, z) d R(S(n, y, z) \mid y, z)
$$

We can see that Spence assumed that the employer acts as if he solves this hypothetical integration problem over the unobservable variable $\mathrm{n}$. In neoclassical models of the firm we usually assume that the firm is a wage taker and that the derived demand for labour is determined from the relation that equates the wage rate with the value of the marginal product. 86 spence did not explain why his employer would adjust the "offered wage schedule" rather than simply terminate unproductive employees. In his model there is no cost or consideration of cost to the employer if staff are terminated.

Spence's assumption regarding individual behaviour is equally implausible. Solution of the problem posed in equation 2 requires that the individual behave as if he were equating the marginal cost of acquiring the signal, $y$, with the marginal income from having acquired it. It is difficult to believe that the individual would know the properties of the schedule $W_{R}(y)$ let alone the properties of $\mathrm{dW}_{\mathrm{R}}(\mathrm{y}) / \mathrm{dy}$. Of course, the "as if" assumption could provide an explanation but that leaves a weak foundation for the model. Spence defined equilibrium in his model as follows: 87

For all $y \in \Lambda_{R}$ let $R_{R}^{*}(s \mid y, z)$ be the empirical conditional distribution of $s$ given $y$ and $z$ which turns up in the sample hired. In an equilibrium, for all $y \in \Lambda_{R}$

$$
R(s \mid y, z)=R_{R}^{*}(s \mid y, z)
$$


In traditional neoclassical models equilibrium is defined in terms of market clearing mechanisms, i.e. the condition where supply equals demand in all markets. Spence defined equilibrium in his model as the state where the conditional cumulative frequency distribution of $\mathrm{s}$, given $\mathrm{y}$ and $\mathrm{z}$ as imagined by the employer, is identical to the distribution observed by the employer. Spence failed to comment on why we should assume that such an "empirical distribution" would be observable. Even if $\mathrm{R}_{R}^{*}(s \mid y, z)$ were observable Spence failed to discuss why the employer would take the sample that resulted from his hiring decisions as more representative of reality than his imagined distribution. He did go on to discuss the dynamic consequences of various adjustment reactions when $\mathrm{R}(\mathrm{s} \mid \mathrm{y}, \mathrm{z}) \neq \mathrm{R}_{\mathrm{R}}^{*}(\mathrm{~s} \mid \mathrm{y}, \mathrm{z}) .8$ When the questions surrounding the basic behaviour equations in Spence's model have not been addressed, a cynic might regard the dynamic considerations as mere mathematical extensions along the lines of the traditional literature. ${ }^{89}$ The stability of equilibrium can be of interest only after the foundations of the model are accepted.

It can be argued that a model should not be criticized on the basis of its assumptions but rather on the basis of its predictive power. Spence deduced several propositions from his model; however, no empirical work was performed by Spence to assess his model against his deductions. His first proposition was a demonstration of the existence of equilibrium. This proof depended on the assertion that $\mathrm{dn} / \mathrm{dy} \neq 0$ and $\mathrm{dn} / \mathrm{d} \mathrm{z} \neq 0.90$ The assumption that a relation between productivity and an index, $z$, or a signal, $y$, 
existed was clear from Spence's definition of statistical discrimination. This assumption, however, is inconsistent with Spence's definitions of both signals and indices. ${ }^{91}$ His concept of productivity depends on an "unobservable unalterable personal characteristic", $n$, which may or may not be correlated to signals or indices, i.e. $\mathrm{dn} / \mathrm{dy} \geqq 0$ and it is possible that $\mathrm{dn} / \mathrm{d} z=0$. Statistical Discrimination: Employer Investment

Kenneth Arrow developed a model that also employs a concept that may be termed "statistical discrimination".92 In addition to discussing discrimination in the form modeled by Beckex 93 and in a form similar to Spence's model, 94 Arrow suggested a third approach. While Arrow did not define the term "statistical discrimination" the definition we will use is consistent with the context of his discussion. 95 In the balance of this study statistical discrimination refers to a situation in which employers draw inferences about productivity from unal terable attributes of individuals, e.g. race or sex, even though the attributes are not correlated with productivity in the population. This definition emphasizes an opposite relation than that chosen by Spence, ${ }^{96}$ between productivity and an index. Of course, an employer who statistically discriminates would believe that the index was correlated with productivity. Arrow wrote "... what I have referred to as the discriminatory tastes of the employer might in fact be better described as a problem in perception. That is, employers discriminate against blacks because they believe them to be inferior workers. "97

Statistical discrimination would not last long if employers 
learned of their misperceptions and adjusted their subjective assessments of the probability that a person is productive so as to reflect the realities of the actual population, i.e. if equilibrium as defined by Spence were attained. Like Spence, Arrow discussed adjustment mechanisms and suggested that an equilibrium may not be stable. 98 stability rather than instability might be the actual reason for the persistence of statistical discrimination. If traditional (and therefore stable) cultural values, e.g. a woman's place is in the home, affect the adjustment of employers' assessments of the actual population, the process of adjustment might takes hundreds of years. Arrow commented on the persistence of discrimination as follows:

One possible explanation is to be found in theories of psychological equilibrium, such as Festinger's theory of cognitive dissonance. If an individual acts in a discriminatory fashion, he would, according to this theory, tend to have beliefs that justify his actions. Indeed, precisely the fact that discriminatory behavior is in conflict with an important segment of our ethical beliefs will, according to this theory, intensify the willingness to entertain cognitive beliefs that will supply a socially acceptable justification for this conduct. 99

In his essay, "The Subjection of Women", John Stuart Mill anticipated Arrow's observation by one hundred years when he wrote:

So long as an opinion is strongly rooted in the feelings, it gains rather than loses in stability by having a preponderating weight of argument against it. And there are so many causes tending to make the feelings connected with this subject the most intense and most deeply-rooted of all those which gather round and protect old institutions and customs, that we need not wonder to find them as yet less undermined and loosened than any of the rest by the progress of the great modern spiritual and social transition; nor suppose that the barbarisms to which men cling longest must be less barbarisms than those which they earlier shake off.100 
Arrow developed a simple model in which he considered two types of labour, unskilled labour (type 1) and skilled labour (type 2). Human capital is invested by both the employer and the employee in type 2 labour. Employers do not know whether a particular job applicant has made the investment necessary to become type 2 labour. "An employer cannot know whether or not a worker is qualified, but he holds subjective beliefs about the respective probabilities, to be denoted by $p_{w}$ and $p_{n}$, that white and black workers, respectively, are qualified". 101

If the employer hires an individual who is not qualified to receive the employer's investment, the employer will eventually lose the investment when the employee proves incapable of performing type 2 work. The reasons why an individual might not be capable of performing type 2 work are varied. For example, if the employee has personal problems, e.g. illness or family problems, the employee might be forced to terminate employment. On the other hand, the employee might simply not possess the aptitudes necessary to perform in type 2 work. In either case, the employee must terminate employment.

The employer may choose to reduce the risk of losing employees by purchasing knowledge, i.e. by testing job applicants. For example, the U.S. Department of Labor reported that the use of the General Aptitude Test Battery in choosing power-sewing-machine operators reduced their turnover rate from 4.5 per cent per month to 2.0 per cent per month. ${ }^{102}$ The cost of testing can be considered to be part of the investment by the employer. The employer faces a tradeoff 
between increasing investment in each employee and increasing the expected turnover rate. Knowing the technical properties of this tradeoff, the employer can decide on an optimal testing program. This process is not of importance to Arrow's model since the testing costs can be considered as part of the employer investment. Since all uncertainty is not removed by testing, employers may test and then base their conditional expectations of whether an employee is qualified on a characteristic such as race.

Assuming that employers are risk neutral, Arrow maintained that the following relation holds in equilibrium:

$$
\text { (A) } R=\left(f_{2}-w_{2 w}\right) p_{w}=\left(f_{2}-w_{2 n}\right) p_{n}
$$

Where: $R$ is the return per worker that employers expect to earn on their human capital investments; $f_{2}$ is the partial derivative of the firm's pro2 duction function with respect to type 2 labour; $W_{2 W}$ is the white real wage rate for type 2 labour; $\mathrm{w}_{2 \mathrm{n}}^{2 \mathrm{w}}$ is the black real wage rate for type 2 labour.

Equation A may be rewritten as,

(B) $w_{2 w}=q W_{2 n}+(I-q) f_{2}$

Where: $q=p_{n} / p_{w}$.

Arrow extended this model in a manner similar to spence so as to consider adjustment mechanisms for $p_{n}$ and $p_{W} \cdot$ He considered changes in supply that might affect $p_{n}$ and $p_{w}$. These extensions require relaxing the assumption that the employer's perceptions are imperfect. 103 If we maintain the strong assumption that the employer's perceptions are imperfect, we are left with a simple model that can be solved for the derived demand for each type of labour. 
Edmund S. Phelps has proposed a mathematical extension of Arrow's model. Phelps maintained that a job applicant's "promise or degree of qualification" might be estimated by an employer as a linear function of the applicant's test score, $y_{i}$, and an error term. He suggested that another error term that is dependent upon the applicant's race could be added to the model. The manner in which the race determined error term enters the model then affects the comparison of predictions of the degree of qualification for applicants of different race. 104

Phelps' proposal is similar to the traditional errors in the variables problem that is discussed in most econometric textbooks. Determining the effects of errors in the variables requires either more assumptions or more data than is required in the simple case of a single additive error term. 105 These requirements render Phelps' proposal impractical as a means for gaining insight for our problem.

The basis of Arrow's simple model is used in the next chapter to develop a model of occupational segregation by sex. The model permits analysis of statistical discrimination. 


\section{$-44-$ \\ Chapter 2: Notes}

1. John Stuart Mill, "The Subjection of Women" (1869) in Alice S. Rossi (ed.), Essays on Sex Equality (Chicago: The University of Chicago Press), p. 125 .

2. Ibid., p. 181 .

3. Sidney Webb and Beatrice Webb, Industrial Democracy (London: Longmans, Green, and Co., 1902), p. 506.

4. Ioid., p. 507.

5. Eleanor F. Rathbone, "The Remuneration of Women's Services", The Economic Journal, March, 1917, pp. 55-56.

6. Tbid., pp. 57-58.

7. Tbid., p. 63.

8. Ibid., p. 68.

9. Tbid., p. 59.

10. Millicent G. Fawcett, "Equal Pay for Equal Work", The Economic Journal, March, 1918, p. 2.

11. Ibid., p. 4.

12. Op. Cit.

13. Department of Labour, Equal Pay for Equal Work (Ottawa: Queen's Printer, 1960), p. 8.

14. Proceeding 6Ist Annual Convention, The Trades and Labor Congress of Canada, resolution number 240 by the Toronto Jewellery Workers Local 33, p. 416.

15. Department of Labour, Equal Pay for Equal Work, p. 8; and Report of the Royal Commission on The Status of Women in Canada (Ottawa: Information Canada, 1970), pp. 68-70.

16. U.S. Department of Labor, Economic Indicators Relating to Equal Pay (Washington: U.S. Government Printing Office, 1963), p. I.

17. House of Commons Debates (Ottawa: Queen's Printer), May 5, 1971, p. 1.0809. Factors that render the equal pay laws inoperable are discussed in The Status of Women in Canada, pp. 75-76.

18. A.C. Pigou, The Economis of Welfare (London: MacMillan and Co., Ltd., 1920), p. 521 . 
19. Tbid., pp. 522-523.

20. Valerie Kincade Oppenheimer, The Female Labour Force in the United States (Berkely: The University of California Press, 1970), pp. 156-157.

21. Ibid., pp. 64-120, p. 157; also see, Valerie Kincade Oppenheimer, "The Sex Labeling of Jobs", Industrial Relations, May, 1968, pp. 219-234.

22. Noah M. Meltz, Changes in the Occupational Composition of the Canadian Labour Force, 1931-1961, Economics and Research Branch, Department of Labour, Occasional Paper No. 2 (Ottawa: Queen's Printer, 1965), p. 35.

23. Ibid., p. 61.

24. Ibid., pp. 63-66.

25. Ibid., p. 66.

26. Pigou, Op. Cit., p. 525.

27. Ibid., pp. 525-526.

28. P. Sargant Florence, "A Statistical Contribution to the Theory of Women's Wages", The Economic Journal, March, 1931, p. 37.

29. Gustav Cassel, The Theory of Social Economy (New York: Harcourt, Brace and Co., 1924), Joseph McCabe (ed.), p. 315.

30. Op. Cit.

31. Op. Cit.

32. Ibid., p. 316.

33. F.Y. Edgeworth, "Equal Pay to Men and Women for Equal Work", The Economic Journal, December, 1922, p. 431.

34. Fawcett, Op. Cit.

35. Edgeworth, Op. Cit., p. 439.

36. Francine D. Blau and Carol I. Jusenius, "Economists' Approaches to Sex Segregation in the Labor Market: An Appraisal" in Martha Blaxall and Barbara Reagan (eds.), Women and the Workplace (Chicago: The University of Chicago Press, 1976), p. $18 \overline{3 .}$

37. Theodore Caplow, The Sociology of Work (Toronto: McGraw-Hill Book Co., 1964), Chapter 10, pp. 220-247. 
38. Ibid., pp. 237-238.

39. Ibid., p. 246.

40. Edgeworth, Op. Cit., p. 439; also see, P. Sargant Florence, Op. Git.

41. Florence, Op. Cit., p. 37.

42. Joan Robinson, The Economics of Imperfect Competition (London: MacMillian \& Co., Ltd., 1965), Chapter 26, pp. 292-304.

43. Edmund S. Phelps, "Money Wage Dynamics and Labor Market Equilibrium" in Phelps et al., Microeconomic Foundations of Employment and Inflation Theory (New York: W.W. Norton \& Company, Inc., 1970), p. 131 .

44. Dale T. Mortensen, "A Theory of Wage and Employment Dynamics" in Phelps et al.., Microeconomic Foundations of Employment and Inflation Theory, p. 182 .

45. A.P. Lerner, "The Concept of Monopoly and the Measurement of Monopoly Power", Review of Economic Studies, 1934, pp. 157-175.

46. Jacob Mincer, "The Distribution of Labor Incomes: A Survey with Special Reference to the Human Capital Approach", Journal of Economic Literature, March, 1970, p. 23.

47. Henry Sanborn, "Pay Differences Between Men and Women", Industrial and Labor Relations Review, July, 1964, pp. 534-535. Sanborn's article is based on his unpublished University of Chicago, $\mathrm{Ph} . \mathrm{D}$. dissertation by the same title.

48. Ibid., pp. 549-550.

49. Ioid., p. 535.

50. Ibid., p. 546.

51. Ioid., pp. 546-549.

52. Sylvia Ostry, The Female Worker in Canada (Ottawa: Queen's Printer, 1968), pp. 39-45.

53. Gideon Rosenbluth and R.A. Holmes, "The Structure of Academic Salaries in Canada". The Canadian Association of University Teachers Bulletin, April, 1967.

54. Ibid., p. 23.

55. Women's Action Group, A Report on the Status of Women at the University of British Columbia (Vancouver: Talconbooks, 1973). 
56. Hartley V. Lewis, "The Importance of Turnover Costs in the Male-Female Wage Differential", unpublished Ph.D. dissertation, The University of Rochester, 1970.

57. Kathleen Archibald, Sex and the Public Service (Ottawa: Queen's Printer, 1970), p. 104.

58. Ibid., p. 204 .

59. Ibid., pp. 204-206.

60. Ibid., p. 207.

61. L.S. Fidell, "Empirical Verification of Sex Discrimination in Hiring Practices in Psychology", American Psychologist, 1970, pp. 1094-1098.

62. Op. Cit.

63. Op. Git.

64. Arie Y. Lewin and Linda Duchan, "Women in Academia", Science, September, 1971, pp. 892-895.

65. Gary S. Becker, The Economics of Discrimination (Chicago: The University of Chicago Press, Second Edition, 1971), pp. 14-15.

66. Ibid., p. 47 .

67. Ibid., p. 48.

68. Tbid.. pp. 123-125.

69. Ibid., p. 126 .

70. Sanborn, Op. Cit.; also see p. 21 above.

71. Ronald I. Oaxaca, "Male-Female Wage Differentials in Urban Labor Markets", Working Paper No. 23, Industrial Relations Section, Princeton University (mimeographed, 1971), p. 2. This is based on Oaxaca's 1971 Princeton Ph.D. dissertation by the same title.

72. Op. Git.

73. Ioid., p. 32 .

74. Becker, Op. Cit., p. 13.

75. Archibald, Op. Cit., p. 104.

76. Edmund S. Phelps, Inflation Policy and Unemployment Theory

(New York: W.W. Norton and Company, Inc., 1972); Michael Spence, 
Market Signaling (Cambridge: Harvard University Press, 1974); and Kenneth Arrow, "Some Models of Racial Discrimination in the Labor Market", RAND Corporation research memorandum RM-6253-RC, multilith, Santa Monica, Feb. 1971.

77. Edmund S. Phelps, "The Statistical Theory or Racism and Sexism", American Economic Review, September, 1972, pp. 659-661.

78. Spence, Op. Cit., p. 104.

79. Ibid. , p. 10.

80. Ibid., p. 10, p. 119.

81. Ibid., p. 104.

82. See page 8 above.

83. Spence, Op. Cit., p. 119.

84. Ibid.; Spence: $n$ refers to the $n^{\text {th }}$ equation as numbered by Spence.

85. Spence, Op. Git., p. 120.

86. Milton Friedman, Price Theory A Provisional Text (Chicago: Aldine Publishing Company, 1962), pp. 172-174.

87. Spence, Op. Cit., p. 120.

88. Spence, Op. Cit., p. 191.

89. Paul Anthony Samuelson, Foundations of Economic Analys is

(New York: Athoneum, 1965), Part II, pp. $\frac{1}{27-356 .}$

90. Spence, Op. Cit., p. 121, p. 127.

91. 'Ibid., p. 10, p. 119.

92. Arrow, Op. Cit., p. 48.

93. Ibid., pp. 29-36.

94. Ibid., p. 50 .

95. Ibid., pp. 2l-22, p. 49.

96. See page 33 above.

97. Arrow, Op. Cit., pp. 20-21. 


$$
-49-
$$

98. Ibid., pp. 48-54.

99. Ibid., pp. 22-23.

100. Mill, Op. Cit., p. 126.

101. Arrow, Op. Git., p. 48.

102. U.S. Department of Labor, Manual for the General Aptitude Test Battery, Section III: Development (Washington: U.S. Government Printing Office, 1967), p. 173.

103. Arrow, Op. Cit., p. 23.

104. Phelps, "The Statistical Theory of Racism and Sexism", pp. 659-661.

105. J. Johnston, Econometric Methods (Toronto: MeGraw-Hill Book Company, 1963), pp. 148-175. 
Chapter 3: A Model of Occupational Segregation by Sex There would be no occupational segregation by sex if the difference in the number of males relative to the number of females between occupations were due only to chance variations. The 1961 Canadian census reported $3,752,307$ males and $1,528,875$ females who worked for wages or salary. ${ }^{I}$ This aggregate male-female employment ratio of 2.45 can be compared to a ratio of 1001.93 for mine labourers or to a ratio of 0.06 for typists. The purpose of this chapter is to develop a theoretical framework that can be used to explain the variance in the male-female employment ratio by occupation.

Economists generally model any market through the use of demand relations, supply relations, and market clearing mechanisms. We will develop a model of derived demand for labour by sex and occupation so as to permit consideration of statistical discrimination. As defined in chapter 2, statistical discrimination refers to a situation in which employers draw inferences about productivity from unalterable attributes of individuals, e.g. sex, even though the attributes are not correlated with productivity in the population. In this study we assume that a disequilibrium model exists but we will specify only its demand equations. We will discuss supply considerations and market clearing mechanisms but we assume that employment is always achieved at a point on the firm's derived demand schedule for labour. In other words, we assume pure but not necessarily perfect competition. 2 Perfect competition involves further assumptions regarding perfect knowledge and lack of impediments to long run adjustments. Arrow has shown that it is useful to relax these assumptions of the 
perfectly competitive model in the analysis of discrimination. ${ }^{3}$ Tradition, including traditional attitudes regarding sex sterotypes, can be a barrier both to perfect knowledge and to rapid market adjustments.

\section{Derived Demand}

In micro economic models we typically assume that a firm's output is a function of its inputs of capital and labour. When several occupations are considered, the labour in each occupation can be considered to be a different input in the firm's production function. However, a firm cannot actually hire homogeneous labour for any occupation. In this study we are particularly interested in any difference in labour services between the sexes.

Both Spence and Arrow implicitly assumed that male and female labour differed only with respect to the employer's assessment of the productivity of each type of labour. They both aggregated male and female labour through summation after multiplying each factor by its respective probability of being productive. ${ }^{4}$ As discussed throughout chapter 2, most writers recognized that even when their particular explanation for segregation or wage differences was eliminated other differences between male and female labour might remain. Joan Robinson's concept of aggregating labour in terms of efficiency units is useful for solving the problem posed by heterogeneous labour inputs. We will assume that the output of a firm is a function of the services of labour measured in efficiency units. 5

The use of Robinson's concept of efficiency units of labour is 
an important assumption. It is commonplace in economics to discuss production functions that use labour as an input. The model developed below can be interpreted as one way of explaining the process of aggregating different types of labour into one homogeneous type of efficiency unit labour. There is little in economic theory that offers guidance in specifying the form of production functions. We will assume that the process, or production function, for producing or aggregating to efficiency unit labour is the same for all occupations. This approach permits the examination of the elasticity of substitution between male and female labour services.

In chapter 2 we reviewed the emotional exchanges over differing assessments of the relative productivity of men and women. ${ }^{6}$ Consideration of an elasticity of substitution may provoke such exchanges. Nevertheless, since we can separate male and female labour in any occupation and since male and female wages are rarely the same, we can consider the elasticity of substitution between male and female labour as we would consider the elasticity of substitution between any two factors of production.

Like Arrow, we assume that every occupation requires investment in human capital by both the employee and the employer. A job applicant will be defined as qualified for an occupation when the applicant has made the appropriate employee investment for the occupation. The employee's investment includes not only formal training but also the acquisition of work habits; e.g. punctuality, initiative, and proper manners, and the acquisition of worker traits, e.g. aptitudes, interests, temperaments and tolerances to working conditions.? 
We will assume that the efficiency labour services in each occupation are a function of the amount of qualified male and female labour that the firm hires for the occupation.

If hiring unsuitable employees were costless to employers, then employers would not care whom they hired. They would simply hire and fire until sufficiently qualified labour was obtained. However, all hiring involves a cost to the employer.

An employer's investment in human capital always involves at least the cost of the paper rork of putting a person on the payroll. The employer's investment in each employee may also include costs due to recruitment, training, testing and personal equipment. 8

If perfect knowledge about each potential employee's qualifications were available without cost, the employer's investment in human capital would never be wasted. The problem in hiring is that it takes place in the presence of uncertainty regarding qualifications. It is both costly to make mistakes and costly to acquire information that would prevent mistakes.

Cost minimizing (risk neutral) firms will seek to minimize the expected value of the loss of their investments that. results from hiring unqualified workers. 9 We assume that the employer's uncertainty is expressed in the form of judgments about the probabilities that male and female workers are qualified. The probability in the employer's mind, but not the amount of investment, depends on the sex of the job applicant.

If these subjective probability distributions were used by employers in their hiring decisions we could say that there is 


$$
-54-
$$

"qualified discrimination". ${ }^{10}$ Owing to the aggregate nature of the census data we seek to explain, we are not able to detect qualified discrimination. We could not determine from census data whether employers actually hire both sexes without discrimination and then dismiss the unqualified workers.

An employer's subjective probability that a person is qualified does not depend on sex alone. The U.S. National Manpower Council observed, "Employers hire persons of the sex supposedly possessing the characteristics considered necessary for effective job performance. "Il That is, the subjective evaluation will vary by occupation. We will assume that the subjective probability that a person is qualified for an occupation is a function of the person's sex and of the characteristics considered necessary for effective performance in the occupation. We will say that the evidence indicates the presence of statistical discrimination if we find that a characteristic is significantly related to the male-female employment ratio and yet there is no significant difference in the mean values by sex of the quantitative indicators of the characteristic.

It would be possible to assume that employers consider higher moments of their subjective probability distributions as well as joint distributions of two or more characteristics by sex. However, these complications will not be examined here, since we lack the necessary data. Even when we restrict our examination to mean values of single characteristics by sex, relatively little suitable data can be found.

The preceding discussion can be expressed as follows. 

(1) $I_{e i}=f_{i}\left(I_{q f i}, I_{q m i}\right)$
(2) $L_{q j i}=P_{j}\left(x_{i}\right) L_{j i}$

Where: $L_{e i}$ is the amount of the efficiency services of labour in the $i^{\text {th }}$ occupation that the firm expects to have available;

$f_{i}$ is a homogeneous production function of degree one that has continuous partial derivatives of the second order;

$L_{q j i}$ is the amount of qualified labour whose sex is

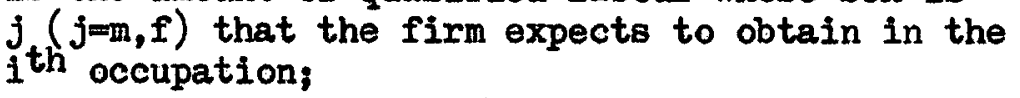

$x_{i}$ is a vector of quantitative indicators of the characteristics considered necessary for effective job performance in the $i^{\text {th }}$ occupation;

$P_{j}\left(x_{i}\right)$ is the subjective probability that a person whose ${ }_{\text {sex }}$ is $j(j=m, f)$ is qualified for the $i^{\text {th }}$ occupation;

$I_{j i}$ is the amount of labour whose sex is $j$ that is
hired for the $i^{\text {th }}$ occupation.

(3) $c_{i}=W_{m i} I_{q m i}+r K_{i} L_{m i}+w_{f i} L_{q f i}+r K_{i} L_{f i}$

Where: $c_{i}$ is the total cost of labour for the $i^{\text {th }}$ occupation;

Wi is the wage rate paid to persons whose sex is $j$ in
the $i$ th occupation;

$r$ is the rate of return the firm expects to earn on its human capital investments;

$K_{i}$ is the amount of human capital per person (independent of sex) in the ith occupation that is invested by the firm.

As expressed by the following Lagrangean, the firm maximizes

the amount of labour available to it for a given cost.

$$
\begin{aligned}
& \text { (4) } \max _{\left(L_{f i}, I_{m i}\right)} f_{i}\left(P_{f}\left(x_{i}\right) L_{f i}, P_{m}\left(x_{i}\right) L_{m i}\right)-\lambda\left(c_{i}-W_{f i} P_{f}\left(X_{i}\right) L_{f i}\right. \\
& \left.-W_{m i} P_{m}\left(X_{i}\right) L_{m i}-r K_{i}\left(L_{f i}+L_{m i}\right)\right)
\end{aligned}
$$

The first order conditions for a maximum are given by equations 5 and 6. We will assume the second order conditions are satisfied. 
(5) $0=\lambda\left(W_{f i} P_{f}\left(X_{i}\right)+r K_{i}\right)+P_{f}\left(X_{i}\right) \delta f_{i} / \delta L_{q f i}$

(6) $0=\lambda\left(W_{m i} P_{m}\left(X_{i}\right)+r K_{i}\right)+P_{m}\left(X_{i}\right) \delta f_{i} / \delta L_{q m i}$

Equations 5 and 6 can be solved to eliminate $\lambda$.

(7) $\frac{w_{f i} P_{f}\left(X_{i}\right)+r K_{i}}{W_{m i} P_{m}\left(X_{i}\right)+r K_{i}}=\frac{P_{f}\left(X_{i}\right) \delta f_{i} / \delta L_{q f i}}{P_{m}\left(X_{i}\right) \delta f_{i} / \delta L_{q m i}}$

Since $f$ is homogeneous of degree one the ratio of the marginal products can be written as a function, F, of the ratio of the factors of production.

(8) $\frac{W_{f i} P_{f}\left(X_{i}\right)+r K_{i}}{W_{m i} P_{m}\left(X_{i}\right)+r K_{i}}=\frac{P_{f}\left(X_{i}\right) F\left(L_{q f i} / L_{q m i}\right)}{P_{m}\left(X_{i}\right)}$

Equation 8 implies that a relation, G, could be determined between the male-female employment ratio and the wage rates, expected investment return, and the factors considered necessary for effective job performance.

(9) $I_{q m i} / L_{q f i}=G_{i}\left(W_{f i}, W_{m i}, r K_{i}, x_{i}\right)$

Equation 9 establishes a relation for a firm. We wish to explain aggregate-census data; therefore, we will introduce the common Marshallian assumption that the preceding argument applies to the typical firm and, as such, to the entire market.

The Marshallian argument is particularly strong here since we are assuming that firms may discriminate. Ignoring aggregation problems by introducing the Marshallian assumptions means that all firms must behave as if they share the same prejudices. If some firms displayed prejudice any single nondiscriminating firm might dominate the market by reducing costs.

Two reasons can be given for rejecting the argument that one 
nondiscriminating. firm would eliminate all discriminating firms. First, in neoclassical theory we assume that any single firm is small relative to the size of the market but we assume nothing else as to its size. A homegeneous of degree one production function permits a firm to be any size, i.e. its output is not limited by increasing costs. If a firm enjoys an economic profit we usually assume it retains this profit until other firms copy the profitable firm and bid down the price. In our case, a nondiscriminating firm might simply continue to enjoy unusually large profits relative to discriminating firms. Other firms might not copy the first if they do not attribute its success to its behaviour in the labour market. Second, the traditional prejudices attached to sex are sufficiently strong that adjustment mechanisms are likely to be very slow, 12 Supply

Equation 9 established a relation that determines the male-female employment ratio. We have assumed that employment is always attained on the firm's derived demand schedule for labour; therefore, equation 9 provides the basis for our explanation of male-female employment ratios. The purpose of this section is to motivate the assumption that male-female employment ratios can be considered as if they were simply determined by derived demand.

In a comment during a conference held in May 1975 on occupational segregation, Kenneth Arrow described the adaption of labour supply to discrimination. Arrow wrote as follows:

Rational adaptation by women to employer attitudes justifies employer attitudes to some extent. I am thinking particularly of high female mobility in and out of the labor force, an 
essential part of the mechanism Ferber and Lowry describe. It is correctly referred to as a rational adaptation to female job opportunities.

However, it is also true that employers are adapting rationally to this differential female reaction. Female workers perceive a lack of reward for certain kinds of accomplishments; therefore, there is a lack of necessary accomplishments, and therefore employers do not expect these accomplishments to exist in women. It is essential to this argument that workers are being treated as groups and not as individuals. If employers would differentiate among individuals, all these phenomena would disappear.13

For our problem we do not need to determine which force, supply or demand, determines the male-female employment ratio. In order to analyze the ratio it is sufficient to be correct in the statement that the ratio behaves as if it were demand determined. Arrow's comment indicates that separating supply and demand considerations could be like determining whether the chicken or the egg came first. This adaptation of supply to demand (or demand to supply) is the essence of tradition.

For the purpose of completing our theoretical framework we can speculate on supply considerations. Both Spence and Arrow provided such speculations in the process of discussing the dynamics of market clearing mechanisms. ${ }^{14}$ we can follow their example. Market Clearing

The simplest market clearing mechanism exists when we equate supply and demand in each market without consideration of time. Once we deviate from this simple mechanism a wide variety of alternatives are available. The change inprice per unit of time can be made a function of the difference between supply and demand. The rate of change of the wage level, for example, could be expressed as a function of the unemployment rate. The change in quantity 
supplied (or demanded) could be made a function of the difference between the price asked and the price offered. When expectations are introducéd into a model additional market clearing mechanisms become possible. Employers' expectations can be modeled as changing over time as a function of differences in either quantities supplied and demanded or of differences between demand price and supply price. There is little to guide the modeler in the selection of a dynamic market clearing mechanism. Some assistance can be obtained by introducing assumptions regarding the stability of the clearing mechanism. At best this limits the modeler's imagination to alternative monotonic or oscillating stable systems. 15

Arrow dropped his assumption of imperfect employer perceptions when he introduced his dynamic considerations. He assumed that the probability that each group was qualified, and therefore the labour supply, was a function of the difference between skilled and unskilled wage rates paid to each type, black or white, of labour. He then assumed that the probabilities changed over time as a function of the difference between the supply and the demand for labour. 16

Spence defined equilibrium as the condition when employer expectations correspond to actual circumstances. He assumed that each individual's investment in a signal, and therefore the labour supply, was determined by equating the marginal cost of acquiring the signal to the marginal income from increasing the level of the signal. He introduced dynamic considerations by assuming that the employer's derived demand for labour in period $t$ was a function of the productivity experienced in period $t-1$. Like Arrow, Spence then 
speculated on alternative forms for the dynamic relationship and the resulting stability of the model. 17

We can complete our model by adding assumptions regarding labour supply and market clearing mechanisms. He can start with a market labour supply schedule rather than individual labour market behaviour. We assume that the amount of labour whose sex is $j$ that is offered to the $i^{\text {th }}$ occupation, $L_{j i}^{s}$, is a function of all of the alternative wage rates for a person whose sex is $j$ and of the characteristics considered necessary for the $i^{\text {th }}$ occupation. (10) $L_{j i}^{s}=I_{j i}^{s}\left(W_{j 1}, W_{j 2}, \ldots, W_{j n}, x_{i}\right) ; j=m, f$

In order to recognize unemployment, we assume that supply is always greater than demand. (11) $\mathrm{L}_{j i}^{\mathrm{s}} \geqq \mathrm{L}_{j i}$

Like Arrow or Spence, we could make the model dynamic by adding a time subscript to all of our variables and by assuming that the rate of change in relative wage rates by occupation and sex is a function of the excess supply in each occupation.

While speculation on supply and market clearing mechanisms completes the theoretical framework, it is not necessary for the purpose of this study. We have assumed that the male-female employment ratio behaves as if it were demand determined.

\section{Simplifying Assumptions}

Equation 9 established a relation between the ratio of male to female qualified labour and wage rates, expected investment return, and the factors considered necessary for effective job performance. Using census data, we are able to observe the number of men and women 
who are actually employed in each occupation. We are not able to observe the number of men and women who are hired for any occupation, $\mathrm{L}_{\mathrm{ji}}$. We assume that the number of men and women who are employed in an occupation is equal to the number of men and women that firms expect to obtain as qualified labour.

Similarly, neither $r$ nor $\mathrm{K}_{i}$ are observable. We must choose a quantitative indicator of $\mathrm{rK}_{i}$ that can be observed with our limited data. We assume that $x K_{i}$ is a function of the amount of specific vocational training time required by each occupation, $S P_{i}$. Specific vocational training time can be contrasted with general educational development. General educational development is "education of a general academic nature ordinarily obtained in elementary school, high school, or college which does not have a recognized, fairly specific occupational objective." 18 specific vocational training includes (a) vocational education, (b) apprentice training, (c) inplant training given by an employer in classrooms, (d) on-the-job training, and/or (e) essential experience in other jobs. ${ }^{19}$ In-plant training and on-the-job training are costs to employers. We assume that in-plant training and on-the-job training are necessary complements to other farms of vocational training. Staff development departments in most large companies demonstrate this complementary form of training offered by employers.

There are other assumptions that could be utilized to measure IK $K_{1}$. Employers' investment could be expressed as the sum of a fixed investment $\left(\overline{\mathrm{K}}_{i}\right)$ and the product of the wage rate and the training period $\left(T_{i}\right), K_{i}=\bar{K}_{i}+W_{i} T_{i}$. The use of this alternative assumption 
does not provide a useful measure for $\mathrm{rK}_{i}$. The alternative assumption merely introduces additional questions. In particular it can be argued that on-the-job training uses more of the employer's resources than just the new employee's wage. Capital can be tied up by the trainees as well as staff trainers or supervisors. These factors would modify the alternative assumption to $K_{i}=\bar{K}_{i}+Q_{i} T_{i}$ where $Q_{i}$ is a price representing the price per unit of time of all of the resources used in staff training. It is far simpler to merely assume that $r K_{i}$ is a function of the amount of specific vocational training time required by each occupation. This means that we are assuming that the cost to the employer for training a person is the same in two occupations if the specific vocational training time is the same. Furthermore, the fixed cost, $\bar{K}_{i}$, is assumed to be the same for all occupations. The use of $\mathrm{SVP}_{i}$ as a proxy variable for $\mathrm{rK}_{i}$ could present problems of interpretation. Proxy variables must be chosen on the basis of common sense and intuition. If better information were available to assess the reliability of the proxy variable it might not be necessary to use the proxy. In this particular case it is possible that SVP actually serves as a proxy variable for employee investment or for both employer and employee investment. Since we lack both better information and an alternative proxy variable we will have to remain aware of the possible alternative interpretations of our proxy.

In order to obtain numberical results we must transform equation 9 into a specific form. Whatever actual functional forms are appropriate to equations 8 and 9, we assume that the relation in equation 9 can be approximated by equation 12 . 
(12) $\log \left(L_{q m i} / L_{q f i}\right)=\sigma \cdot \log \left(W_{f i} / W_{m i}\right)+\theta \cdot S V P_{i}+X_{i} A+u_{i}$

Where: $\sigma$ and $\theta$ are scalar parameters;

$A$ is a column vector of parameters;

$u_{i}$ is a normally distributed disturbance term with

$x_{i}$ is a row vector of quantitative indicators of the

characteristics considered necessary for effective job performance in the $i^{\text {th }}$ occupation.

By using the logarithm of the employment ratio and by assuming that the wage rates enter equation 12 as the logarithm of their ratio, $\sigma$ can be interpreted as the elasticity of substitution of male and female qualified labour with respect to the observable female-male wage rates. If the actual value of $\sigma$ is zero we would say that male and female labour were completely different factors of production. In other words this would indicate complete occupational segregation by sex; consequently, we will devote particular attention to examining our estimate of the value for $\sigma$. 
Chapter 3: Notes

1. Dominion Bureau of Statistics, 1961 Census of Canada, Labour Force, Bulletin 3.3-7 (Ottawa: Queen's Printer, 1963), Table 21, p. 21-1.

2. Joan Robinson, The Economics of Imperfect Competition (London: MacMillian \& Co., Itd., 1965), Appendix, p. 332.

3. Kenneth Arrow, "The Theory of Discrimination", paper presented at conference on "discrimination in labour markets", October 1971, Industrial Relations Section, Hoodrow Wilson School and Conference Office, Princeton University, pp. 2-3.

4. Michael Spence, Market Signaling (Cambridge: Harvard University Press, 1974); and Kenneth Arrow, "Some Models of Racial Discrimination in the Labor Market". RAND Corporation research memorandum RM-6253-RC, multilith, Santa Monica, Feb. 1971.

5. Robinson, Op. Cit.

6. See p. 8 above.

7. Arrow, Op. Cit., p. 21, p. 48.

8. Frederick J. Gaudit, Labor Turnover: Calculation and Cost (New York: American Management Association, Inc., 1960), pp. 37-38.

9. By risk neutral, I mean to assume that firms consider only the first moments of the subjective probability functions.

10. See p. 25 above.

11. National Manpower Council, Womanpower (New York: Columbia University Press, 1957), p. 233.

12. See p. 40 above.

13. Kenneth Arrow, "Economic Dimensions of Occupational Segregation: Comment I" in Martha Blaxall and Barbara Regan (eds.), Women and the Horkplace (Chicago: The University of Chicago Press, 1976), p. 234 .

14. Spence, Op. Cit., p. 191; Arrow, "Some Models", p. 50.

15. Paul Anthony Samuelson, Foundations of Economic Analysis (New York: Atheneum, 1965), Part II, pp. 257-356.

16. Arrow, "Some Models", p. 50.

17. Spence, Op. Cit. 
18. U.S. Department of Labor, Bureau of Employment Security, Estimates of Worker Trait Requirements for 4,000 Jobs (Washington: U.S. Government Printing office, 1956), p. i10.

19. Ibid. 
Chapter 4: Construction and Sources of Data

Census Data

A major difficulty in any study of occupational segregation by sex is to find data on employment and wage rates broken down by sex and occupation. For the purposes of this study, data must be found for a large number of occupations so that regression equations can be estimated using each occupation as an observation. The only available Canadian data that meet these criteria are found in the census. 1 Since occupational classification schemes change between census years, this study is restricted to the census year 1961 .

Occupations are divided into groups, classes, and titles in the Canadian census. The 1961 census contained 273 occupational classes divided into 13 occupational groups. There were 16,000 occupational titles in the 1961 census, but data by occupational titles are not published. 2 The Occupational classification Manual for the 1961 census lists the occupational titles that are aggregated into each census occupational class. In this study, we must treat census occupational classes as if they were homogeneous occupations. This means that we will assume that men and women do not differ in their distributions among the occupational titles within an occupational class, or it means that there are assumed to be no differences, that are important for this study, between occupational titles within an occupational class. He cannot predict the bias that would result, if this is an incorrect assumption, without access to data by job title. Of course, the extreme case of complete occupational segregation by sex is possible if jobs are narrowly defined. We assert 
that even if this is the case such narrow definitions are useful as nothing more than labels. They should not restrict mobility within a job class.

Inaccurate answers to the census questionnaire are an obvious source of error in the census data. 3 Problems would exist, however, even if the questions were answered accurately. The number of hours usually worked, the number of weeks worked in the census year, and the gross wage and salary income were recorded in terms of intervals. Unfortunately, the possible answers for usual hours worked per week and gross wage and salary income included open ended intervals. The problems posed by this method of recording are discussed below. The precision of the occupational classification of each individual must vary with the type of response given to the question, "What kind of work did you do in this industry?" 4 Furthermore, each individual was classified into only one occupation. Errors are contained in the data resulting from the grouping of individuals with more than one job into only the occupation given in answer to the census question. We hope that individuals with multiple jobs are few in number and importance, or else that the errors will cancel each other. No data are available for fringe benefits. Traditionally, studies of labour markets avoid this problem by assuming that fringe benefits are proportional to wage rates. 5 We must also make that simplifying assumption.

Employment is measured in person-years, person-weeks, or personhours, but wage rates can be measured in dollars per year, dollars per week, or dollars per hour. As shown by Sylvia Ostry, a year is 
not the appropriate unit of time for this study. She found that the ratio of female to male aggregate annual earnings was 54.2 per cent for all wage earners and 59.3 per cent for only full time wage earners. 6 In this study we estimate person hours and hourly wage rates by adjusting the annual employment and earnings data for the differences in weeks worked per year and hours worked per week by men and women. A shorter working period for women could also be the result of discrimination. The problem of participation rates is beyond the scope of this study.

The census provides tabulations of the number of wage-earners who worked for wages or salary and of average annual earnings by sex and census occupational class. 7 These data were converted into units based on time measured in hours by equations 1 and 2 .
(1) $L_{q j i}=I_{j i}^{a} \overline{W k}_{j i}{ }_{j i}$
(2) $w_{j i}=w_{j i}^{2} /\left(\overline{w k}_{j i} H_{j i}\right)$

Where: $I_{q j i}$ is the amount of qualified labour whose sex is $j(j=\mathbb{R}, f)$ and who are employed in the $i$ th occupation measured in person-hours;

$W_{j i}$ is the wage rate paid to persons whose sex is $j i$ in the $i^{\text {th }}$ occupation measured in dollars per hour; $I^{a}$ is the number of person-years employed in the $i^{\text {th }}$
occupation whose sex is $j ;$

$W_{j i}^{a}$ is the annual earnings paid in the $i^{\text {th }}$ occupation
to persons whose sex is $j ;$

$\overline{W k}_{j i}$ is the average number of weeks per year that are worked by persons in the $i^{\text {th }}$ occupation whose sex is $j$;

$\mathrm{H}_{\mathrm{jl}}$ is the average number of hours per week that are worked by persons in the $i^{\text {th }}$ occupation whose sex is $j$. 
The average number of weeks per year, $\overline{\mathrm{kk}}_{j \mathrm{j}}$, and the average number of hours per week, $\mathrm{H}_{j i}$, are not readily obtained from the census. The response to the question of how many weeks were worked in the census year was recorded in intervals. The published census data contained intervals that were aggregated even further, i.e. 1-4 weeks and 5-13 weeks were reported as 1-13 weeks, and $40-48$ weeks and 49-52 weeks were reported as 40-52 weeks. Unpublished data were obtained from Statistics Canada. ${ }^{8}$ These data reported the distributions of wage earners among the intervals as given in the questionnaire by sex and occupational class. For each sex and occupational class, the average number of weeks worked pex year, $\overline{\mathrm{Wk}}_{j i}$, was calculated from this data using equation 3.

(3) $\overline{W k}_{j i}=\left(\sum_{i j k} \overline{W k M}_{i j k}\right) / \sum_{k} n_{i j k}$ Where: $n_{i j k}$ is the number of individuals in the $i^{\text {th }}$ occupation whose sex is $j$ that were recorded in the $\mathrm{k}^{\text {th }}$ interval of weeks;

$\overline{W k M}_{i j k}$ is the midpoint of the $k^{\text {th }}$ interval of weeks. The values of $\overline{W K M}_{i j k}$ are given in Table $I$. We assume the interval $1-4$ includes $0-4.5$ and that the interval 49-52 includes $48.5-52$

Table I

Midpoints used to calculate $\overline{\mathrm{Kk}}_{j i}$

k Interval $\overline{W k M}_{\mathbf{i j k}}$

$1 \quad 1-4 \quad 2.25$

$2 \quad 5-13 \quad 9.00$

$3 \quad 14-26 \quad 20.00$

$47-39 \quad 33.00$
5

$5 \quad 40=48 \quad 44.00$

$6 \quad 49-52 \quad 50.25$ 
The response to the question of how many hours were usually worked each week was also recorded in intervals. The calculation of $\mathrm{H}_{j i}$ is further complicated by the presence of an open-ended interval, 50+. Furthermore, the hourly data were not published by census occupational class. In place of occupational classes, these data were published by broader occupational groupings that were more specific than census occupational groups but more general than census occupational classes. 9 The problem of an open-ended interval was solved by calculating a mean for the interval, $50+$, of 54.83 hours per woek. ${ }^{10}$ since we have no other data, the problem of occupational grouping was solved by using the data in each of the broad groups for all of the census occupational classes within each broad group. For each sex and occupational class, the average number of hours worked per week, $\mathrm{H}_{\mathrm{ji}}$, was therefore calculated using equation 4. (4) $\mathrm{H}_{j i}=\left(\sum_{\mathrm{k}} \mathrm{n}_{i j \mathrm{j}} \overline{\mathrm{HM}}_{\mathrm{k}}\right) / \sum_{\mathrm{K}} n_{i j k}$

Where: $n_{i j k}^{\prime}$ is the number of individuals in the $i^{\text {th }}$ occupation whose sex is $j$ that were recorded in the $k^{\text {th }}$ interval of hours;

$\overline{\mathrm{HM}}_{\mathrm{k}}$ is the midpoint (except for $50+$ ) of the $\mathrm{k}^{\text {th }}$

The values of $\overline{\mathrm{HM}}_{\mathrm{k}}$ are given in Table II. The calculation of $\overline{\mathrm{HM}}_{8}(54.83)$ is explained above.

$\begin{array}{ccc}\text { Midpoints used to calculate } \mathrm{H}_{j i} \\ \underline{k} & \text { Interval } & \overline{\mathrm{HM}}_{\mathrm{k}} \\ 1 & 1-19 & 10.0 \\ 2 & 20=29 & 24.5 \\ 3 & 30-34 & 32.0 \\ 4 & 35-39 & 37.0 \\ 5 & 40 & 40.0 \\ 6 & 41-44 & 42.5 \\ 7 & 45-49 & 47.0 \\ 8 & 50+ & 54.83\end{array}$


Data on age and education were also obtained from the census. ${ }^{11}$ These data referred to the labour force rather than just wage earners. The labour force includes the unemployed, the self-employed, and unpaid family workers as well as wage earners. ${ }^{12}$ However, we could assume that the average age and education of these components of the labour force are the same as the average age and education of wage earners. We cannot determine whether this assumption is reasonable. Alternatively, we assume that the number of "non-wage earners" is sufficiently small so that the data for the labour force will be approximately the same as data for wage earners.

There were no ambiguities in the recording of age. Data on the average age of individuals by sex and occupational class were obtained directly from the published census tables.

Data on education were recorded by intervals. Furthermore, the data refer to highest grade or year of schooling attained (started) rather than to the highest grade completed. The published census data reported the educational interval "secondary 4-5". Unpublished data were obtained from Statistics Canada that reported secondary 4 and secondary 5 separately. ${ }^{13}$ We need to obtain from these data quantitative indicators of education by sex and occupational class. In her work on female-male wage ratios, Sylvia Ostry used the per cent of the work farce that completed high school as an indicator of educational level. She adjusted the wage ratio for the sex difference in education by simply multiplying the female wage rate in each occupation by the ratio of the per cent of males that had completed high school to the per cent of females. ${ }^{14}$ In this study, we 
calculated the average number of years of school attended by individuals of each sex and occupational class. The average number of years of school attended was calculated using equation 5.

(5) $E_{j i}=\left(\sum_{i j k} n_{k}^{\prime} \overline{E M}_{k}\right) / \sum_{i j k}^{n}$

Where: $\mathrm{E}_{j i}$ is the average number of years of school

$j i$ attended py persons whose sex is $j$ and who are in the $i^{\text {th }}$ occupational class;

$n_{i j k}^{\prime \prime}$ is the number of individuals in the $i^{\text {th }}$ occupation whose sex is $j$ that were recorded in the $\mathrm{k}^{\text {th }}$ educational interval;

$\overline{E M}_{k}$ is the assumed mean of the $k^{\text {th }}$ educational interval. The values of $\overline{\mathrm{EM}}_{k}$ are given in Table III.

\begin{tabular}{|c|c|c|}
\hline$\underline{\mathbf{k}}$ & Interval & $\overline{\mathrm{EM}}_{\mathrm{k}}$ \\
\hline $\begin{array}{l}1 \\
2 \\
3 \\
4 \\
5 \\
6 \\
7 \\
8 *\end{array}$ & $\begin{array}{ll}0-4 & \text { elementary } \\
5+ & \text { elementary } \\
1-2 & \text { secondary } \\
3 & \text { secondary } \\
4 & \text { secondary } \\
5 & \text { secondary } \\
\text { university } \\
\text { university degree }\end{array}$ & $\begin{array}{r}2.5 \\
6.5 \\
9.5 \\
11.0 \\
12.0 \\
13.0 \\
14.0 \\
16.0\end{array}$ \\
\hline
\end{tabular}

* $\overline{\mathrm{EM}}_{8}$ was given a value of 18.0 for two occupational classes: 140 (physidians and surgeons) and 153 (lawyers and notaries). These exceptions were based on the number (greater than 16) of years of general educational development (defined below) required for these occupations.

Worker Traits

The major data contribution of this study is the construction of a series of quantitative indicators of worker traits for census occupational classes. The United States Employment Service has estimated and published data on 48 worker traits for each of 4,000 jobs drawn from the second edition of the Dictionary of Occupational 
Titles. ${ }^{15}$ Since the occupational classification system for the 1961 Census of Canada was based in part on the Dictionary of occupational Titles, many of the 4,000 jobs correspond to occupational titles that make up the 273 census occupational classes. 16 Using the Classification Manual Census of Canada, 1961, the 4,000 jobs were sorted into the appropriate census occupational classes, and average worker traits for each census occupational class were calculated. The 4,000 jobs were matched with the census occupational titles that make up the census occupational classes on the basis of job name and industry in which the job is usually found. Not all of the 4,000 jobs correspond to the census occupational titles used to define the census occupational classes. The average worker traits for the census occupational classes are based on 2,526 jobs which are included in both the sample of 4,000 and in the Classification Manual. No jobs could be found in the sample of 4,000 for 32 of the census occupational classes. Appendix A to this study lists the census occupational classes with the jobs that were sorted into each class.

The quantitative indicators of worker traits include measurements of the training time, aptitudes, interests, temperaments, and physical capacities that a worker must possess in order to perform at an average level of competence in each occupation, as well as of working conditions that a worker must tolerate in each occupation. The worker traits were quantified by raters trained by the U.S. Employment Service. The raters used the job definitions in the Dictionary of Occupational Titles for their primary source of 
information in making their ratings. ${ }^{17}$ Raters were given instruction manuals on how to rate each trait. ${ }^{18}$ The manuals defined each trait and provided benchmark jobs for the different levels (values of the quantitative indicators) of each trait. In order to minimize correlations between the traits that might result from the rating procedure, no single rater rated more than one or two worker traits for any job. Symbols that are used to identify the quantitative indicators of traits in the remainder of this study and short descriptions of the traits are given in Table IV.

Table IV

Worker Traits

Symbol

CED

SVP

G

$\mathrm{V}$

$\mathrm{N}$

$\mathrm{S}$

$P$

Q

$\mathrm{K}$

F

M

E

C

$\mathrm{T}$

T2

T3

$\mathrm{T} 4$

T5

T6

T7

T8

T9

To

$\mathrm{TX}$

TY
Short Description 20

Training time general educational development specific vocational training Aptitudes

intelligence

verbal

numerical

spatial

form

clerical

motor coordination

finger dexterity

manual dexterity

eye-hand-foot coordination

color discrimination

Temperaments

variety and change

repetitive, short cycle

under specific instructions

direction, control, planning

dealing with people

isolation

influencing people performing under stress sensory or judgmental criteria measurable or verifiable criteria feelings, ideas, facts set limits, tolerances or standards 
Table IV / continued

Symbol

II

I2

I3

14

15

I6

I7.

I8

I9

IO

MW

P2

P3

$\mathrm{P} 4$

P5
P6

WI

W2

W3

W4

H5

w6

w7
Short Description

Interests

things and objects

business contact

routine concrete

social welfare

prestige

people, ideas

scientific, technical

abstract, creative

nonsocial

tangible, productive satisfaction

Physical capacities

maximum weight lifted

climbing-balancing

stooping-kneeling

reaching-handling

talking-hearing

seeing

Working conditions

inside

cold

heat

wet-hüid

noise-vibration

hazards

fumes, odors, etc.

The 48 worker traits are divided into six catagories: training time, aptitudes, temperaments, interests, physical capacities, and working conditions. "The Training Time component is defined as the amounts of educational development and vocational preparation necessary for a worker to have acquired the knowledge and abilities essential for average performance in a specific job". ${ }^{19}$ General educational development, CED, is education of a general academic nature that includes reasoning development, mathematical development and language development. Raters scored the amount of CED required for each job on a scale from 1 to 7. Each level of the scale corresponds to a description of a degree of development in reasoning, mathematics, and language. 
The rater's manual included benchmark jobs to illustrate the seven levels of GED. ${ }^{21}$ The seven levels of CaD can be converted to approximate school grade equivalents. However, the levels of CED may be achieved without formal study. For the purposes of this study, the seven levels of GED were converted into the corresponding number of years of formal education. The quantitative indicator of $\operatorname{GED}$ for each census occupational class was then obtained as the simple average of the number of years of formal schooling required by the jobs from the sample of 4,000 that were sorted into each census class. Since no data were available on the employment in each job within the census occupational classes, construction of an employment-weighted average was not possible. The seven levels of GED and the corresponding number of years of formal education are given in Table v. 22

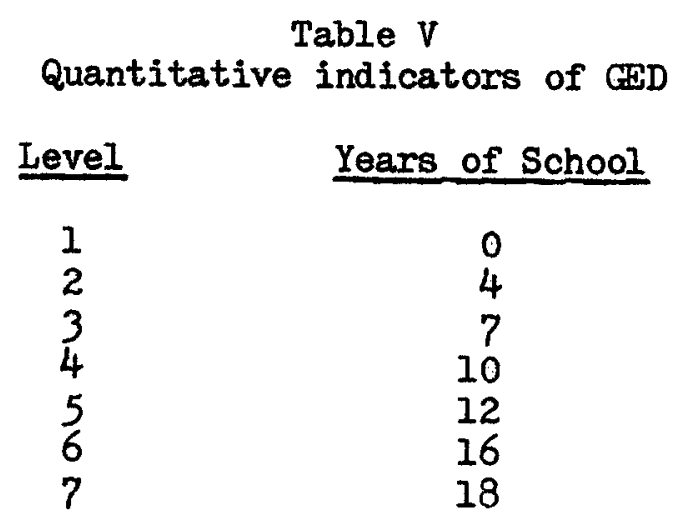

Specific vocational preparation, SVP, includes training given in rocational education, apprentice training, in-plant training, on-the-job training, and essential experience in other jobs. This is the type of training "required to leam the techniques, acquire information, and develop the facility needed for average performance 
in a specific job-worker situation". 23 Raters scored the amount of SVP required for each job on a scale from 1 to 9. Each level of the scale corresponds to an interval of time required for training. For the purposes of this study, the intervals for levels $2-8$ were replaced with their midpoints measured in the number of years of training as shown in Table VI. ${ }^{24}$ The quantitative indicator of SVP for each census occupational class was obtained as the simple average of the number of years of training required by the jobs from the sample of 4,000 that were sorted into each census class.

Table VI

Quantitative indicators of SVP

\begin{tabular}{clr} 
Level & Interval $^{25}$ & Averag \\
\hline & short demonstration & 0.000 \\
2 & up to 30 days & 0.041 \\
3 & over 30 days to 3 months & 0.165 \\
4 & over 3 months to 6 months & 0.375 \\
5 & over 6 months to 1 year & 0.750 \\
6 & over 1 year to 2 years & 1.500 \\
7 & over 2 years to 4 years & 3.000 \\
8 & over 4 years to 10 years & 7.000 \\
9 & over 10 years & 14.000
\end{tabular}

The aptitude component of the worker traits is defined as "the specific capacities or abilities required of an individual in order to facilitate the learning of some task or job duty". 26 Table VII, taken from the manual for rating aptitudes, lists the definitions of the eleven aptitudes included in this component. Table VII 27

"Definitions of Aptitude Factors"

"V--VERBAL: Ability to understand meanings of words and ideas associated with them, and to use them effectively. To comprehend language, to understand relationships between words and to understand meanings of whole sentences and paragraphs. To present information or ideas clearly." 


\section{$-78-$ \\ Table VII / continued}

"N-NUMERICAL: Ability to perform arithmetic operations quickly and accurately."

"S--SPATIAL: Ability to comprehend forms in space and understand relationships of plane and solid objects. May be used in such tasks as blueprint reading and in solving geometry problems. Frequently described as the ability to 'visualize' objects of two or three dimensions, or to think visually of geometric forms."

"P-FORM PERCEPTION: Ability to perceive pertinent detail in objects or in pictorial or graphic material. To make visual comparisons and discriminations and see slight differences in shapes and shadings of figures and widths and lengths of lines."

"Q--CLERICAL PERCEPTION: Ability to perceive pertinent detail in verbal or tabular material. To observe differences in copy, to proofread words and numbers, and to avoid perceptual errors in arithmetic computation."

"K--MOTOR COORDINATION: Ability to coordinate eyes and hands or fingers rapidly and accurately in making precise movements with speed. Ability to make a movement response accurately and quickly."

"F--FINGER DEXTERITY: Ability to move the fingers, and manipulate small objects with the fingers, rapidly or accurately."

"M--MANUAL DEXTERITY: Ability to move the hands easily and skillfully. To work with the hands in placing and turning motions."

"E--EYE-HAND-FOOT COORDINATION: Ability to perceive or recognize similarities or differences in colors, or in shades or other values of the same color. To identify a particular color, or to recognize harmonious or contrasting color combinations, or to match colors accurately."

"G--INTELLICENCE: General learning ability. The ability to 'catch on' or understand instructions and underlying principles. Ability to reason and make judgments. Closely related to doing well in school."

Raters scored the amount of each of the eleven aptitudes required by each job on a scale from 1 to 5 . The scale corresponds to how high an individual must rank in a cumulative frequency distribution of the working population with respect to each aptitude 
in order to perform satisfactorily in each job. Table VIII shows the correspondence between the scale and the intervals of a cumulative frequency distribution. 28 For the purposes of this study, the intervals were replaced by their midpoints. The quantitative indicator of each aptitude for each census occupational class was then obtained as the simple average of the ranks (midpoints) required by the jobs from the sample of 4,000 that were sorted into each census class. 29

Table VIII

Quantitative indicators of aptitudes

$\begin{array}{cll}\text { Level } & \text { Interval } & \text { Midpoint } \\ 1 & \text { upper 10\% } & 0.95000 \\ 2 & \text { upper } 1 / 3 \text { less I } & 0.78334 \\ 3 & \text { middle } 1 / 3 & 0.50000 \\ 4 & \text { lower } 1 / 3 \text { less } 5 & 0.21667 \\ 5 & \text { lowest 10\% } & 0.05000\end{array}$

The temperament component of the worker traits "consists of twelve different types of occupational situations to which workers must adjust". 30 Table IX, taken from the manual for rating temperaments, lists the definitions of the twelve temperaments included in this component.

$$
\begin{gathered}
\text { Table IX }{ }^{31} \\
\text { "Definitions of Temperament Factors" }
\end{gathered}
$$

"Tl--VARCH: Situations involving a variety of duties often characterized by frequent change."

"T2--HEPSC: Situations involving repetitive or short cycle operations carried out according to set procedures or sequences."

"T3--USI: Situations involving doing thing only under specific instruction, allowing little or no room for independent action or judgment in working out job problems." 
Table IX / continued

"T4--DCP: Situations involving the direction, control, and planning of an entire activity or the activities of others."

"T:5-DEPL: Situations involving the necessity of dealing with people in actual job duties beyond giving and receiving instructions."

"T6--ISOL: Situations involving working al one and apart in physical isolation from others, although activity may be integrated with that of others."

"T7--INFLU: Situations involving influencing people in their opinions, attitudes, or judgments about ideas or things."

"T8--PUS: Situations involving performing adequately under stress when confronted with the critical or unexpected or taking risks."

"T9--SJC: Situations involving the evaluation (arriving at generalizations, judgments, or decisions) of information against sensory or judgmental criteria."

"TO--MVC: Situations involving the evaluation (arriving at generalizations, judgments, or decisions) of information against measurable or verifiable criteria."

"TX--FIF: Situations involving the interpretation of feelings, ideas, or facts in terms of personal viewpoint."

"TY--STS: Situations involving the precise attainment of set limits, tolerances, or standards."

Raters scored only the presence or absence of each temperament for each job. "Only the two most characteristic temperament factors are indicated" as present for each job. 32 The quantitative indicator of each temperament for the census occupational classes is a dummy variable with values of either 0 or 1 . For each census class, the dumm variable corresponding to each temperament was given a value of 1 if 50 per cent or more of the jobs sorted into the census class had the temperament present. Since each job had only two temperaments indicated as present, each census class can have a maximum of only four temperaments whose quantitative indicators have a value of 1 . 
The Interests Component is defined as a preference for certain types of work activities or experiences, with accompanying rejection of contrary types of activities or experiences. Five pairs of interest factors are provided so that a positive preference for one factor of a pair also implies rejection of the other factor of that pair. Only the two most characteristic interest factors are indicated. "33 Table $\mathrm{X}$, taken from the manual for rating interests, lists the definitions of the five pairs of interest factors included in this component.

\section{Table $x^{34}$}

"Definitions of Interest Factors"

"Il--Situations involving a preference for activities dealing with Things and Objects."

"I2--Situations involving a preference for activities involving Business Contact with People."

"I3--Situations involving a preference for activities of a Routine, Concrete, Organized nature."

"I4--Situations involving a preference for Working for People for their presumed good as in the Social Welfare sense, or for dealing with People and Language in Social Situations."

"I5--Situations involving a preference for activities resulting in Prestige or the Esteem of Others."

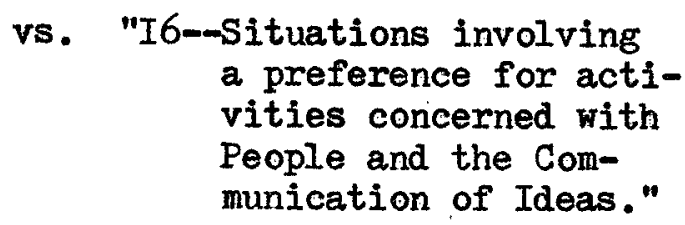
a preference for activities concerned with People and the Communication of Ideas."

vs. "I7--Situations involving a preference for activities of a Scientific and Technical nature."

vs. "I8--Situations involving a preference for activities of an Abstract and Creative nature."

vs. "I9--Situations involving a preference for activities that are Nonsocial in nature, and are carried on in relation to Process, Machines, and Techniques."

vs. "IO--Situations involving a preference for activities resulting in Tangible, Productive Satisfaction." 
The quantitative indicator of each interest for the census occupational classes is a dummy variable with values of either 1 or 0 . For each census class, the dummy variable corresponding to each interest was given a value of 1 if 50 per cent or more of the jobs sorted into the census class had the interest present. Since each job had only two interests indicated as present, each census class can have a maximum of only four interests whose quantitative indicators have a value of 1 .

The physical capacities component of the worker traits "reflects the specific physical aspects of occupations that must be performed". 35 Each job was rated on a five point scale for the strength required by the job. The manual for rating physical capacities and working conditions defined the scale in terms of an amount of weight lifted and carried. For the purposes of this study, a maximum amount of weight lifted was assigned to each of the five points of the scale. The quantitative indicator of strength, MW, for each census occupational class was then obtained as the simple average of the maximum weight lifted in each of the jobs that were sorted into the census class. The strength scale, its definitions, and the assigned maximum weights are given in Table XI.

$$
\begin{gathered}
\text { Table XI } \\
\text { Quantitative indicators of Strength }
\end{gathered}
$$

Scale

S - Sedentary

L - Light
Definition $^{36}$

"Lifting 10 poünds maximum."

"Lifting 20 pounds maximum with frequent lifting and/or carrying of objects weighing up to 10 pounds."
Maximum Weight ${ }^{*}$ 1 2 
Table XI / continued

Scale

M - Medium

H - Heavy

V - Very Heavy
Definition

Maximum Weight

"Lifting 50 pounds maximum with

frequent lifting and carrying of objects weighing up to 25 pounds."

"Lifting 100 pounds maximum

with frequent lifting and carrying of objects weighing up to 50 pounds."
"Lifting objects in excess of 100 pounds with frequent lifting and carrying of objects weighing up to 80 pounds."

* Maximum weight is measured in tens of pounds, i.e. $S$ is 10 pounds.

The remaining five physical capacities (climbing-balancing, stooping-kneeling, reaching-handling, talking-hearing, and seeing) were rated only for their presence or absence in each job. Each of these conditions was judged by the raters to be present only when a job met certain hazard or precision criteria with respect to the capacity. ${ }^{37}$ The quantitative indicators for each of these physical capacities for the census occupational classes is a dummy variable with values of either $I$ or 0 . For each census class, the dummy variable corresponding to each capacity was given a value of 1 if 50 per cent or more of the jobs sorted into the census class had the capacity scored as present. For each census occupational class, all five of these capacities may have indicators with values of 1 (or all may be 0 ).

The working conditions component of the worker traits "reflects the physical surroundings in which specific occupational activities 


$$
-84-
$$

are carried out". 38 Each job was rated "Inside or Outside or Both, depending on whether three-quarters of the working time were spent indoors or outdoors". 39 The quantitative indicator of inside-outside, WI, for the census classes is a dummy variable with values of either 1 or 0 . For each census class, the dummy variable was given a value of $I$ if 50 per cent or more of the jobs sorted into the census class were scored "Inside".

The remaining six working conditions (cold, heat, wet-humid, noise-vibration, hazards, and fumes, odors, etc.) were rated only for their presence or absence. As in the case of physical capacities, these conditions were only judged to be present when certain specific criteria were met. 40 The quantitative indicator for each of these working conditions for the census classes is a dummy variable. As in previous instances, the dummy variable corresponding to each working condition was given a value of 1 if 50 per cent or more of the jobs sorted into the census class were scored with the condition present. For each census occupational class, all six of these conditions mave indicators with values of 1 (or all may be 0 ). Sample Size

The regression equations that are presented in the following chapter were estimated by considering each occupation as an observation. Not all of the 273 census occupational classes could be used for this purpose. Forty five of the 273 census occupational classes contain no women. While zero is an acceptable value for employment, zero is not an acceptable value for the female wage rate in these occupations. We have no way of knowing how much 
employers would be willing to pay to hire one woman in these occupations, or how little a woman would be willing to accept in order to take a job in these occupations. Consequently, these occupations are excluded from our analysis. Similarly, there are five census occupational classes in which less than five women are employed. Employment and wage data are not published for these occupations, therefore they too are excluded from our analysis. As mentioned earlier, data for worker traits could not be found for 32 of the census occupational classes, so these occupations are also excluded from our analysis due to the incomplete data. For two occupations, delivery managers and oilers and greasers, employment, wage, and worker trait data are available, but age and education data are not published. Since these occupations include only 15 women, they are excluded from our analysis. The occupational class "farmers and stockraisers" is excluded from our analysis since it is defined so as not to include any wage-earners. Finally, the occupational class "judges and magistrates" is excluded from our sample. This exclusion was based on the questionable estimate of 14 years for the amount of specific vocational training required for the occupation. This exclusion could also be justified by the difference in selection procedures for U.S. judges as compared to the procedure for selecting Canadian judges.

The sample used for the regressions in the following chapter consists of the remaining 194 occupations. Since the data used in these regressions are not easily obtained, Appendix B to this study lists the 194 occupations with their corresponding data. 
It is possible that the method of selecting our sample could affect the properties of our estimates in the next chapter. We know that 45 of the 273 occupational classes are "bunched" at the value of zero for the male-female employment ratio. Tobin has discussed an estination procedure that yields consistent estimates if the underlying model applies both to a continuous range for the variables and to an upper or lower limit for the dependent variable. For example, when studing individual consumer purchases of automobiles we find that most consumers in a given year will not purchase an automobile. Tobit analysis is based on the assumption that the same variables determine both the decision whether or not to buy as well as the decision of how much to buy. ${ }^{41}$. The maximum likelyhood estimator for the parameters in such a relation is not the same as ordinary least squares. It is possible that the independent variables that determine the male-female employment ratio for our sample of 194 occupations also determine that no women will be hired in the 45 occupations we have excluded. If this is the case, ordinary least squares will not yield consistent estimates.

We will use ordinary least squares in the next chapter. If the assumptions of Tobit analysis apply to our model our estimates will not be consistent, i.e. the probability limit of our estimators will not be equal to the true value of the parameters. The properties of our estimators will always depend on the validity of the underlying assumptions. The concentration of 45 occupations with no women is cause for concern. However we would have to assume that our model applies to these occupations in the same manner as it does 
to our sample of 194 occupations and we would require the corresponding wage data if we were to consider using Tobit analysis. Even if Tobit analysis would yield consistent estimates there is no assurance that it would perform well with the size of our sample. 42 An asymptotic property of an estimator is useful when we can increase our sample size so as to reduce errors. We do not have that luxury. 


\section{$-88-$ \\ Chapter 4: Notes}

1. Dominion Bureau of Statistics, Guide to Federal Government Labour Statistics, 1969. (Ottawa: Queen's Printer, 1970).

2. Dominion Bureau of Statistics, Occupational Classification Manual Census of Canada, 1961 (Ottawa: Queen's Printer, 1961), p. 7.

3. Dominion Bureau of Statistics, 1961 Census of Canada, Introductory Report to Volume III, Bulletin 3.3-15 (ottawa: Queen's Printer, 1965), pp. XXIV-XXVII.

4. Ibid., P. XXXI.

5. Melvin W. Redex, "Wage Differentials: Theory and Measurement" in Aspects of Labor Economics (New York: National Bureau of Economic Research, 1962), pp. 257-299.

6. Sylvia Ostry, The Female Worker in Canada (Ottawa: Queen's Printer, 1968), p. 41 .

7. Dominion Bureau of Statistics, 1961 Census of Canada, Labour Force, Bulletin 3.3-7 (Ottawa: Queen's Printer, 1963), Table 21, pp. 21-1 2I-15.

8. I am grateful to Ms. C. Silver of the Economic Characteristics Section, Census Division, Statistics Canada for providing these data.

9. Dominion Bureau of Statistics, 1961 Census of Canada, Labour Force, Bulletin 3.3-7. Table 24, pp. 24-1 $-24-2$.

10. I am grateful for correspondence with Ms A.J. Kempster, Chief, Economic Characteristics Section, Census Division, Statistics Canada and for her comments on the interval of hours, 50+. Ms. Kempster warned that the census data on hours might be affected by seasonality. However, I was unable to find other data on hours that could be used for all of the census occupational classes. The census questionnaire asked how many hours are usually worked each week. Consequently, seasonality might not be a problem.

M's' Kempster suggested using 56 as the mid-point of the 50+ interval if other sources did not indicate a better value. The value actually used was chosen by considering the distribution of all wage-earners among the intervals of hours. The highest average number of hours worked per week during the 1961 census year was 41.0 for June 1961 for all manufactures and 41.3 for June 1961 for durable goods (DBS, Review of Man-Hours and Hourly Earnings, 1945-1963, p. 27). Using the mid-points for the first five intervals as shown in Table II and the distribution of all wage earners, a value of 54.83 was calculated as the midpoint for the open ended interval that yielded an average work week of 41.3 hours. 
11. Dominion Bureau of Statistics, 1961 Census of Canada, Labour. Force, Bulletin 3.1-9 (Ottawa: Queen's Printer, 1963), Table 17, pp. $17-1,-17-30$.

12. Dominion Bureau of Statistics, 1961 Census of Canada, Introductory Report to Volume III, Bulletin 3.3-15 (0t tawa: Queen's Printer, 1965), pp. XII-XIII.

13. I am grateful to Ms. C. Silver of the Economic Characteristics Section, Census Division, Statistics Canada for providing these data.

14. Oștry, Op. Git., p. 43, Table 17, note f.

15. U.S. Department of Labor, Bureau of Employment Security, Estimates of Horker Trait Requirements for 4,000 Jobs (Washington: U.S. Government Printing Office, 1956), hereafter cited as Traits.

16. This method was discussed through correspondence with the Census Division. I am grateful to Mr. Frank Levin for his comments on the methodology followed here.

17. Traits, p. iv.

18. Traits, p. v, pp. 110-158.

19. Traits, p. v.

20. Traits, template.

21. Traits, pp. 110-120.

22. Traits, p. 111; also see R.S. Eckaus, "Economic Criteria for Education and Training", The Review of Economics and Statistics, May, 1964, pp. 181-190.

23. Traits, p. 110.

24. Traits, p. 110; also see Eckaus, Op. Git.

25. Traits, p. 110.

26. Traits, p. 121.

27. Traits, pp. 121-122.

28. Traits, template.

29. James G. Scoville used these data in his study of The Job Content of the U.S. Economy, 1940-1970 (New York: MeGraw Hill Book Company, 1969) and The Job Content of the Canadian Econony, 1941, 1951, and 1961 (Ottawa: Queen's Printer, 1967). Scoville apparently aggregated the aptitudes required by the jobs in each census class without allowing for the different sizes of the intervals represented by the scale of 1 to 5 . 
30. Traits, p. vi.

31. Traits, p. 131.

32. Traits, p. vi.

33. Traits, p. vi.

34. Traits, p. 136.

35. Traits, p. vi.

36. Traits, pp. 145-146.

37. Traits, p. vi.

38. Traits, p. vi.

39. Traits, p. vi.

40. Traits; p. vi.

41. James Tobin, "Estimation of Relationships for Limited Dependent Variables", Econometrica, 1958, pp. 24-36.

42. Carl F. Christ, Econometric Models and Methods (New York: John Wiley \& Sons, Inc., 1966), p. 264. 
Chapter 5: Results

\section{Data Description}

The male-female employment ratio ranges from a low value of 0.023 for "nurses-in-training" to a high value of 2673.5 for "electricians, wiremen and electrical repairmen". It is interesting to examine our data to determine whether extreme values of the employment ratio are clustered in particular occupational divisions. Table XII presents the distribution of the 194 occupational groups by occupational division and by intervals of the range of values for the employment ratio. Since our regression analysis uses the logarithm of the employment ratio, the intervals used in Table XII were chosen as equal thirds of the range of the ratio in logarithmic form.

A Chi-squared statistic with a value of 37.65 can be computed for Table XII. However, since there are several cells in Table XII in which the expected number of occupational groups is quite small (less than 5), we are unable to interpret the Chi-squared statistic. It is interesting to note that there is no obvious clustering of occupational groups in the table. The two extreme cases are 6 occupational groups dominated by women in the clerical division and 6 occupational groups dominated by men in the "other" division. The two extremes differ from expected frequencies by approximately threefold. Such extremes are unusual in the remainder of the table. 
Actual and Expected ${ }^{a}$ Number of Occupational Groups ${ }^{b}$ by Occupational Division and by Interval of Male-Female Employment Ratioc Interval of Ratio

Division

$0.023 \quad 1.122 \quad 54.781$

$-1.122-54.781-2673.490-2673.490$

Managerial

$\begin{array}{llll}0 & 5 & 0 & 5 \\ (0.9) & (2.9) & (1.2) & \end{array}$

Professional and Technical

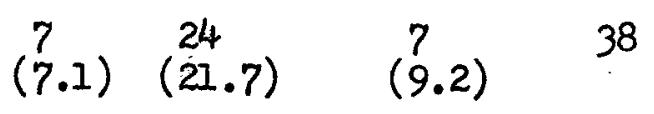

Clerical

$\begin{array}{llll}6 & 3 & 0 & 9\end{array}$

Sales

$\begin{array}{llll}2 & 4 & 1 & 7 \\ (1.3) & (4.0) & (1.7) & \end{array}$

Service and Recreation

$\begin{array}{llll}6 & 10 & 3 & 19\end{array}$

Transport and Communications

$\begin{array}{llll}1 & 4 & 6 & 11\end{array}$

Craftsmen, Production \& Related 14 $(17.8) \quad \begin{array}{ll}58 & 24 \\ 54.9 & (23.3)\end{array}$

96

other ${ }^{d}$

$$
\begin{array}{lllll} 
& 0 & 3 & 6 & 9 \\
& (1.7) & (5.1) & (2.2) & \\
\text { All Divisions } & 36 & 111 & 47 & 194
\end{array}
$$

a) The expected number in parentheses is calculated on the null hypothesis that occupational division and interval of the employment ratio are independent.

b) The table is limited to the 194 groups discussed on page 84 above.

c) This is the adjusted employment ratio; see page 68 above.

d) "Other" includes farmers and farm workers; fishermen, trappers and hunters; miners, quarrymen and related workers; and labourers, n.e.s. 


\section{Regression}

The theory developed in Chapter 3 leads to the following equation that relates the male-female employment ratio to the female-male wage ratio, specific vocational training time and a vector of quantitative indicators of factors considered necessary for effective job performance. ${ }^{1}$

$$
\text { (1) } \log \left(L_{q m i} / L_{q f i}\right)=\sigma \cdot \log \left(W_{f i} / w_{m i}\right)+\theta \cdot S V P_{i}+X_{i} A+u_{i}
$$

Table IV lists variables that may be included as elements in the $X$ vector. A constant, denoted by VC, may be included as an element in the $X$ vector. The inclusion of a constant is justified as a result of the assumption of linear approximation that yielded equation 1. Linear approximation by a Taylor expansion, for example, produces a constant term dependent upon the point of approximation. ${ }^{2}$

The wage and employment data were adjusted by the methods described in Chapter 4 for differences between men and women in time worked. It would be desirable to adjust for other observable variables that affect the quantity or quality of work as opposed to the worker trait variables that indicate requirements of each occupation. Age, sometimes used as a proxy variable for experience (and sometime for job ineligibility), and education are two observable variables which can be included in equation $I$ so as to adjust for their effect on the quantity or quality of male and female labour. The ratio of the average age of males to the average age of females employed in the $i^{\text {th }}$ occupation will be denoted by MATFA $i$.

The value of the correlation coefficient between average education of males and general educational development, GED, is 0.82 . 
The correlation coefficient between average education of females and GED is 0.73. It is not necessary to include each of these variables. GED is included to measure the minimum general educational development required in each occupation. The ratio of the average number of years of school attained by males to the average attained by females, $M E T F E$, is included to adjust for possible differences by sex in the quality of labour. For convenience, MATFA $i$ and METFE $i$ are included as elements of the $x_{i}$ vector.

There are fifty one possible elements in the $\mathrm{X}$ vector. In order to reduce the number of elements in $X$ to manageable proportions the parameters in equation $I$ were estimated by means of a stepwise regression program. The program considered all of the possible elements in $X$ and included only those elements in the regression that had coefficients which were significantly different from zero at or below the 0.05 level.

Table XIII lists estimates for the parameters in equation 1 . In equation 2 the wage ratio was deleted from the regression. In equation 3 the wage ratio was forced to be included in the regression since its coefficient is significantly different from zero at the 0.11 level and the stepwise program would otherwise have deleted it.

Notice that with the exception of the coefficient for TY all coefficients in equation 3 are consistent in size (within 10\%) and sign with those in equation 2 . When the wage ratio was included in equation 3 the stepwise program added $P$ and deleted $I$. With the use of a stepwise program this sort of minor change is not surprising for variables that are close to the cutoff point. 
Table XIII

Estimates of Parameters

equation 2

\begin{tabular}{|c|c|c|c|c|}
\hline Variable $^{a}$ & $\begin{array}{l}\text { Coeffi- } \\
\text { cient }\end{array}$ & $\begin{array}{l}\text { Standard } \\
\text { Error }\end{array}$ & $\begin{array}{l}\text { Coeffi- } \\
\text { cient }\end{array}$ & $\begin{array}{l}\text { Standard } \\
\text { Error }\end{array}$ \\
\hline $\begin{array}{l}\text { VC } \\
\text { SVP } \\
\mathrm{N} \\
\mathrm{S} \\
\mathrm{P} \\
\mathrm{K} \\
\mathrm{E} \\
\mathrm{TX} \\
\mathrm{TY} \\
\mathrm{I} 1 \\
\mathrm{I} 2 \\
\mathrm{I} 4 \\
\mathrm{MW} \\
\mathrm{METFE} \\
\ln \left(\mathrm{W}_{\mathrm{f}} / \mathrm{W}_{\mathrm{m}}\right)\end{array}$ & $\begin{array}{r}8.2662 \\
0.2715 \\
2.8191 \\
4.2661 \\
-2.8437 \\
2.8106 \\
-2.0997 \\
-0.6501 \\
0.4270 \\
-0.6651 \\
-3.0618 \\
0.1400 \\
-8.9857\end{array}$ & $\begin{array}{l}0.7650 \\
0.0614 \\
0.5911 \\
0.6632 \\
0.7892 \\
0.9410 \\
0.4126 \\
0.2116 \\
0.1960 \\
0.2721 \\
0.3579 \\
0.0620 \\
0.6218\end{array}$ & $\begin{array}{r}8.8724 \\
0.2585 \\
3.0106 \\
4.9852 \\
-1.6209 \\
-2.5548 \\
2.1950 \\
-2.0988 \\
-0.4868 \\
-0.7209 \\
-3.2848 \\
0.1581 \\
-8.8841 \\
0.7700\end{array}$ & $\begin{array}{l}0.7556 \\
0.0607 \\
0.6033 \\
0.7118 \\
0.8130 \\
0.8522 \\
0.9859 \\
0.4117 \\
0.2141 \\
0.2719 \\
0.3645 \\
0.0621 \\
0.6222 \\
0.4847\end{array}$ \\
\hline $\begin{array}{r}\text { Coefficie } \\
\text { Dete } \\
\text { Standand }\end{array}$ & $\begin{array}{l}\text { of } \\
\text { ination } \\
\text { ror }\end{array}$ & $\begin{array}{l}0.7839 \\
1.1426\end{array}$ & & $\begin{array}{l}0.7866 \\
1.1385\end{array}$ \\
\hline
\end{tabular}

a) See Table IV, pp. 74-75 for definitions.

We can compare the relative impact of the independent variables on the logarithm of the male-female employment ratio by reference to Table XIV. "Impact" is measured by the product of the square of a variable's regression coefficient and the ratio of the variance of the independent variable to the variance of the dependent variable. 
Table XIV

Means, Standard Deviations and "Impact" ${ }^{a}$ of Independent Variables

$\begin{array}{lllll}\text { Variable } & \text { Mean } & \begin{array}{l}\text { Standard } \\ \text { Deviation }\end{array} & \begin{array}{l}\text { Impact in } \\ \text { equation 2 }\end{array} & \begin{array}{l}\text { Impact } \\ \text { equation }\end{array} \\ \text { In }\left(\mathrm{I}_{\mathrm{qm}} / \mathrm{L}_{\mathrm{qf}}\right) & 2.27984 & 2.38023 & & \\ \mathrm{SVP} & 2.06423 & 1.86431 & 0.04522 & 0.01543 \\ \mathrm{~N} & 0.40104 & 0.22108 & 0.06856 & 0.07819 \\ \mathrm{~S} & 0.40239 & 0.19232 & 0.11882 & 0.16225 \\ \mathrm{P} & 0.48310 & 0.17928 & & 0.01491 \\ \mathrm{~K} & 0.37485 & 0.14527 & 0.03012 & 0.02431 \\ \mathrm{E} & 0.10641 & 0.09776 & 0.01332 & 0.00813 \\ \mathrm{TX} & 0.04639 & 0.21088 & 0.03460 & 0.03457 \\ \mathrm{TY} & 0.56701 & 0.49677 & 0.01841 & 0.01032 \\ \mathrm{II} & 0.31959 & 0.46752 & 0.00703 & \\ \mathrm{I2} & 0.15979 & 0.36736 & 0.01054 & 0.01238 \\ \mathrm{I4} & 0.07217 & 0.25943 & 0.11136 & 0.12817 \\ \mathrm{MW} & 2.98866 & 1.64180 & 0.00933 & 0.01189 \\ \mathrm{METFE} & 0.93357 & 0.16958 & 0.40990 & 0.40069 \\ \mathrm{In}\left(\mathrm{W}_{\mathrm{f}} / \mathrm{W}_{\mathrm{m}}\right) & -0.37068 & 0.17371 & & 0.00316\end{array}$

a) Impact is calculated as the product of the squared regression coefficient from Table XIII and the ratio of the variable's variance to the variance of $\ln \left(\mathrm{L}_{\mathrm{qm}} / \mathrm{L}_{\mathrm{qf}}\right)$.

Education

The impact of the education ratio is from 2.5 to 127 times greater than the impact of any other variable. The education ratio, METFE, was included in the regressions so as to adjust for possible differences in the quality of male and female labour. If this is the actual effect of including NETFE and education is considered to increase productivity, we would expect the coefficient for METFE shown in Table XIII to be positive. The negative coefficient for METFE indicates the rather strange result that male employment decreases relative to female employment as male education increases relative to female education. We could simply change our assumption and maintain that there is an inverse relation between education and productivity. 
A less drastic but similar explanation of this strange result involves "over qualification". Employers might be reluctant to hire staff who are over qualified. A negative correlation between the male-female education ratio and the level of general educational development would be consistent with this explanation. However, the value of the correlation coefficient between METFE and GED is positive, 0.41 .

Multicollinearity can produce incorrectly signed regression coefficients. The Coefficient for METFE is, however, negative even in the simple regression shown as equation 4. The numbers in parenthesis are standard errors of the regression coefficients. (4) $\begin{aligned} & \text { In }\left(\mathrm{I}_{\mathrm{qm}} / \mathrm{L}_{\mathrm{qf}}\right)=\frac{9.9749}{(0.7779)}-\frac{8.2426 \mathrm{METFE}}{(0.8199)} \\ & \mathrm{R}^{2}=0.3449\end{aligned}$

Extreme observations can produce unexpected results in regression analysis. In order to determine whether the negative METFE coefficient is related to extreme observations we can examine simple regressions of In ( $\mathrm{L}_{\mathrm{qm}} / \mathrm{L}_{\mathrm{qf}}$ ) on METFE by the intervals of the malefemale employment ratio used in Table XII. Equation A is based on the interval $0.023-1.122$. Equation $B$ is based on the interval $1.122-54.781$. When an equation was estimated for the interval $54.781-2673.490$ the results were insignificant. However, when the 7 professional and technical occupational groups were excluded from this interval the results became significant. The average education ratio for the 7 occupations is 1.25 compared to an average of 0.73 for the remaining 40 occupations. Equation $C$ is based on 40 occupations for the interval $54.781-2673.490$. 
(A) $\ln \left(\mathrm{L}_{\mathrm{qm}} / \mathrm{L}_{\mathrm{qf}}\right)=\frac{5.2552}{(0.1676)}-\frac{5.95064 \mathrm{METFE}}{(1.79341)}$
$\mathrm{R}^{2}=0.2446$

(B) $\quad \begin{aligned} & \text { In }\left(\mathrm{L}_{\mathrm{qm}} / \mathrm{L}_{\mathrm{qf}}\right)= \\ & \mathrm{R}^{2}=0.2294\end{aligned}$ (C) $\quad$ In $\left(\mathrm{L}_{\mathrm{qm}} / \mathrm{L}_{\mathrm{qf}}\right)=\frac{8.12895-)^{3.9689} \mathrm{METFE}}{(0.15866)(1.80579)}$
$\mathrm{R}^{2}=0.1128$

The coefficient for METHE remained negative in all cases. It is possible that the negative coefficients in equations $A, B$, and $C$ result from a relation between the wage ratio and the education ratio. As male education increases relative to female education we might expect the female-male wage ratio to decline. The simple correlation coefficient between METF and $\ln \left(W_{f} / w_{m}\right)$ for our sample of 194 occupations is only -0.13 . The samples used for equations $A^{\prime}, B^{\prime}$, and $C^{\prime}$ correspond to those used for equations $A$, $B$, and $\mathrm{C}$.

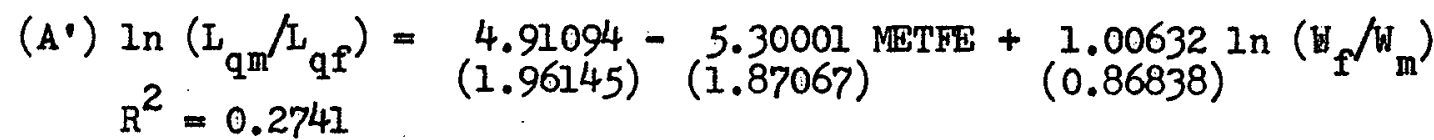
(B') $\ln \left(\mathrm{I}_{\mathrm{qm}} / \mathrm{L}_{\mathrm{qf}}\right)=\underset{(0.75523)}{6.13891}-\frac{4.21201}{(0.74417)} \mathrm{METFE}+\underset{(0.53123)}{0.10102} \ln \left(\mathrm{W}_{\mathrm{f}} / \mathrm{W}_{\mathrm{m}}\right)$ (c.) $\ln \left(\mathrm{I}_{\mathrm{qm}} / \mathrm{L}_{\mathrm{qf}}\right)=\frac{8.73911}{(1.27174)}-\underset{(1.70649)}{3.79142 \mathrm{METFE}}+\frac{2.20211}{(0.92780)} \ln \left(\mathrm{W}_{\mathrm{f}} / \mathrm{W}_{\mathrm{m}}\right)$
$\mathrm{R}^{2}=0.2300$ The coefficient for METFE remained negative even when $\ln \left(W_{f} / W_{m}\right)$ was included in the regressions. The simple correlation between METFE and In $\left(W_{f} / W_{m}\right)$ remained low for each of the subgroups. The simple correlations between METFE and $\ln \left(H_{f} / W_{m}\right)$ are $-0.30,-0.16$, and -0.04 for samples $A^{\prime}, B^{\prime}$, and $C^{\prime}$ respectively. 
It is possible that METFE serves as a proxy variable for strength, MW. The value of the correlation coefficient between NETFE and MW is -0.45 . As male education increases relative to female education the quantitative indicator for strength decreases. Female employment increases relative to male employment as strength required decreases.

Finally, consider occupations that are dominated by one of the sexes. It is possible that employers would only hire members of the non-dominant sex. if they had education in excess of that possessed by the dominant sex. It is sometimes said that a person in a minority group must be exceptional in order to be accepted. A few exceptional women might be accepted into male dominated occupations. A few men training for higher positions, e.g. teachers training to become principals, might be accepted into female dominated occupations. This interpretation is consistent with Caplow's suggestion that few groups consist of both sexes. ${ }^{3}$ It is possible with this interpretation that the negative coefficient indicates discrimination. If more education increases productivity, the acceptance of exceptional individuals of the excluded sex could counteract the effect of discrimination coefficients as described by Becker. 4 Employer Investment

Specific vocational preparation, SVP, was defined in Chapter 4 as the type of training "required to learn the techniques, acquire information, and develop the facility needed for average performance in a specific job-worker situation." 5 This can be contrasted with GED, general educational development, which was not significant in 
equations 2 or 3 . General educational development was defined in Chapter 4 as education of a general academic nature. Interpreting SVP as a measure of employer investment (as was assumed in Chapter 3) the positive coefficients indicate that men are employed in preference to women as employer investment increases. Across the 194 occupations the average value of SVP is 2.06 years of training. The coefficient of SVP is 0.27 . Since the employment ratio is expressed in logarithmic form, this can be interpreted as meaning that an additional year of vocational training requirement results in a 27 per cent increase in the employment ratio.

SVP in our regressions is particularily important since it provides a major reason why employers act under uncertainty. However, as mentioned in Chapter 3, our proxy might actually be a measure of employee investment or a measure of both employee and employer investment. If the alternative interpretation of the proxy were correct, the positive coefficient could be interpreted as being consistent with Mincer's suggestion regarding sex differences in human capital investments. 6

Aptitudes

The aptitudes $N, S, P, K$, and $E$ are included in the regressions in Table XIII. The aptitude component of the worker traits is defined as "the specific capacities or abilities required of an individual in order to facilitate the learning of some task or job duty. "? The aptitudes are measured by the cumulative frequency distribution discussed in Chapter 4.

The numerical aptitude, $\mathrm{N}$, is defined as the "ability to perform 
arithmetic operations quickly and accurately. "8 Men might be believed to be better at numerical tasks than women. Whether there is evidence to support this belief will be examined below. The coefficients in Table XIII on numerical ability, $\mathrm{N}$, are positive. This indicates that, other things equal, as the amount of numerical ability required in order to perform in an occupation increases, the number of men employed in the occupation increases relative to the number of women employed in the occupation.

The spatial aptitude, $\mathrm{S}$, is defined as the "ability to comprehend forms in space and understand relationships of plane and solid objects." 9 This is "frequently described as the ability to visualize objects in two or three dimensions, or to think visually of geometric forms. "10 The coefficients in Table XIII on spatial ability, $S$, are positive and more than six times greater than their standard errors; furthermore, the impact of spatial aptitude as shown in Table XIV is second only to the education ratio. The sign of the coefficient is consistent with the attitude that men have superior spatial ability than women. The magnitude of the impact of spatial ability is consistent with either an actual and important sex difference in spatial ability or a general acceptance of a sex stereotype. Form perception, $P$, is defined as the "ability to perceive detail in objects or in pictorial or graphic material" and the ability to "make visual comparisons and discriminations and see slight differences in shapes and shadings of figures and widths and lengths of lines." Il This is more of an ability related to sorting objects as compared with the spatial aptitude which refers to abstract 
visualization. Unlike $s$ the coefficient on form perception,p, is negative. This corresponds with a stereotype that men are better at spatial perception and women are better at fine detail such as sorting. These stereotypes are examined below.

Motor coordination, $\mathrm{K}$, is defined as the "ability to coordinate eyes and hands or fingers rapidly and accurately in making precise movements with speed. "12 This ability is similar to form perception in that it is a useful trait for such things as typing or sorting. Across the 194 occupations the correlation coefficient between $P$ and $K$ is 0.59 as compared to a value of 0.07 between $N$ and $K$. Like $P$ the coefficient on motor coordination, $\mathrm{K}$, is negative which indicates that there are more women (lower $\mathrm{L}_{\mathrm{qm}} / \mathrm{L}_{\mathrm{qf}}$ ratio) in occupations calling for precision.

Eye-hand-foot coordination, E, is defined as the "ability to move the hand and foot coordinately with each other in accordance with visual stimuli." 13 This is the sort of ability that is required of a truck driver. The coefficient of $E$ is positive.

\section{Temperaments}

The two temperaments $\mathrm{TX}$ and $\mathrm{TY}$ of the twelve discussed in Chapter 4 are included in both regressions in Table XIII. The temperament component of the worker traits "consists of twelve different types of occupational situations to which workers must adjust."14 The temperaments are measured with a zero-one dummy variable.

A value of one for TX indicates "situations involving the interpretation of feelings, ideas or facts in terms of personal 
viewpoint." 15 Only 4.6 per cent of the 194 occupations call for this trait. The negative coefficient for this trait corresponds to a stereotype that women are better at expressing "personal viewpoints" or interpreting "feelings".

A value of one for TY indicates "situations involving the precise attainment of set limits, tolerances, or standards." 16 of the 194 occupations 56.7 per cent call for this trait. The coefficient on this trait is negative. This is consistent with the stereotype that women are better at precision tasks. Compatible results were obtained for the aptitudes $P$ and $K$. Interests

Three interests, II, I2 and I4, are included in Table XIII. "The interests component of the worker traits is defined as a preference for certain types of work activities or experiences, with accompanying rejection of contrary types of activities or experiences. "17 The interests are measured by a zero-one dummy variable.

A value of one for Il indicates "situations involving a preference for activities dealing with things and objects. "18 This indicates a rejection of "situations involving a preference for activities concerned with people and the communication of ideas."19 of the 194 occupations 34 per cent indicate the presence of this interest requirement. The positive coefficient for Il in Table XIII corresponds to a stereotype that men are less people oriented than women. Il had the lowest impact of the variables included in equation 2. The stepwise program delected Il from equation 3.

A value of one for $I 2$ indicates "situations involving a preference for activities involving business contact with people." 20 
This indicates a rejection of "situations involving a preference for activities of a scientific and technical nature. "2l of the 194 occupations 16 per cent indicate the presence of this interest requirement. The coefficient for I2 is negative which (Iike II) corresponds to a stereotype that women are more people oriented than men.

A value of one for I4 indicates "situations involving a preference for working for people for their presumed good as in the social welfare sense, or for dealing with people and language in social situations."22 This indicates a rejection of "situations involving a preference for activities that are nonsocial in nature, and are carried on in relation to process, machines and techniques." 23 Only 7.2 per cent of the 194 occupations indicate the presence of this interest requirement. The negative coefficient corresponds to a stereotype that women are more socially oriented. The value of the coefficient is almost nine times greater than its standard error and the impact of this trait is similar in magnitude to spatial ability.

\section{Working Conditions}

The worker traits also included indicators for working conditions and physical capacities. Physical capacities reflect "the specific physical aspects of occupations that must be performed. ${ }^{24}$ Working conditions reflect "the physical surrounding in which specific occupational activities are carried out." 25 of the 13 indicators of working conditions and physical capacities that were discussed in Chapter 4, only $\mathrm{MW}$ is included as a significant variable in Table XIII. 
MW, the quantitative indicator of strength, indicates the maximum weight that may be lifted in an occupation. $M W$ is measured in tens of pounds and has an average value over the occupations of 2.99 or 29.9 pounds. As might be expected the coefficient for $M W$ is positive. However, its impact makes it the smallest of the values in Table XIV. This is a useful result to recall when one hears allegations that strength determines the exclusion of women from many occupations. Elasticity

Since the employment ratio and the wage ratio were expressed in logarithmic form, the coefficient for the logarithm of the wage ratio in equation $3,0.77$, can be interpreted as the elasticity of substitution between male and female labour with respect to their wage ratio. However the equation 3 estimate of the elasticity of substitution, $\sigma$, is not significantly different from zero at the 0.05 level. If it were accepted that the elasticity of substitution were not significantly different from zero, then the answer to Cassel's paradox would be trivial. If this were the case it would mean that male and female labour are completely distinct factors of production. This would be consistent with complete occupational segregation by sex at a job title level within each occupational group. If we weaken the strength of our test to a significance level of 0.11 , we can accept the equation 3 estimate as being different from zero. Without weakening the strength of our test we can examine alternative estimates of $\sigma$. Examination of alternative estimates and the problems involved in estimating $\sigma$ will allow us to reject the conclusion that there is complete occupational segre- 
gation by sex.

Ernst R. Berndt has discussed the problems of estimating elasticities of substitution. 26 Let $\sigma_{1}$ be the estimate of the elasticity of substitution obtained by regressing the logarithm of a factor input ratio on the logarithm of the factor price ratio and a set of other exogenous variables. Let $R_{1}^{2}$ be the squared correlation coefficient for this regression. Let $\sigma_{2}$ be the estimate of the elasticity of substitution obtained by regressing the logarithm of a factor price ratio on the logarithm of the factor input ratio and the set of exogenous variables, and let $\mathrm{R}_{2}^{2}$ be the squared correlation coefficient for this regression. Berndt has shown that for a simple regression (only) that $\sigma_{1} \leqq \sigma_{2}$ since $\sigma_{1} / \sigma_{2}=R_{1}^{2}=R_{2}^{2} \leqq 1.27$

For purposes of comparing estimates of the elasticity of substitution we can regress the female-male wage ratio on the male-female employment ratio. We have not developed a complete labour market model that would rationalize this inverse specification. However, by assuming that some inverse relation exists we are able to more closely examine our estimate of the elasticity of substitution. Equations 5 and 6 provide alternative estimates of the elasticity of substitution. The numbers in parentheses are standard errors of the regression coefficients.
(5) $\ln \left(W_{f} / W_{m}\right)=\frac{-0.3866+0.006886 \ln \left(L_{q m} / I_{q f}\right)}{(0.0173)}$ $R^{2}=0.0092$
(6) $\ln \left(L_{q m} / L_{q f}\right)=\frac{2.7660}{(0.4028)}+1.3117 \ln \left(W_{f} / W_{m}\right)$ $R^{2}=0.0092$ 


$$
-107-
$$

The estimate of $\sigma$ obtained from equation 5 is 143.1 $(1 / 0.006886)$. While this estimate is not significantly different from zero at the 0.05 level, it serves to illustrate how sensitive our estimate is to variations in the specification of the underlying model. Equations $A^{\prime}, B^{\prime}$, and $C^{\prime}$ provide further alternatives. The equation $C^{\prime}$ estimate ( $\left.p .98\right)$ of $\sigma$ for male dominated occupations is 2.2 , and this estimate is significantly different from zero at the 0.05 level.

Two further alternative estimates can be obtained by utilizing our complete data base. In equation 7 we assume the elasticity of substitution has an infinite value for all occupations. In equation 8 , as in all other equations other than 7, we assume that the elasticity of substitution has a finite but constant value for all occupations.

(7) $\ln \left(\omega_{f} / H_{m}\right)=X^{\prime} A^{\prime}+u^{\prime}$

(8) $\ln \left(W_{f} / W_{m}\right)=X^{\prime \prime} A^{\prime \prime}+(1 / \sigma) \ln \left(L_{q m} / L_{q f}\right)+u^{\prime \prime}$

As in the case of equations 2 and 3 the elements of $X^{\prime}$ and $X^{\prime \prime}$ were chosen by estimating the parameters in equations 7 and 8 with the use of a stepwise regression program. 28 The results of this estimation are shown in Table XV.

Table XV

Estimation of Parameters for Measuring Elasticity

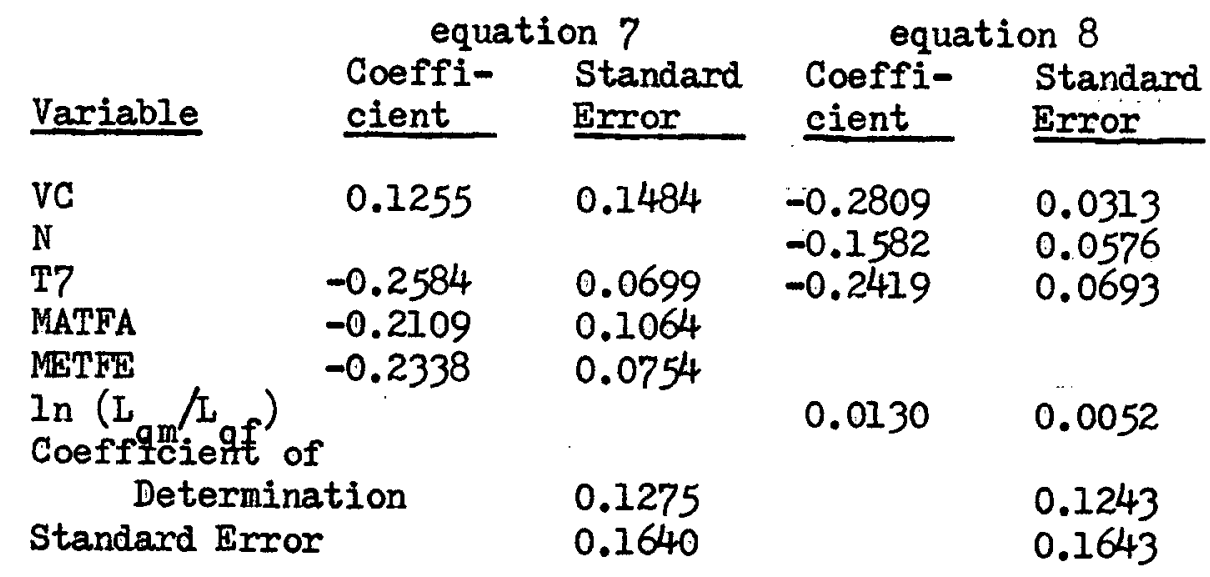


The estimate of the elasticity of substitution obtained from equation 3 is 0.7700 . This estimate is only significant at the 0.1097 level. By contrast, the estimate of one over the elasticity of substitution obtained from equation 8 is 0.0130 . This estimate is significant at the 0.0138 level. Hence, from equation 8 we have an estimate of the elasticity of substitution with the value 72.4710 (1/0.0130). The estimate from equation 8 is 94 times greater than the estimate from equation 3.

The merits of measurement, let alone estimation, without theory, are certainly open to considerable debate. Nevertheless, the preceding discussion serves to cast doubt on our equation 3 estimate of the elasticity of substitution.

\section{Discrimination}

As shown in Table XIII the traits $N, S, P$, and $K$ significantly affect the male-female employment ratio. If there is no difference in the distribution of a worker trait between the sexes and yet the trait affects the male-female employment ratio we may say that the evidence indicates statistical discrimination.

Numerical aptitude $(N)$, spatial aptitude $(S)$, form aptitude $(P)$, and motor co-ordination $(\mathrm{K})$ are defined in terms of tests in the General Aptitude Test Battery. The manual for the test battery includes a discussion of the effect of sex on the test scores. The discussion is based on 29 pairs of samples of boys and girls. A total of 3,598 boys and 3,852 girls are included in the 29 pairs of samples. Twenty of the pairs were those used in the development

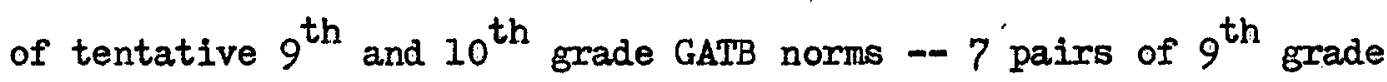


samples, 5 pairs of $10^{\text {th }}$ grade samples and 8 pairs of $12^{\text {th }}$ grade samples. The additional 9 pairs of $12^{\text {th }}$ grade samples were taken from separate state tests. 29 The manual for the test battery reported that "For each pair of samples the difference was found between the mean scores of boys and girls on each aptitude. "30 The manual did not report standard deviations or other statistics that could be used to test the significance of the differences. Table XVI lists the median of the differences between the mean scores of boys less the mean scores of girls.

Table XVI

Median of Difference in Means for Paired Samples of Boys and Girls of General Aptitude Test Battery Scores

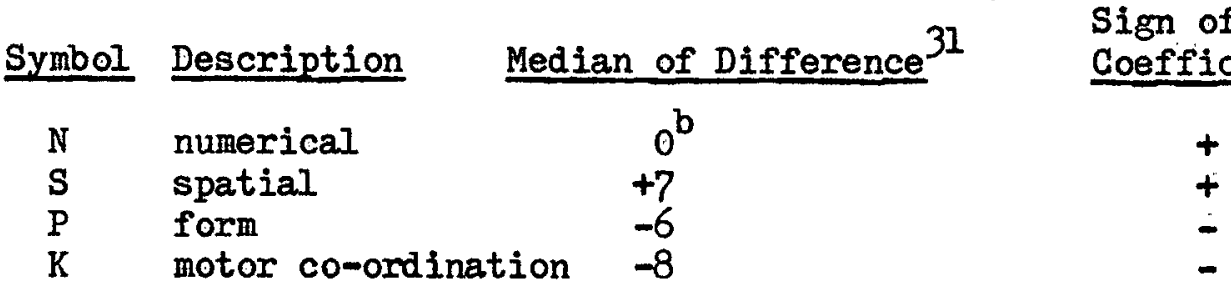

a) from Table XIII b) The manual reports this difference as being 3 points or less and inconsistent in sign between the paired samples. 32

Further indications of the distribution of aptitudes by sex were reported in the manual for a sample of 2,439 persons from four states. The sample consisted of 1239 males and 1200 females. The ages of the sample subjects ranged from 17 years to 74 years. For each of the GATB aptitudes an analysis of variance was performed to test for the significance of age, sex, and the interaction of age and sex on test scores. The effect of age on test scores was significant at the 0.01 level for all aptitudes except verbal (V) and numerical $(N)$. There was a significant effect of age on numerical aptitude at the 0.05 level. The effect of sex on aptitude 
scores was significant at the 0.01 level for clerical perception $(Q)$, motor co-ordination (K), and finger dexterity (F). Mean female scores tended to be higher than mean male scores for these aptitudes. No significant effect of sex was found for the remaining aptitudes. A significant interaction $(0.05$ level) between age and sex was found only for numerical aptitude (N).33

Statistical discrimination is not indicated by the significance in the regression equations of spatial aptitude (S), form aptitude ( $P$ ), or motor co-ordination $(K)$ on the basis of the 29 pairs of samples. These results, however, were not tested for significance. On the basis of the age-sex study only motor co-ordination ( $K$ ) has a distribution between the sexes that is consistent with our regression results. The age-sex study suggests that statistical discrimination is indicated by the significance in the regression equations of numerical aptitude $(N)$, spatial aptitude $(S)$, and form aptitude $(P)$. Any conclusions regarding numerical aptitude must be tempered by the significant age-sex interaction on numerical aptitude. Due to lack of data our regression analysis did not consider such interactions. Although statistical discrimination is not indicated by the significance of motor co-ordination (K), it is possible that qualified discrimination could be rationalized on the basis of sex differences in K. Employers might simply refuse to hire men for jobs requiring a large amount of motor co-ordination. However it might also be the case that employers hire both sexes without discrimination and then dismiss the unqualified workers. If the worker traits were independently distributed and if we knew the variance in the quantitative 
indicator of each trait by sex, we could test between the preceding alternatives. A standard deviation for worker qualification could then be calculated for each sex as the square root of the sum of the variances for each trait by sex weighted by the square of the corresponding regression coefficient. On the basis of the data available to us we cannot explore this alternative.

The five remaining traits shown in Table XIII, E, TX, TY, I2, and I4, do not appear to have been analyzed in any study regarding sex differences. While literature exists related to batteries of tests on interests, this literature does not consider sex differences in the same interest. 34 Nor does any study appear to define interests in precisely the same manner as is done in Worker Traits. 35 Eye-hand-foot co-ordination and the temperaments appear to be uniquely defined variables for the study of Worker Traits. 36 Extensive literature concerning sex differences in child development does exist. 37 I have not been able to find any studies that have extended into the traits we considered when examining occupational requirements.

Lacking any basis for the comparison of the actual distribution of these traits between the sexes we are unable to draw conclusions regarding statistical discrimination that might be indicated by these results. In view of this lack of data, however, it is also unlikely that any employer could say that he "knows" that men perform better than women in an occupation because of their differences with respect to one of these traits. Generalizations regarding sex differences must be based on personal experience or stereotypes. Alter- 
natively, employers might view the lack of data as indicating that there is no evidence to prove that men and women are equal in ability. Stereotypes

While we cannot use five of the traits to determine whether statistical discrimination exists, we can use the results to suggest a sociological or psychological study. It would be worthwhile for a researcher in one of these disciplines to extend this study to measure sex stereotypes as they affect occupational segregation by sex. Our results suggest the presence of stereotypes that women are better at precision tasks, more people oriented, and more interested in social welfare. It would be interesting for a sociologist to determine the prevalence of such stereotypes and for a psychologist to determine whether the stereotypes correspond to reality. Conclusions

1) With the exception of clerical occupations and unskilled manual labour, extreme concentrations of the sexes do not appear to characterize any single occupational division. Occupational segregation is not as apparent at the aggregate census division level as it is at the census occupational class level.

2) The good fit of the regression results supports the U.S. National Manpower Council's observation that "Employers hire persons of the sex supposedly possessing the characteristics considered necessary for effective job performance. "38

3) If it exists, it is difficult to detect any form of discrimination through the use of aggregate data. Data are lacking on 
sex differences for worker traits. The significance of numerical aptitude in determining relative male-female employment indicates statistical discrimination but this indication is weakened by the effect of an interaction between age and sex in numerical aptitude. The significance of spatial aptitude and form aptitude in determining relative male-female employment indicates statistical discrimination. 
Chapter 5: Notes

1. See p. 63.

2. R.E. Johnson and F.L. Kiokemester, Calculus with Analytic Geometry (Boston: Allyn and Bacon, Inc., 1964), p. 399.

3. See p. 16.

4. See p. 28.

5. U.S. Department of Labor, Bureau of Employment Security, Estimates of Worker Trait Requirements for 4,000 Jobs (Washington: U.S.

Government Printing Office, 1956), p. 110, here after cited as Traits.

6. See p. 19.

7. Traits, p. 121.

8. Traits, pp. 121-122.

9. Ibid.

10. Toid.

il. Ibid.

12. Ibid.

13. Ibid.

14. Traits, p. vi.

15. Traits, p. 131.

16. Tbid.

17. Traits, p. vi.

18. Traits, p. 136.

19. Ibid.

20. Ibid.

21. Ibid.

22. Ibid.

23. Ibid.

24. Traits, p. vi. 
25. Ibid.

26. Ernst R. Berndt, "A Reconciliation of Cross-Section and TimeSeries Estimates of the Elasticity of Substitution", University of British Columbia, Department of Economics, Discussion Paper No. 95. mimeographed, 1973.

27. Ibid., p. 8.

28. "UBC TRIP", University of British Columbia, Computing Centre, mïmeographed, 1971.

29. United States Department of Labor, Manual for the General Aptitude Test Battery, Section III (Washington: U.S. Government Printing Office, 1967).

30. Ibid., p. 219.

31. Ibid.

32. Ibid.

33. Ibid., pp. 224-226.

34. E.K. Stong, Jr., Vocational Interests of Men and Women (I ondon: Oxford University Press, 1943).

35. Traits, p. 136.

36. Ioid., p. 131 .

37. Eleanor E. MacCoby, The Psychology of Sex Differences (Standford: Standford University Press, 1974).

38. National Manpowar Council, Homanpower (New York: Columbia University Press, 1957), p. 233; see p. 54 above. 
Selected Bibliography

Archibald, Kathleen, Sex and the Public Service. Ottawa: Queen's Printer, 1970.

Arrow, Kenneth, "Some Models of Racial Discrimination in the Labor Market". RAND Corporation research memorandum RM-6253-RC, multilith, Santa Monica, 1971.

Baetjer, Anna M., Women in Industry. Philadelphia: W.B. Saunders Company, 1946.

Becker, Gary, The Economics of Discrimination. Chicago: University of Chicago Press, 1957.

Berndt, Ernst R., "A Reconciliation of Cross-Section and Time-Series Estimates of the Elasticity of Substitution", University of British Columbia, Department of Economics, Discussion Paper No. 95, 1973.

Blaxall, Martha and Barbara Reagan, Women and the Workplace. Chicago: University of Chicago Press, 1976.

Brown, E.H. Phelps, and J. Wiseman, A Course in Applied Economics. London: Sir Isaac Pitman and Sons Itd., 1964.

Brown, E.H. Phelps, "Equal Pay for Equal Work", The Economic Journal, 59:235 (September, 1949).

Caplow, Thedore, The Sociology of Work. Toronto: McGraw-Hill Book Company, 1964.

Christ, Carl F., Econometric Models and Methods. New York: John Wiley \& Sons, Inc., 1966.

Department of Labour, Equal Pay for Equal Work. Ottawa: Queen's Printer, 1959.

Department of Labour, Implications of Traditional Divisions Between Men's Work and Women's Work in our Society. Ottawa: Women's Bureau, Department of Labour, 1964 .

Department of Labour, Occupational Histories. Ottawa: Queen's Printer, 1959.

Department of Labour, Wage Rates, Salaries and Hours of Labour. Ottawa: Queen's Printer, 1970.

Dominion Bureau of Statistics, 1961 Census of Canada. Ottawa: Queen's Printer, 1963.

Dominion Bureau of Statistics, Occupational Classification Manual Census of Canada, 1961. Ottawa: Queen's Printer, 1961. 
Edgeworth, F.Y., "Equal Pay to Men and Women for Equal Work", The Economic Journal 32:128 (December, 1922).

Fawcett, Millicent G., "Equal Pay for Equal Woris", The Economic Journal 28 (March, 1918).

Friedman, Milton, Price Theory A Provisional Text. Chicago: Aldine Publishing Company, 1962 .

Ginzberg, Eli, "Paycheck and Apron -- Revolution in Womanpower", Industrial Relations 7 (May, 1968).

Gross, Edward, "Plus Ca Change ...? The Sexual Structure of Occupations Over Time", Social Problems 26 (Fall 1968).

House of Commons Debates 115:126 (May, 1971). Ottawa: Queen's Printer.

House of Gommons Debates 115:240 (December, 1971). Ottawa: Queen's Printer.

International Labour Office, Job Evaluation. Geneva: La Tribune De Geneve, 1960.

International Labour Office, Women Workers in a Changing World. Geneva: La Tribune De Geneve, 1954.

Lewis, Hartley V., "The Importance of Turnover Costs in the MaleFemale Wage Differential", unpublished Ph.D. dissertation. New York: The University of Rochester, 1970.

MacCoby, Eleanor E., The Psychology of Sex Differences. Standford: Standford University Press, 1974.

Meltz, Noah M. Changes in the Occupational Composition of the Canadian Labour Force, 1931-1961. Ottawa: Queen's Printer, 1965.

Mill, John Stuart, Principles of Political Economy. New York: Augustus M. Kelly, 1961 reprint of Toronto: Longman's, Green and Co., 1929.

National Bureau of Economic Research, Aspects of Labor Economics. Princeton: Princeton University Press, 1962.

National Manpower Council, Womanpower. New York: Columbia University Press, 1957.

Oaxaca, Ronald L., "Male-Female Wage Differentials in Urban Labor Markets", Princeton University, Industrial Relations Section, Working Paper No. 23, 1971. 
Oppenheimer, Valerie Kincade, The Female Labor Force in the United States. Berkeley: University of California, Institute of International Studies, 1970.

Oppenheimer, Valerie Kincade, "The Sex Labeling of Jobs", Industrial Relations 7 (May, 1968).

Ostry, Sylvia, The Female Worker in Canada. Ottawa: Queen's Printer, 1968.

Phelps, Edmund S., "The Statistical Theory of Racism and Sexism", American Economic Review 62:4 (September, 1972).

Phelps, Edmund S., et al., Microeconomic Foundations of Employment and Inflation Theory. New York: W.W. Norton \& Company, Inc., 1970.

President's Commission on the Status of Women, Private Employment. Washington: U.S. Government Printing Office, 1963.

Rathbone, Eleanor F., "The Remuneration of Women's Services", The Economic Journal 27 (March, 1917).

Reder, Melvin W., "The Theory of Occupational Wage Differentials", American Economic Review 45 (December, 1955).

Robinson, Joan, The Economics of Imperfect Competition. London: MacMilian \& Co. Ltd., 1965).

Rosenbluth, Gideon, "The Structure of Academic Salaries in Canada", Canadian Association of University Teachers Bulletin 15:4 (April, 1967).

Rossi, Alice S. (ed.), Essays on Sex Equality. Chicago: University of Chicago Press, 1970.

Royal Commission on the Status of Women in Canada, Report of the Royal Commission on the Status of Women in Canada. Ottawa: Information Canada, 1970 .

Samuelson, Paul Anthony, Foundations of Economic Analysis. New York: Atheneum, 1967.

Sanborn, Henry, "Pay Differences Between Men and Women", Industrial and Labor Relations Review 17:4 (July, 1964).

Scoville, James G., The Job Content of the U.S. Economy, 1940-1970. New York: McGraw-Hill Book Company, 1969.

Scoville, James G., The Job Content of the Canadian Economy, 1941, 1951, and 1961. Ottawa: Queen's Printer, 1967. 
Spence, Michael, Market Signaling. Cambridge: Harvard University Press, 1974.

Stieber, Jack, The Steel Industry Wage Structure. Cambridge: Harvard University Press, 1959.

Stong, Edward Kellogg, Vocational Interests of Men and Women. London: H. Milford, Oxford University Press, 1943.

Thurow, Lester, Poverty and Discrimination. Washington: The Brookings Institution, 1969.

Tobin, James, "Estimation of Relationships for Limited Dependent Variables", Econometrica 26 (1958).

Turner, Marjorie, Women \& Work. Los Angeles: Institute of Industrial Relations, University of California, 1964.

U.S. Department of Labor, Bureau of Employment Security, Estimates of Worker Trait Requirements for 4,000 Jobs. Washington: U.S. Government Printing Office, 1956.

U.S. Department of Labor, Economic Indicators Relating to Equal Pay. Washington: U.S. Government Printing Office, 1963.

U.S. Department of Labor, Manual for the General Aptitude Test Battery. Washington: U.S. Government Printing office, 1967.

Webb, Sidney, "The Alleged Difference Between the Wages of Men and Women", The Economic Journal 1:4 (December, 1891).

Webb, Sidney and Beatrice, Industrial Democracy. London: Longmans, Green and Co., 1902. 
Appendix A: Job Content of Census Occupational Classes

The results of this study could not be replicated without reference to the construction of the data series for worker traits. The quantitative indicators of the traits for each census occupational class depend on the jobs that were sorted into the class.

This computer produced appendix lists the occupations by number as they are referred to in the Classification Manual Census of Canada, 1961. Beneith each occupational class is listed the page number from Estimates of Worker Traits for 4,000 Jobs and the line number from the page that identifies a job sorted into the class. Also given are the volume I and volume II codes that identify the job from the Dictionary of Occupational Titles. 
PAGE COL. VOL. I VOL. II PAGE GOL. VOL. I VOL. II

$26 \quad 81040 \quad 0 \times 35$

60. 5. $97610 \quad 0 \times 810$

$94.27,97610,6 \times 810$

$59 \quad 37: 97120 \quad 0 \times 810$

14: $7 \quad 74110 \quad 0 \times 715$

$\begin{array}{llll}76 & 31 & 91600 & 0 \times 715\end{array}$

OCCUPATION 10

$\begin{array}{rrrl}4 & 32 & 94920 & 0 \times 711 \\ 14 & 9 & 91620 & 0 \times 715 \\ 17 & 5 & 71010 & 0 \times 825 \\ 23 & 7 & 240210 & 1 \times 57 \\ 25 & 14 & 94930 & 0 \times 702 \\ 26 & 34 & 94220 & 0 \times 625 \\ 26 & 36 & 95010 & 0 \times 625 \\ 28 & 16 & 118740 & 1 \times 50 \\ 59 & 30 & 71210 & 0 \times 825 \\ 60 & 4 & 72210 & 0 \times 810 \\ 61 & 6 & 95050 & 0 \times 625 \\ 75 & 16 & 99840 & 0 \times 625 \\ 76 & 8 & 26100 & 0 \times 702 \\ 78 & 37 & 99320 & 0 \times 614 \\ 80 & 38 & 98710 & 0 \times 849 \\ 94 & 19 & 98810 & 0 \times 849 \\ 94 & 22 & 98850 & 0 \times 849 \\ 94 & 28 & 31100 & 0 \times 600 \\ 109 & 13 & 98730 & 0 \times 849\end{array}$

OCCUPATION 101

20. $23 \quad 16010: 0 \times 742$

$\begin{array}{llll}49 & 15 & 16010 & 0 \times 742\end{array}$

$\begin{array}{llll}83 & 21 & 16010 & 0 \times 742\end{array}$

$\begin{array}{rlll}2 & 18 & 19010 & 0 \times 744 \\ 3 & 35 & 19810 & 0 \times 742 \\ 22 & 26 & 19010 & 0 \times 744 \\ 50 & 29 & 16010 & 0 \times 742 \\ 72 & 14 & 19010 & 0 \times 744 \\ 107 & 11 . & 19050 & 0 \times 744\end{array}$

\section{OCCUPATION 102}

$\begin{array}{llll}14 & 8 & 74120 & 0 \times 715\end{array}$

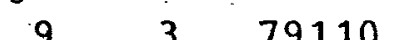

$4 \times 6295$

$91630 \quad 0 \times 715$

$72550 \quad 1 \times 57$

$97050 \quad 0 \times 711$

$95030 \quad 0 \times 625$

$94220 \quad 0 \times 625$

$95040 \quad 0 \times 625$

$26100 \quad 0 \times 702$

$98830 \quad 0 \times 849$

$22300 \quad 0 \times 810$

$98570 \quad 0 \times 810$

$97810 \quad 0 \times 810$

$68210 \quad 3 \times 994$

$94330 \quad 0 \times 712$

$98720 \quad 0 \times 849$

$99110 \cdot 0 \times 842$

$\begin{array}{rrrl}94 & 25 & 98860 & 0 \times 849 \\ 108 & 6 & 553330 & 4 \times 6181\end{array}$

$\begin{array}{rrrr}79 & 1 & 94330 & 0 \times 712 \\ 91 & 18 & 98720 & 0 \times 849 \\ 94 & 21 & 99110 & 0 \times 842 \\ 94 & 25 & 98860 & 0 \times 849 \\ 108 & 6 & 553330 & 4 \times 618\end{array}$

$\begin{array}{llll}44 & 28 & 19010 & 0 \times 744\end{array}$ $\begin{array}{llll}50 & 29 & 16010 & 0 \times 742\end{array}$

$\begin{array}{rlll}2 & 30 & 1.9030 & 0 \times 742 \\ 5 & 18 & 19010 & 0 \times 744 \\ 48 & 38 & 19010 & 6 \times 744 \\ 58 & 30 & 19010 & 0 \times 744 \\ 78 & 31 & 19010 & 0 \times 744\end{array}$


PAGE COL. VOL. I VOL. II

PAGE COL. VOL. I VOL. II OCCUPATION 104

$\begin{array}{rrrrr}61 & 24 & 18010 & 0 \times 741 & \\ 82 & 26 & 18010 & 0 \times 741 & 104 \\ 99 & 7 & 68730 & 0 \times 741 & \\ & & & \text { OCCOPATION } & 105 \\ 14 & 17 & 17020 & 0 \times 748\end{array}$

14. $17 \quad 17020 \quad 0 \times 748$

$72 \quad 14 \quad 19010: 0 \times 744$

$\begin{array}{llll}77 & 16 & 17010 & 0 \times 748\end{array}$
$75 \quad 25 \quad 18010$

$996 \times 18010$

$104 \quad 14 \quad 19010$
$0 \times 741$

$0 \times 741$

$0 \times 741$

$62 \quad 22 \quad 20010 \quad 0 \times 741$

OCCUPATION 107

$82 \quad 26,18010 \quad 0 \times 741$

$\begin{array}{llll}34 & 28 & 17010 & 0 \times 748\end{array}$

$\begin{array}{lll}77 & 15 & 17010\end{array}$

$0 \times 748$

$101 \quad 20 \quad 553920$

$4 \times 6181$

$70 \quad 7 \quad 20110 \quad 0 \times 741$

OCCUPATION 108

$18 \quad 1 \quad 15110 \quad 0 \times 741$

$19 \quad 5 \quad 15010 \quad 0 \times 741$

OCCUPATION 109

$\begin{array}{rrrlllll}2 & 11 & 19100 & 0 \times 741 & 61 & 14 & 14100 & 0 \times 704 \\ 61 & 15 & 14200 & 0 \times 74 & 82 & 37 & 19910 & 0 \times 741 \\ 101 & 5 & 39940 & 0 \times 849 & & & & \end{array}$

OCCUPATION 111

$\begin{array}{rrrr}4 & 22 & 7210 & 0 \times 704 \\ 19 & 11 & 7020 & 0 \times 703 \\ 19 & 13 & 7030 & 0 \times 703 \\ 19 & 16 & 7020: & 0 \times 703 \\ 19 & 18 & 7830: & 0 \times 703 \\ 19 & 20 & 7020 & 0 \times 703 \\ 70: & 12 & 7860 & 0 \times 703\end{array}$

$\begin{array}{llll}19 & 10 & 7020 & 0 \times 703\end{array}$

$\begin{array}{llll}19 & 12 & 7210 & 0 \times 703\end{array}$

$1914.7210 \quad 0 \times 704$

$\begin{array}{llll}19 & 17 & 7020 & 0 \times 703\end{array}$

$\begin{array}{llll}19 & 19 & 7840 & 0 \times 703\end{array}$

$1921.7030^{-} 0 \times 704$

$\begin{array}{llll}70 & 30 & 35730 & 0 \times 704\end{array}$

OCCUPATION 114

45 OCCUPATION 119

$\begin{array}{llll}45 & 31 & 35650 & 0 \times 730 \\ 61 & 18 & 35680 & 0 \times 730\end{array}$

$\begin{array}{llll}51 & 12 & 46880 & 0 \times 12\end{array}$

OCCUPATION 121

$\begin{array}{rrrr}5 & 29 & 35330 & 0 \times 70 \\ 11 & 15 & 35230 & 0 \times 73 \\ 68 & 34 & 35310 & 0 \times 70 \\ 70 & 13 & 35340 & 0 \times 70 \\ 109 & 22 & 35280 & 0 \times 730\end{array}$

$\begin{array}{llll}8 & 35 & 35220 & 0 \times 703\end{array}$

$37 \quad 23 \quad 35300 \quad 0 \times 703$

$\begin{array}{llll}70 & 8 & 25100 & 0 \times 703\end{array}$

$\begin{array}{llll}72 & 16 & 35260 & 0 \times 703\end{array}$

\section{OCCUPATION 124}

$105 \quad 10 \quad 34100 \quad 0 \times 702$

$\begin{array}{llll}105 & 13 & 34100 & 0 \times 702\end{array}$

$105 \quad 11 \quad 34100$

$0 \times 703$ $105 \quad 14.34100$

$0 \times 702$ 
PAGE COL. VOL. I VOL. II

PAGE COL. VOL. I VOL. II OCCUPATION 129

$2 \quad 10 \cdot 348910 \quad 0 \times 703$

$2 \quad 12 \quad 35010 \quad 0 \times 703$

27. $24.35140 \quad 0 \times 730$

OCCOPATION 131

$\begin{array}{rrrrr}27 & 34 & 11200 & 0 \times 600 & 7 \\ 75 & 29 & 11500 & 0 \times 600 & 96 \\ 96 & 27 & 31010 & 0 \times 600 & 10 \\ & & & \text { OCCUPATION } & 135 \\ 52 & 1 & 32300 & 0 \times 604 & 5 \\ 75 & 12 & 31100 & 0 \times 810 & 96 \\ 96 & 25 & 31010 & 0 \times 600 & 96 \\ 96 & 28 & 31010 & 0 \times 600 & 96 \\ 96 & 30 & 30020 & 0 \times 600 & 9 \\ 103 & 22 & 32200 & 0 \times 600 & \\ & & & \text { OCCUPATION } & 139\end{array}$

$\begin{array}{llllrlrr}46 & 27 & 32980 & 0 \times 600 & 52 & 2 & 32330 & 0 \times 749\end{array}$

OCCUPATION 140

$\begin{array}{rrrrrrrr}3 & 23 & 26200 & 0 \times 702 & 15 & 16 & 26100 & 0 \times 702 \\ 28 & 17 & 26100 & 0 \times 702 & 45 & 29 & 26100 & 0 \times 702 \\ 47 & 22 & 26100 & 0 \times 702 & 52 & 23 & 26300 & 0 \times 702 \\ 60 & 40 & 26100 & 0 \times 702 & 64 & 25 & 26100 & 0 \times 702 \\ 65 & 20 & 26100 & 0 \times 702 & 65 & 22 & 26100 & 0 \times 702 \\ 66 & 23 & 26100 & 0 \times 702 & 70 & 29 & 26100 & 0 \times 702 \\ 76 & 5 & 26100 & 0 \times 702 & 77 & 19 & 26100 & 0 \times 702 \\ 95 & 1 & 26100 & 9 \times 702 & 104 & 12 & 26100 & 0 \times 702\end{array}$

66

OCCUPATION 141

$\begin{array}{llll}52 & 3 & 11500 & 0 \times 604\end{array}$

$\begin{array}{llll}96 & 22 & 31010 & 0 \times 603\end{array}$

$\begin{array}{llll}96 & 26 & 30110 & 0 \times 600\end{array}$

$\begin{array}{llll}96 & 29 & 30020 & 0 \times 600\end{array}$

$\begin{array}{llll}96 & 31.31010 & 0 \times 601\end{array}$

$\begin{array}{llll}74 & 34 & 11100 & 0 \times 810 \\ 96 & 23 & 11500 & 0 \times 600\end{array}$

$\begin{array}{llll}03 & 22 & 32200 & 0 \times 600\end{array}$ 
PAGE COL. VOL. I VOL. II PAGE COL. VOL. I VOL. II $\begin{array}{llllllll}19 & 34 & 39900 & 0 \times 702 & 66 & 25 & 39960 & 0 \times 702\end{array}$ $70: \quad 11 \quad 25100 \cdot 0 \times 703$

OCCUPATION 147

$\begin{array}{rrrl}28 & 12 & 50060 & 4 \times 6348 \\ 28 & 14 & 50060 & 4 \times 6348 \\ 36 & 9 & 50050 & 0 \times 702 \\ 67 & 7 & 50030 & 0 \times 702 \\ 70 & 10 & 50020 & 0 \times 703 \\ 109 & 2 & 50040 & 0 \times 702\end{array}$

OCCUPATION 151

$\begin{array}{llll}53 & 29 & 22500 & 0 \times 712\end{array}$

OCCUPATION 146

\section{OCCUPATION 153}

$30 \quad 14,22400 \quad 0 \times 712$

$55 \quad 34: 22100 \cdot 0 \times 712$

\section{5}

$28 \quad 13 \quad 50070$

$0 \times 702$

$28 \quad 15 \quad 50060$

$4 \times 6348$

$61 \quad 1 \quad 50010$

$0 \times 703$

$0 \times 703$

$\begin{array}{lll}69 & 7 & 50010\end{array}$

$0 \times 703$

$83 \quad 23 \quad 66410$

$0 \times 702$

\section{OCCUPATION 171}

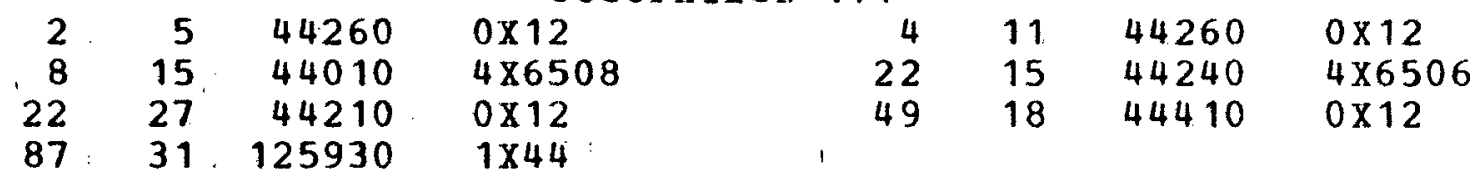

$16 \quad 22 \quad 4410^{\prime} 0 \times 12$

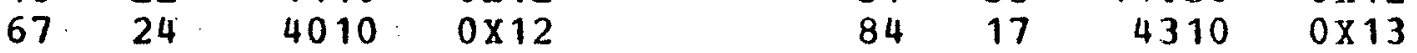

$\begin{array}{rrrlrrrr}23 & 26 & 6230 & 0 \times 31 & 24 & 36 & 6920 & 0 \times 35 \\ 24 & 38 & 6940 & 0 \times 35 & 34 & 3 & 6440 & 0 \times 35 \\ 34 & 4 & 6430 & 0 \times 35 & 34 & 5 & 6300 & 0 \times 35 \\ 34 & 6 & 6450 & 0 \times 35 & 34 & 7 & 116010 & 1 \times 20 \\ 34 & 8 & 6280 & 0 \times 749 & 34 & 9 & 6000 & 0 \times 35 \\ 34 & 10 & 6540 & 0 \times 35 & 34 & 11 & 6460 & 0 \times 35 \\ 34 & 12 & 6470 & 0 \times 35 & 34 & 13 & 6480 & 0 \times 35 \\ 34 & 14 & 6250 & 0 \times 35 & 34 & 15 & 6510 & 0 \times 35 \\ 34 & 16 & 6520 & 0 \times 35 & 34 & 17 & 6530 & 0 \times 35 \\ 42 & 24 & 68320 & 0 \times 35 & 57 & 14 & 6040 & 0 \times 31 \\ 72 & 39 & 6050 & 0 \times 31 & 73 & 11 & 6060 & 0 \times 31 \\ 76 & 9 & 6970 & 0 \times 35 & 79 & 14 & 6710 & 0 \times 35 \\ 79 & 30 & 6930 & 0 \times 35 & 84 & 17 & 6330 & 1 \times 20 \\ 84 & 15 & 6320 & 0 \times 81 & & & & \end{array}$

OCCUPATION 176
$4824420: 0 \times 21$
$22 \quad 37 \quad 24410: 0 \times 21$
$\begin{array}{lll}20 & 2 & 24230\end{array}$
$0 \times 21$
$23624020 \quad 0 \times 25$ 
$\begin{array}{rrrr}\text { PAGE COL. } & \text { VOL. I } & \text { VOL. II } \\ 66 & 7 & 24250 & 0 \times 21\end{array}$

$\begin{array}{rrrr}\text { PAGE } & \text { COL. } & \text { VOL. I } & \text { VOL. II } \\ 66 & 8 & 24430 & 0 \times 21 \\ 105 & 17 & 24120 & 0 \times 26\end{array}$

OCCUPATION 182

$\begin{array}{rrrlrrrr}31 & 9 & 48040 & 0 \times 772 & 31 & 10 & 69450 & 0 \times 772 \\ 31 & 11 & 48050 & 0 \times 772 & 31 & 12 & 48060 & 0 \times 772 \\ 31 & 13 & 48080 & 0 \times 772 & 31 & 14 & 48010 & 0 \times 772 \\ 31 & 15 & 48110 & 0 \times 778 & 31 & 16 & 48120 & 0 \times 772 \\ 31 & 17 & 48160 & 0 \times 772 & 31 & 18 & 48130 & 0 \times 773 \\ 31 & 19 & 48150 & 0 \times 773 & 31 & 20 & 48160 & 0 \times 772 \\ 31 & 21 & 48180 & 0 \times 774 & 31 & 22 & 48210 & 0 \times 772 \\ 31 & 23 & 48180 & 0 \times 774 & 31 & 24 & 48220 & 0 \times 772 \\ 31 & 25 & 48230 & 0 \times 772 & 31 & 26 & 48010 & 0 \times 772 \\ 31 & 27 & 48160 & 0 \times 774 & 31 & 28 & 48250 & 0 \times 772 \\ 31 & 29 & 48180 & 0 \times 774 & 31 & 30 & 48260 & 0 \times 773 \\ 100 & 37 & 48300 & 0 \times 774 & & & & \\ & & & & & & & \\ 22 & 34 & 64500 & 0 \times 773 & 183 & & & \\ 52 & 11 & 64300 & 0 \times 773 & 45 & 30 & 64400 & 0 \times 773 \\ 95 & 4 & 64100 & 0 \times 773 & 95 & 2 & 64100 & 0 \times 773 \\ 95 & 6 & 64100 & 0 \times 737 & 95 & 5 & 64100 & 0 \times 773\end{array}$

$\begin{array}{llll}95 & 6 & 64100 & 0 \times 773\end{array}$

$33 \quad 28 \quad 36110 \quad 0 \times 610$

OCCUPATION 186

OCCUPATION 188

$\begin{array}{rrrrrrrr}1 & 9 & 1200 & 0 \times 711 & 1 & 10 & 1100 & 0 \times 711 \\ 1 & 11 & 1200 & 0 \times 711 & 1 & 12 & 1300 & 0 \times 711 \\ 1 & 13 & 1400 & 0 \times 711 & 5 & 2 & 1600 & 0 \times 711\end{array}$

$\begin{array}{llll}18 & 29 & 103020 & 1 \times 29\end{array}$

$29 \quad 24 \quad 39930 \quad 0 \times 703$

OCCUPATION 191

OCCUPATION 192

$\begin{array}{llll}16 & 24 & 27500 & 0 \times 612\end{array}$

$29 \quad 34.27110 \quad 0 \times 612$

$\begin{array}{llll}16 & 28 & 27210 & 0 \times 612\end{array}$

$6838 \cdot 27200 \quad 0 \times 625$

$47 \quad 11 \quad 27.400 \quad 0 \times 612$

OCCUPATION 195

$30 \quad 10,43300 \cdot 0 \times 15$

$52 \quad 19 \quad 43400 \quad 0 \times 15$

$\begin{array}{llll}42 & 2 & 43600 & 0 \times 15\end{array}$

$107 \quad 36 \quad 43300 \quad 0 \times 15$

$\begin{array}{llll}14: & 33 & 56410 & 0 \times 749 \\ 70: & 20 & 56110 & 0 \times 15 \\ 70: & 22 & 56310 & 0 \times 749 \\ 70 & 24 & 56450 & 1 \times 59\end{array}$

OCCUPATION 196

$\begin{array}{llll}70 & 19 & 56010 & 0 \times 749\end{array}$

$\begin{array}{llll}70 & 21 & 56910 & 0 \times 749\end{array}$

$70.23 \quad 56210 \quad 0 \times 15$ 
PAGE COL. VOL. I VOL. II . PAGE COL. VOL. I VOL. II

$\begin{array}{rrll}5 & 30 & 50010 & 0 \times 703 \\ 19 & 9 & 50220 & 0 \times 704 \\ 21 & 17 & 50420 & 0 \times 704 \\ 23 & 34 & 66030 & 0 \times 748 \\ 27 & 25 & 50450 & 0 \times 703 \\ 68 & 17 & 50380 & 0 \times 704 \\ 85 & 2 & 66930 & 0 \times 703 \\ 89 & 32 & 66020 & 0 \times 49 \\ 94 & 8 & 61400 & 3 \times 749 \\ 109 & 1 & 50400 & 0 \times 749\end{array}$

OCCUPATION 198

OCCUPATION 199

$\begin{array}{rrrl}6 & 25 & 46870 & 0 \times 12 \\ 21 & 7 & 46010 & 0 \times 15 \\ 29 & 2 & 48420 & 0 \times 774 \\ 40 & 23 & 68060 & 3 \times 885 \\ 48 & 17 & 46030 & 0 \times 15 \\ 53 & 17 & 39850 & 0 \times 610 \\ 60 & 2 & 39830 & 0 \times 810 \\ 61 & 3 & 46950 & 0 \times 13 \\ 75 & 28 & 68500 & 0 \times 741 \\ 96 & 21 & 66950 & 4 \times 6309 \\ 101 & 19 & 68320 & 0 \times 31\end{array}$

$\begin{array}{rrrl}21 & 6 & 46910 & 0 \times 741 \\ 22 & 29 & 46920 & 0 \times 12 \\ 37 & 1 & 68710 & 0 \times 614 \\ 40 & 24 & 68070 & 3 \times 885 \\ 49 & 19 & 36910 & 0 \times 610 \\ 59 & 32 & 39820 & 0 \times 810 \\ 60 & 29 & 35760 & 0 \times 704 \\ 67 & 9 & 68060 & 3 \times 885 \\ 76 & 6 & 36250 & 0 \times 610 \\ 100 & 1 & 48410 & 0 \times 774\end{array}$

OCCUPATION 201

$\begin{array}{rrrr}1 & 14 & 101310 & 1 \times 11 \\ 1 & 16 & 101310 & 1 \times 20 \\ 1 & 19 & 101330 & 1 \times 29 \\ 5 & 1 & 101320 & 1 \times 11 \\ 10 & 37 & 101020 & 1 \times 20 \\ 16 & 29 & 101310 & 1 \times 29 \\ 16 & 31 & 101530 & 1 \times 57 \\ 16 & 33 & 101520 & 1 \times 20 \\ 23 & 24 & 101430 & 1 \times 29 \\ 39 & 17 & 125130 & 1 \times 29 \\ 47 & 10 & 103050 & 1 \times 28 \\ 52 & 25 & 101410 & 1 \times 28 \\ 52 & 27 & 101410 & 1 \times 28 \\ 73 & 37 & 101430 & 1 \times 29 \\ 97 & 16 & 106020 & 1 \times 20 \\ 97 & 18 & 106020 & 1 \times 20 \\ 102 & 33 & 101530 & 1 \times 57 \\ 105 & 21 & 101310 & 1 \times 11\end{array}$

$\begin{array}{rr}6 & 13 \\ 21 & 16\end{array}$

$23 \quad 33$

$23 \quad 35$

$27 \quad 26$

$76 \quad 16$

8931

90

98
66310 50320 61100 66030 50920 441910 66150 66040 50340
$0 \times 625$

$0 \times 704$

$0 \times 748$

$0 \times 748$

$0 \times 703$

$4 \times 6381$

$0 \times 749$

$0 \times 810$

$0 \times 704$

\section{$\begin{array}{rrrr}1 & 32 & 125120 & 1 \times 29 \\ 8 & 32 & 125020 & 1 \times 22 \\ 11 & 2 & 102020 & 1 \times 20 \\ 23 & 5 & 125130 & 1 \times 11\end{array}$}

OCCUPATION 203

$\begin{array}{rrrr}1 & 15 & 101030 & 1 \times 20 \\ 1 & 18 & 101310 & 1 \times 29 \\ 1 & 20 & 117010 & 1 \times 40 \\ 6 & 8 & 101330 & 1 \times 29 \\ 13 & 12 & 118840 & 1 \times 50 \\ 16 & 30 & 101520 & 1 \times 20 \\ 16 & 32 & 101530 & 1 \times 57 \\ 16 & 34 & 101530 & 1 \times 57 \\ 29 & 36 & 101520 & 1 \times 20 \\ 45 & 28 & 101020 & 1 \times 20 \\ 52 & 24 & 101410 & 1 \times 28 \\ 52 & 26 & 101410 & 1 \times 28 \\ 53 & 27 & 101360 & 1 \times 29 \\ 97 & 15 & 106020 & 1 \times 20 \\ 97 & 17 & 106020 & 1 \times 20 \\ 02 & 32 & 118940 & 1 \times 57 \\ 1 \times 5 & 20 & 101310 & 1 \times 29 \\ 105 & 22 & 125910 & 1 \times 22\end{array}$

$\begin{array}{rrrr}2 & 1 & 125410 & 1 \times 44 \\ 11 & 1 & 102010 & 1 \times 20 \\ 11 & 3 & 102030 & 1 \times 29 \\ 33 & 17 & 125220 & 1 \times 44\end{array}$




\begin{tabular}{|c|c|c|c|c|c|c|c|}
\hline PAGE & COL. & VOL.I & VOL. II & PAGE & COL. & VOL. I & VOL. \\
\hline 33 & 18 & 125230 & $1 \times 44$ & 33 & 19 & 125240 & $1 \times 44$ \\
\hline 33 & 20 & 125250 & $1 \times 44$ & 33 & 21 & 125230 & $1 \times 44$ \\
\hline 37. & 26 & 125470 & $1 \times 44$ & 46. & 35 & 125430 & $1 \times 44$ \\
\hline 54 & 3 & 125620 & $1 \times 29$ & 62 & 8 & 125220 & $1 \times 44$ \\
\hline 74 & 1 & 102040 & $1 \times 29$ & 78 & 19 & 1259,20 & $1 \times 44$ \\
\hline 89 & 30 & 125630 & $1 \times 44$ & 95. & 33 & 125640 & $1 \times 44$ \\
\hline 105 & 7 & 126660 & $1 \times 29$ & & & & \\
\hline & & & OCCUPATION & 212 & & & \\
\hline 39 & 27 & 138010 & $1 \times 28$ & 45 & 22 & 138010 & $1 \times 28$ \\
\hline 54 & 12 & 103060 & $1 \times 28$ & 54 & 13 & 138010 & $1 \times 28$ \\
\hline 92 & 34 & 118650 & $1 \times 28$ & 92 & 35 & 118660 & $1 \times 28$ \\
\hline 92 & 37 & 138010 & $1 \times 28$ & 92 & 38 & 138040 & $1 \times 28$ \\
\hline 93 & 20 & 788750 & $1 \times 28$ & 105 & 34 & 101420 & $1 \times 28$ \\
\hline 105 & 35 & 1380.10 & $1 \times 28$ & & & & \\
\hline & & & OCCUPATION & 214 & & & \\
\hline 28 & 10 & 134010 & $1 \times 20$ & 38 & 4 & 134230 & $1 \times 11$ \\
\hline 44 & 7 & .112460 & $1 \times 28$ & 51 & 7 & 134230 & $1 \times 11$ \\
\hline 78 & 16 & 134150 & $1 \times 28$ & 79 & 21 & 134040 & $1 \times 28$ \\
\hline 86 & 34 & 134150 & $1 \times 28$ & 87 & 1 & 134130 & $1 \times 28$ \\
\hline 87. & 2 & 134140 & $1 \times 28$ & 87 & 4 & 138010 & $1 \times 28$ \\
\hline & & & occup & 223 & & & \\
\hline 68 & 40 & 144270 & $1 \times 50$ & 91 & 12 & 144220 & $0 \times 810$ \\
\hline & & & OCCUPATION & 232 & & & \\
\hline 25 & 37 & 137180 & $1 \times 23$ & 56 & 20 & 133010 & $1 \times 23$ \\
\hline 56 & 21 & 137120 & $1 \times 23$ & 73 & 19 & 137120 & $1 \times 23$ \\
\hline 84 & 35 & 133010 & $1 \times 23$ & 92 & 9 & 137120 & $1 \times 23$ \\
\hline 92 & 10 & 137140 & $1 \times 23$ & 96 & 36 & 137120 & $1 \times 23$ \\
\hline & & & OCCUPATION & 234 & & & \\
\hline 20 & 40 & 137340 & $1 \times 22$ & 28 & 34 & 137360 & $1 \times 22$ \\
\hline 34 & 2 & 137360 & $1 \times 22$ & 64 & 18 & 137330 & $1 \times 22$ \\
\hline 97 & 14 & 137330 & $1 \times 22$ & 101 & 9 & 137360 & $1 \times 22$ \\
\hline 103 & 27 & 137320 & $1 \times 22$ & 104 & 28 & 137380 & $1 \times 22$ \\
\hline
\end{tabular}

$\begin{array}{llll}65 & 11 & 33870 & 0 \times 702\end{array}$

OCCUPATION 241

OCCUPATION 249

$\begin{array}{rrrr}1 & 6 & 101310 & 1 \times 11 \\ 1 & 34 & 101310 & 1 \times 20 \\ 2 & 3 & 112310 & 1 \times 50 \\ 2 & 8 & 108410 & 1 \times 29 \\ 3 & 32 & 118410 & 1 \times 50 \\ 6 & 23 & 101430 & 1 \times 29 \\ 8 & 30 & 103020 & 1 \times 29 \\ 11 & 9 & 108450 & 1 \times 29 \\ 18 & 30 & 101310 & 1 \times 29\end{array}$

$\begin{array}{rrrl}1 & 31 & 108010 & 1 \times 11 \\ 1 & 35 & 104010 & 1 \times 29 \\ 2 & 4 & 101310 & 1 \times 29 \\ 3 & 12 & 149850 & 0 \times 730 \\ 6 & 22 & 118810 & 1 \times 29 \\ 8 & 20 & 68770 & 0 \times 614 \\ 8 & 31 & 118820 & 1 \times 29 \\ 17 & 25 & 136030 & 1 \times 59 \\ 18 & 31 & 125910 & 1 \times 26\end{array}$




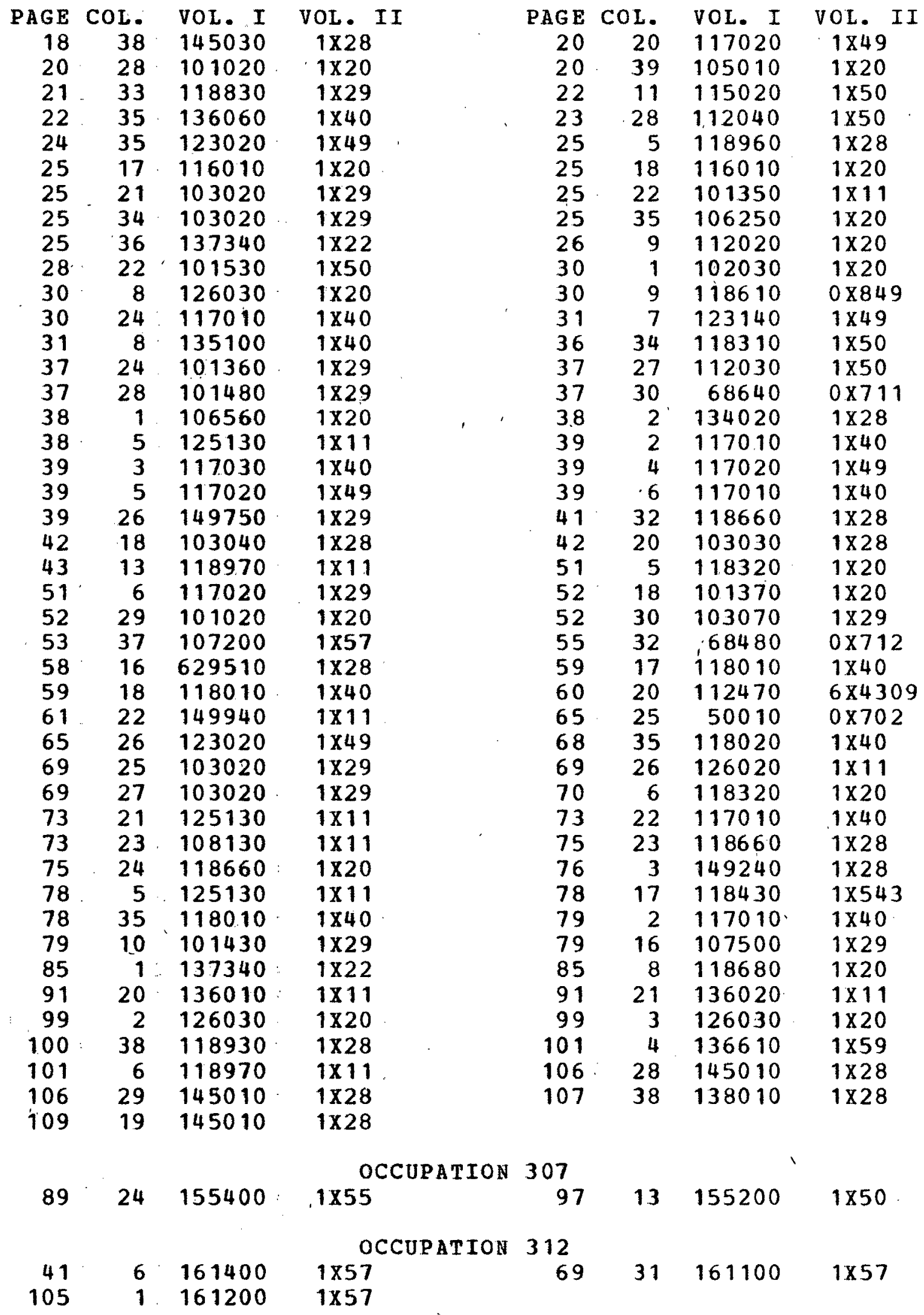




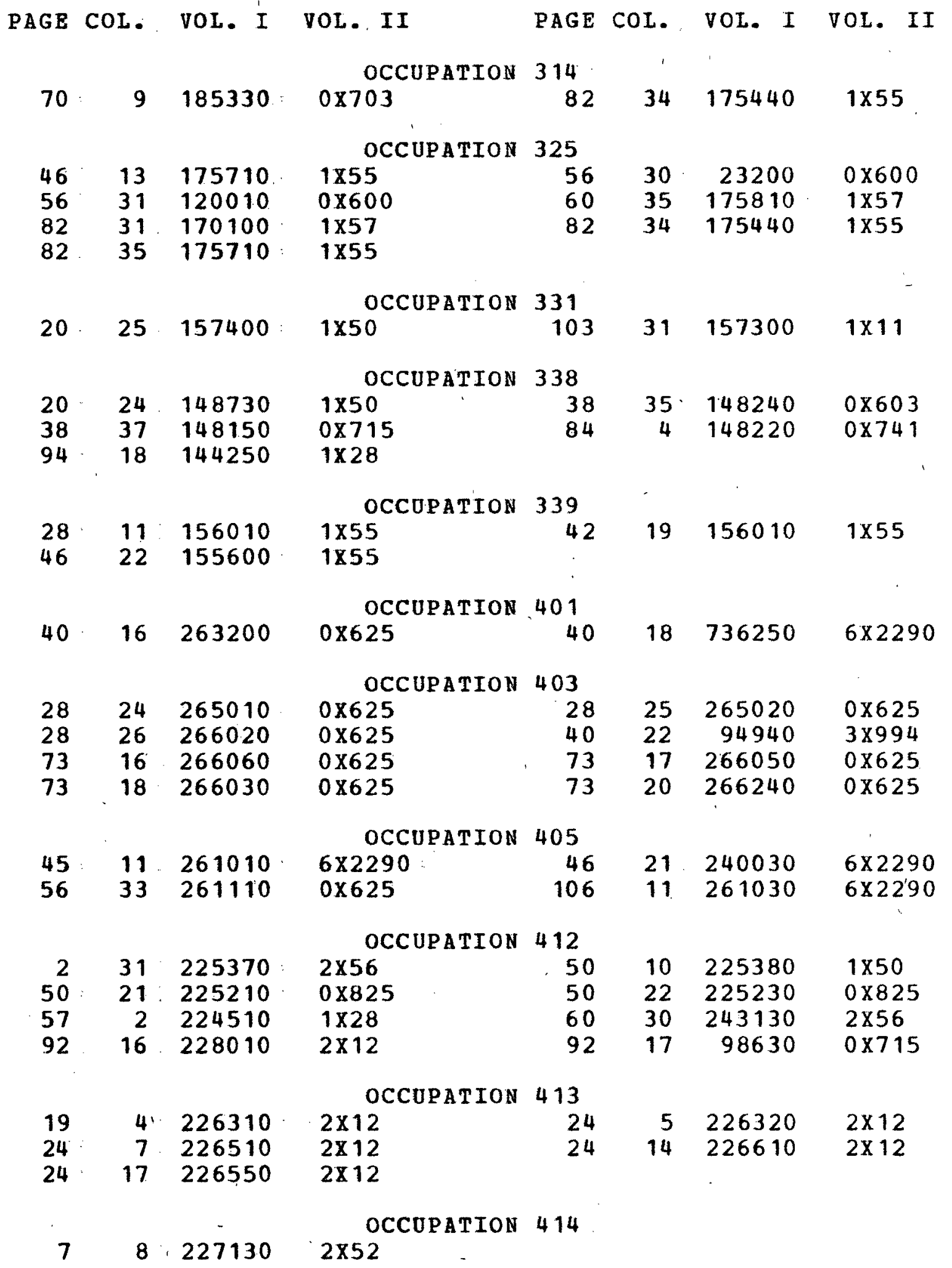


PAGE COL. VOL.'I VOL. II PAGE COL. VOL. I VOL. II

\begin{tabular}{|c|c|c|c|c|c|c|c|}
\hline \multicolumn{8}{|c|}{ OCCUPATION 415} \\
\hline 15 & 19 & 227910 & $2 \times 52$ & 25 & 30 & 227130 & $2 \times 52$ \\
\hline 50 & 11 & 227140 & $0 \times 825$ & 89 & 13 & 227610 & $2 \times 52$ \\
\hline 92 & 1 & 227210 & $2 \times 52$ & 95 & 28 & 805210 & 68664 \\
\hline 105 & 24 & 227110 & $2 \times 52$ & 105 & 25 & 227110 & $2 \times 52$ \\
\hline$r$ & 26 & 227110 & $2 \times 52$ & 105 & 27 & 227120 & $2 \times 52$ \\
\hline & & & $\mathrm{OCCU}$ & 416 & & & \\
\hline 40 & 20 & 238100 & $0 \times 702$ & 65 & 12 & 238200 & $2 \times 56$ \\
\hline & & & OCCUPATIOH & 417 & & & \\
\hline & & 123140 & $1 \times 49$ & 8 & 3 & 222110 & $2 \times 59$ \\
\hline 73 & 33 & 292300 & $2 \times 59$ & 73 & 34 & 292100 & $2 \times 59$ \\
\hline 73 & 35 & 291100 & $2 \times 59$ & & & & \\
\hline
\end{tabular}

OCCUPATION 419

$\begin{array}{rrrlrrrl}6 & 6 & 602910 & 4 \times 6675 & 13 & 36 & 209050 & 0 \times 825 \\ 21 & 34 & 229410 & 2 \times 12 & 22 & 33 & 209030 & 2 \times 56 \\ 24 & 8 & 229710 & 2 \times 12 & 24 & 11 & 229010 & 2 \times 12 \\ 24 & 12 & 229020 & 2 \times 12 & 30 & 3 & 229610 & 6 \times 662 \\ 42 & 22 & 209060: & 2 \times 59 & 55 & 7 & 224210 & 2 \times 59 \\ 59 & 14 & 282150 & 2 \times 59 & 59 & 15 & 206110 & 2 \times 59 \\ 65 & 10 & 207050 & 2 \times 33 & 68 & 24 & 229120 & 2 \times 12 \\ 68 & 37 & 208010 & 2 \times 59 & 83 & 20 & 229130 & 2 \times 12 \\ 104 & 18 & 209070 & 2 \times 59 & & & & \end{array}$

$\begin{array}{rrrrrrrl}1 & 30 & 2110 & 0 \times 42 & 20 & 1 & 45210 & 0 \times 44 \\ 27 & 30 & 45110 & 0 \times 44 & 31 & 33 & 2250 & 0 \times 42 \\ 59 & 10 & 62050 & 0 \times 49 & 76 & 30 & 713013 & 6 \times 4309\end{array}$

$\begin{array}{rrrlrrrr}52 & 4 & 57410 & 0 \times 606 & 52 & 5 & 57410 & 0 \times 606 \\ 53 & 20 & 243040 & 2 \times 59 & 59 & 29 & 57510 & 0 \times 606\end{array}$

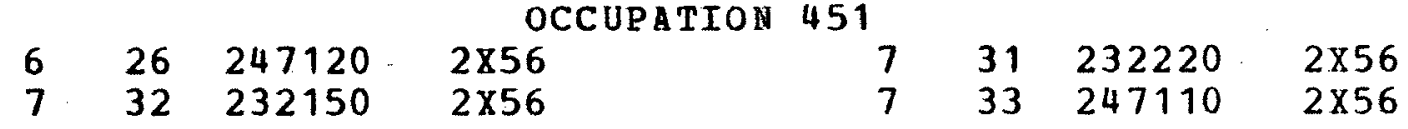

$36 \quad 10: 232230 \quad 2 \times 56$

OCCUPATION 452

$\begin{array}{rrrcrrrr}33 & 5 & 557110 & 4 \times 6651 & 33 & 23 & 557410 & 4 \times 6651 \\ 41 & 28 & 957210 & 6 \times 4457 & 43 & 19 & 557610 & 6 \times 4651 \\ 46 & 37 & 557310 & 4 \times 6651 & 103 & 9 & 957000 & 6 \times 4651 \\ & & & \text { OCCUPATION } & 453 & & & \\ 36 & 22 & 295300 & 6 \times 2493 & 36 & 23 & 295200 & 2 \times 59\end{array}$


PAGE COL. VOL. I VOL. II PAGE COL. VOL. I VOL. II

\begin{tabular}{|c|c|c|c|c|c|c|}
\hline 24 & 282100 & $\begin{array}{l}\text { OCCUPATION } \\
6 \times 662\end{array}$ & $\begin{array}{l}454 \\
107\end{array}$ & 35 & 282300 & $6 \times 662$ \\
\hline 25 & 65100 & $\begin{array}{l}\text { OCCUPATION } \\
2 \times 56\end{array}$ & $\begin{array}{r}455 \\
36\end{array}$ & 26 & 69430 & $2 \times 56$ \\
\hline $\begin{array}{l}13 \\
15\end{array}$ & $\begin{array}{l}236300 \\
396100\end{array}$ & $\begin{array}{l}\text { OCCUPATION } \\
0 \times 810 \\
3 \times 960\end{array}$ & $\begin{array}{r}456 \\
47 \\
47\end{array}$ & $\begin{array}{l}14 \\
16\end{array}$ & $\begin{array}{l}236310 \\
236100\end{array}$ & $\begin{array}{l}1 \times 57 \\
0 \times 810\end{array}$ \\
\hline $\begin{array}{l}28 \\
30 \\
26\end{array}$ & $\begin{array}{l}240350 \\
248300 \\
556210\end{array}$ & $\begin{array}{l}\quad \text { OCCUPATION } \\
1 \times 55 \\
2 \times 59 \\
6 \times 4409 \\
2 \times 59\end{array}$ & $\begin{array}{r}457 \\
30 \\
63 \\
98\end{array}$ & $\begin{array}{l}30 \\
24 \\
27\end{array}$ & $\begin{array}{l}245100 \\
240920 \\
240610\end{array}$ & $\begin{array}{l}2 \times 59 \\
1 \times 57 \\
1 \times 57\end{array}$ \\
\hline
\end{tabular}

\begin{tabular}{rrllccrrr}
\multicolumn{8}{c}{ Occupation } & 459 \\
4 & 33 & 242300 & $2 \times 56$ & 11 & 8 & 234100 & $2 \times 59$ \\
18 & 36 & 243510 & $1 \times 57$ & 19 & 26 & 243960 & $2 \times 33$ \\
21 & 19 & 243320 & $2 \times 59$ & 43 & 18 & 243910 & $2 \times 59$ \\
50 & 19 & 243230 & $2 \times 56$ & 62 & 34 & 243420 & $1 \times 59$ \\
79 & 19 & 243120 & $2 \times 59$ & 100 & 27 & 222710 & $1 \times 50$
\end{tabular}

\begin{tabular}{|c|c|c|c|c|c|c|c|}
\hline \multicolumn{8}{|c|}{ OCCUPATION 510} \\
\hline 13 & 30 & 749201 & $0 \times 849$ & 15 & 22 & 579020 & $4 \times 6209$ \\
\hline & 3 & 79210 & $0 \times 849$ & 77 & 33 & 576020 & $4 \times 6386$ \\
\hline 78 & 2 & 505010 & $4 \times 6385$ & 101 & 7 & 98750 & $0 \times 849$ \\
\hline 101 & 23 & 79220 & $0 \times 849$ & 106 & 22 & 576010 & $0 \times 849$ \\
\hline & & & & 520 & & & \\
\hline 3 & 2 & 41100 & & & & & \\
\hline
\end{tabular}

$3532 \quad 541040$ OCCUPATION 531

\begin{tabular}{|c|c|c|c|c|c|c|c|}
\hline $\begin{array}{l}35 \\
51 \\
64 \\
80\end{array}$ & $\begin{array}{r}32 \\
14 \\
6 \\
37\end{array}$ & $\begin{array}{l}541040 \\
541060 \\
543100 \\
541010\end{array}$ & $\begin{array}{l}4 \times 2492 \\
4 \times 2492 \\
4 \times 2492 \\
4 \times 2492\end{array}$ & $\begin{array}{r}50 \\
57 \\
64 \\
109\end{array}$ & $\begin{array}{r}12 \\
36 \\
7 \\
6\end{array}$ & $\begin{array}{l}541030 \\
541010 \\
543200 \\
541010\end{array}$ & $\begin{array}{r}4 \times 2492 \\
4 \times 2492 \\
4 \times 2492 \\
4 \times 2492\end{array}$ \\
\hline $\begin{array}{l}40 \\
40\end{array}$ & $\begin{array}{r}8 \\
15\end{array}$ & $\begin{array}{l}542200 \\
542100\end{array}$ & $\begin{array}{l}\text { OCCOPATION } \\
4 \times 2492 \\
4 \times 2492\end{array}$ & $\begin{array}{r}532 \\
40\end{array}$ & 10 & 542100 & $4 \times 2492$ \\
\hline 23 & 17 & 92110 & $\begin{array}{l}\text { OCCUPATION } \\
0 \times 849\end{array}$ & $\begin{array}{r}534 \\
23\end{array}$ & 18 & 92210 & $0 \times 849$ \\
\hline & 8 & 905010 & $\begin{array}{l}\text { OCCOPATION } \\
4 \times 2109\end{array}$ & $\begin{array}{r}535 \\
12\end{array}$ & 10 & 538010 & $6 \times 2492$ \\
\hline
\end{tabular}


PAGE, COL. VOL. I VOL. II PAGE COL. VOL. I VOL. II

\begin{tabular}{|c|c|c|c|c|c|c|c|}
\hline 106 & 12 & 262100 & $\begin{array}{l}\text { OCCUPATION } \\
6 \times 2290\end{array}$ & 37 & & & \\
\hline $\begin{array}{r}28 \\
60 \\
76 \\
103\end{array}$ & $\begin{array}{r}18 \\
27 \\
32 \\
6\end{array}$ & $\begin{array}{r}573760 \\
88030 \\
88410 \\
88020\end{array}$ & $\begin{array}{l}\text { OCCUPATION } \\
3 \times 870 \\
3 \times 870 \\
0 \times 810 \\
3 \times 870\end{array}$ & $\begin{array}{r}541 \\
32 \\
73 \\
86 \\
103\end{array}$ & $\begin{array}{r}5 \\
31 \\
33 \\
8\end{array}$ & $\begin{array}{l}88120 \\
88020 \\
88310 \\
88030\end{array}$ & $\begin{array}{l}3 \times 870 \\
3 \times 870 \\
3 \times 870 \\
3 \times 870\end{array}$ \\
\hline $\begin{array}{r}37 \\
37 \\
103\end{array}$ & $\begin{array}{r}8 \\
11 \\
7\end{array}$ & $\begin{array}{l}88250 \\
88210 \\
88230\end{array}$ & $\begin{array}{l}\text { OCCUPATION } \\
4 \times 2102 \\
4 \times 2102 \\
4 \times 2102\end{array}$ & $\begin{array}{r}543 \\
37 \\
73\end{array}$ & $\begin{array}{l}10 \\
32\end{array}$ & $\begin{array}{l}88240 \\
88220\end{array}$ & $\begin{array}{l}4 \times 2102 \\
4 \times 2102\end{array}$ \\
\hline $\begin{array}{r}1 \\
10 \\
84\end{array}$ & $\begin{array}{r}1 \\
5 \\
23\end{array}$ & $\begin{array}{l}548040 \\
548030 \\
748010\end{array}$ & $\begin{array}{l}\text { OCCOPATION } \\
3 \times 870 \\
3 \times 870 \\
3 \times 870\end{array}$ & $\begin{array}{r}545 \\
6 \\
77\end{array}$ & $\begin{array}{r}27 \\
2\end{array}$ & $\begin{array}{l}549102 \\
548020\end{array}$ & $\begin{array}{l}3 \times 870 \\
3 \times 870\end{array}$ \\
\hline 13 & 31 & 536010 & $\begin{array}{l}\text { OCCUPATION } \\
4 \times 2492\end{array}$ & 551 & & & 1 \\
\hline 18 & 28 & 736010 & $\begin{array}{l}\text { OCCUPATION } \\
6 \times 2492\end{array}$ & 552 & & & \\
\hline $\begin{array}{r}6 \\
82\end{array}$ & $\begin{array}{r}7 \\
10\end{array}$ & $\begin{array}{l}735100 \\
735100\end{array}$ & $\begin{array}{l}\text { OCCUPATION } \\
6 \times 2492 \\
6 \times 2492\end{array}$ & $\begin{array}{l}554 \\
28\end{array}$ & 9 & 735300 & $6 \times 610$ \\
\hline $\begin{array}{l}23 \\
64\end{array}$ & $\begin{array}{r}10 \\
2\end{array}$ & $\begin{array}{l}736210 \\
735200\end{array}$ & $\begin{array}{l}\text { OCCUPATION } \\
4 \times 2492 \\
6 \times 2492\end{array}$ & $\begin{array}{r}556 \\
33 \\
102\end{array}$ & $\begin{array}{l}16 \\
14\end{array}$ & $\begin{array}{l}736220 \\
736260\end{array}$ & $\begin{array}{l}4 \times 2492 \\
6 \times 2492\end{array}$ \\
\hline 96 & 32 & 591401 & $\begin{array}{l}\text { OCCOPATION } \\
3 \times 996\end{array}$ & $\begin{array}{c}563 \\
96\end{array}$ & 33 & 737100 & $3 \times 111$ \\
\hline 77 & 14. & 69210 & $\begin{array}{l}1 \text { OCCOPATION } \\
\text { OX42 }\end{array}$ & 581 & & & \\
\hline $\begin{array}{r}3 \\
70 \\
77\end{array}$ & $\begin{array}{r}7 \\
27 \\
23\end{array}$ & $\begin{array}{l}61600 \\
61700 \\
61300\end{array}$ & $\begin{array}{l}\text { OCCUPATION } \\
\text { OX749 } \\
\text { OX749 } \\
\text { OX748 }\end{array}$ & $\begin{array}{r}582 \\
38 \\
77 \\
77\end{array}$ & $\begin{array}{l}36 \\
22 \\
24\end{array}$ & $\begin{array}{l}61500 \\
61330 \\
61320\end{array}$ & $\begin{array}{l}0 \times 748 \\
0 \times 748 \\
0 \times 748\end{array}$ \\
\hline 18 & 19 & 142010 & $\begin{array}{l}\text { OCCUPATION } \\
1 \times 11\end{array}$ & $\begin{array}{r}584 \\
85\end{array}$ & 10 & 1420 & $1 \times 57$ \\
\hline 9 & 9 & 142310 & $1 \times 50$ & 97 & 10 & 142320 & $1 \times 50$ \\
\hline
\end{tabular}


PAGE COL. VOL. I VOL. II PAGE COL. VOL. I VOL. II

\begin{tabular}{|c|c|c|c|c|c|c|c|}
\hline \multirow[b]{2}{*}{$\begin{array}{l}30 \\
97\end{array}$} & \multicolumn{6}{|c|}{ OCCDPATION 585} & \multirow[b]{2}{*}{$1 \times 57$} \\
\hline & $\begin{array}{l}7 \\
4\end{array}$ & $\begin{array}{l}141160 \\
141120\end{array}$ & $\begin{array}{l}1 \times 28 \\
4 \times 6183\end{array}$ & 85 & 10 & 142030 & \\
\hline \multicolumn{8}{|c|}{ OCCUPATION 588} \\
\hline 25 & 15 & 123.140 & $1 \times 49$ & 28 & 8 & 123150 & $6 \times 610$ \\
\hline 9 & 16 & 123140 & $1 \times 49$ & 61 & 8 & 932010 & $6 \times 42$ \\
\hline 67 & 20 & 248150 & $2 \times 59$ & 67 & 21 & 123140 & $1 \times 49$ \\
\hline & 6 & 123130 & $0 \times 810$ & & & & \\
\hline \multicolumn{8}{|c|}{ OCCUPATION 601} \\
\hline 17 & 9 & 307100 & $3 \times 112$ & 17 & 10 & 307100 & $3 \times 113$ \\
\hline 19 & 22 & 308100 & $3 \times 117$ & 38 & 24 & 304100 & $3 \times 112$ \\
\hline 43 & 15 & 305010 & $3 \times 124$ & 46 & 31 & 301100 & $3 \times 121$ \\
\hline 46 & 39 & 338200 & $3 \times 128$ & & & & \\
\hline & & & & 60 & & & \\
\hline 6 & 31 & 344010 & $3 \times 111$ & 59 & 34 & 337100 & $0 \times 831$ \\
\hline
\end{tabular}

\begin{tabular}{rrrrrrrr}
7 & \multicolumn{7}{c}{ OCCUPATION.605 } \\
70 & 307700 & $3 \times 119$ & 25 & 39 & 317200 & $3 \times 113$ \\
46 & 40 & 339100 & $3 \times 128$ & 49 & 11 & 307100 & $3 \times 115$ \\
65 & 14 & 338200 & $3 \times 128$ & & & &
\end{tabular}

44: $19 \quad 340010 \quad 3 \times 128$

OCCUPATION 607.

OCCUPATION 609

$\begin{array}{rccl}9 & 29 & 348010 & 3 \times 117 \\ 22 & 23 & 333220 & 3 \times 121 \\ 48 & 16 & 341100 & 3 \times 117 \\ 52 & 36 & 332150 & 3 \times 100 \\ 53 & 32 & 756730 & 3 \times 119 \\ 85 & 3 & 347200 & 6 \times 2671\end{array}$

$\begin{array}{llll}19 & 23 & 348030 & 3 \times 117\end{array}$ $\begin{array}{llll}30 & 15 & 749525 & 6 \times 2608\end{array}$

$\begin{array}{llll}50 & 3 & 3.49950 & 3 \times 111\end{array}$

$\begin{array}{llll}53 & 31 & 7567.20 & 3 \times 119\end{array}$

$\begin{array}{llll}66 & 6 & 340130 & 3 \times 124\end{array}$

$86,7 \quad 349310 \quad 3 \times 114$

11. $\quad 6 \quad 591401 \quad 3 \times 996$

$87 \quad 23 \quad 591401 ; 3 \times 996$

OCCUPATION 611

\begin{tabular}{|c|c|c|c|c|c|c|c|}
\hline \multicolumn{2}{|c|}{ ! } & & \multicolumn{2}{|c|}{ OCCUPATION 613} & \multicolumn{2}{|r|}{ 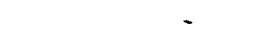 } & \\
\hline $\begin{array}{l}26 \\
40\end{array}$ & $\begin{array}{l}16 \\
17\end{array}$ & $\begin{array}{l}68140 \\
68180\end{array}$ & $\begin{array}{l}0 \times 730 \\
3 \times 994\end{array}$ & $\begin{array}{l}40 \\
88\end{array}$ & $\begin{array}{r}1 \\
36\end{array}$ & $\begin{array}{l}68170 \\
68220\end{array}$ & $\begin{array}{l}3 \times 994 \\
3 \times 994\end{array}$ \\
\hline & & & occ & 615 & & & \\
\hline 9 & 13 & 430010 & $3 \times 996$ & 11 & 5 & 831010 & $6 \times 669$ \\
\hline 11 & 23 & 430310 & $3 \times 996$ & 13 & 7 & 630 & $3 \times 996$ \\
\hline 13 & 8 & 5914 & $3 \times 95$ & 13 & 11 & 5911 & $3 \times 996$ \\
\hline 18 & 26 & 830100 & $6 \times 669$ & 19 & 38 & 830100 & $6 \times 669$ \\
\hline 19 & 39 & 591401 & $3 \times 996$ & 38 & 22 & 630140 & $3 \times 996$ \\
\hline 46 & 28 & 830100 & $6 \times 440 s$ & 49 & 30 & 591401 & $0 \times 839$ \\
\hline
\end{tabular}




$\begin{array}{rrrl}\text { PAGE COL. } & \text { VOL. I } & \text { VOL. II } \\ 53 & 6 & 573330 & 4 \times 2493 \\ 58 & 4 & 631110 & 6 \times 4429 \\ 71 & 12 & 630080 & 3 \times 996 \\ 81 & 1 & 830100 & 6 \times 669 \\ 95 & 34 & 830100 & 6 \times 669 \\ 108 & 22 & 591401 & 3 \times 996\end{array}$

$\begin{array}{rrrc}\text { PAGE } & \text { COL. } & \text { VOL. I } & \text { VOL. II } \\ 57 & 22 & 591401 & 0 \times 839 \\ 65 & 4 & 630150 & 3 \times 996 \\ 77 & 27 & 630340 & 3 \times 996 \\ 95 & 14 & 830100 & 6 \times 669 \\ 108 & 18 & 630130 & 3 \times 996\end{array}$

OCCUPATION 631

$\begin{array}{lrrr}20 & 27 & 387520 & 3 \times 881 \\ 40 & 27 & 387520 & 3 \times 881 \\ 40 & 29 & 387010 & 3 \times 881 \\ 40: & 31 & 387040 & 3 \times 881 \\ 40 & 33 & 387060 & 3 \times 881 \\ 40 & 35 & 387560 & 3 \times 881 \\ 40 & 37 & 387170 & 3 \times 881 \\ 40 & 39 & 387440 & 3 \times 881 \\ 41 & 2 & 387260 & 3 \times 881 \\ 48 & 15 & 341200 & 3 \times 885 \\ 83 & 37 & 387570 & 3 \times 881 \\ 84 & 22 & 387730 & 3 \times 860\end{array}$

$\begin{array}{lll}40 & 26 & 387420\end{array}$

$\begin{array}{lll}40 & 28 & 387530\end{array}$

$3 \times 881$

$40 \quad 30 \quad 387430$

$3 \times 881$

$3 \times 881$

$\begin{array}{lll}40 & 32 & 387230\end{array}$

$3 \times 881$

$40 \quad 34.387550$

$3 \times 881$

$40.36 \quad 387080$

$3 \times 881$

$\begin{array}{lll}40 & 38 & 387580\end{array}$

$3 \times 881$

41.13 .87130

$3 \times 881$

$\begin{array}{lll}45 & 32 & 619753\end{array}$

$6 \times 4359$

5231.388220

$3 \times 881$

$\begin{array}{lll}84 & 19 & 387710\end{array}$

$3 \times 860$

74

$29397400 \quad 3 \times 960$

OCCUPATION 633

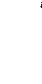

62

66

72

100

21

593110

593210

$9 \quad 593210$

22593310

$94: 16 \quad 521210$

$98 \quad 39 \quad 590210$

\section{OCCUPATION 651}

$0 \times 842$

$0 \times 842$

$0 \times 842$

$0 \times 842$

\section{OCCUPATION 653}

$$
4 \times 2494
$$

$4 \times 6220$

\section{OCCOPATION 654}

$\begin{array}{rrrr}2 & 7 & 788480 & 6 \times 2492 \\ 11 & 19 & 722620: & 6 \times 4295 \\ 20 & 8 & 575240: & 4 \times 2494 \\ 32 & 16 & 575020 & 4 \times 2494 \\ 32 & 22 & 775010 & 6 \times 2494 \\ 53 & 2 & 775710: & 6 \times 4294 \\ 57 & 25 & 721420 & 6 \times 2493 \\ 62 & 12 & 521020 & 4 \times 6295 \\ 62 & 14 & 521010: & 4 \times 6295 \\ 62 & 19 & 721020 & 4 \times 6295 \\ 62 & 21 & 521010 & 4 \times 6295 \\ 77 & 10 & 521210 & 4 \times 2494 \\ 81 & 3 & 521030 & 4 \times 6295 \\ 81 & 28 & 593210 & 4 \times 6295 \\ 85 & 30 & 521010: & 4 \times 6295 \\ 103 & 12 & 521010 & 4 \times 6295\end{array}$

$\begin{array}{llll}7 & 24 & 722510 & 4 \times 6295\end{array}$ $184521210 \quad 4 \times 2494$ $24 \quad 1 \quad 722530$

$\begin{array}{lll}32 & 18 & 521010\end{array}$

$32 \quad 23 \quad 575020$

$57 \quad 24 \quad 721410$

$58 \quad 21 \quad 593210$

$\begin{array}{lll}62 & 13 & 521010\end{array}$

$\begin{array}{lll}62 & 16 \quad 521010\end{array}$

$62 \quad 20 \quad 521010$

$\begin{array}{lll}64 & 1 & 593000\end{array}$

$\begin{array}{lll}78 & 3 & 575020\end{array}$

815575020

$85 \quad 29 \quad 522910$

$85 \quad 31 \quad 521020$
$6 \times 2493$

$4 \times 6295$

$4 \times 2494$

$6 \times 2493$

$4 \times 2494$

$4 \times 6295$

$4 \times 6295$

$4 \times 6295$

$0 \times 849$

$4 \times 2494$

$4 \times 2494$

$4 \times 6220$

$4 \times 6295$ 
PAGE COL. VOL. I VOL. II PAGE COL. VOL. I VOL. II

$\begin{array}{rrrr} & & & \text { OCCU } \\ 2 & 9 & 690511 & 6 \times 2695 \\ 20 & 34 & 490211 & 6 \times 2695 \\ 26 & 17 & 722380 & 6 \times 2695 \\ 53 & 15 & 522310 & 6 \times 2695 \\ 74 & 23 & 690312 & 6 \times 2695 \\ 88 & 32 & 690211 & 4 \times 6695\end{array}$

$3 \quad 15 \quad 490011$

$\begin{array}{lll}21 & 29 & 722360\end{array}$

$\begin{array}{lll}42 & 3 & 490511\end{array}$

$53^{\prime} \quad 16 \quad 490211$

74. $24 \quad 490520$

$95 \quad 30 \quad 688036$
$4 \times 6695$

$6 \times 2695$

$4 \times 6695$

$4 \times 6695$

$4 \times 6695$

$4 \times 2489$

$4 \times 2494$

$4 \times 2494$

$4 \times 6694$

$4 \times 2494$

$4 \times 2494$

$4 \times 6295$

$4 \times 2494$

$4 \times 2493$

\section{OCCUPATION 657}

$\begin{array}{rrr}6 & 14 & 789311 \\ 12 & 19 & 583641 \\ 15 & 17 & 922300 \\ 16 & 13 & 922100 \\ 20 & 12 & 922200 \\ 28 & 29 & 922100 \\ 33 & 14 & 593210 \\ 41 & 27 & 593210 \\ 62 & 18 & 721010 \\ 81 & 7 & 593210 \\ 95 & 23 & 922100\end{array}$

$6 \times 2695$.

$4 \times 2109$

$6 \times 2492$

$6 \times 2492$

$6 \times 4295$

$6 \times 2494$

$0 \times 846$

$0 \times 846$

$4 \times 6295$

$4 \times 6295$

$6 \times 664$

$\begin{array}{ll}14 & 18 \\ 15 & 24\end{array}$

572010

922000

$15 \quad 21$

922500

$20 \quad 9 \quad 593210$

$\begin{array}{lll}28 & 28 & 775410\end{array}$

30

29

922000

$\begin{array}{lll}33 & 15 & 573520\end{array}$

57

20

593210

64

15

593210

84

6

852310

96

573520

$4 \times 2102$

$6 \times 4295$

$6 \times 2493$

$0 \times 849$

$4 \times 2494$

$6 \times 2492$

$4 \times 2493$

$0 \times 849$

$0 \times 849$

$6 \times 669$

$4 \times 2493$

\section{OCCUPATION 659}

$\begin{array}{rrrr}18 & 37 & 79130 & 4 \times 6295 \\ 21 & 22 & 776140 & 4 \times 6381 \\ 32 & 22 & 775010 & 6 \times 2494 \\ 32 & 25 & 775020 & 6 \times 2494 \\ 42 & 7 & 922300 & 4 \times 6220 \\ 55 & 12 & 722970 & 4 \times 6183 \\ 69 & 5 & 722810 & 6 \times 4209 \\ 87 & 16 & 574020 & 4 \times 6295\end{array}$

20

21

32

42

53

62

77

99
8

8
23

23

6

2

20

1

15
575240

79110

575020

522920

775710

521010

521040

593210

$4 \times 2494$

$4 \times 6295$

$4 \times 2494$

$4 \times 6220$

$6 \times 4294$

$4 \times 6295$

$6 \times 4294$

$0 \times 846$

\section{OCCOPATION 701}

$\begin{array}{rrrr}25 & 12 & 407100 & 4 \times 6671 \\ 61 & 30 & 407100 & 4 \times 6671 \\ 62 & 4 & 407200 & 4 \times 6671\end{array}$

$\begin{array}{lll}41 & 16 & 608212 \\ 61 & 33 & 607100 \\ 81 & 20 & 607400\end{array}$

$6 \times 2671$

$4 \times 6671$

$6 \times 2671$

\section{OCCUPATION 702}

$\begin{array}{rrrr}6 & 4 & 401100 & 4 \times 6675 \\ 7 & 19 & 401600 & 4 \times 6671 \\ 8 & 8 & 401200 & 4 \times 6375\end{array}$

$\begin{array}{rrr}6 & 5 & 401400 \\ 8 & 7 & 401200 \\ 24 & 6 & 247020\end{array}$

$4 \times 6675$ $4 \times 6375$ $2 \times 12$ 
$\begin{array}{rrrr}\text { PAGE } & \text { COL. VOL. I' } & \text { VOL. II } \\ 30 & 19 & 602123 & 6 \times 4479 \\ 66 & 34 & 401800 & 4 \times 6675\end{array}$

PAGE COL. VOL. I

$31 \quad 2 \quad 401700$

869602125

OCCUPATION 703

$\begin{array}{rrrr}7 & 36 & 409205 & 4 \times 6376 \\ 10 & 34 & 409204 & 4 \times 6376 \\ 13 & 33 & 409205 & 4 \times 6376 \\ 13 & 35 & 409206 & 4 \times 6376 \\ 47 & 32 & 609297 & 6 \times 4376 \\ 60 & 36 & 558100 & 4 \times 6376\end{array}$

OCCUPATION 704

$50: \quad 14 \quad 809110 \quad 6 \times 4379$

$\begin{array}{llll}60 & 38 & 809110 & 6 \times 4379\end{array}$

$24.4 \quad 226910 \quad 2 \times 12$

OCCUPATION 705

OCCUPATION 706

$\begin{array}{lll}24 & 16 & 604360 \\ 69 & 35 & 804100 \\ 79 & 23 & 604450\end{array}$

$4 \times 6671$

$6 \times 2479$

$24 \quad 18 \quad 604380$

$4 \times 6671$

$6 \times 2671$

OCCUPATION 707

$\begin{array}{rrr}13 & 37 & 406330 \\ 19 & 1 & 406430 \\ 19 & 37 & 406560 \\ 24 & 22 & 591011 \\ 32 & 12 & 606530 \\ 104 & 32 & 406570\end{array}$

$4 \times 6671$

$4 \times 6671$

$4 \times 6671$

$0 \times 846$

$6 \times 2604$

$4 \times 6671$

73

2604660

$6 \times 2671$

OCCUPATION 708

$\begin{array}{rrrl}7 & 37 & 609351 & 6 \times 2381 \\ 14 & 25 & 402311 & 4 \times 6375 \\ 23 & 36 & 408421 & 4 \times 6671 \\ 39 & 12 & 804100 & 6 \times 2479 \\ 41 & 5 & 95120 & 0 \times 625 \\ 42 & 5 & 804100 & 6 \times 4479 \\ 55 & 17 & 409401 & 4 \times 6671 \\ 79 & 11 & 409401 & 4 \times 6671 \\ 88 & 22 & 602420 & 6 \times 4479\end{array}$

$9 \quad 16 \quad 602012$ $\begin{array}{lll}14 & 38 & 605242\end{array}$

$39 \quad 11 \quad 768032$

$39 \quad 13 \quad 805010$

424.810230

$\begin{array}{lll}51 & 3 & 602331\end{array}$

$\begin{array}{lll}64 & 26 & 408411\end{array}$

$88 \quad 20 \quad 602430$

$96 \quad 5 \quad 609415$

$6 \times 2383$

$4 \times 6671$

$4 \times 6671$

$6 \times 2671$

$4 \times 6671$

$4 \times 6671$

$4 \times 6671$

$6 \times 4679$

$6 \times 4409$

$6 \times 2479$

$6 \times 4679$

$6 \times 4479$

$4 \times 6671$

$6 \times 2479$

$6 \times 2671$

OCCUPATION 709

$\begin{array}{lll}12 & 22 & 403210 \\ 59 & 28 & 403240 \\ 92 & 22 & 403260\end{array}$

$4 \times 6671$

$4 \times 6671$

$4 \times 6671$

$\begin{array}{lll}53 & 34 & 403280\end{array}$

$4 \times 6671$

$\begin{array}{lll}60 & 24 & 403270\end{array}$

$4 \times 6671$

$4 \times 6671$

\section{OCCUPATION 711}

2. $13 \quad 657141 \quad 4 \times 6357$

$51 \quad 20 \cdot 857010 \quad 6 \times 4349$

$99 \quad 18 \quad 457112$. $4 \times 6357$

$99 \quad 22 \quad 457212 \quad 4 \times 6357$

$10920 \quad 403030$
$0 \times 841$

$4 \times 6357$

$4 \times 6357$

$6 \times 4356$ 
PAGE COL. VOL. I VOL. II $10128 \cdot 789426^{\prime} \cdot 6 \times 4356$

PAGE COL. VOL. I VOL. II

OCCUPATION 719

17. $23.657017 \quad 4 \times 6641$

$99 \quad 20 \quad 780422 \quad 6 \times 2381$

$27 \quad 12 \quad 657961$

$6 \times 4356$

$99 \quad 21 \quad 457213$

$4 \times 6381$

OCCUPATION 721

$\begin{array}{rrrr}5 & 27 & 461011 & 6 \times 4356 \\ 12 & 1 & 461041 & 6 \times 4459 \\ 27 & 6 & 661011 & 6 \times 4356 \\ 49 & 9 & 461043 & 6 \times 4459 \\ 89 & 22 & 461045 & 6 \times 4459 \\ & & & \\ & & & 0 \times C \\ 7 & 34 & 467681 & 4 \times 6355 \\ 21 & 30 & 461171 & 6 \times 4351 \\ 46 & 23 & 461218 & 6 \times 4352 \\ 46 & 25 & 461222 & 6 \times 4352 \\ 49 & 7 & 661713 & 6 \times 4459 \\ 51 & 23 & 661716 & 6 \times 4459 \\ 57 & 6 & 461224 & 6 \times 4352 \\ 76 & 12 & 461683 & 6 \times 4358 \\ 92 & 30 & 661211 & 6 \times 4352 \\ 100 & 26 & 461233 & 6 \times 4352 \\ 107 & 18 & 461235 & 6 \times 4352\end{array}$

$\begin{array}{lll}5 & 33 & 859010\end{array}$

$6 \times 4359$

$26 \quad 11 \quad 461012$

$4 \times 6355$

$27 \quad 11 \quad 459032$

$6 \times 4356$

$\begin{array}{lll}66 & 30 \quad 461046\end{array}$

$6 \times 4459$

$8923 \quad 461046$

$6 \times 4459$

OCCUPATION 722

$6 \times 4351$

$14.3 \quad 661512$

$6 \times 6352$

$6 \times 4459$

$6 \times 4352$

$6 \times 4459$

$6 \times 4459$

$6 \times 4358$

$6 \times 4359$

$6 \times 4459$

$6 \times 4352$

$6 \times 4352$

$87 \quad 11 \quad 660100$

OCCUPATION 724

\section{OCCUPATION 729}

$48 \quad 11,662070$

$4 \times 6335$

$48 \quad 9.662060$

$4 \times 6355$

$51.25 \quad 461861$

$4 \times 6355$

48

12

462120

$4 \times 6355$

$4 \times 6381$

$56 \cdot 18 \cdot 662160$

$4 \times 6355$

$58 \quad 15: 462110 \quad 4 \times 6355$

$92 \quad 28 \quad 462050$

$6 \times 4351$

OCCUPATION 731

$15 \quad 18 \quad 619031.6 \times 2451$

$\begin{array}{lll}70 & 35 & 619012\end{array}$

$6 \times 2451$

$90 \quad 6 \quad 619024 \quad 4 \times 2$

OCCUPATION 732

$\begin{array}{rrrrr}43 & 11 & 619055 & 6 \times 2451 & 5 \\ 90 & 12 & 470010 & 4 \times 2451 & 9 \\ 90 & 16 & 419042 & 4 \times 2451 & 9 \\ 98 & 23 & 619071 & 4 \times 2451 & 10 \\ & & & \text { OCCUPATION } & 733 \\ 10 & 7 & 661912 & 6 \times 2451 & 79\end{array}$

$10.7 .661912 \quad 6 \times 2451$

$\begin{array}{lll}53 & 4 & 415010\end{array}$

$4 \times 2452$

$90 \quad 15 \quad 619041$

$4 \times 2451$

$4 \times 2451$

$\begin{array}{lll}90 & 17 & 619041\end{array}$

$6 \times 2451$

$90.20 \cdot 619165 \quad 6 \times 4359$

$\begin{array}{lll}79 & 29 & 619117\end{array}$

$6 \times 2451$ 
PAGE COL. VOL. I VOL. II PAGE COL. VOL. I VOL. II

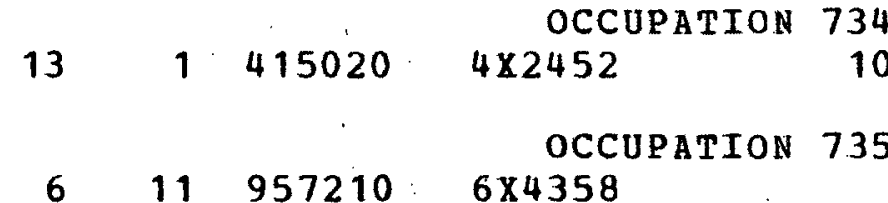

$\begin{array}{lllll}6 & 11 & 957210: 6 \times 4358\end{array}$

31. $36 \quad 619824: 6 \times 2451$

$\begin{array}{llll}48 & 8 & 415030 & 4 \times 2452\end{array}$

$\begin{array}{lllll}58 & 10 & 416010 & 4 \times 2105\end{array}$

$\begin{array}{llll}105 & 36 & 619222 & 4 \times 2451\end{array}$

OCCUPATION 736

$\begin{array}{rrr}21 & 14 & 414064 \\ 50 & 7 & 614331 \\ 54 & 18 & 583321 \\ 54 & 21 & 619751 \\ 57 & 7 & 414072 \\ 93 & 1 & 614235\end{array}$

$$
4 \times 2453
$$

$6 \times 4351$

$4 \times 2105$

$6 \times 4451$

$4 \times 2453$

$6 \times 2381$

OCCUPATION 737

$\begin{array}{rlr}1 & 27 & 451030 \\ 30 & 35 & 619605 \\ 89 & 12 & 619252\end{array}$

$21 \quad 15 \quad 819010$

$\begin{array}{lll}98 & 3 & 819010\end{array}$

\section{$4 \times 6641$}

$6 \times 2601$

$6 \times 2601$

\section{OCCUPATION 738}

$6 \times 4651$

$6 \times 2459$

$\begin{array}{rrrr}39 & 34 & 614221 & 6 \times 2381 \\ 54 & 17 & 41411 & 4 \times 6351 \\ 54 & 20 & 414061 & 4 \times 2453 \\ 54 & 22 & 414063 & 4 \times 2453 \\ 57 & 8 & 414071 & 4 \times 2453 \\ 93 & 2 & 414065 & 6 \times 4451\end{array}$

22. $14 \quad 718320$

$6 \times 2601$

$6 \times 4651$
$6 \times 2451$

$6 \times 2459$

$4 \times 2452$

$4 \times-2452$

$4 \times 2451$

\section{OCCUPATION 739}

$\begin{array}{rll}9 & 35 & 614173 \\ 21 & 10 & 619553 \\ 47 & 12 & 619164 \\ 72 & 36 & 619082\end{array}$

$6 \times 4458$

$6 \times 2381$

21

$6 \times 2451$

$4 \times 2451$

\section{2}

15

4

118660

$1 \times 20$

61

15

619462

$6 \times 2459$

$10829 \quad 419991$

$4 \times 6351$

$4 \times 6381$

\section{OCCUPATION 741}

95

$35 \quad 426101 \quad 4 \times 6352$

96

29419991

$6 \times 4457$

OCCUPATION 742

$\begin{array}{llll}25 & 19 & 625010 \quad 4 \times 6352\end{array}$

$32 \quad 9^{\prime} \quad 425030$

$4 \times 6352$

$84 \quad 29 \quad 425020 \quad 4 \times 6352$

OCCUPATION 743

$\begin{array}{rrrcr}43 & 20 & 421210 & 4 \times 6356 & 43 \\ 44 & 3 & 421310 & 4 \times 6356 & 44 \\ & & & \text { OCCUPATION } & 744 \\ 15 & 10 & 424221 & 6 \times 4351 & 61\end{array}$

$43 \quad 22 \quad 421110$

$4 \times 6356$

$44 \quad 4.421010 .4 \times 6356$

OCCUPATION 744

$15 \quad 10 \cdot 424221.6 \times 4351$

$61 \quad 34 \quad 423100$

$4 \times 6352$ 
PAGE COL. VOL. I VOL. II PAGE COL. VOL. I VOL. II

OCCUPATION 745

$\begin{array}{rrrlrrrr}14 & 2 & 627041 & 6 \times 4356 & 27 & 3 & 799410 & 4 \times 6352 \\ 27 & 9 & 427043 & 4 \times 6352 & 27 & 10 & 427041 & 4 \times 6352 \\ 46 & 12 & 662040 & 6 \times 4352 & 60 & 18 & 627024 & 6 \times 4359 \\ 60 & 19 & 627011 & 6 \times 4359 & 104 & 8 & 435120 & 4 \times 6353\end{array}$

OCCUPation 746

$\begin{array}{rrrl}4 & 5 & 627071 & 6 \times 435 \\ 14 & 4 & 627074 & 6 \times 4351 \\ 16 & 12 & 625420 & 6 \times 4352 \\ 32 & 9 & 425030 & 4 \times 6352 \\ 36 & 32 & 827650 & 6 \times 4352 \\ 39 & 32 & 427261 & 6 \times 4351 \\ 55 & 15 & 427071 & 4 \times 6352 \\ 79 & 33 & 703000 & 6 \times 4351 \\ 84 & 29 & 425020 & 4 \times 6352 \\ 85 & 16 & 627081 & 6 \times 4351 \\ 85 & 18 & 624234 & 6 \times 4351 \\ 85 & 21 & 627508 & 6 \times 4352 \\ 102 & 2 & 624121 & 6 \times 4351\end{array}$

$\begin{array}{rrrr}7 & 13 & 627071 & 6 \times 4351 \\ 14 & 5 & 627073 & 6 \times 4351 \\ 28 & 3 & 624234 & 6 \times 4352 \\ 36 & 31 & 625910 & 6 \times 431 \\ 38 & 16 & 627563 & 6 \times 4352 \\ 44 & 21 & 614410 & 6 \times 4451 \\ 58 & 11 & 614420 & 6 \times 4451 \\ 84 & 24 & 627513 & 6 \times 4352 \\ 85 & 15 & 62711 & 6 \times 4351 \\ 85 & 17 & 627082 & 6 \times 4351 \\ 85 & 19 & 627083 & 6 \times 4351 \\ 92 & 28 & 462050 & 6 \times 4351 \\ 103 & 4 & 627576 & 6 \times 4352\end{array}$

OCCUPATION 747

$\begin{array}{rrrr}5 & 16 & 435610 & 4 \times 6353 \\ 17 & 2 & 635820 & 4 \times 6353 \\ 48 & 33 & 435630 & 4 \times 6353\end{array}$

$\begin{array}{rrr}5 & 17 & 799824 \\ 18 & 7 & 635110 \\ 104 & 6 & 635710\end{array}$

$4 \times 6353$

$4 \times 6353$

$4 \times 6353$

OCCUPATION 749

$\begin{array}{rrrl}2 & 29 & 503010 & 4 \times 6354 \\ 5 & 21 & 627811 & 4 \times 6354 \\ 15 & 9 & 427811 & 4 \times 6354 \\ 21 & 11 & 427121 & 6 \times 2381 \\ 38 & 18 & 503030 & 4 \times 6354 \\ 48 & 18 & 624126 & 6 \times 4359 \\ 55 & 36 & 819010 & 6 \times 664 \\ 74 & 35 & 713256 & 6 \times 4463 \\ 80 & 20 & 627352 & 6 \times 4359 \\ 82 & 8 & 624062 & 6 \times 4459 \\ 82 & 27 & 427812 & 4 \times 6352 \\ 101 & 37 & 627054 & 6 \times 4356 \\ 103 & 28 & 513411 & 4 \times 6352\end{array}$

$\begin{array}{rrrr}4 & 9 & 713252 & 6 \times 4309 \\ 13 & 5 & 624251 & 6 \times 4359 \\ 20 & 32 & 627122 & 6 \times 4359 \\ 25 & 20 & 427981 & 4 \times 6352 \\ 38 & 19 & 780600 & 4 \times 6354 \\ 53 & 11 & 624074 & 6 \times 4458 \\ 63 & 2 & 624456 & 6 \times 4459 \\ 76 & 22 & 627025 & 6 \times 4359 \\ 82 & 7 & 624061 & 6 \times 4356 \\ 82 & 28 & 462060 & 4 \times 6355 \\ 101 & 36 & 703562 & 6 \times 4208 \\ 103 & 15 & 827740 & 6 \times 4359\end{array}$

OCCUPATION 751

$\begin{array}{rrrr}10 & 3 & 525610 & 4 \times 6220 \\ 15 & 24 & 793550 & 4 \times 6220 \\ 15 & 26 & 525010 & 4 \times 6320 \\ 15 & 28 & 525830 & 4 \times 6220 \\ 15 & 30 & 525640 & 4 \times 6220 \\ 15 & 32 & 682610 & 4 \times 6320 \\ 15 & 36 & 525810 & 4 \times 6220 \\ 16 & 1 & 525830 & 4 \times 6220\end{array}$

$\begin{array}{lll}15 & 23 & 525110\end{array}$

$\begin{array}{lll}15 & 25 & 525830\end{array}$

$\begin{array}{lll}15 & 27 & 525150\end{array}$

$15 \quad 29 \quad 525260$

$\begin{array}{lll}15 & 31 & 525150\end{array}$

$\begin{array}{lll}15 & 33 & 525110\end{array}$

$\begin{array}{lll}15 & 37 & 525540\end{array}$

$\begin{array}{lll}16 & 2 & 525320\end{array}$
$4 \times 6220$ $4 \times 6220$ $4 \times 6209$ $4 \times 6220$ $4 \times 6220$ $4 \times 6220$ $4 \times 6220$ $4 \times 6320$ 


$\begin{array}{rrrr}\text { PAGE } & \text { COL. } & \text { VOL. I } & \text { VOL. II } \\ 16 & 4 & 525230 & 4 \times 6220 \\ 16 & 6 & 525670 & 4 \times 6220 \\ 16 & 8 & 525380 & 4 \times 6220 \\ 42 & 32 & 525242 & 4 \times 6220 \\ 81 & 27 & 525220 & 4 \times 6220 \\ 91 & 7 & 525050 & 4 \times 6320\end{array}$

$\begin{array}{rrrr}\text { PAGE } & \text { COL. } & \text { VOL. I } & \text { VOL. II } \\ 16 & 5 & 525640 & 4 \times 6220 \\ 16 & 7 & 525340 & 4 \times 6320 \\ 16 & 9 & 525550 & 4 \times 6220 \\ 48 & 7 & 525160 & 4 \times 6220 \\ 89 & 37 & 525640 & 4 \times 6220\end{array}$

OCCUPATION 752

$\begin{array}{rrr}2 & 2 & 636130 \\ 14 & 14 & 799815 \\ 16 & 3 & 525030 \\ 43 & 35 & 636050 \\ 60 & 23 & 432200\end{array}$

$6 \times 4313$

$4 \times 6320$

$4 \times 6320$

$6 \times 4320$

$4 \times 6328$

$13 \quad 432100$

$4 \times 6320$

$30 \quad 28 \quad 636120$

486320

$6 \times 4320$

$\begin{array}{lll}56 & 28 & 636960\end{array}$

$6 \times 4213$

\section{OCCUPATION 754}

$\begin{array}{rrrr}6 & 17 & 431110: & 4 \times 2029 \\ 10 & 26 & 631130: & 6 \times 4429 \\ 44 & 17 & 631420 & 6 \times 4429 \\ 84 & 9 & 633221: & 6 \times 4429 \\ 98 & 36 & 633227 & 6 \times 4429\end{array}$

$\begin{array}{rrr}6 & 19 & 678611 \\ 24 & 39 & 631220 \\ 54 & 23 & 633217 \\ 91 & 26 & 631180 \\ 102 & 7 & 633223\end{array}$

$6 \times 2416$ $6 \times 4429$ $6 \times 4429$ $6 \times 4429$ $6 \times 4429$

OCCUPATION 756

$\begin{array}{rrr}8 & 4 & 633111 \\ 11 & 13 & 633412 \\ 30 & 38 & 633318 \\ 31 & 4 & 633314 \\ 42 & 9 & 633362 \\ 44 & 11 & 633315 \\ 53 & 26 & 633462 \\ 60 & 26 & 633463 \\ 62 & 3 & 799820 \\ 85 & 35 & 633364 \\ 90 & 10 & 433362 \\ 93 & 3 & 433365 \\ 103 & 16 & 638440\end{array}$

$6 \times 4425$
$6 \times 4429$
$6 \times 429$
$6 \times 4429$
$6 \times 4429$
$6 \times 4429$
$6 \times 4429$
$6 \times 4429$
$4 \times 6320$
$6 \times 4429$
$4 \times 2021$
$4 \times 6328$
$6 \times 2421$

11

20

30

32

43

46

55

62

7.2

85

92

97

108
12

4
39

633411

633361

38

633115

12

633363

17

633316

23

633373

2

433914

13

433461

36

633365

633368

33

633318

433363

OCCUPATION 758

29

$26 \quad 429010$

58
$4 \times 6381$

$1 \times 28$ $\begin{array}{lll}58 & 5 & 429020\end{array}$

$\begin{array}{lll}58 & 18 & 429510\end{array}$

$6 \times 4429$

$6 \times 4429$

$4 \times 2029$

$6 \times 4425$

$6 \times 4429$

$6 \times 4429$

$4 \times 2021$

$4 \times 6320$

$4 \times 2029$

$6 \times 4429$

$6 \times 2429$

$6 \times 4429$

$4 \times 2021$

$4 \times 6381$

$4 \times 6381$

\section{OCCUPATION 759}

$\begin{array}{rrrr}3 & 5 & 433916 & 4 \times 6320 \\ 11 & 28 & 639114 & 6 \times 4320 \\ 24 & 25 & 438010 & 4 \times 6327 \\ 39 & 30 & 516710 & 4 \times 6346 \\ 55 & 22 & 461881 & 4 \times 6320 \\ 68 & 21 & 634120 & 6 \times 4429 \\ 85 & 33 & 636820 & 4 \times 6328 \\ 105 & 2 & 639473 & 4 \times 6625 \\ 105 & 5 & 639473 & 4 \times 6625 \\ 108 & 19 & 638460 & 6 \times 4329\end{array}$

$\begin{array}{rrr}3 & 6 & 633925 \\ 18 & 5 & 631840 \\ 31 & 6 & 633913 \\ 54 & 9 & 433911 \\ 66 & 21 & 639277 \\ 85 & 12 & 638620 \\ 101 & 31 & 439423 \\ 105 & 4 & 439471 \\ 105 & 6 & 636520\end{array}$

$6 \times 4320$ $3 \times 996$ $6 \times 4429$ $4 \times 6625$ $4 \times 6348$ $4 \times 6327$ $4 \times 6621$ $4 \times 6327$ $6 \times 4329$ 
PAGE COL. VOL. I VOL. II PAGE COL. VOL. I VOL. II

$\begin{array}{rrr}1 & 5 & 455010 \\ 23 & 27 & 451640 \\ 40 & 13 & 655070 \\ 90 & 38 & 455020 \\ 92 & 23 & 455010 \\ 92 & 26 & 652428\end{array}$

\section{OCCUPATION 761}

$4 \times 6697$

$4 \times 6601$

$4 \times 6697$

$4 \times 6697$

$4 \times 6693$

$4 \times 6697$

$\begin{array}{rrr}3 & 18 & 651630 \\ 23 & 32 & 655040 \\ 45 & 3 & 652371 \\ 92 & 21 & 455030 \\ 92 & 25 & 455030 \\ 100 & 24 & 655030\end{array}$

\section{OCCUPATION 762}

$\begin{array}{lll}10 & 32 & 653421 \\ 32 & 10 & 652426 \\ 37 & 37 & 651758 \\ 53 & 35 & 650511 \\ 57 & 15 & 650113\end{array}$

$\begin{array}{rrr}22 & 3 & 456010 \\ 37 & 36 & 652312 \\ 43 & 25 & 487412 \\ 56 & 7 & 650111 \\ 81 & 35 & 652732\end{array}$

OCCUPATION 763
$37 \quad 6410,60$

5. 641250

$43 \quad 6 \quad 441420$

15

61. $29 \quad 667030$

$68 \quad 12$

$90 \quad 33$

650001

657033
$6 \times 4661$

$6 \times 4601$

OCCUPATION 765

$4 \times 2109$

OCCUPATION 766

$6 \times 4469$

$27 \quad 642020$

$6 \times 4469$

OCCUPATION 768
$6 \times 2601$

$6 \times 2601$

$6 \times 4651$ $\begin{array}{lll}61 & 32 & 452311\end{array}$

$\begin{array}{lll}72 & 25 & 657014\end{array}$

$98 \quad 18 \quad 650004$
$4 \times 6697$

$4 \times 6697$

$4 \times 6693$

$4 \times 6697$

$4 \times 6697$

$4 \times 6697$

$4 \times 6618$

$6 \times 2604$

$4 \times 6615$

$6 \times 2618$

$4 \times 6693$

$6 \times 4661$

$4 \times 6671$

$4 \times 6641$

$6 \times 2601$

\section{OCCUPATION 769}

1. $25 \quad 641260$

$6 \times 2601$

$4 \times 6285$

$4 \times 6601$

$6 \times 2601$

$4 \times 6694$

$4 \times 6611$

$6 \times 2601$

$4 \times 6641$

$4 \times 6694$

$6 \times 2602$

$6 \times 2601$

$6 \times 2601$

$4 \times 6601$

$4 \times 6694$

$6 \times 2618$

$4 \times 6601$

$4 \times 6694$

$6 \times 2601$

$\begin{array}{rrr}1 & 26 & 655530 \\ 1 & 29 & 655550 \\ 9 & 15 & 852710 \\ 9 & 18 & 655310 \\ 18 & 8 & 452721 \\ 20 & 31 & 655320 \\ 23 & 1 & 455380 \\ 38 & 33 & 452211 \\ 45 & 10 & 754910 \\ 58 & 20 & 652741 \\ 62 & 28 & 452472 \\ 64 & 32 & 652415 \\ 65 & 2 & 452451 \\ 78 & 23 & 651140 \\ 78 & 28 & 451040 \\ 90 & 18 & 451030 \\ 99 & 13 & 450312\end{array}$
$4 \times 6694$ $6 \times 4601$ $6 \times 2694$ $4 \times 6693$ $4 \times 6694$ $4 \times 6694$ $4 \times 6601$ $4 \times 6693$ $6 \times 2601$ $4 \times 6601$ $4 \times 6601$ $4 \times 6601$ $4 \times 6641$ $6 \times 4451$ $4 \times 6641$ $4 \times 6641$
$4 \times 6694$ 
PAGE COL: VOL. I VOL. II PAGE COL. VOL. I VOL. II

OCCUPATION 771

$\begin{array}{rrr}6 & 24 & 444210 \\ 22 & 40 & 798010 \\ 57 & 11 & 444110 \\ 59 & 24 & 444240 \\ 63 & 25 & 444120\end{array}$

$4 \times 6568$

$4 \times 6568$

$4 \times 6567$

$4 \times 6568$

$4 \times 6567$

$22 \quad 39444010$

$4 \times 6568$

$\begin{array}{lll}51 & 8 & 444220\end{array}$

$4 \times 6568$

$\begin{array}{lll}57 & 12 & 798050\end{array}$

$4 \times 6567$

$\begin{array}{lll}59 & 26 & 444230\end{array}$

$4 \times 6568$

$\begin{array}{lll}75 & 13 & 798010\end{array}$

$4 \times 6568$

OCCUPATION 772

$\begin{array}{rrr}36 & 29 & 619030 \\ 65 & 28 & 448050 \\ 106 & 25 & 448030 \\ 106 & 27 & 798430\end{array}$

$4 \times 6361$

$4 \times 2463$

$4 \times 2463$

$4 \times 2463$

$36 \quad 30 \quad 619040 \quad 4 \times 2463$

$82 \quad 2 \quad 448060$

482463

$106 \quad 26 \quad 448030$

$4 \times 2463$

OCCUPATION 773

$\begin{array}{rrrr}57 & 16 & 448070 & 4 \times 2463 \\ 70 & 25 & 446200 & 4 \times 6588 \\ 93 & 38 & 447300 & 4 \times 6588 \\ 101 & 12 & 446300 & 4 \times 6588\end{array}$

$\begin{array}{lll}57 & 17 & 649510\end{array}$

$93 \quad 12: 446100$

$4 \times 6508$

$101 \quad 11 \quad 446400$

$4 \times 6508$

$4 \times 6588$

$\begin{array}{lll}101 & 13 \quad 446500\end{array}$

$4 \times 6508$

OCCUPATION 775

$\begin{array}{lll}70 & 15: & 447100 \\ 70 & 17 & 447100 \\ 72 & 26 & 445010\end{array}$

$4 \times 6588$
$4 \times 6588$
$4 \times 6569$

$70.16 \quad 798120$

$4 \times 6588$

$\begin{array}{lll}70 & 18 & 649510\end{array}$

$4 \times 6508$

$10 \quad 35 \cdot 449010 \quad 4 \times 6361$

'OCCUPATION 776

OCCUPATION 778

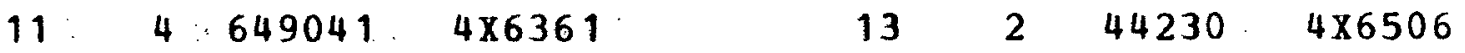

$36 \quad 15: 798110 \quad 4 \times 6569$

OCCUPATION 779

\section{OCCUPATION 778}

$\begin{array}{llll}70 & 2 & 649011 & 6 \times 4469\end{array}$

$92 \quad 29 \quad 649016 \quad 6 \times 4369$

$\begin{array}{lll}75 & 1 & 649012\end{array}$

$6 \times 4469$

OCCOPATION 779

$\begin{array}{rrrr}7 & 23 & 445015 & 4 \times 6569 \\ 9 & 22 & 986370 & 6 \times 4346 \\ 17 & 4 & 649310: & 4 \times 6569 \\ 27 & 18 & 649620: & 6 \times 4415 \\ 27 & 20 & 448010 & 4 \times 2463 \\ 36 & 13 & 445010 & 4 \times 6569 \\ 36 & 16 & 445010 & 4 \times 6569 \\ 72 & 31 & 649420 & 4 \times 2463 \\ 92 & 11 & 445210 & 4 \times 6569 \\ 106 & 20 & 445010 & 4 \times 6569\end{array}$

$\begin{array}{lll}9 & 21 & 649210\end{array}$

$4 \times 2029$ $4 \times 6567$

$1 \times 28$

$4 \times 2463$

$4 \times 6569$

$4 \times 6569$

$4 \times 6508$

$6 \times 2414$

$4 \times 6569$ 
PAGE COL. VOL. I VOL. II PAGE COL. VOL. I VOL. II

\begin{tabular}{|c|c|c|c|}
\hline 8 & 22 & 524130 & $4 \times 6232$ \\
\hline 9 & 12 & 491311 & $4 \times 6618$ \\
\hline 18 & 17 & 691011 & $6 \times 2618$ \\
\hline 26 & 23 & 691052 & $6 \times 2618$ \\
\hline 26 & 26 & 491351 & $4 \times 6618$ \\
\hline 40 & 21 & 491445 & $4 \times 6618$ \\
\hline 43 & 27 & 488081 & $4 \times 6615$ \\
\hline 43 & 32 & 491438 & $4 \times 66.18$ \\
\hline 43 & 34 & 687410 & $6 \times 2615$ \\
\hline 48 & 36 & 688732 & $6 \times 2615$ \\
\hline 73 & 8 & 688082 & $6 \times 2618$ \\
\hline 79 & 27 & 491441 & $4 \times 66.18$ \\
\hline 96 & 18 & 691726 & $6 \times 2616$ \\
\hline
\end{tabular}

OCCOPATION 781

$\begin{array}{rr}8 & 23 \\ 18 & 16\end{array}$

$18 \quad 23$

$26 \quad 25$

34. 30

4323

$43 \quad 31$

$43 \quad 33$

45

52

79

84

98

22

3.3

35
592302

691011

691181

694611

491411

691232

500950

491571

691481

$33 \quad 491573$

491391

691183

491572

\section{OCCUPATION 782}

$\begin{array}{rrrr}9 & 33 & 693777 & 6 \times 2611 \\ 16 & 27 & 487210 & 4 \times 6615 \\ 29 & 6 & 487210 & 4 \times 6615 \\ 46 & 11 & 476220 & 4 \times 6385 \\ 48 & 39 & 487010 & 4 \times 6615 \\ 65 & 3 & 487010 & 4 \times 6615 \\ 97 & 20 & 487310 & 4 \times 6615\end{array}$

$\begin{array}{rrr}9 & 34 & 893180 \\ 27 & 16 & 687210 \\ 32 & 1 & 687130 \\ 48 & 5 & 487220 \\ 49 & 1 & 487020 \\ 80 & 29 & 687010 \\ 100 & 8 & 487230\end{array}$

$6 \times 2615$

$4 \times 6615$

$6 \times 2615$

$4 \times 6615$

$4 \times 6615$

$6 \times 2615$

$4 \times 6615$

\section{OCCDPATION 783}

$\begin{array}{rrrr}22 & 7 & 573020 & 4 \times 2493 \\ 81 & 12 & 688024 & 4 \times 2487 \\ 81 & 17 & 488018 & 6 \times 4487 \\ 86 & 24 & 592301 & 4 \times 2487 \\ 99 & 10 & 488023 & 4 \times 2487\end{array}$

$81 \quad 10 \quad 488028$

$4 \times 2487$

$81.15 \quad 688011$

$6 \times 4487$

$6 \times 4487$

$82 \quad 5 \quad 688033$

$4 \times 2487$

\section{OCCOPATION 784}

$\begin{array}{rrrr}3 & 8 & 486125 & 4 \times 2489 \\ 3 & 27 & 486010 & 4 \times 6315 \\ 9 & 5 & 486010 & 4 \times 6315 \\ 9 & 7 & 486010 & 4 \times 6315 \\ 32 & 28 & 584110 & 4 \times 2015 \\ 32 & 31 & 486110 & 4 \times 2489 \\ 32 & 33 & 486170 & 4 \times 2489 \\ 41 & 22 & 488743 & 4 \times 2489 \\ 42 & 29 & 486125 & 4 \times 2489 \\ 44 & 16 & 486125 & 4 \times 2489 \\ 48 & 23 & 486125 & 4 \times 2489 \\ 50 & 13 & 486125 & 4 \times 2489 \\ 95 & 10 & 486110 & 4 \times 2489 \\ 95 & 13 & 486125 & 4 \times 2489 \\ 100 & 3 & 784010 & 6 \times 4489 \\ 104 & 10 & 486125 & 4 \times 2489\end{array}$

$\begin{array}{rrr}3 & 26 & 488742 \\ 8 & 16 & 486010 \\ 9 & 6 & 486010 \\ 10 & 28 & 486125 \\ 32 & 30 & 686110 \\ 32 & 32 & 486110 \\ 32 & 34 & 486170 \\ 41 & 23 & 694224 \\ 43 & 28 & 486020 \\ 47 & 28 & 486120 \\ 50 & 5 & 486210 \\ 73 & 9 & 686110 \\ 95 & 12 & 486110 \\ 100 & 2 & 584010 \\ 100 & 4 & 575280 \\ 105 & 23 & 486015\end{array}$

$4 \times 2487$

$4 \times 6315$

$4 \times 6315$

$4 \times 2489$

$4 \times 2489$

$4 \times 2489$

$4 \times 2489$

$6 \times 4489$

$4 \times 6315$

$4 \times 2489$

$4 \times 6315$

$4 \times 2489$

$4 \times 2489$

$4 \times 6315$

$4 \times 2494$

$4 \times 6320$ 
PAGE COL. VOL. I VOL. II PAGE COL. VOL. I VOL. II

\begin{tabular}{rrrlrrrr}
\multicolumn{8}{c}{ OCCUPATION 786} \\
28 & 37 & 482920 & $4 \times 6616$ & 41 & 26 & 682620 & $4 \times 6318$ \\
55 & 10 & 491651 & $6 \times 2616$ & 56 & 11 & 481060 & $6 \times 2616$ \\
58 & 24 & 681010 & $6 \times 4443$ & 58 & 25 & 481025 & $4 \times 6343$ \\
58 & 26 & 481050 & $4 \times 6343$ & 63 & 5 & 481020 & $4 \times 6343$ \\
63 & 6 & 481030 & $4 \times 6343$ & 63 & 9 & 491721 & $4 \times 6343$ \\
63 & 11 & 481040 & $4 \times 6343$ & 63 & 12 & 481030 & $4 \times 6343$ \\
63 & 13 & 481030 & $4 \times 6343$ & & & &
\end{tabular}

OCCUPATION 787

$\begin{array}{rrrrrrrr}24 & 40 & 482010 & 4 \times 6343 & 25 & 1 & 799801 & 4 \times 6343 \\ 25 & 2 & 482010 & 4 \times 6343 & 25 & 4 & 682020 & 6 \times 4443 \\ 25 & 6 & 682120 & 6 \times 2605 & & & \end{array}$

$38 \quad 10 \quad 488991 \quad 4 \times 2488$

$\begin{array}{rrrr}38 & 10 & 488991 & 4 \times 2488 \\ 108 & 7 & 488511 & 4 \times 2488\end{array}$

OCCUPATION 789

$\begin{array}{rrrllrll}13 & 19 & 783326 & 6 \times 4419 & 19 & 27 & 878100 & 6 \times 4415 \\ 19 & 28 & 678925 & 6 \times 4319 & 19 & 29 & 478920 & 4 \times 6315 \\ 25 & 7 & 682961 & 4 \times 6343 & 43 & 3 & 882100 & 6 \times 669 \\ 56 & 5 & 690712 & 6 \times 2695 & 56 & 8 & 495031 & 4 \times 6285 \\ 56 & 9 & 695032 & 6 \times 4318 & 62 & 41 & 682960 & 4 \times 6343 \\ 74 & 6 & 892610 & 6 \times 4208 & 76 & 35 & 691585 & 4 \times 6618 \\ 83 & 9 & 690991 & 1 \times 28 & 83 & 10 & 682720 & 6 \times 4319 \\ 83 & 13 & 482310 & 4 \times 6641 & 83 & 17 & 682310 & 6 \times 2601 \\ 83 & 38 & 488292 & 4 \times 2487 & 89 & 20 & 494182 & 4 \times 6618\end{array}$

$17 \quad 3 \quad 472411 \quad 4 \times 6616$

$2831.471220 \quad 0 \times 730$

$\begin{array}{llll}53 & 7 & 471250 & 4 \times 6338\end{array}$

$\begin{array}{llll}53 & 9 & 471010 & 4 \times 6318\end{array}$

73.25872300 . $6 \times 4315$

$\begin{array}{llll}89 & 16 & 472318 & 4 \times 6318\end{array}$

106. $9475010 \quad 4 \times 2010$

$106 \quad 13 \quad 583971 \quad 4 \times 6310$ $\begin{array}{llll}21 & 2 & 471510 & 4 \times 6310\end{array}$

$46 \quad 20 \quad 471010$

$53 \quad 8 \quad 475130$

634441015

$87 \quad 39 \quad 471310$

$93 \quad 11 \quad 471210$

$106 \quad 10 \quad 471510$
$4 \times 2488$

$4 \times 6318$

$4 \times 6310$

$4 \times 6343$

$4 \times 6318$

$4 \times 6338$

$4 \times 6310$

\section{OCCUPATION 793}

$\begin{array}{rrrrr}29 & 10 & 473040 & 4 \times 8508 & 37 \\ 37 & 21 & 473020 & 4 \times 6508 & 3 \\ 37 & 31 & 799350 & 4 \times 6508 & 37 \\ 37 & 33 & 473310 & 4 \times 6508 & 37 \\ 59 & 27 & 913270 & 6 \times 4356 & 8\end{array}$

$\begin{array}{rrrr}28 & 35 & 476127 & 4 \times 6309 \\ 29 & 3 & 476010 & 4 \times 6310 \\ 29 & 8 & 476020 & 4 \times 6508\end{array}$

$37 \quad 20 \quad 473010$

$37 \quad 22 \quad 473510$

$\begin{array}{lll}37 & 32 & 693332\end{array}$

$\begin{array}{lll}37 & 34 & 473320\end{array}$

81.14 .473910

$4 \times 6508$

$4 \times 6508$

$6 \times 4319$

$4 \times 6508$

$4 \times 6508$

$28 \quad 36.476110$

$4 \times 2014$

$4 \times 6310$

$4 \times 2010$ 


\begin{tabular}{|c|c|c|c|c|c|c|c|c|}
\hline $\begin{array}{r}\text { AGE } \\
29 \\
29 \\
29 \\
33 \\
99 \\
100\end{array}$ & $\begin{array}{r}\text { COL } \\
11 \\
19 \\
23 \\
31 \\
35 \\
16\end{array}$ & $\begin{array}{l}\text { VOL. I } \\
794110 \\
476120 \\
476010 \\
476010 \\
476040 \\
476220\end{array}$ & $\begin{array}{l}\text { VOL. II } \\
4 \times 2010 \\
4 \times 2489 \\
4 \times 2010 \\
4 \times 6320 \\
4 \times 2010 \\
4 \times 2010\end{array}$ & - & $\begin{array}{r}\text { PAGE } \\
29 \\
29 \\
29 \\
53 \\
100 \\
100\end{array}$ & $\begin{array}{r}\text { COL. } \\
18 \\
21 \\
25 \\
33 \\
15 \\
21\end{array}$ & $\begin{array}{l}\text { VOL. I } \\
476120 \\
476120 \\
476010 \\
476910 \\
476210 \\
476210\end{array}$ & $\begin{array}{lr}\text { VOL. II } \\
4 \times 2489 \\
4 \times 2489 \\
4 \times 2010 \\
4 \times 2012 \\
4 \times 2010 \\
4 \times 6315\end{array}$ \\
\hline $\begin{array}{l}29 \\
53 \\
58 \\
58 \\
59 \\
59 \\
59\end{array}$ & $\begin{array}{r}15 \\
19 \\
34 \\
38 \\
1 \\
7 \\
9\end{array}$ & $\begin{array}{l}475120 \\
475160 \\
475010 \\
475010 \\
583901 \\
475010 \\
475150\end{array}$ & $\begin{array}{r}\text { occo } \\
4 \times 6410 \\
4 \times 2010 \\
4 \times 2010 \\
4 \times 2010 \\
4 \times 6310 \\
4 \times 2010 \\
4 \times 2100\end{array}$ & ATION & $\begin{array}{r}802 \\
, \quad 52 \\
56 \\
58 \\
58 \\
59 \\
59 \\
63\end{array}$ & $\begin{array}{r}7 \\
1 \\
35 \\
39 \\
2 \\
8 \\
17\end{array}$ & $\begin{array}{l}475130 \\
475140 \\
794100 \\
475120 \\
475010 \\
583642 \\
475010\end{array}$ & $\begin{array}{l}4 \times 6310 \\
4 \times 2010 \\
4 \times 2010 \\
4 \times 6310 \\
4 \times 2010 \\
4 \times 2100 \\
4 \times 2010\end{array}$ \\
\hline $\begin{array}{r}13 \\
38 \\
39 \\
45 \\
49 \\
52 \\
54 \\
83 \\
94 \\
98 \\
100 \\
100 \\
104\end{array}$ & $\begin{array}{r}29 \\
6 \\
8 \\
24 \\
28 \\
21 \\
15 \\
30 \\
35 \\
19 \\
6 \\
12 \\
22\end{array}$ & $\begin{array}{l}677510 \\
678513 \\
478291 \\
678132 \\
478411 \\
478512 \\
584130 \\
784230 \\
478513 \\
678516 \\
784110 \\
678413 \\
678518\end{array}$ & $\begin{array}{r}\text { OCC } \\
6 \times 4315 \\
4 \times 2015 \\
4 \times 2015 \\
4 \times 2015 \\
4 \times 2015 \\
4 \times 2015 \\
4 \times 2015 \\
6 \times 4315 \\
4 \times 2015 \\
4 \times 2015 \\
6 \times 4415 \\
4 \times 2015 \\
6 \times 2415\end{array}$ & PATION & $\begin{array}{r}803 \\
30 \\
39 \\
45 \\
45 \\
49 \\
54 \\
61 \\
85 \\
94 \\
100 \\
100 \\
104\end{array}$ & $\begin{array}{r}4 \\
7 \\
15 \\
25 \\
29 \\
14 \\
12 \\
27 \\
36 \\
5 \\
7 \\
20\end{array}$ & $\begin{array}{l}678512 \\
639993 \\
678413 \\
678413 \\
678412 \\
784110 \\
677530 \\
678511 \\
678522 \\
584120 \\
584110 \\
678632\end{array}$ & $\begin{array}{l}6 \times 4415 \\
6 \times 4325 \\
4 \times 2015 \\
4 \times 2015 \\
6 \times 2415 \\
6 \times 4415 \\
6 \times 4315 \\
1 \times 2015 \\
6 \times 2415 \\
4 \times 6315 \\
4 \times 2015 \\
4 \times 2015\end{array}$ \\
\hline 62 & 6 & 578100 & $\begin{array}{r}\text { OCc } \\
4 \times 2100\end{array}$ & PATION & 805 & & & \\
\hline $\begin{array}{r}2 \\
3 \\
16 \\
30 \\
39 \\
41 \\
45 \\
64 \\
79 \\
87 \\
89 \\
93 \\
108\end{array}$ & $\begin{array}{r}19 \\
13 \\
25 \\
32 \\
18 \\
8 \\
27 \\
4 \\
31 \\
10 \\
34 \\
21 \\
2\end{array}$ & $\begin{array}{l}580130 \\
694431 \\
494351 \\
702353 \\
503572 \\
703562 \\
703562 \\
702312 \\
703542 \\
702311 \\
633925 \\
493411 \\
603552\end{array}$ & $\begin{array}{l}\text { occu } \\
4 \times 2103 \\
4 \times 6310 \\
4 \times 6310 \\
6 \times 4313 \\
4 \times 6210 \\
6 \times 4310 \\
6 \times 4208 \\
4 \times 6210 \\
6 \times 4213 \\
6 \times 4310 \\
6 \times 4320 \\
4 \times 6211 \\
4 \times 6213\end{array}$ & TION & $\begin{array}{r}806 \\
2 \\
12 \\
30 \\
37 \\
39 \\
41 \\
52 \\
68 \\
79 \\
88 \\
89 \\
108 \\
108\end{array}$ & $\begin{array}{l}21 \\
14 \\
26 \\
12 \\
24 \\
30 \\
13 \\
39 \\
32 \\
14 \\
35 \\
1 \\
4\end{array}$ & $\begin{array}{l}580130 \\
694114 \\
702374 \\
503572 \\
633925 \\
678632 \\
503554 \\
475120 \\
703542 \\
503552 \\
478031 \\
633925 \\
703552\end{array}$ & $\begin{array}{l}4 \times 2103 \\
4 \times 6310 \\
6 \times 4213 \\
4 \times 6210 \\
6 \times 4320 \\
4 \times 6310 \\
4 \times 6310 \\
4 \times 6310 \\
6 \times 4213 \\
4 \times 6213 \\
4 \times 2012 \\
6 \times 4320 \\
6 \times 4213\end{array}$ \\
\hline
\end{tabular}


PAGE COL. VOL. I VOL. II PAGE COL. VOL. I VOL. II

OCCUPATION 808

$\begin{array}{rrrl}6 & 32 & 678025 & 4 \times 2014 \\ 7 & 1 & 478214 & 4 \times 2014 \\ 7 & 6 & 478011 & 4 \times 2001 \\ 8 & 19 & 188742 & 4 \times 287 \\ 11 & 11 & 678041 & 6 \times 2414 \\ 12 & 37 & 475120 & 4 \times 6310 \\ 17 & 26 & 678152 & 4 \times 2014 \\ 28 & 30 & 584020 & 4 \times 6318 \\ 42 & 35 & 688627 & 6 \times 4419 \\ 45 & 23 & 178134 & 4 \times 2013 \\ 50 & 2 & 478031 & 4 \times 2012 \\ 60 & 10 & 688733 & 4 \times 2487 \\ 61 & 36 & 678031 & 6 \times 2412 \\ 64 & 17 & 678081 & 4 \times 2014 \\ 71 & 7 & 688351 & 6 \times 4489 \\ 71 & 21 & 695056 & 6 \times 4488 \\ 71 & 25 & 695057 & 6 \times 4419 \\ 72 & 12 & 478071 & 4 \times 2013 \\ 74 & 25 & 478011 & 4 \times 2011 \\ 75 & 31 & 678111 & 6 \times 2412 \\ 81 & 37 & 694204 & 6 \times 4419 \\ 84 & 10 & 478011 & 4 \times 2011 \\ 85 & 34 & 478061 & 4 \times 2013 \\ 88 & 1 & 678083 & 6 \times 2414 \\ 88 & 31 & 478031 & 4 \times 2012 \\ 93 & 22 & 688613 & 6 \times 4419 \\ 95 & 31 & 688623 & 6 \times 4489 \\ 103 & 20 & 478021 & 4 \times 2011 \\ 105 & 8 & 478044 & 4 \times 2014 \\ 107 & 22 & 678214 & 4 \times 2014\end{array}$

OCCUPATION 810

$\begin{array}{lrrr}44: & 31 & 754511 & 6 \times 4601 \\ 71 . & 26 & 530010 & 4 \times 6217 \\ 71 & 28 & 796200 & 4 \times 6217 \\ 71 & 30 & 530010 & 4 \times 6217 \\ 71 & 33 & 530210 & 4 \times 6217 \\ 72 & 2 & 553940 & 4 \times 6217 \\ 73 & 5 & 530260 & 4 \times 6217 \\ 91 & 30 & 530410 & 4 \times 6217 \\ 91 & 32 & 530410 & 4 \times 6217 \\ 91 & 34 & 530410 & 4 \times 6217\end{array}$

OCCUPATION 811

$\begin{array}{rlll}3 & 24 & 480050 & 4 \times 6313 \\ 24 & 31 & 480080 & 4 \times 6217 \\ 25 & 38 & 480050 & 4 \times 6313 \\ 68 & 20 & 480910 & 4 \times 6313 \\ 86 & 13 & 488622 & 4 \times 6213\end{array}$

$6 \quad 34.678216$

$\begin{array}{lll}7 & 5 & 678291\end{array}$

$7 \quad 30 \quad 678411$

$10 \quad 30 \quad 678141$

$\begin{array}{lll}11 & 14 & 478042\end{array}$

$\begin{array}{lll}12 & 38 & 678051\end{array}$

$17 \quad 27 \cdot 678511$

$37 \quad 14 \quad 478011$

$\begin{array}{lll}45 & 18 & 478132\end{array}$

$\begin{array}{lll}50 & 1 & 478042\end{array}$

$\begin{array}{lll}52 & 22 & 678121\end{array}$

$\begin{array}{lll}61 & 35 & 478031\end{array}$

$\begin{array}{lll}61 & 37 & 478031\end{array}$

64. $30 \quad 688626$

$71 \quad 20 \cdot 695055$

$\begin{array}{lll}71 & 22 & 695062\end{array}$

724.688346

$74 \quad 20 \quad 688664$

$75 \quad 30 \quad 478111$

$\begin{array}{lll}77 & 9 & 678082\end{array}$

$82 \quad 6 \quad 478011$

84

86

88

90

93

96

103

105

107
11

1

30

678144

478062

478061

7

478012

23

688612

678142

21

678021

478031

26

678166

$6 \times 2414$

$4 \times 2411$

$4 \times 2015$

$4 \times 2014$

$4 \times 2014$

$4 \times 2013$

$4 \times 2015$.

$4 \times 2011$

$4 \times 2012$

$4 \times 2014$

$4 \times 2013$

$4 \times 2012$

$4 \times 2012$

$6 \times 4489$

$6 \times 4488$

$6 \times 4488$

$6 \times 4488$

$4 \times 2489$

$4 \times 2012$

$4 \times 2014$

$4 \times 2011$

$6 \times 2411$

$4 \times 2013$

$4 \times 2013$

$4 \times 2011$

$6 \times 4489$

$4 \times 2014$

$6 \times 2411$

$4 \times 2012$

$4 \times 2011$

$\begin{array}{lll}71 & 17 & 530030\end{array}$

$4 \times 6217$

$4 \times 6217$

$4 \times 6217$

$4 \times 6217$

$4 \times 6217$

$4 \times 6217$

$4 \times 6217$

$4 \times 6217$

$4 \times 6217$

$4 \times 6217$

$109 \quad 14 \quad 530410$

$4 \times 6313$

$4 \times 6217$

$4 \times 6313$

$6 \times 4213$

$4 \times 6313$ 


$\begin{array}{rrrr}\text { PAGE } & \text { COL. } & \text { VOL. I } & \text { VOL. II } \\ 86 & 15 & 694222 & 4 \times 6313 \\ 86 & 17 & 488622 & 4 \times 6213 \\ 86 & 19 & 480060 & 4 \times 6313 \\ 86 & 21 & 480010 & 4 \times 6313 \\ 89 & 15 & 695001 & 6 \times 4319 \\ 89 & 18 & 485310 & 4 \times 6285 \\ 97 & 22 & 480020 & 4 \times 6313 \\ 99 & 12 & 480010 & 4 \times 6213\end{array}$

$\begin{array}{rrrrr}\text { PAGE } & \text { COL. } & \text { VOL. I } & \text { VOL. II } \\ 86 & 16 & 480010 & 4 \times 6313 \\ 86 & 18 & 480050 & 4 \times 6313 \\ 86 & 20 & 797040 & 4 \times 6313 \\ 86 & 23 & 480010 & 4 \times 6313 \\ 89 & 17 & 695010 & 6 \times 4319 \\ 89 & 19 & 702015 & 4 \times 6285 \\ 99 & 11 & 480010 & 4 \times 6313\end{array}$

OCCUPATION 812

$\begin{array}{rrrr}13 & 9 & 684610 & 6 \times 4284 \\ 29 & 28 & 688622 & 6 \times 4419 \\ 80 & 16 & 695071 & 6 \times 4419 \\ 80 & 18 & 695081 & 6 \times 4284 \\ 80 & 24 & 684630 & 6 \times 4489 \\ 80 & 26 & 484060 & 6 \times 4284 \\ 80 & 30 & 695087 & 6 \times 4419 \\ 80 & 32 & 695074 & 6 \times 4419 \\ 80 & 35 & 695075 & 6 \times 4419 \\ 96 & 13 & 484060 & 6 \times 4284 \\ & & & \\ & & & 0 c c \\ 10 & 14 & 483100 & 4 \times 6211 \\ 10 & 16 & 797020 & 4 \times 6211 \\ 10 & 22 & 483400 & 4 \times 6211 \\ 41 & 13 & 483300 & 4 \times 6211 \\ 66 & 18 & 484020 & 4 \times 6211 \\ 86 & 30 & 484012 & 4 \times 6211 \\ 92 & 3 & 684115 & 6 \times 4211 \\ 96 & 7 & 438050 & 4 \times 6220 \\ 96 & 11 & 438050 & 4 \times 6220\end{array}$

$\begin{array}{lll}29 & 27 & 695084 \\ 48 & 35 & 685230 \\ 80 & 17 & 695080 \\ 80 & 19 & 684440 \\ 80 & 25 & 695082 \\ 80 & 28 & 684650 \\ 80 & 31 & 484010 \\ 80 & 33 & 636850 \\ 80 & 36 & 695086\end{array}$
$6 \times 4284$ $6 \times 2615$ $6 \times 4284$ $6 \times 4284$ $6 \times 4284$ $6 \times 2615$ $4 \times 6211$ $6 \times 4419$ $6 \times 4284$

\section{OCCUPATION 815}

44. $12 \quad 674110.6 \times 2611$

$72 \quad 35 \quad 474010 \quad 4 \times 6611$

$\begin{array}{llll}72 & 33 & 474010 \quad 4 \times 6611\end{array}$

\section{OCCUPATION 817}

$\begin{array}{rrrr}1 & 21 & 685215 & 4 \times 6283 \\ 9 & 10 & 485060 & 4 \times 6280 \\ 12 & 16 & 485310 & 4 \times 6285 \\ 41 & 19 & 685240 & 4 \times 6283 \\ 87 & 18 & 685120 & 4 \times 6280 \\ 106 & 32 & 799030 & 4 \times 6283 \\ 106 & 34 & 485020 & 4 \times 6281 \\ 106 & 36 & 685010 & 6 \times 4281 \\ 106 & 38 & 188341 & 4 \times 2488 \\ 107 & 1 & 485040 & 4 \times 6280 \\ 107 & 6 & 485020 & 4 \times 6281 \\ 107 & 8 & 685060 & 6 \times 4318 \\ 107 & 10 & 685070 & 4 \times 6285\end{array}$

$\begin{array}{rrrr}3 & 34 & 685280 & 4 \times 6281 \\ 10 & 31 & 685110 & 4 \times 6281 \\ 41 & 18 & 685215 & 4 \times 6283 \\ 49 & 31 & 485060 & 4 \times 6280 \\ 106 & 31 & 485020 & 4 \times 6281 \\ 106 & 33 & 799035 & 4 \times 6280 \\ 106 & 35 & 485060 & 4 \times 6280 \\ 106 & 37 & 685020 & 6 \times 4281 \\ 106 & 39 & 485040 & 4 \times 6280 \\ 107 & 2 & 685130 & 4 \times 6281 \\ 107 & 7 & 685100 & 6 \times 4281 \\ 107 & 9 & 685080 & 6 \times 4281\end{array}$


PAGE COL. VOL. I VOL. II PAGE COL. VOL. I VOL. II $\begin{array}{llll}73 & 27 & 884510 & 6 \times 4315\end{array}$

OCCOPATION 818

\begin{tabular}{|c|c|c|c|c|c|c|c|c|}
\hline & & & $\mathrm{OCCU}$ & TION & 819 & & & \\
\hline 5 & 20 & 695051 & $6 \times 4213$ & & 5 & 24 & 478911 & $4 \times 6616$ \\
\hline 6 & 9 & 672205 & $4 \times 6310$ & & 8 & 9 & 672114 & $6 \times 4309$ \\
\hline 8 & 10 & 472321 & $4 \times 6318$ & & 13 & 20 & 491721 & $6 \times 2616$ \\
\hline 21. & 38 & 693667 & $6 \times 4419$ & & 57 & 33 & 472313 & $4 \times 6318$ \\
\hline 72 & 11 & 672298 & $6 \times 4315$ & : & 73 & 12 & 672015 & $4 \times 6318$ \\
\hline 82 & 14 & 694235 & $6 \times 24.14$ & & 84 & 27 & 693072 & $4 \times 6313$ \\
\hline 90 & 14 & 494201 & 486313 & & 90 & 35 & 493661 & $6 \times 4419$ \\
\hline 93 & 25 & 693183 & 682419 & & 102 & 23 & 488342 & $4 \times 2487$ \\
\hline 102 & 24 & 695060 & $6 \times 4319$ & & 102 & 25 & 695053 & $6 \times 4419$ \\
\hline 102 & 26 & 695054 & $6 \times 4419$ & & 102 & 27 & 695052 & $6 \times 4419$ \\
\hline 107. & 23 & 505030 & $4 \times 6211$ & & 108 & 17 & 505610 & $6 \times 4208$ \\
\hline & & & $\mathrm{OCCl}$ & TION & 821 & & & \\
\hline 2 & 20 & 580130 & $4 \times 2103$ & & 2 & 22 & 580130 & $4 \times 2103$ \\
\hline 2 & 23 & 580130 & $4 \times 2103$ & & 2 & 26 & 580130 & $4 \times 2103$ \\
\hline 2 & 27 & 580130 & $4 \times 2103$ & & 2 & 28 & 580120 & $4 \times 2104$ \\
\hline 2 & 34 & 580100 & $4 \times 2103$ & & 3 & 1 & 580120 & $4 \times 2104$ \\
\hline 3 & 4 & 580120 & $4 \times 21.04$ & & 37 & 15 & 580352 & $4 \times 2103$ \\
\hline 75 & 34 & 580130 & $4 \times 2104$ & & & & & \\
\hline & & & $\mathrm{OCCl}$ & TION & 822 & & & \\
\hline 5 & 6 & 581510 & $6 \times 4213$ & & 5 & 7 & 581520 & $4 \times 6320$ \\
\hline 5 & 9 & 581410 & $4 \times 6183$ & & 5 & 10 & 58 & $4 \times 2103$ \\
\hline 5 & 11 & 581010 & $4 \times 2103$ & & 5 & 12 & 581650 & $4 \times 2103$ \\
\hline 5 & 14 & 581530 & $4 \times 2109$ & & 10 . & 11 & 781671 & $4 \times 2109$ \\
\hline 10 . & 12 & 702342 & $4 \times 6208$ & & 12 & 3 & 581110 & $4 \times 2011$ \\
\hline 12 & 4 & 902010 & $6 \times 4310$ & & 12 & 6 & 581120 & $4 \times 2109$ \\
\hline 12 & 7 & 581120 & $4 \times 2109$ & & 12 & 9 & 581120 & $4 \times 2109$ \\
\hline 13 & 32 & 581035 & $4 \times 2103$ & & 15 & 13 & 78 & $4 \times 2103$ \\
\hline 48 & 27 & 78.1420 & $4 \times 2109$ & & 63 & 34 & 579630 & $4 \times 2109$ \\
\hline 64 & 3 & 5810 & $4 \times 2103$ & & 98 & 7 & 58 & $4 \times 2103$ \\
\hline 101 & 2 & 581040 & $4 \times 2103$ & & 102 & 16 & 581030 & $4 \times 2103$ \\
\hline 107 & 21 & 581210 & $4 \times 2109$ & & 107 & 27 & 771210 & $4 \times 6315$ \\
\hline & & & $\mathrm{OCCl}$ & TION & 824 & & & \\
\hline & & 583121 & $4 \times 2106$ & & 1 & 33 & 583122 & $4 \times 2106$ \\
\hline 14 & 28 & 583123 & $4 \times 2106$ & & 65 & 27 & 583111 & $4 \times 2106$ \\
\hline 91. & 22 & 583126 & $4 \times 2106$ & & 103 & 25 & 583127 & $4 \times 2106$ \\
\hline & & & $\mathrm{Cl}$ & TION & 825 & & & \\
\hline 3 & 11 & 579510 & $4 \times 2109$ & & 23 & 31 & 579550 & $4 \times 6.183$ \\
\hline 87 & 29 & 579170 & $4 \times 6183$ & & 93 & 30 & 779070 & $6 \times 4208$ \\
\hline 97 & 29 & 579020 & $4 \times 6211$ & & 97 & 31 & 579120 & $4 \times 6211$ \\
\hline
\end{tabular}


PAGE COL. VOL. I VOL. II PAGE COL. VOL. I VOL. II

OCCUPATION 829

$\begin{array}{rrrr}4 & 6 & 583541 & 4 \times 2107 \\ 22 & 25 & 583326 & 4 \times 2105 \\ 29 & 17 & 583931 & 4 \times 2103 \\ 38 & 38 & 583641 & 4 \times 2100 \\ 44 & 26 & 583040 & 4 \times 2109 \\ 45 & 6 & 583032 & 4 \times 2109 \\ 47 & 19 & 583542 & 4 \times 2107 \\ 51 & 9 & 783512 & 6 \times 4209 \\ 52 & 10 & 583972 & 4 \times 6310 \\ 58 & 12 & 583323 & 4 \times 2105 \\ 61 & 23 & 583465 & 4 \times 6310 \\ 65 & 31 & 583024 & 4 \times 6209 \\ 78 & 33 & 583941 & 4 \times 2109 \\ 85 & 23 & 583641 & 4 \times 2109 \\ 93 & 6 & 583022 & 4 \times 6183 \\ 100 & 18 & 475160 & 4 \times 2012 \\ 100 & 20 & 475160 & 4 \times 2014 \\ 107 & 34 & 583961 & 4 \times 2100\end{array}$

OCCUPATION 831

$\begin{array}{rrr}4 & 1 & 475010 \\ 34 & 20 & 583041 \\ 35 & 2 & 703562 \\ 35 & 5 & 583447 \\ 35 & 7 & 497915 \\ 35 & 9 & 795200 \\ 35 & 11 & 497420 \\ 35 & 13 & 497010 \\ 35 & 15 & 497210 \\ 35 & 20 & 497921 \\ 35 & 22 & 553295 \\ 35 & 24 & 497520 \\ 35 & 26 & 497270 \\ 35 & 28 & 497120 \\ 35 & 30 & 497010 \\ 35 & 33 & 783451 \\ 36 & 5 & 783012 \\ 104 & 16 & 583011\end{array}$

$4 \times 2010$

$4 \times 6183$

$6 \times 4208$

$4 \times 6185$

$4 \times 6183$

$4 \times 6183$

$4 \times 6183$

$4 \times 6181$

$4 \times 6183$

$4 \times 6181$

$4 \times 6181$

$4 \times 61.88$

$4 \times 6183$

$4 \times 6181$

$4 \times 6181$

$4 \times 6181$

$4 \times 6183$

$4 \times 6183$

$\begin{array}{rrr}8 & 27 & 583881 \\ 23 & 22 & 583641 \\ 36 & 24 & 583921 \\ 43 & 24 & 583023 \\ 44 & 32 & 583948 \\ 45 & 8 & 583947 \\ 47 & 23 & 583972 \\ 51 & 13 & 583945 \\ 54 & 19 & 583322 \\ 58 & 32 & 583311 \\ 62 & 10 & 783511 \\ 76 & 21 & 583641 \\ 83 & 36 & 583641 \\ 87 & 30 & 583872 \\ 100 & 17 & 475160 \\ 100 & 19 & 475160 \\ 106 & 17 & 783471\end{array}$

$4 \times 2109$

$4 \times 2109$

$4 \times 6183$

$4 \times 6209$

$4 \times 2109$

$4 \times 2100$

$4 \times 6310$

$4 \times 6310$

$4 \times 2105$

$4 \times 2029$

$6 \times 4208$

$4 \times 2102$

$4 \times 2109$

$4 \times 6209$

$4 \times 2015$

$4 \times 2012$

$6 \times 4219$

OCCUPATION 832

$\begin{array}{rrr}4 & 2 & 699011 \\ 4 & 24 & 700928 \\ 34 & 19 & 500933 \\ 36 & 3 & 583432 \\ 52 & 8 & 500912 \\ 74 & 22 & 499172 \\ 82 & 4 & 499163 \\ 101 & 14 & 698240 \\ 108 & 10 & 909410\end{array}$

$6 \times 4307$
$6 \times 4308$
$4 \times 6308$
$4 \times 6183$
$4 \times 6308$
$4 \times 6308$
$6 \times 4308$
$6 \times 43.08$
$6 \times 4309$

$\begin{array}{lll}7 & 22 & 589411\end{array}$ 34. $27 \quad 497420$

35

35

35

35

35

35

35

35

35

35

35

35

35

36

64

108
497010

497910

795100

$10 \quad 581420$

12497150

14

497010

19

21

23

25

27

29

31

4

24

8

497010

497410

497510

497210

497220

497910

497230

583433

583871

497010

$4 \times 6183$

$4 \times 6183$

$4 \times 6181$

$4 \times 6181$

$4 \times 6181$

$4 \times 6183$

$4 \times 6181$

$4 \times 6181$

$4 \times 6181$

$4 \times 6183$

$4 \times 6188$

$4 \times 6183$

$4 \times 6183$

$4 \times 6181$

$4 \times 6183$

$4 \times 6183$

$4 \times 6181$

$4 \times 6181$

$\begin{array}{rrrr}4 & 4 & 699011 & 6 \times 4307 \\ 4 & 30 & 700921 & 6 \times 4308 \\ 34 & 21 & 678634 & 4 \times 6310 \\ 44 & 5 & 854010 & 6 \times 4310 \\ 59 & 13 & 499012 & 6 \times 4307 \\ 82 & 3 & 499162 & 6 \times 4308 \\ 95 & 22 & 700921 & 6 \times 4308 \\ 101 & 16 & 553362 & 4 \times 6183\end{array}$


PAGE COL. VOL. I VOL. II PAGE COL. VOL. I VOL. II

$74 \quad 16 \quad 551030 \quad 4 \times 6188$

$74: 18 \quad 551020 \quad 4 \times 6188$

$94: \quad 12 \quad 551210 \quad 4 \times 6188$

$10313: 551120 \ldots 4 \times 2102$

OCCUPATION 835

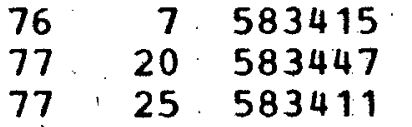

63. $31 \quad 555010$

\section{OCCUPATION 836}

$6 \times 2409$
74

74

95
17

19

21
551510

49010

551130

$\begin{array}{lll}77 & 18 & 783415\end{array}$

$\begin{array}{lll}77 & 21 & 583447\end{array}$

$\begin{array}{lll}77 & 26 & 583411\end{array}$
$4 \times 6188$

$0 \times 744$

$4 \times 6188$

$4 \times 6185$

$4 \times 6185$

$4 \times 6185$

\section{OCCUPATION 838}

$\begin{array}{rrrr}14 & 20 & 553950 & 4 \times 6181 \\ 17 & 32 & 553235 & 4 \times 6183 \\ 56 & 37 & 553420 & 4 \times 6181 \\ 56 & 39 & 753410 & 4 \times 6181 \\ 57 & 31 & 553220 & 4 \times 6181 \\ 91 & 16 & 753030 & 4 \times 6181 \\ 91 & 19 & 553250 & 4 \times 6181 \\ 97 & 2 & 553270 & 4 \times 6183 \\ 97 & 5 & 553260 & 4 \times 6183 \\ 98 & 11 & 553910 & 4 \times 6181 \\ 99 & 5 & 753050 & 4 \times 6181\end{array}$

OCCUPATION 839

$\begin{array}{rrrl}7 & 10 & 700070 & 6 \times 4308 \\ 21 & 36 & 699167 & 6 \times 4308 \\ 21 & 40 & 898010 & 6 \times 4308 \\ 22 & 1 & 699014 & 6 \times 4307 \\ 41 & 25 & 900910 & 6 \times 4310 \\ 64 & 12 & 700016 & 6 \times 4308 \\ 84 & 20 & 898010 & 6 \times 669 \\ 92 & 5 & 500012 & 6 \times 4308\end{array}$

\section{OCCUPATION 841}

$\begin{array}{rrr}9 & 2 & 727120 \\ 15 & 20 & 527910 \\ 46 & 9 & 577010 \\ 67 & 25 & 797540 \\ 67 & 27 & 527110 \\ 67 & 29 & 716940 \\ 67 & 31: & 527110 \\ 67 & 33 & 516710 \\ 68 & 5 & 527010 \\ 68 & 7 & 727010 \\ 68 & 9 & 527310 \\ 68 & 11 & 527110\end{array}$

$6 \times 4246$
$4 \times 6506$
$4 \times 6233$
$4 \times 6246$
$4 \times 6246$
$6 \times 4346$
$4 \times 6246$
$4 \times 6246$
$4 \times 6246$
$6 \times 4246$
$4 \times 6246$
$4 \times 6246$

14. $22 \quad 553340$

$22 \quad 21 \quad 553210$

$\begin{array}{lll}56 & 38 & 553410\end{array}$

$\begin{array}{lll}57 & 1 & 553410\end{array}$

$\begin{array}{lll}72 & 18 & 753020\end{array}$

$\begin{array}{lll}91 & 17 & 553040\end{array}$

$97 \quad 1553070$

$97 \quad 3 \quad 553050$

$\begin{array}{lll}97 & 6 & 553060\end{array}$

$\begin{array}{lll}98 & 24 & 753040\end{array}$

$99 \quad 27 \quad 553310$

$4 \times 6181$

$4 \times 6181$

$4 \times 6181$

$4 \times 6181$

$4 \times 6181$

$4 \times 6181$

$4 \times 6181$

$4 \times 6183$

$4 \times 6181$

$4 \times 6183$

$4 \times 6181$

$6 \times 664$ $6 \times 4308$ $6 \times 2409$ $6 \times 4307$ $6 \times 4308$ $6 \times 4308$ $6 \times 4419$

$\begin{array}{lll}14 & 27 & 527010\end{array}$

$4 \times 6246$

$4 \times 6233$

$4 \times 6233$

$4 \times 6246$

$6 \times 4246$

$4 \times 6246$

$4 \times 6346$

$4 \times 6506$

$4 \times 6246$

$6 \times 4346$

$4 \times 6246$

$4 \times 6246$ 


\begin{tabular}{|c|c|c|c|c|c|c|c|}
\hline $\begin{array}{r}72 \\
104\end{array}$ & $\begin{array}{r}\text { COL. } \\
28 \\
30\end{array}$ & $\begin{array}{l}\text { VOL I I } \\
577010 \\
527140\end{array}$ & $\begin{array}{l}\text { VOL. II } \\
4 \times 6233 \\
4 \times 6244\end{array}$ & $\begin{array}{r}\text { PAGE } \\
104\end{array}$ & $\begin{array}{r}\text { COL. } \\
29\end{array}$ & $\begin{array}{l}\text { VOL. I } \\
716152\end{array}$ & $\begin{array}{r}\text { VOL. II } \\
6 \times 4246\end{array}$ \\
\hline $\begin{array}{l}28 \\
30 \\
91\end{array}$ & $\begin{array}{r}4 \\
36 \\
5\end{array}$ & $\begin{array}{l}716971 \\
516930 \\
716111\end{array}$ & $\begin{array}{l}\text { OCCUPATION } \\
4 \times 6346 \\
4 \times 6246 \\
6 \times 4346\end{array}$ & $\begin{array}{r}843 \\
28 \\
55 \\
93\end{array}$ & $\begin{array}{r}5 \\
4 \\
34\end{array}$ & $\begin{array}{l}716970 \\
716320 \\
716610\end{array}$ & $\begin{array}{r}4 \times 6346 \\
6 \times 4346 \\
4 \times 6346\end{array}$ \\
\hline $\begin{array}{l}13 \\
49\end{array}$ & $\begin{array}{l}17 \\
16\end{array}$ & $\begin{array}{l}79010 \\
79010\end{array}$ & $\begin{array}{l}\text { OCCUPATION } \\
\text { OX742 } \\
\text { OX742 }\end{array}$ & $\begin{array}{r}852 \\
13 \\
94\end{array}$ & $\begin{array}{r}18 \\
2\end{array}$ & $\begin{array}{r}79020 \\
776950\end{array}$ & $\begin{array}{l}0 \times 715 \\
6 \times 2381\end{array}$ \\
\hline $\begin{array}{r}9 \\
12 \\
12 \\
12 \\
26 \\
60 \\
63 \\
93 \\
98\end{array}$ & $\begin{array}{l}27 \\
24 \\
26 \\
31 \\
24 \\
12 \\
26 \\
14 \\
31\end{array}$ & $\begin{array}{l}724630 \\
524010 \\
797 / 410 \\
724610 \\
524130 \\
524020 \\
724210 \\
524210 \\
524410\end{array}$ & $\begin{array}{l}\text { OCCUPATION } \\
4 \times 6232 \\
4 \times 6232 \\
4 \times 6232 \\
4 \times 6232 \\
4 \times 6232 \\
4 \times 6232 \\
4 \times 6231 \\
4 \times 6231 \\
4 \times 6233\end{array}$ & $\begin{array}{r}854 \\
12 \\
12 \\
12 \\
12 \\
55 \\
60 \\
65 \\
98 \\
98\end{array}$ & $\begin{array}{r}23 \\
25 \\
30 \\
32 \\
9 \\
15 \\
37 \\
30 \\
32\end{array}$ & $\begin{array}{l}524110 \\
524120 \\
524010 \\
524020 \\
724130 \\
524310 \\
524130 \\
732332 \\
797480\end{array}$ & $\begin{array}{l}4 \times 6232 \\
4 \times 6232 \\
4 \times 6232 \\
4 \times 6232 \\
4 \times 6244 \\
4 \times 6231 \\
4 \times 6232 \\
6 \times 4297 \\
4 \times 6233\end{array}$ \\
\hline $\begin{array}{l}17 \\
17 \\
23\end{array}$ & $\begin{array}{l}17 \\
22 \\
12\end{array}$ & $\begin{array}{l}526100 \\
520200 \\
526100\end{array}$ & $\begin{array}{l}\text { OCCUPATION } \\
4 \times 6244 \\
4 \times 6244 \\
4 \times 6244\end{array}$ & $\begin{array}{r}855 \\
17 \\
23 \\
98\end{array}$ & $\begin{array}{r}20 \\
8 \\
4\end{array}$ & $\begin{array}{l}526100 \\
797450 \\
524510\end{array}$ & $\begin{array}{l}4 \times 6244 \\
4 \times 6244 \\
4 \times 6244\end{array}$ \\
\hline $\begin{array}{l}55 \\
55 \\
66 \\
72\end{array}$ & $\begin{array}{l}26 \\
28 \\
20 \\
20\end{array}$ & $\begin{array}{l}799860 \\
532761 \\
529200 \\
797460\end{array}$ & $\begin{array}{l}\text { OCCUPATION } \\
6 \times 4213 \\
6 \times 4213 \\
4 \times 6244 \\
4 \times 6244\end{array}$ & $\begin{array}{r}856 \\
55 \\
55 \\
72 \\
94\end{array}$ & $\begin{array}{r}27 \\
29 \\
19 \\
6\end{array}$ & $\begin{array}{l}532763 \\
532762 \\
529100 \\
529300\end{array}$ & $\begin{array}{l}6 \times 4229 \\
6 \times 4229 \\
4 \times 6244 \\
4 \times 6244\end{array}$ \\
\hline $\begin{array}{r}4 \\
4 \\
78\end{array}$ & $\begin{array}{l}13 \\
17 \\
32\end{array}$ & $\begin{array}{l}799850 \\
533100 \\
639561\end{array}$ & $\begin{array}{l}\text { OCCUPATION } \\
4 \times 6244 \\
4 \times 6244 \\
6 \times 4208\end{array}$ & $\begin{array}{r}857 \\
4 \\
71\end{array}$ & $\begin{array}{l}14 \\
23\end{array}$ & $\begin{array}{l}533100 \\
533110\end{array}$ & $\begin{array}{l}4 \times 6244 \\
4 \times 6244\end{array}$ \\
\hline $\begin{array}{r}4 \\
16 \\
42 \\
72 \\
81 \\
81 \\
83 \\
93\end{array}$ & $\begin{array}{r}18 \\
10 \\
1 \\
1 \\
21 \\
23 \\
32 \\
16\end{array}$ & $\begin{array}{l}532010 \\
525150 \\
532752 \\
732320 \\
797730 \\
932010 \\
484010 \\
732577\end{array}$ & $\begin{array}{l}\text { OCCDPATION } \\
4 \times 6244 \\
6 \times 4208 \\
6 \times 4208 \\
6 \times 4297 \\
6 \times 4208 \\
6 \times 4208 \\
0 \times 6211 \\
6 \times 4435\end{array}$ & $\begin{array}{r}859 \\
9 \\
30 \\
43 \\
79 \\
81 \\
81 \\
83 \\
103\end{array}$ & $\begin{array}{r}11 \\
16 \\
1 \\
4 \\
22 \\
26 \\
33 \\
10\end{array}$ & $\begin{array}{l}574010 \\
589011 \\
732072 \\
732251 \\
731100 \\
731400 \\
525230 \\
732375\end{array}$ & $\begin{array}{l}4 \times 6295 \\
4 \times 6209 \\
6 \times 4211 \\
6 \times 4211 \\
6 \times 4208 \\
6 \times 4208 \\
4 \times 6220 \\
6 \times 4208\end{array}$ \\
\hline
\end{tabular}


PAGE COL. VOL. I VOL., II PAGE COL. VOL. I VOL. II

$\begin{array}{rrlllllll}8 & 24 & 508020 & \text { OCCUPATION } & 861 & & & \\ 8 & 245 & 32 & 19 & 708025 & 4 \times 2035 \\ 33 & 29 & 708067 & 4 \times 2035 & 51 & 28 & 508060 & 4 \times 6330 \\ 52 & 9 & 508066 & 4 \times 6330 & 56 & 22 & 708665 & 4 \times 2035 \\ 56 & 23 & 909010 & 4 \times 6381 & 56 & 24 & 708071 & 4 \times 2035 \\ 56 & 25 & 909010 & 4 \times 6508 & 64 & 11 & 708028 & 4 \times 6330 \\ 66 & 3 & 508010 & 4 \times 2035 & 74 & 26 & 508071 & 4 \times 2035 \\ 74 & 27 & 799610 & 4 \times 2035 & 74 & 28 & 508081 & 4 \times 2035 \\ 75 & 15 & 508065 & 4 \times 6385 & & & & \end{array}$

OCCUPATION 862

$\begin{array}{rrrlrrrr}40 & 3 & 666611 & 6 \times 2605 & 40 & 9 & 666611 & 6 \times 2605 \\ 54: & 7 & 666251 & 6 \times 2605 & 54 & 8 & 666265 & 4 \times 6232 \\ 85 & 11 & 666261 & 4 \times 6232 & & & & \\ & & & \text { OCCUPATION } & 864 & & & \\ 20 & 18 & 669010 & 6 \times 2436 & 24 & 28 & 669320 & 6 \times 4239 \\ 32 & 26 & 669180 & 6 \times 2439 & 46 & 34 & 669160 & 6 \times 4435 \\ 83 & 12 & 469160 & 6 \times 4339 & 92 & 7 & 469610 & 4 \times 6508 \\ 93 & 9 & 468100 & 4 \times 6337 & 93 & 10 & 797320 & 4 \times 6377 \\ 93 & 15 & 469150 & 4 \times 2033 & 93 & 17 & 669360 & 6 \times 439 \\ 93 & 18 & 669140 & 6 \times 2439 & 108 & 11 & 669040 & 6 \times 2436\end{array}$

OCCOPATION 869

$\begin{array}{rrrlrrrr}11 & 16 & 606710 & 6 \times 2381 & 12 & 33 & 666321 & 6 \times 2386 \\ 12 & 34 & 666322 & 6 \times 2385 & 22 & 12 & 666211 & 4 \times 6346 \\ 28 & 2 & 465910 & 4 \times 6506 & 39 & 31 & 666561 & 6 \times 4349 \\ 45 & 34 & 465430 & 4 \times 6342 & 45 & 35 & 465440 & 4 \times 6342 \\ 46 & 1 & 865010 & 6 \times 4399 & 46 & 2 & 665240 & 6 \times 4335 \\ 46 & 3 & 665220 & 6 \times 4335 & 47 & 1 & 666164 & 6 \times 4349 \\ 51 & 29 & 666523 & 4 \times 6381 & 53 & 12 & 666453 & 4 \times 6348 \\ 56 & 26 & 665462 & 4 \times 6645 & 56 & 27 & 465446 & 4 \times 6645 \\ 62 & 1 & 666014 & 6 \times 2601 & 63 & 7 & 666116 & 4 \times 6348 \\ 63 & 19 & 666411 & 4 \times 6348 & 69 & 2 & 666361 & 4 \times 6233 \\ 75 & 3 & 666455 & 6 \times 4449 & 75 & 5 & 666162 & 6 \times 4489 \\ 83 & 11 & 665230 & 6 \times 4339 & 103 & 14 & 466453 & 4 \times 6348 \\ & & & & & & & \\ 10 & 21 & 572930 & 4 \times 2102 & 40 & 14 & 770040 & 6 \times 2608 \\ & & & & & & \\ & & & & & & \\ 2 & 15 & 772580 & 4 \times 2102 & 11 & 7 & 572921 & 6 \times 2964 \\ 23 & 4 & 572924 & 4 \times 2102 & 29 & 16 & 572210 & 4 \times 2102 \\ 32 & 6 & 772530 & 4 \times 2102 & 38 & 25 & 572010 & 4 \times 2102 \\ 39 & 36 & 772510 & 4 \times 2109 & 44 & 27 & 572920 & 4 \times 6693 \\ 44 & 29 & 572945 & 4 \times 2103 & 45 & 1 & 572920 & 4 \times 2102 \\ 45 & 2 & 572920 & 4 \times 6693 & 50 & 17 & 572050 & 4 \times 2102 \\ 53 & 3 & 772570 & 4 \times 2102 & 76 & 18 & 772510 & 4 \times 2102 \\ 76 & 19 & 572550 & 0 \times 846 & 76 & 20 & 572925 & 4 \times 2012 \\ 78 & 30 & 572313 & 4 \times 2102 & 91 & 13 & 572010 & 4 \times 2102\end{array}$


PAGE COL. VOL. I VOL. II $99 \quad 16 \quad 572010 \quad 4 \times 2102$

PAGE COL. VOL. I VOL. II $\begin{array}{llll}106 & 2 & 572010 & 4 \times 2102\end{array}$

OCCUPATION 873

$\begin{array}{rrrrr}55 & 8 & 540110 & 4 \times 2492 & 55 \\ 64 & 5 & 556020 & 4 \times 6181 & 66 \\ 91 & 36 & 541060 & 4 \times 2492 & \\ & & & \text { OCCUPATION } 874\end{array}$

$\begin{array}{rrrr}1 & 23 & 573010 & 4 \times 2493 \\ 26 & 4 & 773010 & 6 \times 2493 \\ 35 & 3 & 573040 & 4 \times 2493 \\ 36 & 6 & 773030 & 6 \times 2493 \\ 49 & 24 & 573520 & 4 \times 2493 \\ 49 & 26 & 812100 & 6 \times 2493 \\ 57 & 21 & 573330 & 4 \times 2493 \\ 58 & 7 & 573520 & 4 \times 2493 \\ 60 & 11 & 573510 & 4 \times 2493 \\ 63 & 23 & 573020 & 4 \times 2493 \\ 82 & 22 & 573030 & 4 \times 2493 \\ 84 & 7 & 573520 & 4 \times 2493 \\ 88 & 15 & 573550 & 4 \times 2493 \\ 95 & 18 & 573330 & 4 \times 2493 \\ 107 & 31 & 773740 & 6 \times 2493 \\ 107 & 33 & 773710 & 6 \times 2493\end{array}$

$\begin{array}{rrrl}17 & 8 & 573050 & 4 \times 2493 \\ 34 & 32 & 573010 & 4 \times 2493 \\ 36 & 1 & 573020 & 4 \times 2493 \\ 37 & 9 & 573330 & 4 \times 2402 \\ 49 & 25 & 573520 & 4 \times 2493 \\ 51 & 15 & 573010 & 4 \times 2493 \\ 57 & 35 & 573060 & 4 \times 2493 \\ 59 & 19 & 573520 & 4 \times 2493 \\ 63 & 22 & 573080 & 4 \times 2493 \\ 76 & 10 & 773520 & 6 \times 2493 \\ 84 & 5 & 773060 & 6 \times 2493 \\ 88 & 12 & 830100 & 6 \times 669 \\ 94 & 32 & 573510 & 4 \times 2493 \\ 102 & 11 & 573070 & 4 \times 2493 \\ 107 & 32 & 773720 & 6 \times 2493 \\ 109 & 7 & 573330 & 4 \times 2492\end{array}$

$\begin{array}{rrrl}3 & 3 & 580500 & 4 \times 6208 \\ 79 & 34 & 520000 & 4 \times 6209 \\ 80 & 1 & 591401 & 3 \times 996 \\ 80 & 5 & 630350: & 3 \times 996 \\ 80 & 7 & 573330 & 4 \times 2493 \\ 87 & 5 & 505570 & 4 \times 6207\end{array}$

OCCUPATION 875

$\begin{array}{llll}55 & 18 & 740050 & 6 \times 2492 \\ 66 & 28 & 740050 & 6 \times 2492\end{array}$


PAGE COL. VOL. I VOL. II PAGE COL. VOL. I VOL. II OCCUPATION 881

$\begin{array}{rrrrrrrr}30 & 21 & 947200 & 6 \times 669 & 55 & 2 & 389060 & 6 \times 669 \\ 58 & 8 & 947100 & 6 \times 669 & 92 & 14 & 747100 & 0 \times 849\end{array}$

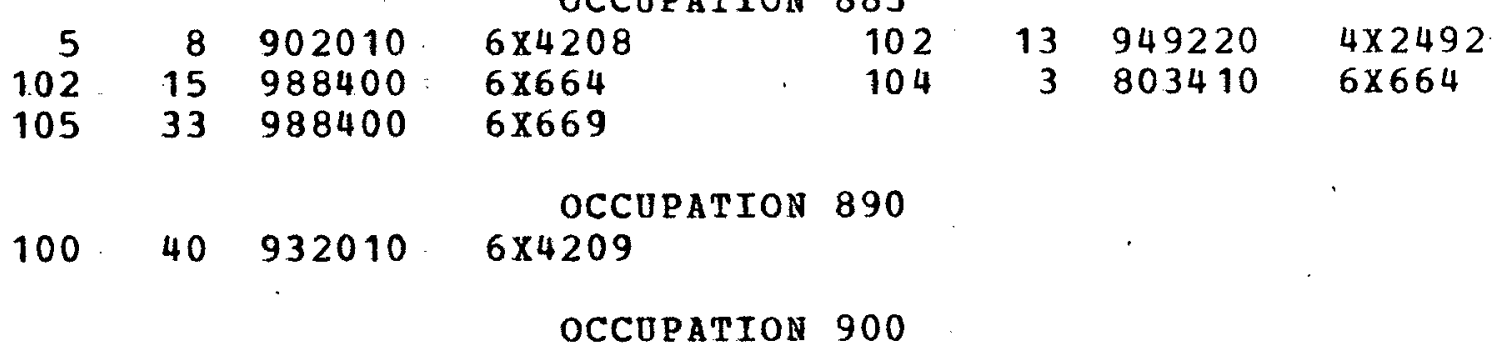

$83 \quad 22.95160 .0 \times 625$

OCCUPATION 911

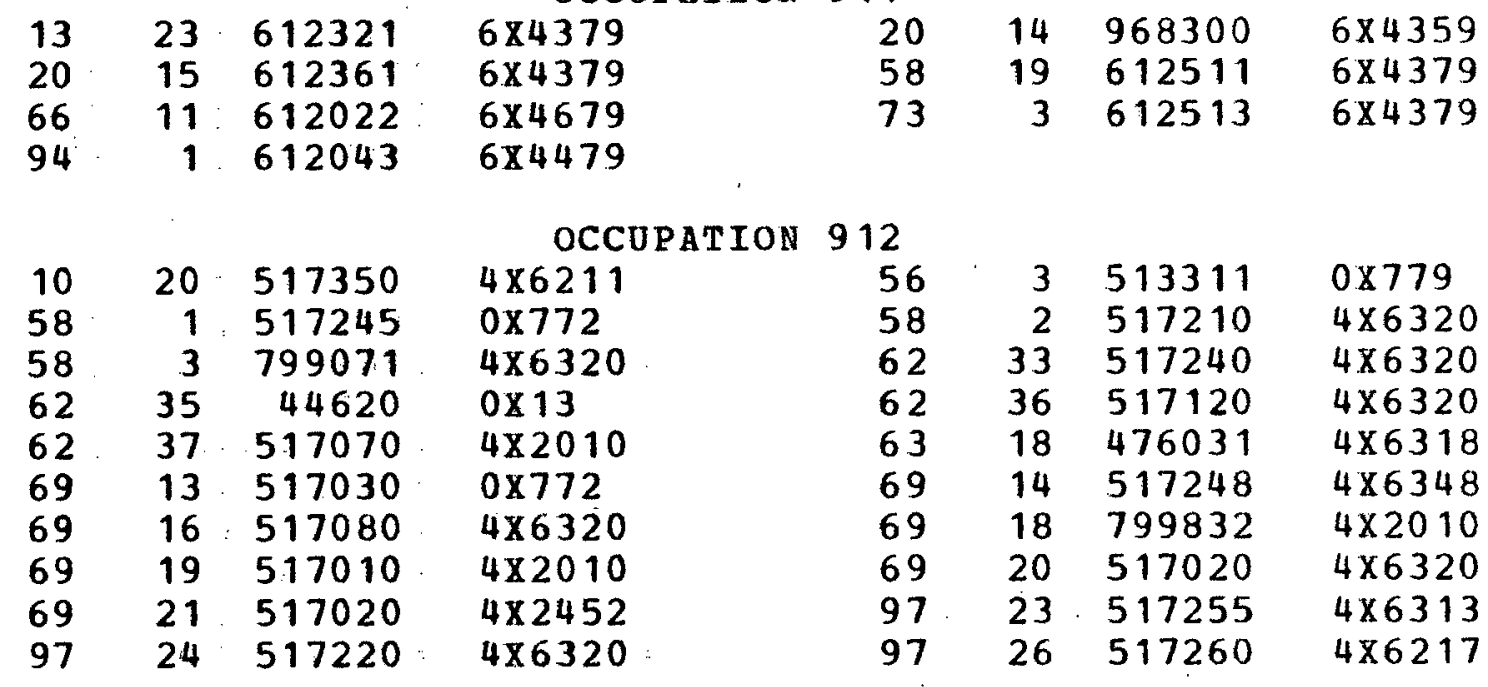

OCCUPATION 913

\begin{tabular}{|c|c|c|c|c|c|c|c|}
\hline 6 & 35 & 803010 & $6 \times 4479$ & 11 & 17 & 591011 & $0 \times 846$ \\
\hline 11 & 18 & 591011 & $0 \times 846$ & 11 & 26 & 768811 & $6 \times 4409$ \\
\hline 11 & 29 & 768212 & $6 \times 4463$ & 12 & 13 & 804100 & $6 \times 44$ \\
\hline 12 & 17 & 802100 & $6 \times 4479$ & 14 & 37 & 805210 & $6 \times 4379$ \\
\hline 15 & 2 & 768831 & $6 \times 2479$ & 15 & 3 & 591901 & $0 \times 846$ \\
\hline 15 & 7 & 900910 & $6 \times 4409$ & 15 & 11 & 968100 & $6 \times 2479$ \\
\hline 19 & 3 & 606450 & $6 \times 4379$ & 20 & 13 & 768225 & $6 \times 4463$ \\
\hline 27 & 35 & 789351 & $4 \times 6346$ & 54 & 26 & 768214 & $6 \times 2409$ \\
\hline 60 & 22 & 968200 & $1 \times 28$ & 67 & 14 & 968300 & $6 \times 4309$ \\
\hline 70 & 1 & 968200 & $1 \times 44$ & 88 & 6 & 861010 & $1 \times 28$ \\
\hline & 35 & 968300 & $6 \times 2409$ & 108 & 36 & 842010 & $6 \times 4469$ \\
\hline & & & & & & & \\
\hline & 27 & 968900 & $6 \times 4369$ & 34 & 18 & 591011 & $6 \times 2479$ \\
\hline
\end{tabular}


PAGE COL. VOL. I VOL. II PAGE COL. VOL. I VOL. II

\begin{tabular}{|c|c|c|c|c|c|c|c|}
\hline $\begin{array}{r}9 \\
70\end{array}$ & $\begin{array}{l}32 \\
14\end{array}$ & $\begin{array}{l}786330 \\
449940\end{array}$ & $\begin{array}{r}\text { OCC } \\
4 \times 6588 \\
4 \times 6588\end{array}$ & $\begin{array}{r}915 \\
27 \\
70\end{array}$ & $\begin{array}{l}31 \\
26\end{array}$ & $\begin{array}{l}586510 \\
786310\end{array}$ & $\begin{array}{l}4 \times 6588 \\
1 \times 59\end{array}$ \\
\hline $\begin{array}{r}7 \\
22 \\
33 \\
49 \\
56 \\
71 \\
90\end{array}$ & $\begin{array}{r}18 \\
17 \\
24 \\
12 \\
17 \\
4 \\
22 \\
14\end{array}$ & $\begin{array}{l}459911 \\
518520 \\
518510 \\
659437 \\
459912 \\
659915 \\
459031 \\
459501\end{array}$ & $\begin{array}{r}\text { OCC } \\
4 \times 6651 \\
4 \times 6651 \\
4 \times 6651 \\
6 \times 2381 \\
4 \times 6381 \\
4 \times 6651 \\
6 \times 4459 \\
4 \times 6651\end{array}$ & $\begin{array}{r}916 \\
22 \\
30 \\
36 \\
56 \\
71 \\
89 \\
90\end{array}$ & $\begin{array}{r}16 \\
37 \\
27 \\
6 \\
3 \\
27 \\
29\end{array}$ & $\begin{array}{r}661833 \\
659261 \\
659926 \\
459413 \\
659065 \\
459912 \\
659235\end{array}$ & $\begin{array}{r}6 \times 4346 \\
6 \times 4359 \\
6 \times 4459 \\
4 \times 6651 \\
4 \times 6651 \\
6 \times 2381 \\
6 \times 4346\end{array}$ \\
\hline
\end{tabular}

OCCUPATION 915

\section{OCCUPATION 917}

$\begin{array}{rrrr}2 & 32 & 503810 & 4 \times 6385 \\ 10 & 8 & 702742 & 6 \times 2381 \\ 18 & 3 & 576040 & 6 \times 2381 \\ 34 & 23 & 497916 & 4 \times 6386 \\ 34 & 29 & 493010 & 4 \times 6381 \\ 37 & 18 & 580350 & 4 \times 2103 \\ 39 & 23 & 499432 & 4 \times 6183 \\ 44 & 10 & 688214 & 6 \times 2385 \\ 47 & 5 & 900910 & 4 \times 6381 \\ 48 & 6 & 687910 & 4 \times 6386 \\ 51 & 27 & 478671 & 4 \times 6385 \\ 53 & 14 & 476220 & 4 \times 6385 \\ 63 & 33 & 579610 & 4 \times 2109 \\ 86 & 8 & 688215 & 4 \times 6385 \\ 107 & 12 & 485070 & 4 \times 6381\end{array}$

OCCOPATIOH 918

$\begin{array}{lll}34 & 18 & 776110 \\ 46 & 33 & 95130\end{array}$

\section{$6 \times 2381$}

$0 \times 730$

OCCUPATION 919

$\begin{array}{rrr}1 & 8 & 513351 \\ 3 & 28 & 713321 \\ 7 & 9 & 662201 \\ 13 & 6 & 713758 \\ 41 & 3 & 713013 \\ 50 & 9 & 583981 \\ 60 & 31 & 436414 \\ 66 & 16 & 512200 \\ 66 & 29 & 91610 \\ 70 & 31 & 583222 \\ 73 & 2 & 510930 \\ 78 & 21 & 698760 \\ 89 & 2 & 913510 \\ 89 & 4 & 783902\end{array}$

$\begin{array}{rrrl}42 & 17 & 95110 & 0 \times 625 \\ 108 & 28 & 776130 & 4 \times 6381\end{array}$

$\begin{array}{rrrl}2 & 33 & 580910 & 4 \times 2103 \\ 10 & 13 & 79030 & 0 \times 742 \\ 20 & 16 & 699433 & 6 \times 4308 \\ 34 & 24 & 497930 & 4 \times 6181 \\ 35 & 35 & 583452 & 4 \times 6183 \\ 39 & 21 & 503812 & 4 \times 6213 \\ 44 & 9 & 476220 & 4 \times 6385 \\ 45 & 21 & 678690 & 4 \times 6386 \\ 47 & 6 & 498020 & 4 \times 6381 \\ 50 & 24 & 505511 & 0 \times 742 \\ 51 & 33 & 698110 & 4 \times 6381 \\ 63 & 32 & 581630 & 4 \times 2103 \\ 81 & 11 & 694658 & 6 \times 2381 \\ 100 & 11 & 476220 & 4 \times 2010\end{array}$

$\begin{array}{rrrl}3 & 14: & 494341 & 4 \times 6386 \\ 4 & 10 & 509430 & 4 \times 6328 \\ 7 & 12 & 480010 & 4 \times 6313 \\ 14 & 35 & 583901 & 4 \times 6310 \\ 41 & 9 & 509442 & 4 \times 6348 \\ 51 & 17 & 710016 & 6 \times 4449 \\ 60 & 32 & 636422 & 6 \times 4352 \\ 66 & 24 & 509410 & 4 \times 6309 \\ 69 & 38 & 713118 & 6 \times 4309 \\ 70 & 32 & 512100 & 4 \times 6383 \\ 76 & 2 & 556540 & 2 \times 59 \\ 88 & 28 & 651528, & 6 \times 4469 \\ 89 & 3 & 513511 & 4 \times 6328 \\ 97 & 32 & 713051 & 6 \times 4309\end{array}$


$\begin{array}{rrrr}\text { PAGE } & \text { COL. } & \text { VOL. I } & \text { VOL. II } \\ 100 & 35 & 513011 & 4 \times 6320\end{array}$

PAGE COI. VOL. I VOL. II $\begin{array}{llll}105 & 18 & 513353 & 4 \times 6328\end{array}$

\begin{tabular}{rrr}
4 & 15 & 932010 \\
5 & 13 & 781010 \\
5 & 28 & 809110 \\
6 & 29 & 841010 \\
8 & 28 & 892010 \\
9 & 8 & 893710 \\
9 & 31 & 583021 \\
10 & 18 & 893450 \\
12 & 27 & 866010 \\
12 & 29 & 932010 \\
13 & 22 & 913750 \\
15 & 34 & 905010 \\
17 & 12 & 804100 \\
18 & 6 & 787200 \\
20 & 7 & 932010 \\
21 & 24 & 988400 \\
24 & 10 & 205030 \\
30 & 31 & 892010 \\
32 & 36 & 80.3210 \\
35 & 17 & 905510 \\
35 & 34 & 954100 \\
38 & 14 & 827010 \\
39 & 9 & 812100 \\
42 & 10 & 849010 \\
45 & 12 & 849010 \\
48 & 2 & 583641 \\
49 & 20 & 932010 \\
51 & 11 & 849010 \\
51 & 35 & 903010 \\
53 & 21 & 842010 \\
54 & 31 & 867610 \\
54 & 33 & 859010 \\
54 & 35 & 932010 \\
55 & 3 & 932010 \\
58 & 22 & 983410 \\
59 & 4 & 905510 \\
65 & 24 & 833050 \\
67 & 35 & 932010 \\
68 & 1 & 716895 \\
68 & 3 & 903010 \\
68 & 22 & 802100 \\
68 & 29 & 932010 \\
70 & 33 & 831010 \\
71 & 35 & 932010 \\
72 & 21 & 932010 \\
74 & 7 & 809010 \\
75 & 10 & 654056 \\
77 & 30 & 989850 \\
& & \\
\hline & &
\end{tabular}

OCCUPATION 920

$4 \times 6244$

$4 \times 2103$

$6 \times 4359$

$6 \times 4429$

$6 \times 664$

$4 \times 6315$

$4 \times 6183$

$4 \times 6211$

$4 \times 6232$

$4 \times 6232$

$6 \times 4309$

$4 \times 6220$

$6 \times 4379$

$6 \times 669$

$6 \times 4297$

$6 \times 669$

$2 \times 11$

$6 \times 2615$

$6 \times 664$

$4 \times 6181$

$4 \times 6181$

$6 \times 4459$

$6 \times 4379$

$4 \times 2463$

$1 \times 28$

$4 \times 2109$

$6 \times 669$

$6 \times 4469$

$4 \times 6210$

$6 \times 610$

$6 \times 2601$

$6 \times 4651$

$6 \times 669$

$6 \times 669$

$6 \times 664$

$4 \times 2100$

$6 \times 664$

$4 \times 6246$

$4 \times 6246$

$6 \times 4346$

$6 \times 4379$

$4 \times 6246$

$6 \times 2381$

$6 \times 4297$

$4 \times 6244$

$6 \times 4676$

$6 \times 2419$

$6 \times 2381$ $\begin{array}{lll}4 & 16 & 932010\end{array}$

$\begin{array}{lll}5 & 23 & 987100\end{array}$

$\begin{array}{lll}6 & 10 & 988400\end{array}$

$7 \quad 2 \quad 803010$

$8 \quad 34 \quad 892610$

$9 \quad 30 \quad 812100$

$10 \quad 6 \quad 819010$

$\begin{array}{lll}10 & 19 & 693421\end{array}$

$12 \quad 28 \quad 932010$

$\begin{array}{lll}12 & 35 & 583631\end{array}$

15

15

17

19

20

23

27

32

35

35

37

38

42

44

46

48

51

51

53

54

54

54

55

55

59

59

65

67

68

68

68

69

71

72

73

74

75

77
6

35

21

31

33

23

32

27

16

18

3

15

8

1

16

3

,

21

1

30

32

34

1

35

3

5
33

36

2

4

23

34

31

10

\section{7}

\section{8}

14

31
831010

932010

932010

682910

893070

932010

819610

842010

900950

903010

893580

824010

810610

949200

853410

495031

810320

849010

866010

850010

892010

855010

988400

841010

878100

905510

672955

916210

905510

916210

802100

830831

732811

902010

732812

809010

849010

819010
$4 \times 6244$ $3 \times 996$

$6 \times 664$

$6 \times 664$

$6 \times 664$

$6 \times 664$

$6 \times 4451$

$4 \times 6211$

$4 \times 6232$

$4 \times 6209$

$6 \times 664$

$4 \times 6220$

$4 \times 6244$

$6 \times 4319$

$6 \times 4315$

$4 \times 2109$

$6 \times 4346$

$6 \times 4469$

$4 \times 6181$

$4 \times 6181$

$6 \times 2611$

$6 \times 4459$

$6 \times 2493$

$6 \times 4209$

$6 \times 669$

$4 \times 6285$

$6 \times 664$

$6 \times 4309$

$6 \times 4294$

$6 \times 669$

$4 \times 6601$

$6 \times 669$

$6 \times 669$

$6 \times 664$

$4 \times 2010$

$4 \times 2100$

$6 \times 4319$

$4 \times 6246$

$4 \times 6246$

$6 \times 4346$

$4 \times 6675$

$3 \times 996$

$4 \times 6217$

$6 \times 4213$

$4 \times 6217$

$6 \times 4379$

$4 \times 6568$

$6 \times 610$ 


$\begin{array}{rrrl}\text { PAGE } & \text { COI. } & \text { VOL. I } & \text { VOL. II } \\ 80 & 2 & 903010 & 4 \times 6208 \\ 81 & 24 & 932010 & 6 \times 4208 \\ 82 & 9 & 920100 & 6 \times 669 \\ 83 & 14 & 916940 & 6 \times 4315 \\ 83 & 18 & 989960 & 6 \times 669 \\ 84 & 13 & 892010 & 4 \times 2487 \\ 86 & 32 & 905510 & 4 \times 6211 \\ 89 & 6 & 878000 & 6 \times 4415 \\ 90 & 28 & 808010 & 6 \times 669 \\ 91 & 27 & 968900 & 6 \times 4469 \\ 92 & 40 & 809110 & 6 \times 663 \\ 93 & 36 & 859010 & 6 \times 664 \\ 95 & 3 & 64200 & 3 \times 773 \\ 96 & 9 & 851410 & 6 \times 4409 \\ 98 & 33 & 732543 & 4 \times 6233 \\ 99 & 36 & 988400 & 6 \times 664 \\ 101 & 26 & 802100 & 6 \times 4379 \\ 106 & 8 & 988400 & 6 \times 669 \\ 107 & 4 & 695045 & 4 \times 6281 \\ 109 & 9 & 204030 & 6 \times 662\end{array}$

$\begin{array}{rrrr}\text { PAGE } & \text { COL. } & \text { VOL. I } & \text { VOL. II } \\ 80 & 3 & 932010 & 4 \times 6207 \\ 81 & 25 & 932010 & 6 \times 4208 \\ 82 & 16 & 457910 & -4 \times 2021 \\ 83 & 15 & 633117 & 6 \times 4325 \\ 83 & 35 & 804100 & 6 \times 2671 \\ 86 & 22 & 694231 & 4 \times 6313 \\ 87 & 28 & 732952 & 4 \times 2493 \\ 89 & 29 & 631860 & 6 \times 2381 \\ 191 & 1 & 988400 & 6 \times 669 \\ 92 & 32 & 988400 & 1 \times 28 \\ 93 & 35 & 716580 & 6 \times 4346 \\ 93 & 37 & 685215 & 4 \times 6283 \\ 96 & 3 & 842010 & 6 \times 664 \\ 98 & 5 & 732542 & 4 \times 6244 \\ 98 & 34 & 932010 & 4 \times 6233 \\ 100 & 31 & 841010 & 6 \times 2601 \\ 105 & 31 & 866510 & 6 \times 664 \\ 107 & 3 & 695041 & 4 \times 6283 \\ 107 & 5 & 695043 & 4 \times 6280 \\ 109 & 10 & 959010 & 6 \times 669\end{array}$




\section{Appendix B: Data Base}

Since the data used in this study are not easily obtained this computer produced appendix presents tables containing the data necessary for replication of the study. 
OCCU - ANN. EARNING WEEKS/YEAR HOURS/WEEK HRLY EARNING PATION MALE FEMALE MALE FEMALE MALE FEMALE MALE FEMALE

\begin{tabular}{|c|c|c|c|c|c|c|c|c|}
\hline $\begin{array}{r}1 \\
4 \\
6 \\
8 \\
10\end{array}$ & $\begin{array}{l}7659 \\
7468 \\
5883 \\
5652 \\
6758\end{array}$ & $\begin{array}{l}4496 \\
3647 \\
3845 \\
3755 \\
3364\end{array}$ & $\begin{array}{l}49.4 \\
49.6 \\
49.4 \\
49.0 \\
49.2\end{array}$ & $\begin{array}{l}47.5 \\
47.3 \\
48.6 \\
48.4 \\
46.9\end{array}$ & $\begin{array}{l}44.0 \\
44.0 \\
44.0 \\
44.0 \\
44.0\end{array}$ & $\begin{array}{lll} & 1.1 \\
4 & 1.1 \\
4 & 1.1 \\
4 & 1.1 \\
4 & 1.1\end{array}$ & $\begin{array}{l}3.52 \\
3.42 \\
2.71 \\
2.62 \\
3.12\end{array}$ & $\begin{array}{l}2.30 \\
1.88 \\
1.92 \\
1.89 \\
1.75\end{array}$ \\
\hline $\begin{array}{l}101 \\
102 \\
105 \\
108 \\
109\end{array}$ & $\begin{array}{l}7112 \\
7055 \\
7329 \\
7625 \\
7411\end{array}$ & $\begin{array}{l}4368 \\
4866 \\
4675 \\
5463 \\
4961\end{array}$ & $\begin{array}{l}47.3 \\
48.1 \\
48.1 \\
48.0 \\
48.5\end{array}$ & $\begin{array}{l}45.8 \\
43.5 \\
43.8 \\
46.9 \\
45.2\end{array}$ & $\begin{array}{l}40.9 \\
40.9 \\
40.9 \\
40.9 \\
40.9\end{array}$ & $\begin{array}{l}38.8 \\
38.8 \\
38.8 \\
38.8 \\
38.8\end{array}$ & $\begin{array}{l}3.68 \\
3.59 \\
3.73 \\
3.88 \\
3.74\end{array}$ & $\begin{array}{l}2.46 \\
2.88 \\
2.75 \\
3.00 \\
2.83\end{array}$ \\
\hline $\begin{array}{l}111 \\
114 \\
119 \\
121 \\
124\end{array}$ & $\begin{array}{l}6187 \\
7439 \\
7182 \\
5991 \\
6362\end{array}$ & $\begin{array}{l}3873 \\
5303 \\
3387 \\
3850 \\
3317\end{array}$ & $\begin{array}{l}47.4 \\
46.3 \\
47.1 \\
45.1 \\
45.8\end{array}$ & $\begin{array}{l}42.7 \\
48.3 \\
41.8 \\
43.0 \\
41.0\end{array}$ & $\begin{array}{l}40.8 \\
40.8 \\
40.8 \\
42.7 \\
42.7\end{array}$ & $\begin{array}{l}38.4 \\
38.4 \\
38.4 \\
38.3 \\
38.3\end{array}$ & $\begin{array}{l}3.20 \\
3.94 \\
3.74 \\
3.11 \\
3.25\end{array}$ & $\begin{array}{l}2.36 \\
2.86 \\
2.11 \\
2.34 \\
2.11\end{array}$ \\
\hline $\begin{array}{l}129 \\
131 \\
135 \\
139 \\
140\end{array}$ & $\begin{array}{l}5232 \\
7112 \\
5529 \\
4748 \\
6883\end{array}$ & $\begin{array}{l}3673 \\
5038 \\
3399 \\
2598 \\
4315\end{array}$ & $\begin{array}{l}45.8 \\
48.8 \\
48.8 \\
47.4 \\
46.7\end{array}$ & $\begin{array}{l}40.5 \\
46.2 \\
46.8 \\
43.7 \\
44.0\end{array}$ & $\begin{array}{l}42.7 \\
41.0 \\
41.0 \\
41.0 \\
44.6\end{array}$ & $\begin{array}{l}38.3 \\
36.9 \\
36.9 \\
36.9 \\
39.4\end{array}$ & $\begin{array}{l}2.68 \\
3.56 \\
2.76 \\
2.44 \\
3.30\end{array}$ & $\begin{array}{l}2.37 \\
2.96 \\
1.97 \\
1.61 \\
2.49\end{array}$ \\
\hline $\begin{array}{l}141 \\
142 \\
143 \\
144 \\
145\end{array}$ & $\begin{array}{l}7303 \\
3458 \\
1795 \\
3772 \\
6409\end{array}$ & $\begin{array}{r}2819 \\
2751 \\
514 \\
2852 \\
1871\end{array}$ & $\begin{array}{l}45.3 \\
47.8 \\
39.4 \\
47.4 \\
48.3\end{array}$ & $\begin{array}{l}43.4 \\
42.6 \\
43.3 \\
42.2 \\
38.9\end{array}$ & $\begin{array}{l}44.6 \\
44.6 \\
44.6 \\
44.6 \\
44.6\end{array}$ & $\begin{array}{l}39.4 \\
39.4 \\
39.4 \\
39.4 \\
39.4\end{array}$ & $\begin{array}{l}3.61 \\
1.62 \\
1.02 \\
1.78 \\
2.98\end{array}$ & $\begin{array}{l}1.65 \\
1.64 \\
0.30 \\
1.72 \\
1.22\end{array}$ \\
\hline $\begin{array}{l}146 \\
147 \\
148 \\
153 \\
171\end{array}$ & $\begin{array}{l}4746 \\
5321 \\
3513 \\
7359 \\
4982\end{array}$ & $\begin{array}{l}2359 \\
3427 \\
2354 \\
4362 \\
2897\end{array}$ & $\begin{array}{l}48.2 \\
46.9 \\
45.6 \\
47.3 \\
47.3\end{array}$ & $\begin{array}{l}44.7 \\
42.7 \\
44.0 \\
45.3 \\
44.1\end{array}$ & $\begin{array}{l}44.6 \\
44.6 \\
44.6 \\
42.7 \\
39.9\end{array}$ & $\begin{array}{l}39.4 \\
39.4 \\
39.4 \\
39.5 \\
31.9\end{array}$ & $\begin{array}{l}2.21 \\
2.54 \\
1.73 \\
3.64 \\
2.64\end{array}$ & $\begin{array}{l}1.34 \\
2.04 \\
1.36 \\
2.44 \\
2.06\end{array}$ \\
\hline $\begin{array}{l}172 \\
174 \\
176 \\
182 \\
183\end{array}$ & $\begin{array}{l}5456 \\
5817 \\
4097 \\
4416 \\
3553\end{array}$ & $\begin{array}{l}3600 \\
3201 \\
1906 \\
3083 \\
2019\end{array}$ & $\begin{array}{l}46.6 \\
47.7 \\
43.6 \\
47.0 \\
41.1\end{array}$ & $\begin{array}{l}42.9 \\
44.9 \\
42.4 \\
45.4 \\
34.1\end{array}$ & $\begin{array}{l}39.9 \\
39.9 \\
39.9 \\
40.5 \\
40.5\end{array}$ & $\begin{array}{l}31.9 \\
31.9 \\
31.9 \\
37.6 \\
37.6\end{array}$ & $\begin{array}{l}2.93 \\
3.06 \\
2.36 \\
2.32 \\
2.14\end{array}$ & $\begin{array}{l}2.63 \\
2.23 \\
1.41 \\
1.81 \\
1.57\end{array}$ \\
\hline $\begin{array}{l}186 \\
188 \\
191 \\
192 \\
195\end{array}$ & $\begin{array}{l}6993 \\
6194 \\
4543 \\
4024 \\
3725\end{array}$ & $\begin{array}{l}3753 \\
3984 \\
2998 \\
3020 \\
2057\end{array}$ & $\begin{array}{l}48.2 \\
49.4 \\
45.8 \\
44.2 \\
46.5\end{array}$ & $\begin{array}{l}41.9 \\
47.8 \\
42.7 \\
42.2 \\
42.4\end{array}$ & $\begin{array}{l}40.5 \\
40.5 \\
40.5 \\
40.5 \\
40.5\end{array}$ & $\begin{array}{l}37.6 \\
37.6 \\
37.6 \\
37.6 \\
37.6\end{array}$ & $\begin{array}{l}3.58 \\
3.10 \\
2.45 \\
2.25 \\
1.98\end{array}$ & $\begin{array}{l}2.38 \\
2.22 \\
1.87 \\
1.90 \\
1.29\end{array}$ \\
\hline
\end{tabular}


OCCU- ANN. EARNING WEEKS/YEAR HOURS/WEEK HRLY EARNING PATION MALE FEMALE MALE FEMALE MALE FEMALE MALE FEMLE

\begin{tabular}{|c|c|c|c|c|c|c|c|c|}
\hline $\begin{array}{l}196 \\
198 \\
199 \\
201 \\
203\end{array}$ & $\begin{array}{l}4171 \\
4373 \\
5529 \\
3461 \\
3829\end{array}$ & $\begin{array}{l}2342 \\
2571 \\
3072 \\
2170 \\
2531\end{array}$ & $\begin{array}{l}46.7 \\
44.4 \\
47.4 \\
47.2 \\
47.5\end{array}$ & $\begin{array}{l}44.3 \\
43.5 \\
44.4 \\
44.1 \\
44.8\end{array}$ & $\begin{array}{l}40.5 \\
40.5 \\
40.5 \\
40.4 \\
40.4\end{array}$ & $\begin{array}{l}37.6 \\
37.6 \\
37.6 \\
37.3 \\
37.3\end{array}$ & $\begin{array}{l}2.21 \\
2.43 \\
2.88 \\
1.82 \\
2.00\end{array}$ & $\begin{array}{l}1.41 \\
1.57 \\
1.84 \\
1.32 \\
1.51\end{array}$ \\
\hline $\begin{array}{l}212 \\
214 \\
223 \\
232 \\
234\end{array}$ & $\begin{array}{l}3298 \\
3229 \\
4498 \\
3918 \\
3175\end{array}$ & $\begin{array}{l}1913 \\
1890 \\
3236 \\
2640 \\
2187\end{array}$ & $\begin{array}{l}46.1 \\
46.1 \\
48.6 \\
47.3 \\
45.8\end{array}$ & $\begin{array}{l}43.2 \\
42.9 \\
45.6 \\
45.6 \\
43.2\end{array}$ & $\begin{array}{l}40.4 \\
40.4 \\
40.4 \\
40.4 \\
40.4\end{array}$ & $\begin{array}{l}37.3 \\
37.3 \\
37.3 \\
37.3 \\
37.3\end{array}$ & $\begin{array}{l}1.77 \\
1.73 \\
2.29 \\
2.05 \\
1.72\end{array}$ & $\begin{array}{l}1.19 \\
1.18 \\
1.90 \\
1.55 \\
1.36\end{array}$ \\
\hline $\begin{array}{l}241 \\
249 \\
307 \\
312 \\
314\end{array}$ & $\begin{array}{l}2585 \\
3392 \\
3623 \\
1819 \\
5279\end{array}$ & $\begin{array}{r}2034 \\
2184 \\
666 \\
717 \\
2531\end{array}$ & $\begin{array}{l}40.7 \\
45.7 \\
43.1 \\
35.9 \\
48.2\end{array}$ & $\begin{array}{l}43.8 \\
43.0 \\
31.8 \\
28.1 \\
41.7\end{array}$ & $\begin{array}{l}40.4 \\
40.4 \\
43.1 \\
43.1 \\
43.1\end{array}$ & $\begin{array}{l}37.3 \\
37.3 \\
33.9 \\
33.9 \\
33.9\end{array}$ & $\begin{array}{l}1.57 \\
1.84 \\
1.95 \\
1.18 \\
2.54\end{array}$ & $\begin{array}{l}1.24 \\
1.36 \\
0.62 \\
0.75 \\
1.79\end{array}$ \\
\hline $\begin{array}{l}325 \\
331 \\
338 \\
339 \\
403\end{array}$ & $\begin{array}{l}2897 \\
5282 \\
5027 \\
3406 \\
4328\end{array}$ & $\begin{array}{l}1307 \\
2944 \\
2899 \\
1229 \\
2930\end{array}$ & $\begin{array}{l}44.5 \\
48.2 \\
48.0 \\
40.2 \\
48.5\end{array}$ & $\begin{array}{l}39.6 \\
46.5 \\
46.5 \\
33.3 \\
44.8\end{array}$ & $\begin{array}{l}43.1 \\
43.1 \\
43.1 \\
43.1 \\
42.8\end{array}$ & $\begin{array}{l}33.9 \\
33.9 \\
33.9 \\
33.9 \\
38.4\end{array}$ & $\begin{array}{l}1.51 \\
2.54 \\
2.43 \\
1.97 \\
2.08\end{array}$ & $\begin{array}{l}0.97 \\
1.87 \\
1.84 \\
1.09 \\
1.70\end{array}$ \\
\hline $\begin{array}{l}405 \\
412 \\
413 \\
414 \\
415\end{array}$ & $\begin{array}{l}2798 \\
3055 \\
2616 \\
2644 \\
1979\end{array}$ & $\begin{array}{r}1590 \\
1895 \\
1418 \\
1430 \\
995\end{array}$ & $\begin{array}{l}43.8 \\
44.9 \\
42.1 \\
44.4 \\
41.5\end{array}$ & $\begin{array}{l}38.7 \\
44.1 \\
38.5 \\
40.0 \\
34.7\end{array}$ & $\begin{array}{l}42.8 \\
44.1 \\
44.1 \\
44.1 \\
44.1\end{array}$ & $\begin{array}{l}38.4 \\
39.6 \\
39.6 \\
39.6 \\
39.6\end{array}$ & $\begin{array}{l}1.49 \\
1.54 \\
1.41 \\
1.35 \\
1.08\end{array}$ & $\begin{array}{l}1.07 \\
1.09 \\
0.93 \\
0.90 \\
0.72\end{array}$ \\
\hline $\begin{array}{l}416 \\
417 \\
419 \\
431 \\
433\end{array}$ & $\begin{array}{l}2680 \\
2352 \\
1527 \\
3487 \\
3920\end{array}$ & $\begin{array}{r}1614 \\
1494 \\
857 \\
2411 \\
2744\end{array}$ & $\begin{array}{l}45.7 \\
42.4 \\
36.4 \\
39.0 \\
39.4\end{array}$ & $\begin{array}{l}41.1 \\
33.6 \\
37.3 \\
35.6 \\
37.4\end{array}$ & $\begin{array}{l}44.1 \\
44.1 \\
44.1 \\
41.6 \\
41.6\end{array}$ & $\begin{array}{l}39.6 \\
39.6 \\
39.6 \\
30.2 \\
30.2\end{array}$ & $\begin{array}{l}1.33 \\
1.26 \\
0.95 \\
2.15 \\
2.39\end{array}$ & $\begin{array}{l}0.99 \\
1.12 \\
0.58 \\
2.24 \\
2.43\end{array}$ \\
\hline $\begin{array}{l}451 \\
452 \\
453 \\
454 \\
455\end{array}$ & $\begin{array}{l}2642 \\
2553 \\
2482 \\
2500 \\
4060\end{array}$ & $\begin{array}{l}1678 \\
1423 \\
1588 \\
1039 \\
2814\end{array}$ & $\begin{array}{l}44.4 \\
44.6 \\
45.5 \\
44.8 \\
48.1\end{array}$ & $\begin{array}{l}40.0 \\
41.5 \\
42.3 \\
41.7 \\
45.2\end{array}$ & $\begin{array}{l}41.3 \\
41.3 \\
41.3 \\
41.3 \\
41.3\end{array}$ & $\begin{array}{l}34.0 \\
34.0 \\
34.0 \\
34.0 \\
34.0\end{array}$ & $\begin{array}{l}1.44 \\
1.39 \\
1.32 \\
1.35 \\
2.04\end{array}$ & $\begin{array}{l}1.23 \\
1.01 \\
1.10 \\
0.73 \\
1.83\end{array}$ \\
\hline $\begin{array}{l}456 \\
457 \\
459 \\
510 \\
520\end{array}$ & $\begin{array}{l}1366 \\
1064 \\
2494 \\
4579 \\
8352\end{array}$ & $\begin{array}{r}964 \\
717 \\
1456 \\
1522 \\
4439\end{array}$ & $\begin{array}{l}24.8 \\
32.0 \\
41.9 \\
48.8 \\
47.8\end{array}$ & $\begin{array}{l}25.5 \\
32.1 \\
36.8 \\
40.1 \\
49.0\end{array}$ & $\begin{array}{l}41.3 \\
41.3 \\
41.3 \\
42.6 \\
40.0\end{array}$ & $\begin{array}{l}34.0 \\
34.0 \\
34.0 \\
39.7 \\
27.9\end{array}$ & $\begin{array}{l}1.33 \\
0.81 \\
1.44 \\
2.20 \\
4.37\end{array}$ & $\begin{array}{l}1.11 \\
0.66 \\
1.16 \\
0.96 \\
3.25\end{array}$ \\
\hline
\end{tabular}


OCCU - ANN. EARNING WEEKS/YEAR HOURS/WEEK HRLY EARNING

PATION MALE FEMALE MALE FEMALE MALE FEMALE MALE FEMALE

\begin{tabular}{|c|c|c|c|c|c|c|c|c|}
\hline $\begin{array}{l}551 \\
552 \\
554 \\
556 \\
581\end{array}$ & $\begin{array}{l}3583 \\
2449 \\
2805 \\
3048 \\
5036\end{array}$ & $\begin{array}{l}1302 \\
1472 \\
1512 \\
2005 \\
2677\end{array}$ & $\begin{array}{l}47.1 \\
43.4 \\
44.3 \\
42.4 \\
46.6\end{array}$ & $\begin{array}{l}38.3 \\
38.4 \\
41.1 \\
40.9 \\
42.4\end{array}$ & $\begin{array}{l}45.1 \\
45.1 \\
45.1 \\
45.1 \\
39.6\end{array}$ & $\begin{array}{l}32.0 \\
32.0 \\
32.0 \\
32.0 \\
37.6\end{array}$ & $\begin{array}{l}1.69 \\
1.25 \\
1.40 \\
1.59 \\
2.73\end{array}$ & $\begin{array}{l}1.06 \\
1.20 \\
1.15 \\
1.53 \\
1.68\end{array}$ \\
\hline $\begin{array}{l}582 \\
584 \\
585 \\
588 \\
603\end{array}$ & $\begin{array}{l}4701 \\
4020 \\
4093 \\
1718 \\
3135\end{array}$ & $\begin{array}{r}2772 \\
2170 \\
2873 \\
777 \\
1546\end{array}$ & $\begin{array}{l}47.5 \\
47.5 \\
48.7 \\
39.5 \\
47.0\end{array}$ & $\begin{array}{l}46.2 \\
44.3 \\
46.5 \\
34.8 \\
39.3\end{array}$ & $\begin{array}{l}39.6 \\
39.6 \\
39.6 \\
39.6 \\
47.9\end{array}$ & $\begin{array}{l}37.6 \\
37.6 \\
37.6 \\
37.6 \\
41.4\end{array}$ & $\begin{array}{l}2.50 \\
2.14 \\
2.12 \\
1.10 \\
1.39\end{array}$ & $\begin{array}{l}1.60 \\
1.30 \\
1.64 \\
0.59 \\
0.95\end{array}$ \\
\hline $\begin{array}{l}605 \\
607 \\
609 \\
613 \\
615\end{array}$ & $\begin{array}{l}1182 \\
1892 \\
1888 \\
2199 \\
1913\end{array}$ & $\begin{array}{r}579 \\
955 \\
1055 \\
935 \\
1321\end{array}$ & $\begin{array}{l}34.2 \\
33.2 \\
33.7 \\
33.5 \\
27.7\end{array}$ & $\begin{array}{l}20.9 \\
28.3 \\
34.1 \\
20.8 \\
22.3\end{array}$ & $\begin{array}{l}47.9 \\
47.9 \\
47.9 \\
48.4 \\
48.4\end{array}$ & $\begin{array}{l}41.4 \\
41.4 \\
41.4 \\
48.5 \\
48.5\end{array}$ & $\begin{array}{l}0.72 \\
1.19 \\
1.17 \\
1.36 \\
1.43\end{array}$ & $\begin{array}{l}0.67 \\
0.82 \\
0.75 \\
0.93 \\
1.22\end{array}$ \\
\hline $\begin{array}{l}631 \\
657 \\
701 \\
702 \\
703\end{array}$ & $\begin{array}{l}1531 \\
3253 \\
2953 \\
2946 \\
3288\end{array}$ & $\begin{array}{r}658 \\
1895 \\
2190 \\
1666 \\
2071\end{array}$ & $\begin{array}{l}25.8 \\
42.0 \\
46.3 \\
46.2 \\
46.7\end{array}$ & $\begin{array}{l}17.6 \\
31.7 \\
47.2 \\
42.3 \\
42.1\end{array}$ & $\begin{array}{l}50.2 \\
42.8 \\
44.3 \\
44.3 \\
44.3\end{array}$ & $\begin{array}{l}41.0 \\
42.1 \\
40.2 \\
40.2 \\
40.2\end{array}$ & $\begin{array}{l}1.18 \\
1.81 \\
1.44 \\
1.44 \\
1.59\end{array}$ & $\begin{array}{l}0.91 \\
1.42 \\
1.15 \\
0.98 \\
1.22\end{array}$ \\
\hline $\begin{array}{l}704 \\
705 \\
706 \\
707 \\
708\end{array}$ & $\begin{array}{l}3472 \\
1428 \\
2541 \\
2925 \\
3213\end{array}$ & $\begin{array}{r}2289 \\
666 \\
1140 \\
1746 \\
1708\end{array}$ & $\begin{array}{l}46.0 \\
30.7 \\
38.6 \\
44.7 \\
46.0\end{array}$ & $\begin{array}{l}41.6 \\
23.4 \\
29.3 \\
40.1 \\
41.4\end{array}$ & $\begin{array}{l}44.3 \\
44.3 \\
44.3 \\
44.3 \\
44.3\end{array}$ & $\begin{array}{l}40.2 \\
40.2 \\
40.2 \\
40.2 \\
40.2\end{array}$ & $\begin{array}{l}1.70 \\
1.05 \\
1.49 \\
1.48 \\
1.58\end{array}$ & $\begin{array}{l}1.37 \\
0.71 \\
0.97 \\
1.08 \\
1.03\end{array}$ \\
\hline $\begin{array}{l}709 \\
711 \\
719 \\
721 \\
722\end{array}$ & $\begin{array}{l}4121 \\
4017 \\
3479 \\
2786 \\
2505\end{array}$ & $\begin{array}{l}2237 \\
2675 \\
2032 \\
1597 \\
1605\end{array}$ & $\begin{array}{l}47.2 \\
46.5 \\
46.8 \\
45.6 \\
44.2\end{array}$ & $\begin{array}{l}41.6 \\
43.6 \\
42.5 \\
41.4 \\
41.8\end{array}$ & $\begin{array}{l}44.3 \\
42.2 \\
42.2 \\
42.9 \\
42.9\end{array}$ & $\begin{array}{l}40.2 \\
42.1 \\
42.1 \\
41.7 \\
41.7\end{array}$ & $\begin{array}{l}1.97 \\
2.05 \\
1.76 \\
1.42 \\
1.32\end{array}$ & $\begin{array}{l}1.34 \\
1.46 \\
1.14 \\
0.93 \\
0.92\end{array}$ \\
\hline $\begin{array}{l}724 \\
729 \\
731 \\
732 \\
733\end{array}$ & $\begin{array}{l}2251 \\
2590 \\
2706 \\
2717 \\
2335\end{array}$ & $\begin{array}{l}1710 \\
1626 \\
1967 \\
1899 \\
1852\end{array}$ & $\begin{array}{l}43.2 \\
45.3 \\
45.6 \\
45.9 \\
42.9\end{array}$ & $\begin{array}{l}39.5 \\
42.2 \\
43.9 \\
42.9 \\
41.8\end{array}$ & $\begin{array}{l}42.9 \\
42.9 \\
43.1 \\
43.1 \\
43.1\end{array}$ & $\begin{array}{l}41.7 \\
41.7 \\
41.1 \\
41.1 \\
41.1\end{array}$ & $\begin{array}{l}1.22 \\
1.33 \\
1.38 \\
1.37 \\
1.26\end{array}$ & $\begin{array}{l}1.04 \\
0.92 \\
1.09 \\
1.08 \\
1.08\end{array}$ \\
\hline $\begin{array}{l}734 \\
735 \\
736 \\
737 \\
738\end{array}$ & $\begin{array}{l}2854 \\
3098 \\
2684 \\
2986 \\
2826\end{array}$ & $\begin{array}{l}1925 \\
2027 \\
1642 \\
1654 \\
1642\end{array}$ & $\begin{array}{l}46.4 \\
47.8 \\
43.5 \\
46.6 \\
45.9\end{array}$ & $\begin{array}{l}43.3 \\
44.6 \\
41.7 \\
42.3 \\
42.0\end{array}$ & $\begin{array}{l}43.1 \\
43.1 \\
43.1 \\
43.1 \\
43.1\end{array}$ & $\begin{array}{ll}4 & 1.1 \\
4 & 1.1 \\
4 & 1.1 \\
4 & 1.1 \\
4 & 1.1\end{array}$ & $\begin{array}{l}1.43 \\
1.50 \\
1.43 \\
1.49 \\
1.43\end{array}$ & $\begin{array}{l}1.08 \\
1.11 \\
0.96 \\
0.95 \\
0.95\end{array}$ \\
\hline
\end{tabular}


OCCU- ANN. EARNING WEERS/YEAR HOURS/WEEK HRLY EARNING

PATION MALE FEMALE MALE FEMALE MALE FEMALE MALE FEMAL

\begin{tabular}{|c|c|c|c|c|c|c|c|c|}
\hline $\begin{array}{l}739 \\
741 \\
742 \\
743 \\
744\end{array}$ & $\begin{array}{l}2786 \\
2967 \\
2638 \\
3331 \\
3005\end{array}$ & $\begin{array}{l}1836 \\
1710 \\
1553 \\
1944 \\
1734\end{array}$ & $\begin{array}{l}46.2 \\
45.8 \\
44.7 \\
44.0 \\
45.7\end{array}$ & $\begin{array}{l}42.9 \\
42.4 \\
42.0 \\
40.7 \\
42.1\end{array}$ & $\begin{array}{l}43.1 \\
41.0 \\
41.0 \\
41.0 \\
41.0\end{array}$ & $\begin{array}{l}41.1 \\
39.6 \\
39.6 \\
39.6 \\
39.6\end{array}$ & $\begin{array}{l}1.40 \\
1.58 \\
1.44 \\
1.85 \\
1.60\end{array}$ & $\begin{array}{l}1.04 \\
1.02 \\
0.93 \\
1.21 \\
1.04\end{array}$ \\
\hline $\begin{array}{l}745 \\
746 \\
747 \\
749 \\
752\end{array}$ & $\begin{array}{l}3222 \\
2701 \\
3187 \\
2748 \\
3012\end{array}$ & $\begin{array}{l}1625 \\
1592 \\
1951 \\
1534 \\
1835\end{array}$ & $\begin{array}{l}46.2 \\
43.6 \\
45.4 \\
44.3 \\
44.6\end{array}$ & $\begin{array}{l}41.2 \\
41.6 \\
41.0 \\
41.3 \\
41.7\end{array}$ & $\begin{array}{l}41.0 \\
41.0 \\
41.0 \\
41.0 \\
43.4\end{array}$ & $\begin{array}{l}39.6 \\
39.6 \\
39.6 \\
39.6 \\
41.6\end{array}$ & $\begin{array}{l}1.70 \\
1.51 \\
1.71 \\
1.51 \\
1.56\end{array}$ & $\begin{array}{l}1.00 \\
0.97 \\
1.20 \\
0.94 \\
1.06\end{array}$ \\
\hline $\begin{array}{l}754 \\
756 \\
758 \\
759 \\
761\end{array}$ & $\begin{array}{l}2602 \\
2826 \\
3324 \\
2800 \\
5131\end{array}$ & $\begin{array}{l}1633 \\
1928 \\
2187 \\
1875 \\
2371\end{array}$ & $\begin{array}{l}38.0 \\
43.2 \\
42.4 \\
42.4 \\
48.9\end{array}$ & $\begin{array}{l}35.2 \\
40.2 \\
40.2 \\
39.5 \\
41.0\end{array}$ & $\begin{array}{l}43.4 \\
43.4 \\
43.4 \\
43.4 \\
40.9\end{array}$ & $\begin{array}{l}41.6 \\
41.6 \\
41.6 \\
41.6 \\
40.6\end{array}$ & $\begin{array}{l}1.58 \\
1.51 \\
1.81 \\
1.52 \\
2.57\end{array}$ & $\begin{array}{l}1.12 \\
1.15 \\
1.31 \\
1.14 \\
1.44\end{array}$ \\
\hline $\begin{array}{l}762 \\
763 \\
766 \\
768 \\
769\end{array}$ & $\begin{array}{l}4019 \\
4236 \\
4079 \\
3902 \\
4161\end{array}$ & $\begin{array}{l}2013 \\
2034 \\
2123 \\
2399 \\
2133\end{array}$ & $\begin{array}{l}46.7 \\
47.0 \\
46.9 \\
47.4 \\
47.5\end{array}$ & $\begin{array}{l}42.8 \\
37.1 \\
43.0 \\
47.3 \\
43.3\end{array}$ & $\begin{array}{l}40.9 \\
40.9 \\
40.9 \\
40.9 \\
40.9\end{array}$ & $\begin{array}{l}40.3 \\
40.3 \\
40.3 \\
40.3 \\
40.3\end{array}$ & $\begin{array}{l}2.10 \\
2.20 \\
2.13 \\
2.01 \\
2.14\end{array}$ & $\begin{array}{l}1.17 \\
1.36 \\
1.23 \\
1.26 \\
1.22\end{array}$ \\
\hline $\begin{array}{l}771 \\
772 \\
773 \\
775 \\
776\end{array}$ & $\begin{array}{l}4206 \\
4359 \\
4873 \\
5876 \\
4055\end{array}$ & $\begin{array}{l}2331 \\
2166 \\
2333 \\
2029 \\
1987\end{array}$ & $\begin{array}{l}48.0 \\
48.2 \\
48.3 \\
48.7 \\
47.7\end{array}$ & $\begin{array}{l}44.3 \\
45.1 \\
43.4 \\
41.8 \\
43.2\end{array}$ & $\begin{array}{l}39.6 \\
39.6 \\
39.6 \\
39.6 \\
39.6\end{array}$ & $\begin{array}{l}38.0 \\
38.0 \\
38.0 \\
38.0 \\
38.0\end{array}$ & $\begin{array}{l}2.21 \\
2.28 \\
2.55 \\
3.05 \\
2.15\end{array}$ & $\begin{array}{l}1.39 \\
1.26 \\
1.42 \\
1.28 \\
1.21\end{array}$ \\
\hline $\begin{array}{l}778 \\
779 \\
781 \\
782 \\
786\end{array}$ & $\begin{array}{l}3722 \\
4376 \\
4416 \\
4331 \\
3682\end{array}$ & $\begin{array}{l}1923 \\
1951 \\
2182 \\
2812 \\
2182\end{array}$ & $\begin{array}{l}46.0 \\
48.0 \\
47.2 \\
47.2 \\
45.5\end{array}$ & $\begin{array}{l}42.8 \\
43.2 \\
39.9 \\
45.0 \\
41.0\end{array}$ & $\begin{array}{l}39.6 \\
39.6 \\
41.0 \\
41.0 \\
41.0\end{array}$ & $\begin{array}{l}38.0 \\
38.0 \\
40.3 \\
40.3 \\
40.3\end{array}$ & $\begin{array}{l}2.04 \\
2.30 \\
2.28 \\
2.24 \\
1.97\end{array}$ & $\begin{array}{l}1.18 \\
1.19 \\
1.36 \\
1.55 \\
1.32\end{array}$ \\
\hline $\begin{array}{l}787 \\
788 \\
789 \\
791 \\
793\end{array}$ & $\begin{array}{l}3645 \\
3901 \\
4069 \\
3420 \\
4230\end{array}$ & $\begin{array}{l}2444 \\
2552 \\
2321 \\
1713 \\
2253\end{array}$ & $\begin{array}{l}45.6 \\
46.5 \\
45.6 \\
47.2 \\
47.9\end{array}$ & $\begin{array}{l}41.5 \\
42.6 \\
42.1 \\
42.4 \\
44.9\end{array}$ & $\begin{array}{l}41.0 \\
41.0 \\
41.0 \\
41.7 \\
41.7\end{array}$ & $\begin{array}{l}40.3 \\
40.3 \\
40.3 \\
38.8 \\
38.8\end{array}$ & $\begin{array}{l}1.95 \\
2.05 \\
2.18 \\
1.74 \\
2.12\end{array}$ & $\begin{array}{l}1.46 \\
1.49 \\
1.37 \\
1.04 \\
1.29\end{array}$ \\
\hline $\begin{array}{l}801 \\
803 \\
806 \\
808 \\
811\end{array}$ & $\begin{array}{l}4484 \\
3762 \\
3598 \\
3633 \\
3640\end{array}$ & $\begin{array}{l}2472 \\
1961 \\
2439 \\
2277 \\
1921\end{array}$ & $\begin{array}{l}47.3 \\
45.0 \\
44.3 \\
44.9 \\
44.1\end{array}$ & $\begin{array}{l}42.3 \\
39.5 \\
41.9 \\
42.0 \\
38.1\end{array}$ & $\begin{array}{l}41.4 \\
41.4 \\
41.4 \\
41.4 \\
41.4\end{array}$ & $\begin{array}{l}40.4 \\
40.4 \\
40.4 \\
40.4 \\
40.4\end{array}$ & $\begin{array}{l}2.29 \\
2.02 \\
1.96 \\
1.95 \\
1.99\end{array}$ & $\begin{array}{l}1.45 \\
1.23 \\
1.44 \\
1.34 \\
1.25\end{array}$ \\
\hline
\end{tabular}


OCCU - ANN. EARNING WEEKS/YEAR HOURS/WEEK HRLY EARING PATION MALE FEMALE MALE FEMALE MALE FEMALE MALE FEMALE

\begin{tabular}{|c|c|c|c|c|c|c|c|}
\hline $\begin{array}{l}812 \\
815 \\
817 \\
818 \\
819\end{array}$ & $\begin{array}{l}3251 \\
3524 \\
3807 \\
3369 \\
3513\end{array}$ & $\begin{array}{l}1907 \\
1991 \\
2354 \\
2147 \\
2413\end{array}$ & $\begin{array}{l}41.3 \\
45.9 \\
44.1 \\
44.8 \\
44.3\end{array}$ & $\begin{array}{l}38.4 \\
42.1 \\
41.9 \\
41.3 \\
42.8\end{array}$ & $\begin{array}{l}41.4 \\
41.4 \\
41.4 \\
41.4 \\
41.4\end{array}$ & $\begin{array}{l}40.4 \\
40.4 \\
40.4 \\
40.4 \\
40.4\end{array}$ & $\begin{array}{l}1.90 \\
1.86 \\
2.09 \\
1.82 \\
1.92\end{array}$ \\
\hline $\begin{array}{l}821 \\
822 \\
824 \\
829 \\
831\end{array}$ & $\begin{array}{l}4439 \\
3279 \\
3845 \\
3812 \\
4140\end{array}$ & $\begin{array}{l}2866 \\
2300 \\
2892 \\
2005 \\
2963\end{array}$ & $\begin{array}{l}48.1 \\
45.4 \\
47.8 \\
46.2 \\
45.7\end{array}$ & $\begin{array}{l}48.7 \\
42.2 \\
46.2 \\
43.3 \\
44.1\end{array}$ & $\begin{array}{l}43.8 \\
43.8 \\
43.8 \\
43.8 \\
41.3\end{array}$ & $\begin{array}{l}37.6 \\
37.6 \\
37.6 \\
37.6 \\
40.2\end{array}$ & $\begin{array}{l}2.11 \\
1.65 \\
1.84 \\
1.88 \\
2.19\end{array}$ \\
\hline $\begin{array}{l}832 \\
835 \\
836 \\
839 \\
841\end{array}$ & $\begin{array}{l}3753 \\
3357 \\
3779 \\
3454 \\
2751\end{array}$ & $\begin{array}{l}2411 \\
2527 \\
2175 \\
2324 \\
1508\end{array}$ & $\begin{array}{l}46.1 \\
45.6 \\
46.5 \\
44.9 \\
37.6\end{array}$ & $\begin{array}{l}42.8 \\
46.6 \\
44.7 \\
43.0 \\
33.4\end{array}$ & $\begin{array}{l}41.3 \\
41.3 \\
41.3 \\
41.3 \\
41.5\end{array}$ & $\begin{array}{l}40.2 \\
40.2 \\
40.2 \\
40.2 \\
38.9\end{array}$ & $\begin{array}{l}1.97 \\
1.78 \\
1.97 \\
1.86 \\
1.76\end{array}$ \\
\hline $\begin{array}{l}843 \\
854 \\
859 \\
861 \\
862\end{array}$ & $\begin{array}{l}3315 \\
3050 \\
2685 \\
3458 \\
3463\end{array}$ & $\begin{array}{l}1850 \\
1786 \\
1456 \\
2171 \\
2015\end{array}$ & $\begin{array}{l}44.1 \\
36.9 \\
36.2 \\
47.8 \\
43.9\end{array}$ & $\begin{array}{l}41.7 \\
28.5 \\
29.4 \\
45.4 \\
41.0\end{array}$ & $\begin{array}{l}41.5 \\
42.9 \\
42.9 \\
42.3 \\
42.3\end{array}$ & $\begin{array}{l}38.9 \\
40.5 \\
40.5 \\
40.6 \\
40.6\end{array}$ & $\begin{array}{l}1.81 \\
1.93 \\
1.73 \\
1.71 \\
1.86\end{array}$ \\
\hline $\begin{array}{l}864 \\
869 \\
877 \\
900 \\
911\end{array}$ & $\begin{array}{l}2743 \\
3390 \\
3284 \\
4970 \\
3442\end{array}$ & $\begin{array}{l}1911 \\
2147 \\
2086 \\
2765 \\
2795\end{array}$ & $\begin{array}{l}39.7 \\
45.2 \\
41.9 \\
49.1 \\
45.6\end{array}$ & $\begin{array}{l}38.7 \\
41.3 \\
39.4 \\
48.0 \\
44.6\end{array}$ & $\begin{array}{l}42.3 \\
42.3 \\
44.3 \\
41.6 \\
41.6\end{array}$ & $\begin{array}{l}40.6 \\
40.6 \\
43.5 \\
39.4 \\
39.4\end{array}$ & $\begin{array}{l}1.63 \\
1.77 \\
1.77 \\
2.43 \\
1.82\end{array}$ \\
\hline $\begin{array}{l}912 \\
913 \\
914 \\
915 \\
916\end{array}$ & $\begin{array}{l}4244 \\
2595 \\
3416 \\
3312 \\
3116\end{array}$ & $\begin{array}{l}2352 \\
1652 \\
1937 \\
1939 \\
1864\end{array}$ & $\begin{array}{l}47.1 \\
41.9 \\
46.2 \\
45.7 \\
46.0\end{array}$ & $\begin{array}{l}42.3 \\
39.5 \\
43.0 \\
42.9 \\
41.8\end{array}$ & $\begin{array}{l}41.6 \\
41.6 \\
41.6 \\
41.6 \\
41.6\end{array}$ & $\begin{array}{l}39.4 \\
39.4 \\
39.4 \\
39.4 \\
39.4\end{array}$ & $\begin{array}{l}2.17 \\
1.49 \\
1.78 \\
1.74 \\
1.63\end{array}$ \\
\hline $\begin{array}{l}917 \\
918 \\
919 \\
920\end{array}$ & $\begin{array}{l}4286 \\
3682 \\
3038 \\
2156\end{array}$ & $\begin{array}{l}2663 \\
1494 \\
1784 \\
1449\end{array}$ & $\begin{array}{l}47.4 \\
45.3 \\
44.1 \\
35.5\end{array}$ & $\begin{array}{l}44.9 \\
39.6 \\
40.8 \\
37.4\end{array}$ & $\begin{array}{l}41.6 \\
41.6 \\
41.6 \\
41.8\end{array}$ & $\begin{array}{l}39.4 \\
39.4 \\
39.4 \\
37.8\end{array}$ & $\begin{array}{l}2.17 \\
1.95 \\
1.66 \\
1.45\end{array}$ \\
\hline
\end{tabular}




\begin{tabular}{|c|c|c|c|c|c|c|c|}
\hline $\begin{array}{l}\text { CCU- } \\
\text { ATION }\end{array}$ & $\begin{array}{c}\text { WAGE-EA } \\
\text { MALE }\end{array}$ & $\begin{array}{l}\text { RNERS } \\
\text { FEMALE }\end{array}$ & $\begin{array}{c}\text { EMPLOYMEN } \\
\text { UNADJ. }\end{array}$ & $\begin{array}{l}\text { XT RATIO } \\
\text { ADJUSTED }\end{array}$ & MALE & $\begin{array}{c}\text { AGE } \\
\text { FEMALE }\end{array}$ & R AT IO \\
\hline $\begin{array}{r}1 \\
4 \\
6 \\
8 \\
10\end{array}$ & $\begin{array}{r}2175 \\
22589 \\
11946 \\
13005 \\
194985\end{array}$ & $\begin{array}{r}193 \\
610 \\
2847 \\
1500 \\
13760\end{array}$ & $\begin{array}{r}11.269 \\
37.031 \\
4.195 \\
8.671 \\
14.170\end{array}$ & $\begin{array}{r}12.547 \\
41.572 \\
4.565 \\
9.398 \\
15.914\end{array}$ & $\begin{array}{l}39 \\
41 \\
41 \\
41 \\
45\end{array}$ & $\begin{array}{l}40 \\
42 \\
42 \\
43 \\
47\end{array}$ & $\begin{array}{l}0.97 \\
0.98 \\
0.98 \\
0.95 \\
0.96\end{array}$ \\
\hline $\begin{array}{l}101 \\
102 \\
105 \\
108 \\
109\end{array}$ & $\begin{array}{r}11086 \\
7923 \\
8564 \\
2937 \\
4592\end{array}$ & $\begin{array}{l}24 \\
15 \\
39 \\
13 \\
13\end{array}$ & $\begin{array}{l}443.440 \\
528.267 \\
214.125 \\
209.786 \\
353.231\end{array}$ & $\begin{array}{l}482.750 \\
615.744 \\
247.873 \\
226.327 \\
399.533\end{array}$ & $\begin{array}{l}37 \\
38 \\
37 \\
35 \\
39\end{array}$ & $\begin{array}{l}34 \\
36 \\
31 \\
34 \\
33\end{array}$ & $\begin{array}{l}1.09 \\
1.06 \\
1.19 \\
1.03 \\
1.18\end{array}$ \\
\hline $\begin{array}{l}111 \\
114 \\
119 \\
121 \\
124\end{array}$ & $\begin{array}{r}5593 \\
661 \\
1357 \\
1373 \\
712\end{array}$ & $\begin{array}{r}433 \\
24 \\
69 \\
267 \\
10\end{array}$ & $\begin{array}{r}12.919 \\
26.440 \\
19.681 \\
5.146 \\
64.818\end{array}$ & $\begin{array}{r}15.238 \\
26.929 \\
23.563 \\
6.017 \\
80.725\end{array}$ & $\begin{array}{l}37 \\
35 \\
36 \\
37 \\
40\end{array}$ & $\begin{array}{l}32 \\
35 \\
34 \\
34 \\
36\end{array}$ & $\begin{array}{l}1.16 \\
1.00 \\
1.06 \\
1.09 \\
1.11\end{array}$ \\
\hline $\begin{array}{l}129 \\
131 \\
135 \\
139 \\
140\end{array}$ & $\begin{array}{r}2623 \\
7256 \\
46878 \\
4821 \\
7112\end{array}$ & $\begin{array}{r}61 \\
1213 \\
108406 \\
4048 \\
933\end{array}$ & $\begin{array}{r}42.323 \\
5.978 \\
0.432 \\
1.191 \\
7.623\end{array}$ & $\begin{array}{r}53.359 \\
7.016 \\
0.501 \\
1.436 \\
9.158\end{array}$ & $\begin{array}{l}40 \\
40 \\
36 \\
40 \\
42\end{array}$ & $\begin{array}{l}33 \\
42 \\
36 \\
40 \\
38\end{array}$ & $\begin{array}{l}1.21 \\
0.95 \\
1.00 \\
1.00 \\
1.11\end{array}$ \\
\hline $\begin{array}{l}141 \\
142 \\
143 \\
144 \\
145\end{array}$ & $\begin{array}{r}449 \\
2255 \\
236 \\
445 \\
183\end{array}$ & $\begin{array}{r}166 \\
54759 \\
10671 \\
1842 \\
17\end{array}$ & $\begin{array}{r}2.711 \\
0.041 \\
0.022 \\
0.242 \\
10.167\end{array}$ & $\begin{array}{r}3.203 \\
0.052 \\
0.023 \\
0.308 \\
14.289\end{array}$ & $\begin{array}{l}46 \\
39 \\
24 \\
44 \\
44\end{array}$ & $\begin{array}{l}36 \\
36 \\
20 \\
35 \\
40\end{array}$ & $\begin{array}{l}1.28 \\
1.08 \\
1.20 \\
1.26 \\
1.10\end{array}$ \\
\hline $\begin{array}{l}146 \\
147 \\
148 \\
153 \\
171\end{array}$ & $\begin{array}{r}43 \\
3479 \\
4017 \\
3595 \\
3496\end{array}$ & $\begin{array}{r}35 \\
785 \\
8748 \\
181 \\
735\end{array}$ & $\begin{array}{r}1.257 \\
4.433 \\
0.459 \\
19.758 \\
4.758\end{array}$ & $\begin{array}{r}1.534 \\
5.512 \\
0.539 \\
22.302 \\
6.383\end{array}$ & $\begin{array}{l}42 \\
43 \\
36 \\
42 \\
36\end{array}$ & $\begin{array}{l}47 \\
38 \\
29 \\
40 \\
33\end{array}$ & $\begin{array}{l}0.89 \\
1.13 \\
1.24 \\
1.05 \\
1.09\end{array}$ \\
\hline $\begin{array}{l}172 \\
174 \\
176 \\
182 \\
183\end{array}$ & $\begin{array}{r}870 \\
8817 \\
3102 \\
19554 \\
7977\end{array}$ & $\begin{array}{r}438 \\
2998 \\
3105 \\
852 \\
56\end{array}$ & $\begin{array}{r}1.989 \\
2.940 \\
0.999 \\
22.924 \\
142.446\end{array}$ & $\begin{array}{r}2.702 \\
3.907 \\
1.285 \\
25.562 \\
184.929\end{array}$ & $\begin{array}{l}41 \\
39 \\
38 \\
33 \\
30\end{array}$ & $\begin{array}{l}45 \\
39 \\
44 \\
32 \\
36\end{array}$ & $\begin{array}{l}0.91 \\
1.00 \\
0.86 \\
1.03 \\
0.83\end{array}$ \\
\hline $\begin{array}{l}186 \\
188 \\
191 \\
192 \\
195\end{array}$ & $\begin{array}{r}1895 \\
24869 \\
64 \\
4944 \\
2050\end{array}$ & $\begin{array}{r}262 \\
1394 \\
1779 \\
5262 \\
1364\end{array}$ & $\begin{array}{r}7.233 \\
17.841 \\
0.036 \\
0.940 \\
1.504\end{array}$ & $\begin{array}{r}8.962 \\
19.860 \\
0.042 \\
1.060 \\
1.776\end{array}$ & $\begin{array}{l}37 \\
40 \\
42 \\
39 \\
35\end{array}$ & $\begin{array}{l}34 \\
41 \\
37 \\
39 \\
37\end{array}$ & $\begin{array}{l}1.09 \\
0.98 \\
1.14 \\
1.00 \\
0.95\end{array}$ \\
\hline
\end{tabular}




\begin{tabular}{|c|c|c|c|c|c|c|c|}
\hline 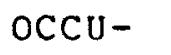 & WAGE- & RNERS & EMPLOYMEN & TT RATIO & & AGE & \\
\hline ATION & MALE & FEMALE & UNADJ & ADJUSTED & MALE & FEMALE & RATIO \\
\hline $\begin{array}{l}196 \\
198 \\
199 \\
201 \\
203\end{array}$ & $\begin{array}{r}1984 \\
35557 \\
22369 \\
58169 \\
5991\end{array}$ & $\begin{array}{r}226 \\
3904 \\
7010 \\
94755 \\
22335\end{array}$ & $\begin{array}{l}8.779 \\
9.108 \\
3.191 \\
0.614 \\
0.268\end{array}$ & $\begin{array}{r}9.968 \\
10.014 \\
3.669 \\
0.712 \\
0.308\end{array}$ & $\begin{array}{l}37 \\
33 \\
39 \\
35 \\
30\end{array}$ & $\begin{array}{l}38 \\
32 \\
39 \\
33 \\
30\end{array}$ & $\begin{array}{l}0.97 \\
1.03 \\
1.00 \\
1.06 \\
1.00\end{array}$ \\
\hline $\begin{array}{l}212 \\
214 \\
223 \\
232 \\
234\end{array}$ & $\begin{array}{r}32994 \\
52341 \\
7225 \\
4494 \\
2307\end{array}$ & $\begin{array}{r}3756 \\
3725 \\
1312 \\
159169 \\
48535\end{array}$ & $\begin{array}{r}8.782 \\
14.048 \\
5.507 \\
0.028 \\
0.048\end{array}$ & $\begin{array}{r}10.150 \\
16.350 \\
6.357 \\
0.032 \\
0.055\end{array}$ & $\begin{array}{l}38 \\
37 \\
40 \\
40 \\
29\end{array}$ & $\begin{array}{l}38 \\
35 \\
32 \\
32 \\
28\end{array}$ & $\begin{array}{l}1.00 \\
1.06 \\
1.25 \\
1.25 \\
1.04\end{array}$ \\
\hline $\begin{array}{l}241 \\
249 \\
307 \\
312 \\
314\end{array}$ & $\begin{array}{r}132 \\
157113 \\
6991 \\
398 \\
67651\end{array}$ & $\begin{array}{r}3678 \\
162981 \\
4109 \\
37 \\
815\end{array}$ & $\begin{array}{r}0.036 \\
0.964 \\
1.702 \\
10.757 \\
82.906\end{array}$ & $\begin{array}{r}0.036 \\
1.110 \\
2.932 \\
17.472 \\
121.835\end{array}$ & $\begin{array}{l}31 \\
36 \\
40 \\
43 \\
39\end{array}$ & $\begin{array}{l}33 \\
34 \\
40 \\
40 \\
40\end{array}$ & $\begin{array}{l}0.94 \\
1.06 \\
1.00 \\
1.07 \\
0.97\end{array}$ \\
\hline $\begin{array}{l}325 \\
331 \\
338 \\
339 \\
403\end{array}$ & $\begin{array}{r}94475 \\
22632 \\
4913 \\
143 \\
29576\end{array}$ & $\begin{array}{r}120542 \\
1444 \\
550 \\
804 \\
369\end{array}$ & $\begin{array}{r}0.784 \\
15.662 \\
8.933 \\
0.178 \\
80.152\end{array}$ & $\begin{array}{r}1.120 \\
20.641 \\
11.723 \\
0.273 \\
96.714\end{array}$ & $\begin{array}{l}34 \\
39 \\
40 \\
35 \\
36\end{array}$ & $\begin{array}{l}37 \\
40 \\
39 \\
40 \\
39\end{array}$ & $\begin{array}{l}0.92 \\
0.97 \\
1.03 \\
0.88 \\
0.92\end{array}$ \\
\hline $\begin{array}{l}405 \\
412 \\
413 \\
414 \\
415\end{array}$ & $\begin{array}{r}33559 \\
3949 \\
23934 \\
9043 \\
16455\end{array}$ & $\begin{array}{r}1194 \\
9920 \\
20496 \\
246 \\
59423\end{array}$ & $\begin{array}{r}28.107 \\
0.398 \\
1.168 \\
36.615 \\
0.277\end{array}$ & $\begin{array}{r}35.456 \\
0.451 \\
1.422 \\
45.262 \\
0.369\end{array}$ & $\begin{array}{l}52 \\
44 \\
40 \\
40 \\
35\end{array}$ & $\begin{array}{l}42 \\
45 \\
43 \\
34 \\
32\end{array}$ & $\begin{array}{l}1.24 \\
0.98 \\
0.93 \\
1.18 \\
1.09\end{array}$ \\
\hline $\begin{array}{l}416 \\
417 \\
419 \\
431 \\
433\end{array}$ & $\begin{array}{r}13062 \\
5067 \\
15980 \\
1024 \\
2442\end{array}$ & $\begin{array}{r}46899 \\
64 \\
114876 \\
787 \\
943\end{array}$ & $\begin{array}{r}0.279 \\
79.187 \\
0.139 \\
1.299 \\
2.590\end{array}$ & $\begin{array}{r}0.345 \\
111.282 \\
0.151 \\
1.961 \\
3.758\end{array}$ & $\begin{array}{l}39 \\
37 \\
36 \\
36 \\
32\end{array}$ & $\begin{array}{l}36 \\
41 \\
39 \\
32 \\
29\end{array}$ & $\begin{array}{l}1.08 \\
0.90 \\
0.92 \\
1.13 \\
1.10\end{array}$ \\
\hline $\begin{array}{l}451 \\
452 \\
453 \\
454 \\
455\end{array}$ & $\begin{array}{r}7321 \\
7793 \\
3842 \\
67669 \\
1472\end{array}$ & $\begin{array}{r}13647 \\
21401 \\
1404 \\
30533 \\
21\end{array}$ & $\begin{array}{r}0.536 \\
0.364 \\
2.736 \\
2.216 \\
70.095\end{array}$ & $\begin{array}{r}0.723 \\
0.475 \\
3.575 \\
2.892 \\
90.608\end{array}$ & $\begin{array}{l}43 \\
38 \\
49 \\
49 \\
42\end{array}$ & $\begin{array}{l}32 \\
37 \\
33 \\
45 \\
52\end{array}$ & $\begin{array}{l}1.34 \\
1.03 \\
1.48 \\
1.09 \\
0.81\end{array}$ \\
\hline $\begin{array}{l}456 \\
457 \\
459 \\
510 \\
520\end{array}$ & $\begin{array}{r}2545 \\
4041 \\
3201 \\
17735 \\
2649\end{array}$ & $\begin{array}{r}135 \\
930 \\
2152 \\
410 \\
4\end{array}$ & $\begin{array}{r}18.721 \\
4.342 \\
1.487 \\
43.256 \\
530.000\end{array}$ & $\begin{array}{r}22.116 \\
5.257 \\
2.056 \\
56.486 \\
741.248\end{array}$ & $\begin{array}{l}38 \\
30 \\
40 \\
43 \\
35\end{array}$ & $\begin{array}{l}28 \\
27 \\
40 \\
39 \\
32\end{array}$ & $\begin{array}{l}1.36 \\
1.11 \\
1.00 \\
1.10 \\
1.09\end{array}$ \\
\hline
\end{tabular}




\begin{tabular}{|c|c|c|c|c|c|c|c|}
\hline $\mathrm{CO}-$ & WAGE-EA & ERS & PLCYM & RATIO & & $A G E$ & \\
\hline ATION & MALE & FEMAIE & UNADJ. & ADJUSTED & MALE & FEMALE & RATIO \\
\hline $\begin{array}{l}551 \\
552 \\
554 \\
556 \\
581\end{array}$ & $\begin{array}{r}17281 \\
13553 \\
48223 \\
143305 \\
1529\end{array}$ & $\begin{array}{l}439 \\
240 \\
373 \\
279 \\
105\end{array}$ & $\begin{array}{r}39.367 \\
56.241 \\
129.284 \\
511.807 \\
14.562\end{array}$ & $\begin{array}{r}68.230 \\
89.585 \\
196.397 \\
747.783 \\
16.856\end{array}$ & $\begin{array}{l}41 \\
41 \\
32 \\
35 \\
29\end{array}$ & $\begin{array}{l}40 \\
40 \\
34 \\
33 \\
33\end{array}$ & $\begin{array}{l}1.02 \\
1.02 \\
0.94 \\
1.06 \\
0.88\end{array}$ \\
\hline $\begin{array}{l}582 \\
584 \\
585 \\
588 \\
603\end{array}$ & $\begin{array}{l}3335 \\
1685 \\
3918 \\
6371 \\
3048\end{array}$ & $\begin{array}{r}157 \\
33466 \\
455 \\
639 \\
57\end{array}$ & $\begin{array}{r}21.242 \\
0.050 \\
8.594 \\
9.956 \\
53.474\end{array}$ & $\begin{array}{r}23.001 \\
0.057 \\
9.480 \\
11.902 \\
73.991\end{array}$ & $\begin{array}{l}33 \\
40 \\
36 \\
32 \\
43\end{array}$ & $\begin{array}{l}33 \\
33 \\
38 \\
21 \\
44\end{array}$ & $\begin{array}{l}1.00 \\
1.21 \\
0.95 \\
1.52 \\
0.98\end{array}$ \\
\hline $\begin{array}{l}605 \\
607 \\
609 \\
613 \\
615\end{array}$ & $\begin{array}{r}82207 \\
21597 \\
4154 \\
7539 \\
63162\end{array}$ & $\begin{array}{r}8496 \\
221 \\
208 \\
15 \\
78\end{array}$ & $\begin{array}{r}9.676 \\
97.724 \\
19.876 \\
502.667 \\
799.531\end{array}$ & $\begin{array}{r}18.320 \\
132.644 \\
22.726 \\
807.914 \\
991.092\end{array}$ & $\begin{array}{l}30 \\
43 \\
37 \\
38 \\
34\end{array}$ & $\begin{array}{l}40 \\
45 \\
39 \\
34 \\
31\end{array}$ & $\begin{array}{l}0.75 \\
0.96 \\
0.95 \\
1.12 \\
1.10\end{array}$ \\
\hline $\begin{array}{l}631 \\
657 \\
701 \\
702 \\
703\end{array}$ & $\begin{array}{r}10286 \\
14876 \\
2039 \\
9991 \\
19292\end{array}$ & $\begin{array}{r}147 \\
19 \\
10 \\
1819 \\
593\end{array}$ & $\begin{array}{r}69.973 \\
743.850 \\
185.455 \\
5.490 \\
32.478\end{array}$ & $\begin{array}{r}125.590 \\
1001.929 \\
200.472 \\
6.608 \\
39.701\end{array}$ & $\begin{array}{l}39 \\
36 \\
39 \\
37 \\
38\end{array}$ & $\begin{array}{l}37 \\
32 \\
35 \\
37 \\
34\end{array}$ & $\begin{array}{l}1.05 \\
1.13 \\
1.11 \\
1.00 \\
1.12\end{array}$ \\
\hline $\begin{array}{l}704 \\
705 \\
706 \\
707 \\
708\end{array}$ & $\begin{array}{l}2828 \\
6071 \\
1494 \\
5755 \\
5369\end{array}$ & $\begin{array}{r}2970 \\
4529 \\
2059 \\
337 \\
3369\end{array}$ & $\begin{array}{r}0.952 \\
1.341 \\
0.726 \\
17.027 \\
1.594\end{array}$ & $\begin{array}{r}1.160 \\
1.938 \\
1.053 \\
20.916 \\
1.951\end{array}$ & $\begin{array}{l}37 \\
36 \\
37 \\
35 \\
38\end{array}$ & $\begin{array}{l}32 \\
34 \\
39 \\
33 \\
34\end{array}$ & $\begin{array}{l}1.16 \\
1.06 \\
0.95 \\
1.06 \\
1.12\end{array}$ \\
\hline $\begin{array}{l}709 \\
711 \\
719 \\
721 \\
722\end{array}$ & $\begin{array}{l}2866 \\
2538 \\
3661 \\
2246 \\
5725\end{array}$ & $\begin{array}{r}234 \\
181 \\
1862 \\
439 \\
7020\end{array}$ & $\begin{array}{r}12.252 \\
13.945 \\
1.967 \\
5.105 \\
0.816\end{array}$ & $\begin{array}{r}15.319 \\
14.908 \\
2.171 \\
5.784 \\
0.887\end{array}$ & $\begin{array}{l}39 \\
39 \\
38 \\
38 \\
33\end{array}$ & $\begin{array}{l}36 \\
39 \\
34 \\
31 \\
32\end{array}$ & $\begin{array}{l}1.08 \\
1.00 \\
1.12 \\
1.23 \\
1.03\end{array}$ \\
\hline $\begin{array}{l}724 \\
729 \\
731 \\
732 \\
733\end{array}$ & $\begin{array}{r}1362 \\
1190 \\
1331 \\
1901 \\
751\end{array}$ & $\begin{array}{r}32 \\
2088 \\
334 \\
1862 \\
2034\end{array}$ & $\begin{array}{r}42.563 \\
0.570 \\
3.973 \\
1.020 \\
0.370\end{array}$ & $\begin{array}{r}47.889 \\
0.630 \\
4.328 \\
1.145 \\
0.398\end{array}$ & $\begin{array}{l}48 \\
39 \\
39 \\
34 \\
30\end{array}$ & $\begin{array}{l}45 \\
34 \\
35 \\
32 \\
35\end{array}$ & $\begin{array}{l}1.07 \\
1.15 \\
1.11 \\
1.06 \\
0.86\end{array}$ \\
\hline $\begin{array}{l}734 \\
735 \\
736 \\
737 \\
738\end{array}$ & $\begin{array}{l}3206 \\
1453 \\
1946 \\
1821 \\
1689\end{array}$ & $\begin{array}{r}1246 \\
276 \\
3774 \\
116 \\
718\end{array}$ & $\begin{array}{r}2.574 \\
5.264 \\
0.516 \\
15.564 \\
2.350\end{array}$ & $\begin{array}{r}2.892 \\
5.917 \\
0.564 \\
17.981 \\
2.694\end{array}$ & $\begin{array}{l}35 \\
39 \\
33 \\
38 \\
36\end{array}$ & $\begin{array}{l}34 \\
35 \\
33 \\
32 \\
34\end{array}$ & $\begin{array}{l}1.03 \\
1.11 \\
1.00 \\
1.19 \\
1.06\end{array}$ \\
\hline
\end{tabular}




\begin{tabular}{|c|c|c|c|c|c|c|c|}
\hline $\begin{array}{l}\text { OCCU - } \\
\text { PATION }\end{array}$ & $\begin{array}{c}\text { WAGE-EA } \\
\text { MALE }\end{array}$ & $\begin{array}{l}\text { RNERS } \\
\text { FEMALE }\end{array}$ & $\begin{array}{l}\text { EMPLO YMED } \\
\text { UNADJ. }\end{array}$ & $\begin{array}{c}\text { RATIO } \\
\text { DJUSTED }\end{array}$ & MALE & $\begin{array}{c}\text { AGE } \\
\text { FEMALE }\end{array}$ & RATIO \\
\hline $\begin{array}{l}739 \\
741 \\
742 \\
743 \\
744\end{array}$ & $\begin{array}{r}5003 \\
4288 \\
545 \\
2383 \\
152\end{array}$ & $\begin{array}{r}4041 \\
866 \\
10312 \\
1748 \\
717\end{array}$ & $\begin{array}{l}1.238 \\
4.947 \\
0.053 \\
1.363 \\
0.212\end{array}$ & $\begin{array}{l}1.398 \\
5.533 \\
0.058 \\
1.526 \\
0.238\end{array}$ & $\begin{array}{l}36 \\
44 \\
44 \\
41 \\
44\end{array}$ & $\begin{array}{l}33 \\
43 \\
46 \\
42 \\
44\end{array}$ & $\begin{array}{l}1.09 \\
1.02 \\
0.96 \\
0.98 \\
1.00\end{array}$ \\
\hline $\begin{array}{l}745 \\
746 \\
747 \\
749 \\
752\end{array}$ & $\begin{array}{l}4887 \\
5211 \\
4484 \\
4451 \\
7036\end{array}$ & $\begin{array}{r}1614 \\
50363 \\
299 \\
5928 \\
183\end{array}$ & $\begin{array}{r}3.028 \\
0.103 \\
14.997 \\
0.751 \\
38.448\end{array}$ & $\begin{array}{r}3.515 \\
0.112 \\
17.193 \\
0.834 \\
42.901\end{array}$ & $\begin{array}{l}38 \\
40 \\
37 \\
39 \\
39\end{array}$ & $\begin{array}{l}34 \\
34 \\
36 \\
35 \\
36\end{array}$ & $\begin{array}{l}1.12 \\
1.18 \\
1.03 \\
1.11 \\
1.08\end{array}$ \\
\hline $\begin{array}{l}754 \\
756 \\
758 \\
759 \\
761\end{array}$ & $\begin{array}{r}12131 \\
9262 \\
6225 \\
10866 \\
1376\end{array}$ & $\begin{array}{r}92 \\
742 \\
221 \\
1072 \\
24\end{array}$ & $\begin{array}{r}130.452 \\
12.467 \\
28.172 \\
10.128 \\
55.040\end{array}$ & $\begin{array}{r}146.922 \\
13.977 \\
30.999 \\
11.342 \\
66.623\end{array}$ & $\begin{array}{l}38 \\
38 \\
39 \\
38 \\
39\end{array}$ & $\begin{array}{l}31 \\
32 \\
30 \\
32 \\
37\end{array}$ & $\begin{array}{l}1.23 \\
1.19 \\
1.30 \\
1.19 \\
1.05\end{array}$ \\
\hline $\begin{array}{l}762 \\
763 \\
766 \\
768 \\
769\end{array}$ & $\begin{array}{r}1395 \\
3621 \\
11116 \\
1071 \\
13383\end{array}$ & $\begin{array}{r}21 \\
61 \\
796 \\
19 \\
1989\end{array}$ & $\begin{array}{r}63.455 \\
58.403 \\
13.949 \\
53.600 \\
6.729\end{array}$ & $\begin{array}{r}70.267 \\
75.089 \\
15.440 \\
54.513 \\
7.492\end{array}$ & $\begin{array}{l}41 \\
41 \\
38 \\
42 \\
38\end{array}$ & $\begin{array}{l}31 \\
39 \\
31 \\
33 \\
34\end{array}$ & $\begin{array}{l}1.32 \\
1.05 \\
1.23 \\
1.27 \\
1.12\end{array}$ \\
\hline $\begin{array}{l}771 \\
772 \\
773 \\
775 \\
776\end{array}$ & $\begin{array}{r}14626 \\
8237 \\
2862 \\
1116 \\
1295\end{array}$ & $\begin{array}{r}903 \\
495 \\
130 \\
30 \\
2520\end{array}$ & $\begin{array}{r}16.180 \\
16.640 \\
21.855 \\
36.000 \\
0.514\end{array}$ & $\begin{array}{r}18.270 \\
18.533 \\
25.347 \\
43.709 \\
0.592\end{array}$ & $\begin{array}{l}36 \\
36 \\
33 \\
37 \\
37\end{array}$ & $\begin{array}{l}35 \\
34 \\
33 \\
29 \\
37\end{array}$ & $\begin{array}{l}1.03 \\
1.06 \\
1.00 \\
1.28 \\
1.00\end{array}$ \\
\hline $\begin{array}{l}778 \\
779 \\
781 \\
782 \\
786\end{array}$ & $\begin{array}{r}537 \\
1901 \\
5838 \\
1020 \\
6663\end{array}$ & $\begin{array}{r}1354 \\
781 \\
24 \\
15 \\
65\end{array}$ & $\begin{array}{r}0.397 \\
2.434 \\
243.292 \\
68.000 \\
100.970\end{array}$ & $\begin{array}{r}0.445 \\
2.818 \\
292.802 \\
72.563 \\
113.998\end{array}$ & $\begin{array}{l}35 \\
35 \\
41 \\
43 \\
40\end{array}$ & $\begin{array}{l}39 \\
34 \\
36 \\
39 \\
35\end{array}$ & $\begin{array}{l}0.90 \\
1.03 \\
1.14 \\
1.10 \\
1.14\end{array}$ \\
\hline $\begin{array}{l}787 \\
788 \\
789 \\
791 \\
793\end{array}$ & $\begin{array}{r}913 \\
865 \\
8876 \\
2751 \\
704\end{array}$ & $\begin{array}{r}69 \\
61 \\
92 \\
523 \\
133\end{array}$ & $\begin{array}{r}13.246 \\
13.952 \\
95.441 \\
5.262 \\
5.301\end{array}$ & $\begin{array}{r}14.808 \\
15.493 \\
105.171 \\
6.295 \\
6.078\end{array}$ & $\begin{array}{l}43 \\
39 \\
40 \\
41 \\
38\end{array}$ & $\begin{array}{l}42 \\
36 \\
36 \\
34 \\
34\end{array}$ & $\begin{array}{l}1.02 \\
1.08 \\
1.11 \\
1.21 \\
1.12\end{array}$ \\
\hline $\begin{array}{l}801 \\
803 \\
806 \\
808 \\
811\end{array}$ & $\begin{array}{r}10407 \\
5532 \\
15668 \\
25102 \\
15548\end{array}$ & $\begin{array}{r}43 \\
111 \\
1875 \\
2946 \\
638\end{array}$ & $\begin{array}{r}236.545 \\
49.847 \\
8.356 \\
8.521 \\
24.333\end{array}$ & $\begin{array}{r}271.053 \\
58.193 \\
9.054 \\
9.335 \\
28.863\end{array}$ & $\begin{array}{l}39 \\
42 \\
39 \\
40 \\
36\end{array}$ & $\begin{array}{l}32 \\
32 \\
34 \\
34 \\
32\end{array}$ & $\begin{array}{l}1.22 \\
1.31 \\
1.15 \\
1.18 \\
1.13\end{array}$ \\
\hline
\end{tabular}




\begin{tabular}{|c|c|c|c|c|c|c|c|}
\hline $\mathrm{CCU}-$ & WAGE-E & NERS & MPLCYMED & NT RATIO & & A GE & \\
\hline ATION & MALE & FEMALE & UNADJ. & ADJUSTED & MALE & FEMALE & RAT IO \\
\hline $\begin{array}{l}812 \\
815 \\
817 \\
818 \\
819\end{array}$ & $\begin{array}{r}1298 \\
1979 \\
36352 \\
2647 \\
8461\end{array}$ & $\begin{array}{r}96 \\
106 \\
764 \\
125 \\
1420\end{array}$ & $\begin{array}{r}13.521 \\
18.495 \\
47.519 \\
21.184 \\
5.955\end{array}$ & $\begin{array}{r}14.902 \\
20.664 \\
51.252 \\
23.548 \\
6.316\end{array}$ & $\begin{array}{l}39 \\
38 \\
37 \\
39 \\
38\end{array}$ & $\begin{array}{l}35 \\
34 \\
31 \\
37 \\
35\end{array}$ & $\begin{array}{l}1.11 \\
1.12 \\
1.19 \\
1.05 \\
1.09\end{array}$ \\
\hline $\begin{array}{l}821 \\
822 \\
824 \\
829 \\
831\end{array}$ & $\begin{array}{r}6755 \\
77835 \\
3720 \\
70856 \\
45201\end{array}$ & $\begin{array}{r}24 \\
125 \\
48 \\
507 \\
17\end{array}$ & $\begin{array}{r}281.458 \\
622.680 \\
77.521 \\
139.755 \\
2511.167\end{array}$ & $\begin{array}{r}323.830 \\
780.359 \\
93.431 \\
173.704 \\
2673.482\end{array}$ & $\begin{array}{l}37 \\
35 \\
32 \\
40 \\
36\end{array}$ & $\begin{array}{l}33 \\
32 \\
34 \\
40 \\
40\end{array}$ & $\begin{array}{l}1.12 \\
1.09 \\
0.94 \\
1.00 \\
0.90\end{array}$ \\
\hline $\begin{array}{l}832 \\
835 \\
836 \\
839 \\
841\end{array}$ & $\begin{array}{r}8251 \\
4798 \\
1307 \\
1460 \\
33548\end{array}$ & $\begin{array}{r}7079 \\
66 \\
11 \\
1963 \\
286\end{array}$ & $\begin{array}{r}1.166 \\
71.627 \\
109.000 \\
0.744 \\
117.301\end{array}$ & $\begin{array}{r}1.290 \\
72.008 \\
116.492 \\
0.798 \\
140.877\end{array}$ & $\begin{array}{l}37 \\
35 \\
46 \\
36 \\
40\end{array}$ & $\begin{array}{l}32 \\
32 \\
38 \\
32 \\
37\end{array}$ & $\begin{array}{l}1.16 \\
1.09 \\
1.21 \\
1.13 \\
1.08\end{array}$ \\
\hline $\begin{array}{l}843 \\
854 \\
859 \\
861 \\
862\end{array}$ & $\begin{array}{r}7180 \\
17783 \\
12390 \\
1380 \\
1151\end{array}$ & $\begin{array}{r}362 \\
22 \\
13 \\
183 \\
13\end{array}$ & $\begin{array}{r}19.780 \\
773.217 \\
885.071 \\
7.546 \\
88.538\end{array}$ & $\begin{array}{r}22.316 \\
1060.438 \\
1154.362 \\
8.278 \\
98.770\end{array}$ & $\begin{array}{l}37 \\
36 \\
36 \\
35 \\
41\end{array}$ & $\begin{array}{l}34 \\
29 \\
35 \\
36 \\
31\end{array}$ & $\begin{array}{l}1.09 \\
1.24 \\
1.03 \\
0.97 \\
1.32\end{array}$ \\
\hline $\begin{array}{l}864 \\
869 \\
877 \\
900 \\
911\end{array}$ & $\begin{array}{r}1559 \\
6576 \\
26720 \\
65462 \\
1387\end{array}$ & $\begin{array}{r}19 \\
1140 \\
45 \\
4958 \\
2673\end{array}$ & $\begin{array}{r}82.053 \\
5.769 \\
593.778 \\
13.201 \\
0.519\end{array}$ & $\begin{array}{r}87.697 \\
6.578 \\
643.067 \\
14.257 \\
0.561\end{array}$ & $\begin{array}{l}39 \\
36 \\
36 \\
43 \\
39\end{array}$ & $\begin{array}{l}35 \\
31 \\
30 \\
41 \\
34\end{array}$ & $\begin{array}{l}1.11 \\
1.16 \\
1.20 \\
1.05 \\
1.15\end{array}$ \\
\hline $\begin{array}{l}912 \\
913 \\
914 \\
915 \\
916\end{array}$ & $\begin{array}{r}1894 \\
19960 \\
5782 \\
1647 \\
2300\end{array}$ & $\begin{array}{r}46 \\
28098 \\
4144 \\
1246 \\
389\end{array}$ & $\begin{array}{r}40.298 \\
0.710 \\
1.396 \\
1.321 \\
5.897\end{array}$ & $\begin{array}{r}47.376 \\
0.796 \\
1.583 \\
1.486 \\
6.852\end{array}$ & $\begin{array}{l}41 \\
33 \\
34 \\
33 \\
40\end{array}$ & $\begin{array}{l}33 \\
32 \\
33 \\
31 \\
35\end{array}$ & $\begin{array}{l}1.24 \\
1.03 \\
1.03 \\
1.06 \\
1.14\end{array}$ \\
\hline $\begin{array}{l}917 \\
918 \\
919 \\
920\end{array}$ & $\begin{array}{r}12182 \\
3000 \\
11104 \\
290613\end{array}$ & $\begin{array}{r}2404 \\
1295 \\
5802 \\
20281\end{array}$ & $\begin{array}{r}5.067 \\
2.315 \\
1.914 \\
14.329\end{array}$ & $\begin{array}{r}5.648 \\
2.796 \\
2.184 \\
15.041\end{array}$ & $\begin{array}{l}41 \\
41 \\
36 \\
36\end{array}$ & $\begin{array}{l}36 \\
36 \\
33 \\
33\end{array}$ & $\begin{array}{l}1.14 \\
1.14 \\
1.09 \\
1.09\end{array}$ \\
\hline
\end{tabular}




\begin{tabular}{|c|c|c|c|c|c|c|c|c|}
\hline \multirow{2}{*}{$\begin{array}{l}\text { OCCU- } \\
\text { PATION }\end{array}$} & \multicolumn{3}{|c|}{ EDUCATION } & \multicolumn{2}{|c|}{ TRAINING } & \multicolumn{3}{|c|}{ AFTITUEES } \\
\hline & MALE & FEMALE & RATIO & GED & SVP & G & V & $N$ \\
\hline $\begin{array}{r}1 \\
4 \\
6 \\
8 \\
10\end{array}$ & $\begin{array}{l}12.4 \\
11.6 \\
11.7 \\
11.0 \\
10.1\end{array}$ & $\begin{array}{l}12.1 \\
11.9 \\
11.7 \\
11.5 \\
10.8\end{array}$ & $\begin{array}{l}1.02 \\
0.97 \\
1.00 \\
0.96 \\
0.94\end{array}$ & $\begin{array}{c}16.00 \\
16.0 .0 \\
16.00 \\
13.33 \\
14.70\end{array}$ & $\begin{array}{l}3.00 \\
7.00 \\
7.00 \\
3.83 \\
5.71\end{array}$ & $\begin{array}{l}0.7833 \\
0.7833 \\
0.7833 \\
0.8389 \\
0.7851\end{array}$ & $\begin{array}{l}0.7833 \\
0.9500 \\
0.7833 \\
0.8389 \\
0.7077\end{array}$ & $\begin{array}{l}0.5000 \\
0.7833 \\
0.5000 \\
0.7833 \\
0.6239\end{array}$ \\
\hline $\begin{array}{l}101 \\
102 \\
105 \\
108 \\
109\end{array}$ & $\begin{array}{l}15.4 \\
16.1 \\
16.7 \\
17.4 \\
16.4\end{array}$ & $\begin{array}{l}12.2 \\
12.2 \\
12.4 \\
13.2 \\
12.2\end{array}$ & $\begin{array}{l}1.26 \\
1.32 \\
1.35 \\
1.32 \\
1.34\end{array}$ & $\begin{array}{l}15.60 \\
17.27 \\
16.33 \\
18.00 \\
17.20\end{array}$ & $\begin{array}{l}6.20 \\
5.91 \\
6.33 \\
7.00 \\
4.60\end{array}$ & $\begin{array}{l}0.9500 \\
0.9348 \\
0.8750 \\
0.9500 \\
0.9500\end{array}$ & $\begin{array}{l}0.9167 \\
0.8288 \\
0.7917 \\
0.9500 \\
0.8500\end{array}$ & $\begin{array}{l}0.9500 \\
0.9348 \\
0.8750 \\
0.9500 \\
0.9500\end{array}$ \\
\hline $\begin{array}{l}111 \\
114 \\
119 \\
121 \\
124\end{array}$ & $\begin{array}{l}16.2 \\
17.5 \\
16.5 \\
17.1 \\
15.5\end{array}$ & $\begin{array}{l}14.5 \\
16.8 \\
13.2 \\
16.5 \\
13.6\end{array}$ & $\begin{array}{l}1.12 \\
1.04 \\
1.25 \\
1.04 \\
1.14\end{array}$ & $\begin{array}{r}17.85 \\
18.00 \\
16.67 \\
17.11 \\
16.00\end{array}$ & $\begin{array}{l}3.92 \\
3.00 \\
3.00 \\
3.44 \\
5.00\end{array}$ & $\begin{array}{l}0.9500 \\
0.9500 \\
0.9500 \\
0.9500 \\
0.9500\end{array}$ & $\begin{array}{l}0.9372 \\
0.9500 \\
0.8389 \\
0.9130 \\
0.9500\end{array}$ & $\begin{array}{l}0.9372 \\
0.9500 \\
0.8944 \\
0.7204 \\
0.7250\end{array}$ \\
\hline $\begin{array}{l}129 \\
131 \\
135 \\
139 \\
140\end{array}$ & $\begin{array}{l}14.2 \\
17.5 \\
14.2 \\
11.0 \\
19.7\end{array}$ & $\begin{array}{r}12.6 \\
16.0 \\
13.4 \\
8.9 \\
18.8\end{array}$ & $\begin{array}{l}1.13 \\
1.09 \\
1.06 \\
1.24 \\
1.05\end{array}$ & $\begin{array}{l}13.67 \\
17.33 \\
16.00 \\
16.00 \\
17.75\end{array}$ & $\begin{array}{l}3.39 \\
6.17 \\
2.95 \\
2.25 \\
7.00\end{array}$ & $\begin{array}{l}0.8000 \\
0.8944 \\
0.8439 \\
0.7833 \\
0.9500\end{array}$ & $\begin{array}{l}0.5944 \\
0.8944 \\
0.8136 \\
0.7833 \\
0.9500\end{array}$ & $\begin{array}{l}0.6500 \\
0.7639 \\
0.5515 \\
0.7833 \\
0.7125\end{array}$ \\
\hline $\begin{array}{l}141 \\
142 \\
143 \\
144 \\
145\end{array}$ & $\begin{array}{l}17.7 \\
12.8 \\
13.0 \\
12.0 \\
15.1\end{array}$ & $\begin{array}{l}14.1 \\
12.7 \\
12.5 \\
13.3 \\
13.0\end{array}$ & $\begin{array}{l}1.26 \\
1.01 \\
1.04 \\
0.90 \\
1.16\end{array}$ & $\begin{array}{c}18.00 \\
11.87 \\
12.00 \\
13.50 \\
16.00\end{array}$ & $\begin{array}{l}7.00 \\
2.65 \\
0.0 \\
1.63 \\
3.00\end{array}$ & $\begin{array}{l}0.9500 \\
0.7125 \\
0.7833 \\
0.6417 \\
0.7833\end{array}$ & $\begin{array}{l}0.9500 \\
0.7125 \\
0.7833 \\
0.6417 \\
0.7833\end{array}$ & $\begin{array}{l}0.7833 \\
0.5000 \\
0.7833 \\
0.4292 \\
0.7833\end{array}$ \\
\hline $\begin{array}{l}146 \\
147 \\
148 \\
153 \\
171\end{array}$ & $\begin{array}{l}16.4 \\
15.4 \\
11.7 \\
18.6 \\
11.2\end{array}$ & $\begin{array}{l}12.8 \\
14.4 \\
12.2 \\
16.5 \\
12.0\end{array}$ & $\begin{array}{l}1.28 \\
1.07 \\
0.96 \\
1.13 \\
0.93\end{array}$ & $\begin{array}{l}17.00 \\
16.00 \\
12.33 \\
17.33 \\
13.71\end{array}$ & $\begin{array}{l}5.00 \\
3.00 \\
1.86 \\
8.00 \\
2.79\end{array}$ & $\begin{array}{l}0.8667 \\
0.9500 \\
0.6556 \\
0.9500 \\
0.6214\end{array}$ & $\begin{array}{l}0.7250 \\
0.7833 \\
0.6083 \\
0.9500 \\
0.5405\end{array}$ & $\begin{array}{l}0.5000 \\
0.7833 \\
0.5708 \\
0.5944 \\
0.3381\end{array}$ \\
\hline $\begin{array}{l}172 \\
174 \\
176 \\
182 \\
183\end{array}$ & $\begin{array}{l}11.6 \\
13.4 \\
11.9 \\
11.8 \\
11.9\end{array}$ & $\begin{array}{l}12.4 \\
13.0 \\
12.2 \\
12.0 \\
12.0\end{array}$ & $\begin{array}{l}0.94 \\
1.03 \\
0.98 \\
0.98 \\
0.99\end{array}$ & $\begin{array}{l}14.50 \\
16.37 \\
16.50 \\
12.87 \\
15.43\end{array}$ & $\begin{array}{l}6.00 \\
4.85 \\
9.62 \\
2.75 \\
2.57\end{array}$ & $\begin{array}{l}0.7958 \\
0.9025 \\
0.8458 \\
0.7804 \\
0.7833\end{array}$ & $\begin{array}{l}0.7542 \\
0.9315 \\
0.7833 \\
0.5370 \\
0.6619\end{array}$ & $\begin{array}{l}0.5708 \\
0.4056 \\
0.4646 \\
0.7659 \\
0.8548\end{array}$ \\
\hline $\begin{array}{l}186 \\
188 \\
191 \\
192 \\
195\end{array}$ & $\begin{array}{l}15.9 \\
13.5 \\
13.0 \\
13.2 \\
10.6\end{array}$ & $\begin{array}{l}13.9 \\
12.1 \\
13.4 \\
13.7 \\
10.7\end{array}$ & $\begin{array}{l}1.14 \\
1.12 \\
0.97 \\
0.96 \\
0.99\end{array}$ & $\begin{array}{l}18.00 \\
15.14 \\
16.00 \\
16.40 \\
13.00\end{array}$ & $\begin{array}{l}3.00 \\
4.29 \\
3.00 \\
5.10 \\
1.31\end{array}$ & $\begin{array}{l}0.9500 \\
0.8857 \\
0.7833 \\
0.9167 \\
0.7125\end{array}$ & $\begin{array}{l}0.9500 \\
0.7667 \\
0.7833 \\
0.9167 \\
0.5708\end{array}$ & $\begin{array}{l}0.9500 \\
0.8857 \\
0.7833 \\
0.5567 \\
0.3167\end{array}$ \\
\hline
\end{tabular}


OCCU-

PATION
EDUCATION MALE FEMALE RATIO
TRAINING

GED SVP
10.5

11.4

12.3

11.8

11.9

20

203

212

214

223

232

234

241

249

307

312

314

325

331

338

339

403

405

412

413

414

415

416

417

419

431

433

451

452

453

454

455

456

457

459

510

520

$$
\begin{array}{r}
9.2 \\
8.6
\end{array}
$$

10.7

12.9

12.7

12.8

10.9

9.5

7.1

10.7

10.0

11. 1

11.3

11.4

9.8

$$
7.4
$$

9.9

7.5

8.2

9.0

10.0

8.6

10.2

11.5

8.4

7.9

7.3

7.2

10.3

$$
6.4
$$

8.6

9.0

8. 9

11.8
11.
11.
12.
10.

10.4

10.3

10.0

11.9

11.3

10.5

10.9

10.6

9.6

9.5

11.9

9.3

11.9

$11: 7$

10.0

11.8

10.4

8.6

7.7

10.6

8.3

8.9

11.1

11.3

12.9

$$
9.1
$$

7.3

8.6

7.2

11.8

11.3

9.7

9.2

11.2

12.0

\subsection{3 \\ 0.97 \\ 1.01 \\ 1.12 \\ 1. 14}

0.89

0.86

0.90

1. 14

1.21

1. 17

1.03

0.99

0.75

0.90

\subsection{8}

0.93

0.97

1. 14

0.83

0.71

1.15

0.97

0.77

1.08

12.29
13.16
15.62
10.33
8.43

2.83

2.27

4.08

0.32

0.21

9.64

9.90

11.00

10.25

10.50

0.41

0.31

0.75

0.94

0.42

12.00

10.17

10.00

8.00

12.00

3.00

0.45

0.10

0.12

1. 12

11.00

16.00

13.60

9.67

13.25

1.26

1. 50

2.25

0.12

2.39

10.50

11.50

12.00

0.19

1.61

3. 80

7.00

0.16

7. 50

0.10

\subsection{2}

0.77

9.67

1.15

5. 80

0.68

0.04

7.12

0.90

12. 17

0.27

2. 60

11.75

3.29

$$
0.92
$$

11. 20

0.71

1.08

8.83

0.85

1.00

7.00

0.83

0.04

7.00

0.04

0.87

12.00

0.57

10.50

0.89

7.86

1.55

0.98

7.50

0.24

0.04

12.00

2.75

0.79

0.98

12.00
APTITUDES

G $\mathrm{V}$ N

$\begin{array}{llll}0.6619 & 0.5405 & 0.4190\end{array}$

$\begin{array}{llll}0.7237 & 0.6430 & 0.5597\end{array}$

$\begin{array}{llll}0.8143 & 0.7738 & 0.6079\end{array}$

$0.5394 \quad 0.53150 .5944$

$\begin{array}{llll}0.4865 & 0.4325 & 0.3976\end{array}$

$\begin{array}{llll}0.5515 & 0.5000 & 0.5515\end{array}$

$\begin{array}{llll}0.5283 & 0.4717 & 0.4433\end{array}$

$0.5000 \quad 0.5000 \quad 0.5000$

$\begin{array}{llll}0.6417 & 0.8042 & 0.2875\end{array}$

$0.5000 \quad 0.5000 \div 0.2521$

$\begin{array}{llll}0.5000 & 0.7833 & 0.5000\end{array}$

$0.5486 \quad 0.5178 \quad 0.4930$

$0.5000 \quad 0.5000 \quad 0.5000$

$\begin{array}{llll}0.4056 & 0.4056 & 0.4056\end{array}$

$\begin{array}{lllll}0.6417 & 0.6417 & 0.3583\end{array}$

$\begin{array}{llll}0.5810 & 0.5810 & 0.4595\end{array}$

$\begin{array}{llll}0.8667 & 0.8667 & 0.8667\end{array}$

$\begin{array}{llll}0.6700 & 0.6700 & 0.5567\end{array}$

$\begin{array}{llll}0.5944 & 0.6889 & 0.2556\end{array}$

$\begin{array}{llll}0.6417 & 0.6417 & 0.4292\end{array}$

$\begin{array}{llll}0.4292 & 0.4292 & 0.1750\end{array}$

$\begin{array}{llll}0.5563 & 0.5208 & 0.3375\end{array}$

$0.5000 \quad 0.27330 .3300$

$0.5000 \quad 0.5000 \quad 0.5000$

$0.4150 \quad 0.3300 \quad 0.2850$

$0.5000 \quad 0.5000 \quad 0.2556$

$0.5000 \quad 0.4433 \quad 0.2167$

$0.3500 \quad 0.31670 .1520$

$\begin{array}{llll}0.7167 & 0.5750 & 0.1528\end{array}$

$\begin{array}{lllll}0.6417 & 0.6417 & 0.3583\end{array}$

$\begin{array}{llll}0.4433 & 0.5000 & 0.1833\end{array}$

$\begin{array}{llll}0.4528 & 0.3583 & 0.2556\end{array}$

$\begin{array}{llll}0.2167 & 0.2167 & 0.2167\end{array}$

0.21670 .21670 .0500

$0.5000 \quad 0.5000 \quad 0.5000$

$\begin{array}{llll}0.5708 & 0.7125 & 0.2458\end{array}$

$0.5000 \quad 0.5000 \quad 0.1452$

$\begin{array}{llll}0.3583 & 0.3017 & 0.1617\end{array}$

$\begin{array}{llll}0.5708 & 0.5354 & 0.4292\end{array}$

$0.9500 \quad 0.78330 .9500$ 
OCCU

551

552

554

556

581

582

584

585

588

603

605

607

609

613

615

63

657

701

702

703

704

705

706

707

708

709

711

719

721

722

724

729

731

732

733

734

735

736

737
EDUCATION

MALE FEMALE RATIO
TRAINING

GED SVP
AETITUEES

G V N

$$
\begin{array}{rrrrrrrr}
8.1 & 10.5 & 0.77 & 12.00 & 0.75 & 0.5000 & 0.5000 & 0.5000 \\
7.8 & 10.9 & 0.72 & 7.00 & 0.04 & 0.5000 & 0.2167 & 0.2167 \\
8.3 & 11.4 & 0.73 & 10.00 & 0.04 & 0.5000 & 0.5000 & 0.5000 \\
7.5 & 11.7 & 0.64 & 9.25 & 0.13 & 0.5000 & 0.2875 & 0.2167 \\
12.3 & 12.2 & 1.01 & 16.00 & 0.38 & 0.7833 & 0.7833 & 0.5000 \\
& & & & & & & \\
11.0 & 11.6 & 0.95 & 12.67 & 1.92 & 0.7361 & 0.6889 & 0.5000 \\
12.3 & 9.7 & 1.27 & 10.50 & 0.31 & 0.5000 & 0.5000 & 0.3583 \\
10.2 & 11.1 & 0.92 & 11.33 & 1.37 & 0.5000 & 0.5000 & 0.5000 \\
8.3 & 10.0 & 0.83 & 7.71 & 0.09 & 0.4595 & 0.5000 & 0.2738 \\
8.5 & 11.0 & 0.77 & 14.00 & 5.00 & 0.6417 & 0.5000 & 0.5000 \\
7.6 & 7.4 & 1.03 & 10.20 & 1.65 & 0.6133 & 0.5000 & 0.4433 \\
7.3 & 10.6 & 0.69 & 7.00 & 1.50 & 0.5000 & 0.5000 & 0.2167 \\
7.6 & 9.5 & 0.80 & 8.42 & 0.62 & 0.4292 & 0.3347 & 0.2181 \\
7.5 & 11.8 & 0.64 & 12.00 & 0.90 & 0.5708 & 0.5000 & 0.4292 \\
6.2 & 11.2 & 0.55 & 7.61 & 0.77 & 0.3522 & 0.2587 & 0.1399
\end{array}
$$

$\begin{array}{rr}11.0 & 11.6 \\ 12.3 & 9.7 \\ 10.2 & 11.1 \\ 8.3 & 10.0 \\ 8.5 & 11.0\end{array}$

$$
6.2
$$

9.7

0.64

7.00

0.11

$\begin{array}{llll}0.4261 & 0.2094 & 0.1804\end{array}$

$7.2 \quad 11.8$

0.61

0.69

7.36

0.98

1.87

$\begin{array}{llll}0.3712 & 0.3068 & 0.2053\end{array}$

$7.4 \quad 10.8$

0.94

10.33

1.88

$\begin{array}{llll}0.4528 & 0.3583 & 0.2556\end{array}$

$8.0 \quad 10.0$

0.80

10.00

1. 37

$\begin{array}{llll}0.4717 & 0.2450 & 0.2283\end{array}$

$\begin{array}{llll}0.4227 & 0.2788 & 0.1773\end{array}$

\section{$7.8 \quad 7.9$}

0.99

5.50

0.04

$\begin{array}{lllll}0.3583 & 0.2167 & 0.1333\end{array}$

6.4

6.9

0.93

10.00

0.75

0.2167

0.2167

0.2167

7.87 .2

1.08

7.60

0.30

0.3867

0.2167

0.1833

10.751 .41

$\begin{array}{llll}0.5000 & 0.3111 & 0.3347\end{array}$

1.03

8.33

0.40

$\begin{array}{llll}0.3898 & 0.2796 & 0.2361\end{array}$

$8.3 \quad 9.2$

0.90

11.33

2.23

$\begin{array}{llll}0.5944 & 0.5000 & 0.5000\end{array}$

8.19 .0

0.90

7.89

1.38

0.4056

0

$7.3 \quad 7.9$

0.92

9.25

0.70

0.5000

0.24820 .1741

8.80

1.54

0.4433

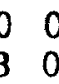

24500.1333

7.37 .3

1.00

7.71

0.70

0.4595

$\begin{array}{lll}0.2167 & 0.1056\end{array}$

$6.5 \quad 9.5$

0.68

10.00

1.58

$0.5000: 0.2167 \quad 0.3583$

10.00

1.33

0.4646

0
0

$8.37 \quad 1.22$

$\begin{array}{lll}0.3111 & 0.2167 & 0.2167\end{array}$

$7.3 \quad 7.3$

1.00

8.00

0.19

0.42920 .2875

0.1479

1.01

12.00

3.00

$\begin{array}{llll}0.5000 & 0.3583 & 0.3583\end{array}$

$\begin{array}{ll}7.2 & 7.7\end{array}$

0.94

8.45

1.25

$\begin{array}{llll}0.3197 & 0.2530 & 0.2076\end{array}$

8.07 .5

1.07

9.50

1.63

$\begin{array}{llll}0.5000 & 0.4056 & 0.2694\end{array}$

7.3

9.3

0.78

9.40

0.33

$\begin{array}{llll}0.5000 & 0.2733 & 0.3300\end{array}$

0.97

5.00

0.08

$\begin{array}{lll}0.2167 & 0.2167 & 0.0500\end{array}$ 


\begin{tabular}{|c|c|c|c|c|c|c|c|c|}
\hline \multirow{2}{*}{$\begin{array}{l}\text { OCCU- } \\
\text { PATION }\end{array}$} & \multicolumn{3}{|c|}{ EDUCATION } & \multicolumn{2}{|c|}{ TRAIN ING } & \multicolumn{3}{|c|}{ APTITUDES } \\
\hline & MALE & FEMALE & BATIO & GED & $S \nabla P$ & G & $\nabla$ & $\mathrm{N}$ \\
\hline $\begin{array}{l}739 \\
741 \\
742 \\
743 \\
744\end{array}$ & $\begin{array}{r}7.5 \\
7.5 \\
10.8 \\
7.9 \\
8.9\end{array}$ & $\begin{array}{l}7.6 \\
8.5 \\
7.8 \\
7.7 \\
8.1\end{array}$ & $\begin{array}{l}0.99 \\
0.88 \\
1.38 \\
1.03 \\
1.10\end{array}$ & $\begin{array}{r}9.00 \\
11.00 \\
10.00 \\
10.50 \\
10.00\end{array}$ & $\begin{array}{l}1.03 \\
2.25 \\
3.00 \\
2.62 \\
1.87\end{array}$ & $\begin{array}{l}0.3938 \\
0.5000 \\
0.5000 \\
0.5000 \\
0.6417\end{array}$ & $\begin{array}{l}0.2875 \\
0.3583 \\
0.4056 \\
0.2875 \\
0.3583\end{array}$ & $\begin{array}{l}0.2104 \\
0.5000 \\
0.3111 \\
0.2042 \\
0.1333\end{array}$ \\
\hline $\begin{array}{l}745 \\
746 \\
747 \\
749 \\
752\end{array}$ & $\begin{array}{l}8.0 \\
8.2 \\
8.0 \\
7.2 \\
7.9\end{array}$ & $\begin{array}{r}7.9 \\
7.0 \\
9.3 \\
7.1 \\
10.5\end{array}$ & $\begin{array}{l}1.01 \\
1.17 \\
0.86 \\
1.01 \\
0.75\end{array}$ & $\begin{array}{r}9.62 \\
7.35 \\
10.67 \\
7.68 \\
10.56\end{array}$ & $\begin{array}{l}1.42 \\
0.57 \\
2.03 \\
0.85 \\
1.52\end{array}$ & $\begin{array}{l}0.5000 \\
0.3801 \\
0.5000 \\
0.4093 \\
0.4685\end{array}$ & $\begin{array}{l}0.3229 \\
0.2667 \\
0.2639 \\
0.2507 \\
0.2796\end{array}$ & $\begin{array}{l}0.3583 \\
0.1526 \\
0.3583 \\
0.2180 \\
0.2611\end{array}$ \\
\hline $\begin{array}{l}754 \\
756 \\
758 \\
759 \\
761\end{array}$ & $\begin{array}{l}7.0 \\
7.3 \\
8.5 \\
7.4 \\
9.2\end{array}$ & $\begin{array}{r}10.4 \\
8.5 \\
10.4 \\
8.7 \\
11.3\end{array}$ & $\begin{array}{l}0.67 \\
0.86 \\
0.82 \\
0.85 \\
0.81\end{array}$ & $\begin{array}{r}8.70 \\
9.38 \\
10.50 \\
9.26 \\
10.83\end{array}$ & $\begin{array}{l}0.98 \\
0.75 \\
4.29 \\
1.12 \\
1.06\end{array}$ & $\begin{array}{l}0.4150 \\
0.4891 \\
0.5000 \\
0.4553 \\
0.5708\end{array}$ & $\begin{array}{l}0.2450 \\
0.3474 \\
0.3583 \\
0.2614 \\
0.4056\end{array}$ & $\begin{array}{l}0.2167 \\
0.3192 \\
0.5000 \\
0.2649 \\
0.4056\end{array}$ \\
\hline $\begin{array}{l}762 \\
763 \\
766 \\
768 \\
769\end{array}$ & $\begin{array}{l}7.5 \\
7.6 \\
7.9 \\
7.7 \\
8.5\end{array}$ & $\begin{array}{r}10.8 \\
10.4 \\
9.4 \\
10.4 \\
9.0\end{array}$ & $\begin{array}{l}0.69 \\
0.73 \\
0.84 \\
0.74 \\
0.94\end{array}$ & $\begin{array}{l}9.10 \\
8.00 \\
7.00 \\
8.50 \\
9.83\end{array}$ & $\begin{array}{l}0.68 \\
0.32 \\
0.10 \\
0.50 \\
1.21\end{array}$ & $\begin{array}{l}0.5000 \\
0.2167 \\
0.5000 \\
0.4528 \\
0.5000\end{array}$ & $\begin{array}{l}0.3300 \\
0.2167 \\
0.2167 \\
0.2167 \\
0.3624\end{array}$ & $\begin{array}{l}0.2567 \\
0.3500 \\
0.2167 \\
0.1889 \\
0.3495\end{array}$ \\
\hline $\begin{array}{l}771 \\
772 \\
773 \\
775 \\
776\end{array}$ & $\begin{array}{l}9.6 \\
9.0 \\
9.6 \\
9.6 \\
9.3\end{array}$ & $\begin{array}{r}11.0 \\
10.3 \\
11.3 \\
11.4 \\
8.3\end{array}$ & $\begin{array}{l}0.87 \\
0.87 \\
0.85 \\
0.84 \\
1.12\end{array}$ & $\begin{array}{r}11.60 \\
12.00 \\
11.50 \\
12.00 \\
12.00\end{array}$ & $\begin{array}{l}3.60 \\
4.67 \\
6.00 \\
5.63 \\
3.00\end{array}$ & $\begin{array}{l}0.5000 \\
0.5000 \\
0.5000 \\
0.5000 \\
0.5000\end{array}$ & $\begin{array}{l}0.5567 \\
0.5000 \\
0.5000 \\
0.5000 \\
0.2167\end{array}$ & $\begin{array}{l}0.3867 \\
0.4190 \\
0.5000 \\
0.4433 \\
0.2167\end{array}$ \\
\hline $\begin{array}{l}778 \\
779 \\
781 \\
782 \\
786\end{array}$ & $\begin{array}{l}9.3 \\
8.9 \\
7.4 \\
7.9 \\
7.2\end{array}$ & $\begin{array}{r}8.3 \\
8.5 \\
11.4 \\
11.1 \\
10.9\end{array}$ & $\begin{array}{l}1.12 \\
1.05 \\
0.65 \\
0.71 \\
0.66\end{array}$ & $\begin{array}{r}10.00 \\
10.53 \\
9.88 \\
10.36 \\
9.23\end{array}$ & $\begin{array}{l}0.23 \\
3.37 \\
1.28 \\
2.44 \\
2.37\end{array}$ & $\begin{array}{l}0.4056 \\
0.4702 \\
0.5000 \\
0.4595 \\
0.5000\end{array}$ & $\begin{array}{l}0.2167 \\
0.3956 \\
0.3256 \\
0.3179 \\
0.4564\end{array}$ & $\begin{array}{l}0.1611 \\
0.3009 \\
0.2654 \\
0.3060 \\
0.4090\end{array}$ \\
\hline $\begin{array}{l}787 \\
788 \\
789 \\
791 \\
793\end{array}$ & $\begin{array}{l}7.2 \\
8.0 \\
7.5 \\
8.9 \\
9.2\end{array}$ & $\begin{array}{r}8.4 \\
9.0 \\
10.8 \\
9.8 \\
9.6\end{array}$ & $\begin{array}{l}0.86 \\
0.89 \\
0.69 \\
0.91 \\
0.96\end{array}$ & $\begin{array}{r}11.20 \\
10.67 \\
7.94 \\
10.93 \\
10.60\end{array}$ & $\begin{array}{l}1.68 \\
2.25 \\
1.01 \\
3.87 \\
3.32\end{array}$ & $\begin{array}{l}0.4433 \\
0.5000 \\
0.4370 \\
0.5567 \\
0.4717\end{array}$ & $\begin{array}{l}0.4433 \\
0.3111 \\
0.2639 \\
0.4811 \\
0.4150\end{array}$ & $\begin{array}{l}0.4433 \\
0.4056 \\
0.1926 \\
0.4322 \\
0.3983\end{array}$ \\
\hline $\begin{array}{l}801 \\
803 \\
806 \\
808 \\
811\end{array}$ & $\begin{array}{l}9.4 \\
7.8 \\
8.1 \\
7.8 \\
8.4\end{array}$ & $\begin{array}{r}11.9 \\
10.6 \\
9.3 \\
8.9 \\
10.0\end{array}$ & $\begin{array}{l}0.79 \\
0.74 \\
0.87 \\
0.88 \\
0.84\end{array}$ & $\begin{array}{r}11.78 \\
9.00 \\
9.92 \\
9.58 \\
11.00\end{array}$ & $\begin{array}{l}3.50 \\
0.73 \\
1.08 \\
0.91 \\
2.39\end{array}$ & $\begin{array}{l}0.5000 \\
0.4660 \\
0.4782 \\
0.4717 \\
0.5113\end{array}$ & $\begin{array}{l}0.5000 \\
0.2960 \\
0.2821 \\
0.2875 \\
0.4207\end{array}$ & $\begin{array}{l}0.4843 \\
0.2673 \\
0.2917 \\
0.3472 \\
0.4527\end{array}$ \\
\hline
\end{tabular}




\begin{tabular}{|c|c|c|c|c|c|c|c|c|}
\hline \multirow{2}{*}{$\begin{array}{l}\text { OCCU - } \\
\text { PATION }\end{array}$} & \multicolumn{3}{|c|}{ EDUCATION } & \multicolumn{2}{|c|}{ TRAINING } & \multicolumn{3}{|c|}{ AETITULES } \\
\hline & MALE & FEMALE & RATIO & GED & SVP & G & V & $\mathrm{N}$ \\
\hline $\begin{array}{l}812 \\
815 \\
817 \\
818 \\
819\end{array}$ & $\begin{array}{l}7.2 \\
7.9 \\
8.0 \\
7.4 \\
7.7\end{array}$ & $\begin{array}{r}8.8 \\
9.6 \\
10.4 \\
9.1 \\
8.5\end{array}$ & $\begin{array}{l}0.82 \\
0.82 \\
0.77 \\
0.81 \\
0.91\end{array}$ & $\begin{array}{r}9.16 \\
10.33 \\
9.92 \\
4.00 \\
9.23\end{array}$ & $\begin{array}{l}0.74 \\
2.01 \\
0.59 \\
0.04 \\
0.95\end{array}$ & $\begin{array}{l}0.3509 \\
0.5000 \\
0.5000 \\
0.2167 \\
0.4614\end{array}$ & $\begin{array}{l}0.2316 \\
0.4056 \\
0.3300 \\
0.2167 \\
0.2682\end{array}$ & $\begin{array}{l}0.1965 \\
0.3500 \\
0.3053 \\
0.0500 \\
0.2432\end{array}$ \\
\hline $\begin{array}{l}821 \\
822 \\
824 \\
829 \\
831\end{array}$ & $\begin{array}{r}9.6 \\
8.1 \\
10.0 \\
8.2 \\
9.3\end{array}$ & $\begin{array}{l}11.9 \\
11.8 \\
11.9 \\
11.5 \\
12.0\end{array}$ & $\begin{array}{l}0.81 \\
0.69 \\
0.84 \\
0.71 \\
0.77\end{array}$ & $\begin{array}{l}11.82 \\
11.33 \\
11.00 \\
11.26 \\
11.83\end{array}$ & $\begin{array}{l}3.73 \\
2.41 \\
3.00 \\
2.51 \\
3.17\end{array}$ & $\begin{array}{l}0.5258 \\
0.4882 \\
0.5000 \\
0.5000 \\
0.5236\end{array}$ & $\begin{array}{l}0.2939 \\
0.2993 \\
0.5278 \\
0.4433 \\
0.4843\end{array}$ & $\begin{array}{l}0.4742 \\
0.2597 \\
0.4056 \\
0.4433 \\
0.4685\end{array}$ \\
\hline $\begin{array}{l}832 \\
835 \\
836 \\
839 \\
841\end{array}$ & $\begin{array}{l}8.6 \\
9.7 \\
8.9 \\
8.7 \\
7.7\end{array}$ & $\begin{array}{r}8.4 \\
11.8 \\
11.7 \\
8.4 \\
11.3\end{array}$ & $\begin{array}{l}1.02 \\
0.82 \\
0.76 \\
1.04 \\
0.68\end{array}$ & $\begin{array}{r}9.71 \\
12.00 \\
12.00 \\
6.53 \\
10.00\end{array}$ & $\begin{array}{l}1.36 \\
2.75 \\
3.00 \\
0.27 \\
2.22\end{array}$ & $\begin{array}{l}0.4833 \\
0.5000 \\
0.5000 \\
0.3678 \\
0.4685\end{array}$ & $\begin{array}{l}0.3333 \\
0.4528 \\
0.5000 \\
0.2167 \\
0.4056\end{array}$ & $\begin{array}{l}0.2578 \\
0.4056 \\
0.5000 \\
0.1056 \\
0.3432\end{array}$ \\
\hline $\begin{array}{l}843 \\
854 \\
859 \\
861 \\
862\end{array}$ & $\begin{array}{l}7.8 \\
7.2 \\
7.2 \\
9.6 \\
7.0\end{array}$ & $\begin{array}{r}9.4 \\
11.8 \\
11.8 \\
10.4 \\
10.4\end{array}$ & $\begin{array}{l}0.83 \\
0.61 \\
0.61 \\
0.92 \\
0.67\end{array}$ & $\begin{array}{r}8.00 \\
11.06 \\
9.81 \\
10.33 \\
9.40\end{array}$ & $\begin{array}{l}0.68 \\
2.06 \\
1.60 \\
1.70 \\
0.71\end{array}$ & $\begin{array}{l}0.5000 \\
0.4843 \\
0.4646 \\
0.5189 \\
0.4433\end{array}$ & $\begin{array}{l}0.2167 \\
0.2796 \\
0.3229 \\
0.4433 \\
0.4433\end{array}$ & $\begin{array}{l}0.1333 \\
0.3583 \\
0.3344 \\
0.3867 \\
0.2733\end{array}$ \\
\hline $\begin{array}{l}864 \\
869 \\
877 \\
900 \\
911\end{array}$ & $\begin{array}{l}7.1 \\
7.6 \\
7.7 \\
8.8 \\
7.8\end{array}$ & $\begin{array}{r}11.0 \\
8.5 \\
11.6 \\
10.1 \\
7.4\end{array}$ & $\begin{array}{l}0.65 \\
0.89 \\
0.66 \\
0.87 \\
1.05\end{array}$ & $\begin{array}{r}9.92 \\
9.67 \\
8.67 \\
16.00 \\
7.43\end{array}$ & $\begin{array}{l}1.39 \\
1.17 \\
0.68 \\
3.00 \\
0.09\end{array}$ & $\begin{array}{l}0.5000 \\
0.4410 \\
0.4056 \\
0.7833 \\
0.2976\end{array}$ & $\begin{array}{l}0.3583 \\
0.2757 \\
0.3111 \\
0.7833 \\
0.2167\end{array}$ & $\begin{array}{l}0.3583 \\
0.1847 \\
0.1611 \\
0.5000 \\
0.0500\end{array}$ \\
\hline $\begin{array}{l}912 \\
913 \\
914 \\
915 \\
916\end{array}$ & $\begin{array}{r}9.1 \\
8.3 \\
8.2 \\
10.1 \\
7.2\end{array}$ & $\begin{array}{r}11.0 \\
7.8 \\
7.9 \\
9.7 \\
7.4\end{array}$ & $\begin{array}{l}0.83 \\
1.06 \\
1.04 \\
1.04 \\
0.97\end{array}$ & $\begin{array}{r}11.70 \\
6.09 \\
8.00 \\
11.00 \\
9.73\end{array}$ & $\begin{array}{l}3.72 \\
0.81 \\
0.77 \\
1.58 \\
1.05\end{array}$ & $\begin{array}{l}0.6133 \\
0.3068 \\
0.3583 \\
0.5000 \\
0.5000\end{array}$ & $\begin{array}{l}0.5142 \\
0.2682 \\
0.2750 \\
0.4292 \\
0.3489\end{array}$ & $\begin{array}{l}0.5850 \\
0.1288 \\
0.2750 \\
0.3167 \\
0.2211\end{array}$ \\
\hline $\begin{array}{l}917 \\
918 \\
919 \\
920\end{array}$ & $\begin{array}{l}9.2 \\
9.7 \\
8.0 \\
7.1\end{array}$ & $\begin{array}{l}9.6 \\
8.6 \\
7.9 \\
8.5\end{array}$ & $\begin{array}{l}0.96 \\
1.13 \\
1.01 \\
0.84\end{array}$ & $\begin{array}{r}11.31 \\
11.25 \\
9.57 \\
5.24\end{array}$ & $\begin{array}{l}3.06 \\
1.04 \\
1.82 \\
0.16\end{array}$ & $\begin{array}{l}0.5782 \\
0.6417 \\
0.4622 \\
0.2667\end{array}$ & $\begin{array}{l}0.4316 \\
0.5000 \\
0.3961 \\
0.2176\end{array}$ & $\begin{array}{l}0.4144 \\
0.4292 \\
0.3417 \\
0.1110\end{array}$ \\
\hline
\end{tabular}


OCCU-

PATION
$0.5000 \quad 0.7833$
0.5000
0.2167
$0.5000 \quad 0.2167$
$0.0500 \quad 0.5000$
$\begin{array}{lll}0.2167 & 0.2167\end{array}$
0.5000
0.216 .7
0.2167
0.2167
0.0500
0.0500
$\begin{array}{llll}0.4056 & 0.7833 & 0.5000\end{array}$
0.2167
0.2167
0.21670 .2167
0.0500
0.0500
10
$0.3775 \quad 0.4221$
0.3622
0.2689
0.2779
0.0500
0.5000
101
$\begin{array}{llll}0.8267 & 0.5567 & 0.4433\end{array}$
$\begin{array}{llll}0.2167 & 0.3300 & 0.3300\end{array}$
0.08330 .1500
.102
$\begin{array}{llll}0.9348 & 0.6803 & 0.2682\end{array}$
0.1712
$\begin{array}{ll}0.2682 & 0.2227 \\ 0.4528 & 0.4528\end{array}$
0.0652
0.1212
108
0.9500 .0 .78330 .3583
0.21670 .35830 .3583
0.0500
0.1889
109
0.88330 .7267
0.2167
0.1833
0.21670 .1833
0.0500
0.5000
111
0.61280 .7615
0.4564
$\begin{array}{lll}0.4564 & 0.4782 & 0.4782\end{array}$
0.0500
0.2967
114
$\begin{array}{lll}0.9500 & 0.7833 \\ 0.8944 & 0.7833 & 0 .\end{array}$
0.2167
0.5000
$0.5000 \cdot 0.5000$
0.0500
0.5654
121
0.61300 .8204
0.2482
$0.40560 .5000 \quad 0.5000$
0.0500
0.2167
124
$0.9500 \quad 0.7833$
0.2167
$\begin{array}{llll}0.5315 & 0.5944 & 0.5315\end{array}$
0.0685
0.3111
$\begin{array}{llll}0.7833 & 0.8667 & 0.6417\end{array}$
0.0500
0.5944
129
$\begin{array}{lll}0.3111 & 0.5944 & 0 .\end{array}$
0.2167
0.4056
0.31110 .4056
0.1056
0.5000
131
$0.3306 \quad 0.1889$
0.3111
0.1889
0.2167
0.2639
0.0500
0.4056
139
0.5000
0.5000
0.5000
0.3970
0.4485
0.4485
0.1106
0.0500
0.3583
0.8385
0.3583
0.2167
$0.3583 \quad 0.3583$
0.3583
0.0500
0.2333
140
$\begin{array}{ll}0.9500 & 0.7833 \\ 0.4646 & 0.4646\end{array}$
0.2698
$\begin{array}{llll}0.8177 & 0.8417 & 0.7865\end{array}$
0.0885
0.0500
141
0.2167
$\begin{array}{llll}0.7833 & 0.9500 & 0.7833\end{array}$
0.13330 .3583
143
0.78330 .7833
0.3229
0.4646
0.4646
0.5000
0.1750
0.3583
0.35830 .4292
0.2167
0.2875
$\begin{array}{ll}0.5000 & 0.5000 \\ 0.3583 & 0.4292\end{array}$
0.5000
0.21670 .5000
145
0.78330 .7833
0.2167
0.5000
0.5000
0.5708
0.5000
0.09170 .2458
146
$0.7250 \quad 0.5000$
0.2167
0.5000
0.7250 .0 .7250
$0.0500 \quad 0.5000$
147
0.21670 .7833
0.5000
0.2167
0.50000 .5000
$0.0500 \quad 0.2750$
148
153
$\begin{array}{lll}0.5708 & 0.7125 \\ 0.1611 & 0.7611 & 0\end{array}$
0.2639
$\begin{array}{llll}0.5000 & 0.6181 & 0.5236\end{array}$
0.0500
0.7833
0.16110 .1611
0.5000
0.1611
0.1611
0.1611
$\begin{array}{lll}0.0639 & 0.3681\end{array}$
171
0.5810
0.7024
0.4190
0.5000
0.5810
0.5405
$0.0500 \quad 0.0500$
172
$\begin{array}{llllllll}0.8375 & 0.8667 & 0.2167 & 0.8250 & 0.8250 & 0.7542\end{array}$
$0.0500 \quad 0.6690$
174
$\begin{array}{lll}0.2568 & 0.2377 \\ 0.2313 & 0.7833 & 0\end{array}$
0.4327
$\begin{array}{llll}0.2272 & 0.2272 & 0.2272\end{array}$
0.09170 .5000
176
0.23130 .7833
0.6063
0.42920 .3938
0.3938
$0.0500 \quad 0.0809$
182
$\begin{array}{lll}0.8551 & 0.7833\end{array}$
0.4877
0.72170 .7094
0.5246
0.1833
0.0917
183
0.78330 .7024
0.4595
0.37860 .4190
0.4190
$0.0500 \cdot 0.2254$
186
0.21670 .21670 .5000 .
$\begin{array}{llll}0.2167 & 0.2167 & 0.2167\end{array}$
0.14520 .0738
188
$0.0500 \quad 0.1929$
0.7429
$\begin{array}{llll}0.1929 & 0.2167 & 0.2167\end{array}$
$0.0500 \quad 0.0500$
191
0.21670 .5000
0.2167
0.21670 .2167
0.2167
0.0500
0.0500
192
0.20670 .2400
0.2733
$0.2400 \cdot 0.2733$
0.2733
$0.0500 \quad 0.2167$
195
$0.1750: 0$
0.31670 .4292
$0.1400 \quad 0.1400$
0.07920 .5167

APTITUDES

$\mathrm{S}$

$\mathrm{P}$

$\mathrm{K}$

$F$

$M$

E

c 
$\mathrm{OCCU}-$

PATION

196

198

199

201

203

212

214

223

232

234

241

249

307

312

314

325

331

338

339

403

405

412

413

414

415

416

417

419

431

433

451

452

453

454

455

456

457

459

51.0

520
APTITUDES

$$
\mathrm{Q}
$$

F

M

E

C

$\begin{array}{llllllll}0.7024 & 0.7024 & 0.2167 & 0.4595 & 0.4595 & 0.5000 & 0.0738 & 0.5000 \\ 0.4254 & 0.5895 & 0.3360 & 0.2974 & 0.3509 & 0.3360 & 0.0588 & 0.3281 \\ 0.6071 & 0.5270 & 0.2976 & 0.3516 & 0.4191 & 0.3571 & 0.0738 & 0.2802 \\ 0.1565 & 0.3301 & 0.7046 & 0.4292 & 0.4056 & 0.3662 & 0.0500 & 0.1412 \\ 0.3302 & 0.4381 & 0.4730 & 0.4730 & 0.4460 & 0.4190 & 0.0500 & 0.0817\end{array}$

$\begin{array}{llllllllll}0.2682 & 0.3712 & 0.5879 & 0.2167 & 0.2424 & 0.2939 & 0.0955 & 0.1561\end{array}$

$\begin{array}{llllllll}0.2283 & 0.3867 & 0.5567 & 0.3017 & 0.2167 & 0.3300 & 0.3\end{array}$

0.06670 .1950

$\begin{array}{lllllll}0.2167 & 0.2167 & 0.5000 & 0.3583 & 0.3583 & 0.3583\end{array}$

$\begin{array}{lllllll}0.1750 & 0.7833 & 0.7833 & 0.7479 & 0.5354 & 0.5000\end{array}$

$0.0500 \quad 0.1333$

0.23130 .4292

0.6417

0.60630 .64170 .4646

0.0708

$\begin{array}{llllllll}0.5000 & 0.5000 & 0.2167 & 0.5000 & 0.5000 & 0.5000\end{array}$

0.21670 .2167

0.17780 .3340

0.5702

0.32090 .35160 .3183

(1)

0.0516

0.0989

0.2167

0.2167

0.3583

0.2167

0.2167

0.2167

0.0500

0.1333

0.21670 .3111

0.2167

0.2167

(

0.1611

0.2167

0.35830 .3583

0.2167

$\begin{array}{llll}0.2167 & 0.2167 & 0.2167\end{array}$

0.0500

0.3583

$\begin{array}{llllllllll}0.2976 & 0.5000 & 0.4191 & 0.2976 & 0.2167 & 0.3786 & 0.0500 & 0.4357\end{array}$

$\begin{array}{lllllllll}0.2750 & 0.5000 & 0.6417 & 0.2167 & 0.2167 & 0.2167 & 0.0500 & 0.1333\end{array}$

$\begin{array}{llllllllll}0.2967 & 0.5000 & 0.3300 & 0.2167 & 0.2167 & 0.2167 & 0.0833 & 0.1733\end{array}$

$\begin{array}{llllllllll}0.2167 & 0.3111 & 0.1611 & 0.2167 & 0.3111 & 0.3111 & 0.0500 & 0.1056\end{array}$

$\begin{array}{llllllll}0.2167 & 0.3229 & 0.3229 & 0.3229 & 0.3229 & 0.3229 & 0.1333 & 0.0917\end{array}$

$\begin{array}{lllllllll}0.2167 & 0.2167 & 0.1750 & 0.2167 & 0.2167 & 0.2167 & 0.1625 & 0.0917\end{array}$

$\begin{array}{llllllll}0.2521 & 0.2875 & 0.2813 & 0.2521 & 0.2167 & 0.3229\end{array}$

$\begin{array}{llllllll}0.2167 & 0.5000 & 0.2167 & 0.2167 & 0.2167 & 0.5000 & 0.0\end{array}$

0.16250 .1750

0.21670 .2167

0.0500

0.21670 .21670 .5000

0.2167

$0.2000 \quad 0$.

30

$0.3867 \quad 0.2450 \quad 0.4433$

$.0500 \quad 0.2167$

$\begin{array}{llllllllll}0.3111 & 0.4056 & 0.1611 & 0.3111 & 0.4056 & 0.5000 & 0.1611 & 0.1611\end{array}$ $\begin{array}{llllllll}0.2167 & 0.2167 & 0.2400 & 0.2167 & 0.2167 & 0.3300\end{array}$

0.17330 .0500

$\begin{array}{llll}0.2069 & 0.3000 & 0.1353\end{array}$

$\begin{array}{llll}0.2402 & 0.2833 & 0.3333\end{array}$

$0.0598 \quad 0.1912$

0.37780 .3306

0.2556

$0.4806 \quad 0.4528$

0.3583

0.39720 .2083

0.28750.

70

0.29670 .7267

0.1833

0.2875

0.2167

0.3583

0.2750

0.0500

$\begin{array}{llllllllll}0.2167 & 0.4528 & 0.1611 & 0.2167 & 0.2639 & 0.4528 & 0.0500 & 0.3972\end{array}$

$\begin{array}{lllllllllll}0.2167 & 0.2167 & 0.2167 & 0.2167 & 0.2167 & 0.2167 & 0.0500 & 0.0500\end{array}$

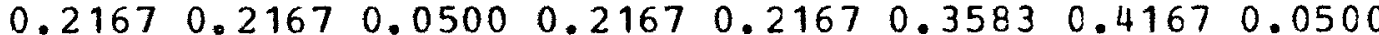

$\begin{array}{llllllllll}0.5000 & 0.5000 & 0.2167 & 0.5000 & 0.5000 & 0.5000 & 0.0500 & 0.5000\end{array}$

$\begin{array}{lllllllll}0.2875 & 0.2167 & 0.1750 & 0.2167 & 0.2167 & 0.2167 & 0.1333 & 0.2167\end{array}$

$\begin{array}{llllllllll}0.2095 & 0.2095 & 0.2095 & 0.2333 & 0.2333 & 0.2738 & 0.0738 & 0.1857\end{array}$

0.13330 .2283

0.07380 .1857

0.42920 .4292

0.1167

0.2283

0.1833

0.3017

0.0667

0.1617

0.78330.

$0.2875 \quad 0.2521$

0.28750 .3229

0.18330 .1125

$\begin{array}{llllll}0.7833 & 0.5000 & 0.5000 & 0.5000 & 0.2167\end{array}$ 
OCCU-

PATION

$$
\text { S }
$$

$\mathrm{p}$

APTITUDES

55

$0.5000 \quad 0.5000$

$Q$

$\mathrm{K}$

F

$M$

E

C

552

$0.5000 \quad 0.2167$

0.5000

$0.5000 \quad 0.5000$

0.5000

$0.5000 \quad 0.2167$

554

$0.4056 \quad 0.2167$

0.2167

$\begin{array}{llll}0.5000 & 0.2167\end{array}$

0.2167

0.5000

0.2167

556

$0.4292 \quad 0.2167$

0.2167

$0.4056 \quad 0.2167$

0.4056

0.4056

0.1611

581

0.2167

0.1750

$\begin{array}{llll}0.4292 & 0.2167 & 0.4292\end{array}$

$0.5000 \quad 0.1750$

582

$0.5944 \quad 0.5944$

0.2167

0.21670 .2167

$0.0500 \quad 0.0500$

584

585

588

0.21670 .3583

0.31110 .5000

0.3111

$0.4056 \quad 0.5000 \quad 0.5000$

$0.0500 \cdot 0.2083$

603

0.23330 .1929

0.3583

0.3583

0.35830 .3583

0.05000 .1750

$0.5000 \quad 0$.

0.3143

0.4056

0.5000

0.3111

$0.0500 \quad 0.1611$

605

$0.3300 \quad 0.5000$

0.2167

0.2167

0.2167

70

$\begin{array}{lll}0.1381 & 0.0976\end{array}$

607

0.21670 .2167

0.1833

0.3867

0.5000

0.3583

0.13330 .2167

609

0.28750 .4292

0.2167

$\begin{array}{lll}0.2167 & 0.2167\end{array}$

0.5000

$\begin{array}{lll}0.1733 & 0.3867\end{array}$

613

0.35830 .2875

0.1750

0.28750 .3111

0.2167

0.2167

0.2167

615

0.3275

0.2145

0.1058

0.2167

0.2167

0.4528

0.1389

0.1708

63

0.21670 .2413

0.0572

0.2659

0.2167

0.2875

0.2167

0.2167

657

0.31970 .2735

0.1462

0.2536

0.2413

30

0.

$0.1913 \quad 0.0717$

701

0.3583

0.5944

0.1611

0.2682

0.2424

0.3029

$0.1326 \quad 0.0862$

0.3017

0.5283

0.1783

0.2167

0.2639

0.3068

0.1417

0.0727

703

0.3712

0.4485

0.0803

0.3300

0.3867

0.3111

0.0500

0.1333

0.3712

0.34550 .5000

0.0500

0.2233

704

0.21670 .2167

0.2167

0.2167

0.3583

0.5000

0.0500

0.2227

705

0.2167

0.5000

0.2167

0.2167

0.2167

0.5000

$0.0500 \quad 0.2167$

706

707

0.33470 .4292

0.1500

0.2167

0.2167

0.3300

$0.0500 \quad 0.2167$

708

0.2639

0.3898

0.2028

0.3111

0.2403

0.3111

$\begin{array}{lll}0.0500 & 0.2067\end{array}$

709

$\begin{array}{lll}0.3583 & 0.5472\end{array}$

0.2639

0.2639

0.2482

0.3898

0.0500

0.2458

711

$\begin{array}{lll}0.2796 & 0.4685\end{array}$

0.2639

0.4056

0.2639

0.3583

$\begin{array}{lll}0.0778 & 0.2639\end{array}$

719

$\begin{array}{lll}0.2167 & 0.4292\end{array}$

0.1185

0.3583

0.3741

0.5000

0.10560 .0870

721

0.3133

0.4433

0.1750

0.4150

0.2875

0.2875

$0.0500 \quad 0.1333$

722

$\begin{array}{lll}0.3516 & 0.3921\end{array}$

0.07380 .4460

0.4717

0.5000

$\begin{array}{lll}0.1167 & 0.0833\end{array}$

72

$0.2750 \quad 0.5000$

0.2167

0.5000

0.5000

0.5135

0.1056

0.1429

729

73

0.39380 .5354

0.1542

0.5000

0.5000

$0.0500 \quad 0.6417$

73

0.31110 .4056

0.0500

0.4056

\section{6}

0.4056

0.4292

0.05000 .3229

73

0.31110 .4056

0.0500

0.4646

60

.

$0.0500 \quad 0.1056$

$0.0500 \quad 0.1542$

734

$\begin{array}{lll}0.5000 & 0.6417\end{array}$

0.2167

0.5000

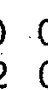

.5000

00.

$0.1056 \quad 0.1611$

735

736

0.37120 .5258

0.13640 .4742

0.47420.

$000 \quad 0.0500 \quad 0.3583$

737

0.5236

0.7125

$\begin{array}{lll}0.1986 & 0.5708\end{array}$

0.5236

0.4742

$0.0500 \quad 0.2076$

738

0.27330 .3867

0.2167

0.2167

0.2167

0.5236

$0.0500 \quad 0.2875$

0.21670 .3

0.3111

0.0500

0.3111

0.3111

0.4056

$0.0500 \quad 0.3867$

$0.0500 \quad 0.1056$ 
OCCU -

PATION

APTITUDES

\begin{tabular}{|c|c|c|c|c|c|c|c|c|}
\hline $\begin{array}{l}739 \\
741 \\
742 \\
743 \\
744\end{array}$ & $\begin{array}{l}0.2875 \\
0.6417 \\
0.5000 \\
0.3583 \\
0.5000\end{array}$ & $\begin{array}{l}0.5000 \\
0.5000 \\
0.5000 \\
0.6417 \\
0.5000\end{array}$ & $\begin{array}{l}0.1688 \\
0.2167 \\
0.2167 \\
0.1333 \\
0.2167\end{array}$ & $\begin{array}{l}0.3938 \\
0.5000 \\
0.5000 \\
0.5000 \\
0.5000\end{array}$ & $\begin{array}{l}0.3938 \\
0.5000 \\
0.5000 \\
0.5000 \\
0.6417\end{array}$ & $\begin{array}{l}0.4292 \\
0.5000 \\
0.5000 \\
0.5000 \\
0.5000\end{array}$ & $\begin{array}{l}0.0917 \\
0.2167 \\
0.0500 \\
0.0917 \\
0.0500\end{array}$ & $\begin{array}{l}0.3521 \\
0.6417 \\
0.4056 \\
0.4292 \\
0.5000\end{array}$ \\
\hline $\begin{array}{l}745 \\
746 \\
747 \\
749 \\
752\end{array}$ & $\begin{array}{l}0.3229 \\
0.3256 \\
0.4528 \\
0.3393 \\
0.4056\end{array}$ & $\begin{array}{l}0.4646 \\
0.4673 \\
0.5472 \\
0.4773 \\
0.4056\end{array}$ & $\begin{array}{l}0.2167 \\
0.1269 \\
0.1611 \\
0.1167 \\
0.1611\end{array}$ & $\begin{array}{l}0.5354 \\
0.5000 \\
0.4528 \\
0.4433 \\
0.4685\end{array}$ & $\begin{array}{l}0.4292 \\
0.5000 \\
0.5000 \\
0.4207 \\
0.4370\end{array}$ & $\begin{array}{l}0.5000 \\
0.4891 \\
0.5000 \\
0.4547 \\
0.5630\end{array}$ & $\begin{array}{l}0.0708 \\
0.0821 \\
0.0500 \\
0.0833 \\
0.1000\end{array}$ & $\begin{array}{l}0.3375 \\
0.2827 \\
0.3111 \\
0.2293 \\
0.1926\end{array}$ \\
\hline $\begin{array}{l}754 \\
756 \\
758 \\
759 \\
761\end{array}$ & $\begin{array}{l}0.3300 \\
0.5000 \\
0.2875 \\
0.2912 \\
0.4764\end{array}$ & $\begin{array}{l}0.3583 \\
0.4891 \\
0.5000 \\
0.4404 \\
0.4528\end{array}$ & $\begin{array}{l}0.1333 \\
0.2147 \\
0.2458 \\
0.1789 \\
0.2403\end{array}$ & $\begin{array}{l}0.3583 \\
0.4019 \\
0.2167 \\
0.3509 \\
0.3819\end{array}$ & $\begin{array}{l}0.2450 \\
0.4019 \\
0.2167 \\
0.3509 \\
0.3819\end{array}$ & $\begin{array}{l}0.4433 \\
0.5545 \\
0.2167 \\
0.4851 \\
0.4764\end{array}$ & $\begin{array}{l}0.0667 \\
0.0756 \\
0.0500 \\
0.0675 \\
0.0639\end{array}$ & $\begin{array}{l}0.1000 \\
0.0756 \\
0.2458 \\
0.1088 \\
0.2694\end{array}$ \\
\hline $\begin{array}{l}762 \\
763 \\
766 \\
768 \\
769\end{array}$ & $\begin{array}{l}0.3583 \\
0.2167 \\
0.3583 \\
0.3111 \\
0.3819\end{array}$ & $\begin{array}{l}0.3867 \\
0.3111 \\
0.3583 \\
0.4056 \\
0.4352\end{array}$ & $\begin{array}{l}0.1833 \\
0.1056 \\
0.2167 \\
0.1333 \\
0.2233\end{array}$ & $\begin{array}{l}0.2167 \\
0.2167 \\
0.3583 \\
0.2167 \\
0.2652\end{array}$ & $\begin{array}{l}0.2450 \\
0.2167 \\
0.3583 \\
0.2639 \\
0.2814\end{array}$ & $\begin{array}{l}0.3583 \\
0.2167 \\
0.5000 \\
0.3583 \\
0.4029\end{array}$ & $\begin{array}{l}0.0500 \\
0.0500 \\
0.2167 \\
0.0778 \\
0.0629\end{array}$ & $\begin{array}{l}0.1783 \\
0.1056 \\
0.0500 \\
0.1611 \\
0.2229\end{array}$ \\
\hline $\begin{array}{l}771 \\
772 \\
773 \\
775 \\
776\end{array}$ & $\begin{array}{l}0.4717 \\
0.5000 \\
0.5000 \\
0.5000 \\
0.5000\end{array}$ & $\begin{array}{l}0.6700 \\
0.6214 \\
0.7479 \\
0.7833 \\
0.5000\end{array}$ & $\begin{array}{l}0.5283 \\
0.2167 \\
0.2167 \\
0.2167 \\
0.2167\end{array}$ & $\begin{array}{l}0.4717 \\
0.3786 \\
0.5000 \\
0.6133 \\
0.5000\end{array}$ & $\begin{array}{l}0.5567 \\
0.5000 \\
0.5708 \\
0.6133 \\
0.5000\end{array}$ & $\begin{array}{l}0.5000 \\
0.5000 \\
0.6063 \\
0.7267 \\
0.5000\end{array}$ & $\begin{array}{l}0.0500 \\
0.1452 \\
0.0708 \\
0.0833 \\
0.2167\end{array}$ & $\begin{array}{l}0.1117 \\
0.3143 \\
0.3229 \\
0.2967 \\
0.5000\end{array}$ \\
\hline $\begin{array}{l}778 \\
779 \\
781 \\
782 \\
786\end{array}$ & $\begin{array}{l}0.3111 \\
0.3272 \\
0.4128 \\
0.2774 \\
0.4346\end{array}$ & $\begin{array}{l}0.4056 \\
0.5447 \\
0.3583 \\
0.4595 \\
0.4346\end{array}$ & $\begin{array}{l}0.1611 \\
0.2175 \\
0.1462 \\
0.1690 \\
0.1397\end{array}$ & $\begin{array}{l}0.4056 \\
0.4254 \\
0.3147 \\
0.2369 \\
0.2821\end{array}$ & $\begin{array}{l}0.4056 \\
0.4553 \\
0.2494 \\
0.2369 \\
0.3038\end{array}$ & $\begin{array}{l}0.5000 \\
0.4553 \\
0.4237 \\
0.3786 \\
0.5000\end{array}$ & $\begin{array}{l}0.0500 \\
0.0588 \\
0.0821 \\
0.0619 \\
0.1141\end{array}$ & $\begin{array}{l}0.1611 \\
0.1860 \\
0.2551 \\
0.3107 \\
0.0628\end{array}$ \\
\hline $\begin{array}{l}787 \\
788 \\
789 \\
791 \\
793\end{array}$ & $\begin{array}{l}0.4433 \\
0.4056 \\
0.2796 \\
0.6133 \\
0.4150\end{array}$ & $\begin{array}{l}0.4433 \\
0.5000 \\
0.4370 \\
0.7645 \\
0.6983\end{array}$ & $\begin{array}{l}0.2167 \\
0.1611 \\
0.1426 \\
0.1944 \\
0.2567\end{array}$ & $\begin{array}{l}0.2733 \\
0.3111 \\
0.3269 \\
0.6511 \\
0.6700\end{array}$ & $\begin{array}{l}0.2167 \\
0.2167 \\
0.3583 \\
0.6700 \\
0.6700\end{array}$ & $\begin{array}{l}0.4433 \\
0.4056 \\
0.4685 \\
0.5944 \\
0.5283\end{array}$ & $\begin{array}{l}0.0500 \\
0.1611 \\
0.0843 \\
0.0500 \\
0.0500\end{array}$ & $\begin{array}{l}0.0500 \\
0.2000 \\
0.0963 \\
0.2444 \\
0.1783\end{array}$ \\
\hline $\begin{array}{l}801 \\
803 \\
306 \\
808 \\
811\end{array}$ & $\begin{array}{l}0.6574 \\
0.3980 \\
0.4782 \\
0.4622 \\
0.6020\end{array}$ & $\begin{array}{l}0.7204 \\
0.5907 \\
0.4891 \\
0.5425 \\
0.5340\end{array}$ & $\begin{array}{l}0.2167 \\
0.1567 \\
0.1718 \\
0.2011 \\
0.2013\end{array}$ & $\begin{array}{l}0.5472 \\
0.4093 \\
0.4455 \\
0.4481 \\
0.5113\end{array}$ & $\begin{array}{l}0.5315 \\
0.4093 \\
0.4891 \\
0.4244 \\
0.4367\end{array}$ & $\begin{array}{l}361 \\
227 \\
090 \\
236 \\
360\end{array}$ & $\begin{array}{l}0.0593 \\
0.0500 \\
0.1212 \\
0.0789 \\
0.1640\end{array}$ & $\begin{array}{l}0.0750 \\
0.0567 \\
0.0692 \\
0.0528 \\
0.0767\end{array}$ \\
\hline
\end{tabular}


OCCDPATION

$$
\mathrm{S}
$$

P

APTITUDES

812

$\begin{array}{lll}0.3868 & 0.3868\end{array}$

Q

$\mathrm{K}$

F

M

E

C

815

817

0.2167

0.4433

0.5944

0.1202

0.4851

0.3509

0.4702

$0.3070 \quad 0.0912$

818

0.2167

0.5000

0.1611

0.4056

0.4056

0.4056

0.0500

0.4056

819

$\begin{array}{lll}0.4356 & 0.5644\end{array}$

0.2033

$\begin{array}{lll}0.4660 & 0.4207\end{array}$

0.5000

0.1080

0.2520

821

$\begin{array}{lll}0.7576 & 0.7576\end{array}$

0.0500

$\begin{array}{lll}0.2167 & 0.2167\end{array}$

0.5000

0.05000 .2167

822

824

829

$\begin{array}{lll}0.5118 & 0.5236\end{array}$

0.2424

0.5000

0.46140 .5386

0.0727

0.0780

831

$\begin{array}{lll}0.6889 & 0.6889\end{array}$

0.1403

$0.4646 \quad 0.46460 .6063$

$0.2273 \quad 0.0652$

$0.5648 \quad 0.6214$

0.3111

$0.4528 \quad 0.547$

$0.1062 \quad 0.1333$

$0.5157 \quad 0.7440$

0.2152

0.5944

$0.0500 \quad 0.1333$

832

$0.5000 \quad 0.6000$

0.2120

0.45950 .5324

0.6457

0.09330 .1200

835

$0.5000 \quad 0.68890 .8$

0.1480

0.4833

0.7204

0.3310

0.2357

836

$0.5000 \quad 0.7833$

0.2167

$\begin{array}{llll}0.4833 & 0.5000 & 0.5667\end{array}$

0.07650 .0990

839

0.34890 .4622

0.2167

$\begin{array}{llll}0.7833 & 0.7833 & 0.5000\end{array}$

0.0778

.1889

841

$0.24820 .4790 \quad 0.1920$

$\begin{array}{llll}0.4244 & 0.4811 & 0.4056\end{array}$

0.0500

0.5000

843

$\begin{array}{llll}0.3111 & 0.5472 & 0.2083\end{array}$

0.39510 .4265

0.5000

0.0611

0.3395

0.0944

854

$\begin{array}{lll}0.4370 & 0.5000\end{array}$

0.1889

0.45280 .5000

0.5000

0.0500

0.5568

859

0.3229

0.4469

0.1542

0.4528

0.4056

(

0.3406

0.3406

0.6417

0.4093

0.3778

861

0.4622

0.7078

0.2056

0.5756

0.6133

0.5000

0.4333

0.1676

862

$\begin{array}{lll}0.2733 & 0.3867\end{array}$

0.1833

0.2733

0.3300

0.5000

0.0611

0.0813

864

0.42920 .4

0.4292

0.1889

0.5000

0.4056

0.3300

0.0833

0.1322

869

877

0.2924

0.5000

0.1542

0.3465

0.3632

0.5236

0.06390 .1431

0.5000

0.2167

0.1611

0.4056

0.3111

0.4646

$0.0500 \quad 0.2063$

0.5000

0.2167

0.2167

0.4056

0.40560 .0500

911

0.2167

0.5000

0.21670

0.2976

0.21670 .2167

$\begin{array}{lll}0.0500 & 0.2167\end{array}$

912

0.2308

0.5992

0.4595

$0.0738 \quad 0.1619$

913

914

915

0.29170 .3250

0.1333

0.59920

0.5567

0.6700

0.08330 .1250

$\begin{array}{lll}0.3583 & 0.358\end{array}$

0.1333

0.2167

0.2939

0.3712

$\begin{array}{lll}0.0652 & 0.1538\end{array}$

$\begin{array}{lll}0.3583 & 0.5708\end{array}$

0.1750

0.3583

0.3583

0.5000

$0.0500 \quad 0.0500$

916

0.24330 .518

0.1611

0.25440 .4292

0.4292

$0.0500 \quad 0.4292$

917

0.43160 .6

0.6563

0.2247

$0.3046 \quad 0.3828$

0.3300

$0.0500 \quad 0.4589$

918

919

$\begin{array}{lll}0.2167 & 0.6417\end{array}$

$\begin{array}{llll}0.1750 & 0.2167 & 0.3\end{array}$

0.38280 .4023

$0.1195 \quad 0.1362$

920

$\begin{array}{lll}0.5039 & 0.5094\end{array}$

0.1872

0.4244

0.2875

0.3583

$0.0500 \quad 0.2875$

$\begin{array}{lll}0.2411 & 0.2788\end{array}$

$\begin{array}{lll}0.0991 & 0.2687\end{array}$

$\begin{array}{lll}0.0706 & 0.1561\end{array}$

$0.1678 \quad 0.1238$ 
OCCU-

PATION $1 \begin{array}{llllllllllllllllllllll} & 2 & 3 & 4 & 5 & 6 & 7 & 8 & 9 & 0 & \mathrm{X} & \mathrm{Y} & 1 & 2 & 3 & 4 & 5 & 6 & 7 & 8 & 9 & 0\end{array}$

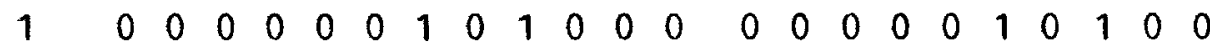

$4 \begin{array}{lllllllllllllllllllllll}4 & 0 & 0 & 0 & 1 & 1 & 0 & 0 & 0 & 0 & 0 & 0 & 0 & 0 & 0 & 0 & 0 & 1 & 1 & 0 & 0 & 0 & 0\end{array}$

$6 \begin{array}{lllllllllllllllllllllll}6 & 0 & 0 & 0 & 1 & 1 & 0 & 0 & 0 & 0 & 0 & 0 & 0 & 0 & 1 & 0 & 0 & 1 & 0 & 0 & 0 & 0 & 0\end{array}$

$8 \begin{array}{lllllllllllllllllllllll}8 & 0 & 0 & 0 & 0 & 1 & 0 & 0 & 0 & 1 & 0 & 0 & 0 & 0 & 1 & 0 & 0 & 1 & 0 & 0 & 0 & 0 & 0\end{array}$

$10 \begin{array}{lllllllllllllllllllllll} & 0 & 0 & 0 & 1 & 0 & 0 & 0 & 0 & 0 & 0 & 0 & 0 & 0 & 1 & 0 & 0 & 1 & 0 & 0 & 0 & 0 & 0\end{array}$

$101 \quad 0 \begin{array}{lllllllllllllllllllll}10 & 0 & 1 & 0 & 0 & 0 & 0 & 0 & 0 & 0 & 0 & 0 & 0 & 0 & 0 & 1 & 0 & 1 & 0 & 0 & 0\end{array}$

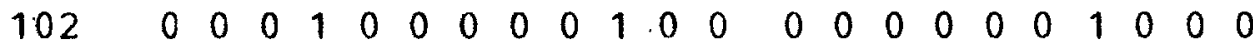

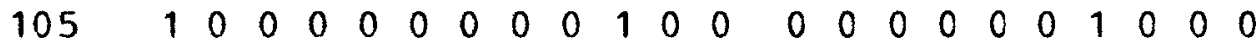
$\begin{array}{lllllllllllllllllllllll}108 & 0 & 0 & 0 & 1 & 0 & 0 & 0 & 0 & 0 & 1 & 0 & 1 & 1 & 0 & 0 & 0 & 0 & 0 & 1 & 1 & 0 & 0\end{array}$

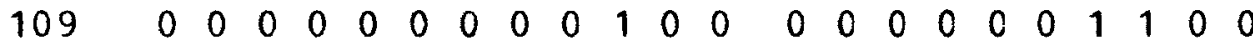

$\begin{array}{lllllllllllllllllllllll}111 & 0 & 0 & 0 & 0 & 0 & 0 & 0 & 0 & 0 & 1 & 0 & 1 & 0 & 0 & 0 & 0 & 0 & 0 & 1 & 1 & 0 & 0\end{array}$

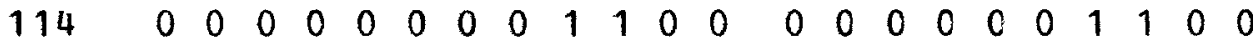

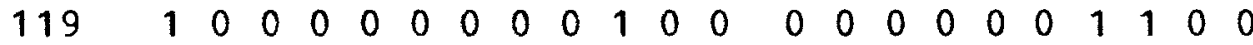

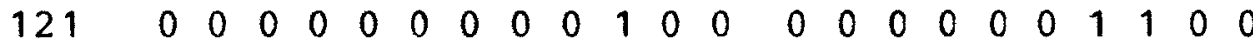

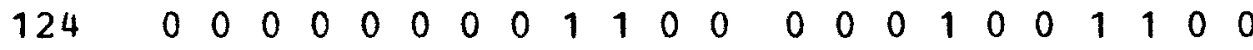

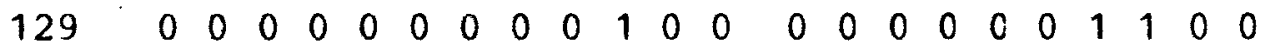

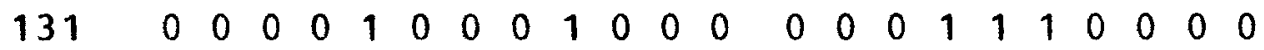

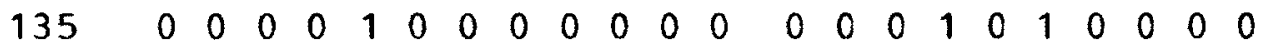
$1390 \begin{array}{llllllllllllllllllllll}139 & 0 & 0 & 1 & 1 & 0 & 0 & 0 & 0 & 0 & 0 & 0 & 0 & 0 & 0 & 1 & 1 & 1 & 0 & 0 & 0 & 0\end{array}$

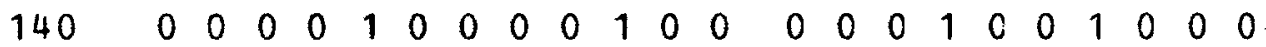

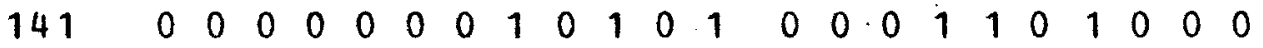
$142 \quad 0 \begin{array}{llllllllllllllllllllll} & 0 & 0 & 0 & 1 & 0 & 0 & 0 & 0 & 0 & 0 & 1 & 0 & 0 & 0 & 1 & 0 & 0 & 1 & 0 & 0 & 0\end{array}$

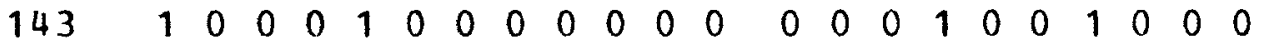

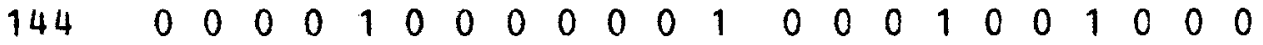

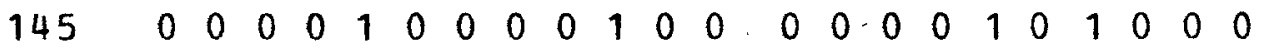

$\begin{array}{lllllllllllllllllllllll}146 & 0 & 0 & 0 & 0 & 1 & 0 & 0 & 0 & 0 & 1 & 0 & 1 & 0 & 0 & 0 & 1 & 0 & 0 & 1 & 1 & 0 & 0\end{array}$

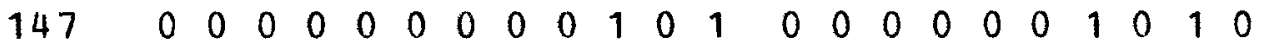

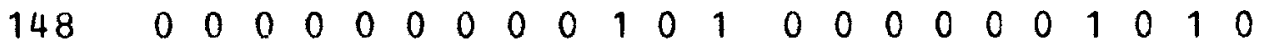

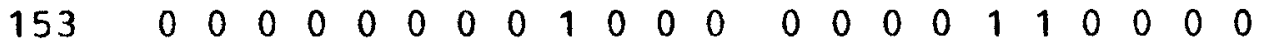

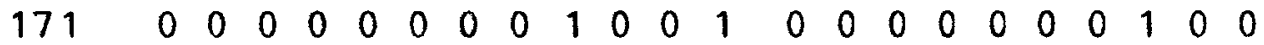

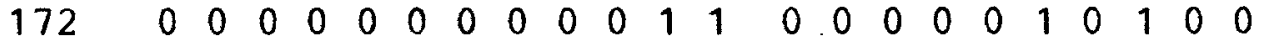

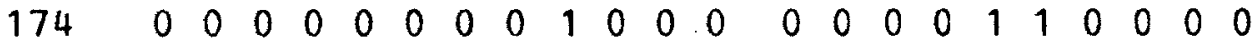
$176 \quad 0 \begin{array}{lllllllllllllllllllll}176 & 0 & 0 & 0 & 0 & 0 & 0 & 0 & 0 & 1 & 1 & 0 & 0 & 0 & 0 & 1 & 1 & 0 & 0 & 0 & 0\end{array}$

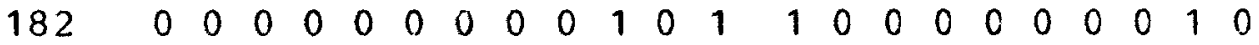

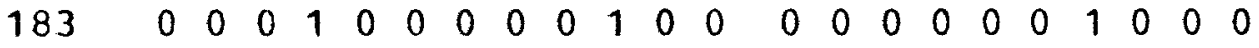

$\begin{array}{lllllllllllllllllllllll}186 & 0 & 0 & 0 & 0 & 0 & 0 & 0 & 0 & 1 & 0 & 0 & 1 & 0 & 0 & 0 & 0 & 0 & 0 & 1 & 1 & 0 & 0\end{array}$ $188 \quad \begin{array}{llllllllllllllllllllll}18 & 0 & 0 & 1 & 0 & 0 & 0 & 0 & 0 & 1 & 0 & 0 & 1 & 1 & 0 & 0 & 0 & 0 & 0 & 0 & 0 & 0\end{array}$

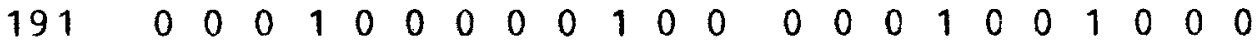

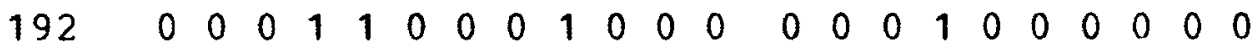

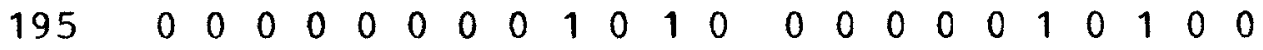


OCCU-

PATION $1 \begin{array}{llllllllllllllllllllll} & 2 & 3 & 4 & 5 & 6 & 7 & 8 & 9 & 0 & \mathrm{X} & \mathrm{Y} & 1 & 2 & 3 & 4 & 5 & 6 & 7 & 8 & 9 & 0\end{array}$

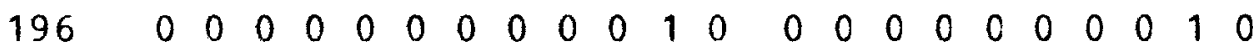

$198 \quad 0 \begin{array}{llllllllllllllllllllll} & 0 & 0 & 0 & 0 & 0 & 0 & 0 & 0 & 1 & 0 & 1 & 0 & 0 & 0 & 0 & 0 & 0 & 1 & 0 & 0 & 0\end{array}$

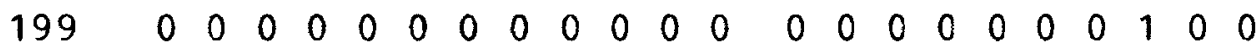

$201 \quad 0 \begin{array}{lllllllllllllllllllll}20 & 0 & 0 & 0 & 0 & 0 & 0 & 0 & 0 & 0 & 0 & 1 & 0 & 1 & 0 & 0 & 0 & 0 & 0 & 0 & 0\end{array}$

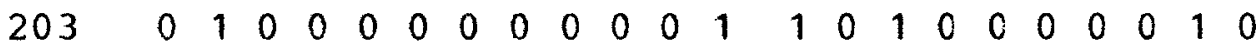

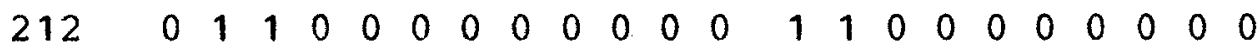

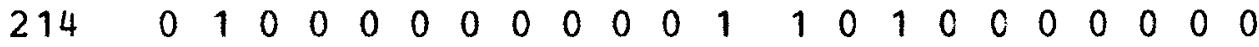

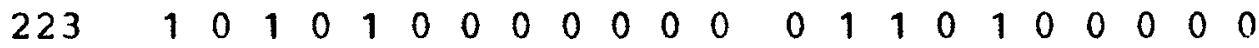

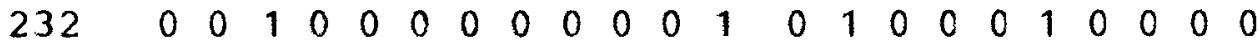

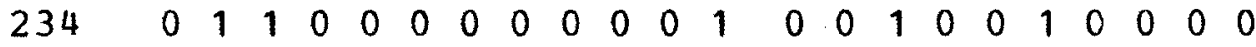

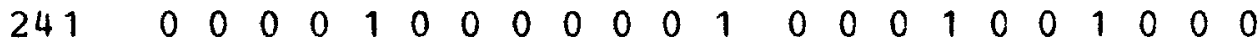

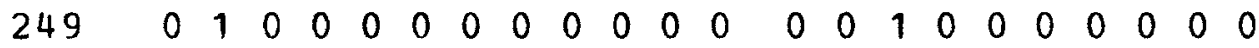

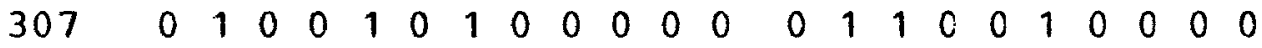

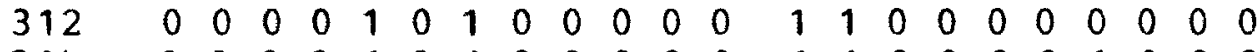
$\begin{array}{lllllllllllllllllllllll}314 & 0 & 0 & 0 & 0 & 1 & 0 & 1 & 0 & 0 & 0 & 0 & 0 & 1 & 1 & 0 & 0 & 0 & 0 & 1 & 0 & 0 & 0\end{array}$

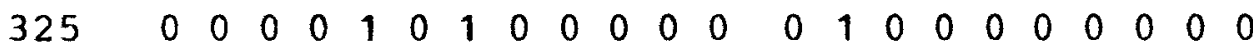

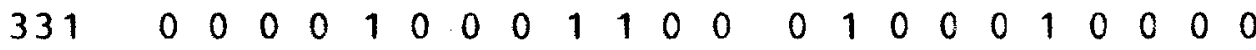

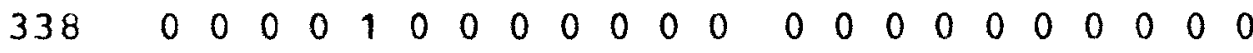

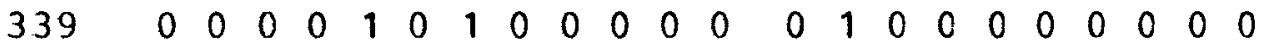

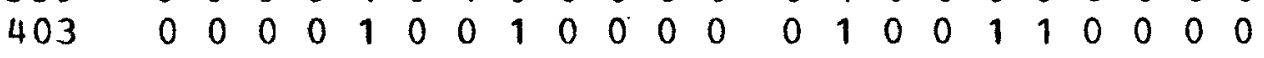

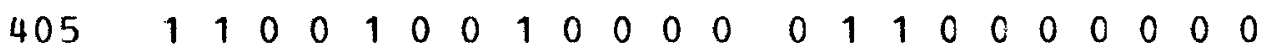

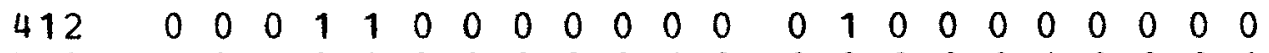

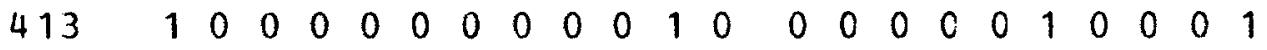
$\begin{array}{lllllllllllllllllllllll}414 & 0 & 0 & 1 & 0 & 1 & 0 & 0 & 0 & 0 & 0 & 0 & 0 & 1 & 1 & 0 & 0 & 0 & 0 & 0 & 0 & 0 & 0\end{array}$ $\begin{array}{lllllllllllllllllllllll}415 & 0 & 0 & 1 & 0 & 1 & 0 & 0 & 0 & 0 & 0 & 0 & 0 & 0 & 1 & 1 & 0 & 0 & 0 & 0 & 0 & 0 & 0\end{array}$

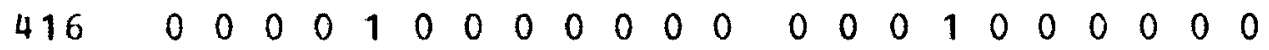

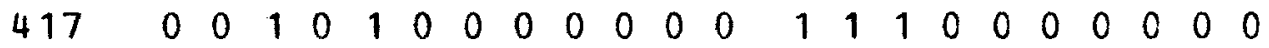

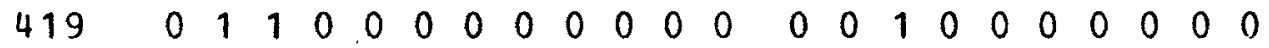

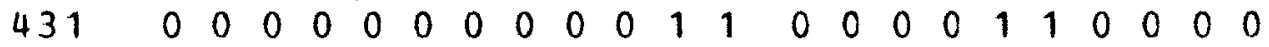

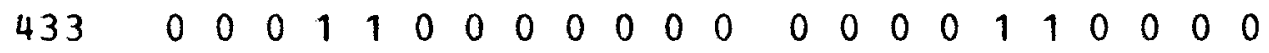

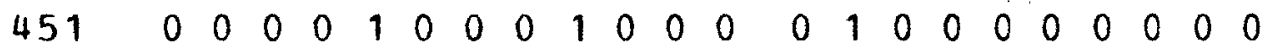

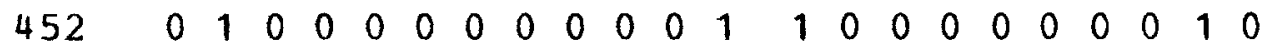

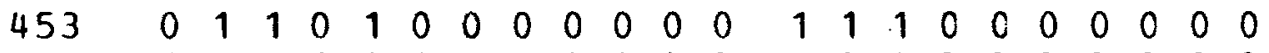

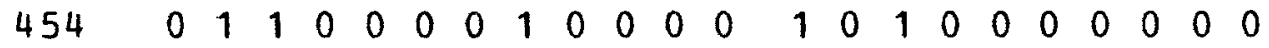

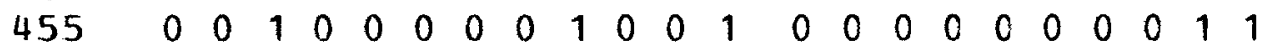

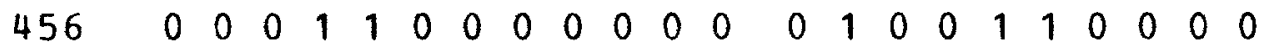

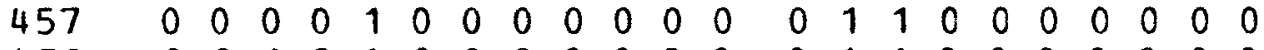
$459 \begin{array}{lllllllllllllllllllllll}45 & 0 & 1 & 0 & 1 & 0 & 0 & 0 & 0 & 0 & 0 & 0 & 0 & 1 & 1 & 0 & 0 & 0 & 0 & 0 & 0 & 0\end{array}$

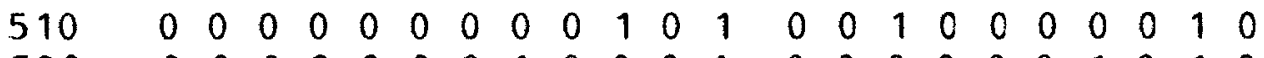

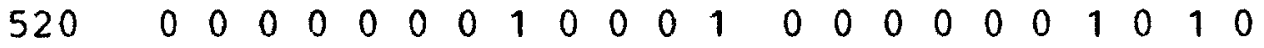


OCCU- TEMPERAMENTS

INTERESTS

PATION $1 \begin{array}{lllllllllllllllllllllll} & 2 & 3 & 4 & 5 & 6 & 7 & 8 & 9 & 0 & \mathrm{X} & \mathrm{Y} & 1 & 2 & 3 & 4 & 5 & 6 & 7 & 8 & 9 & 0\end{array}$

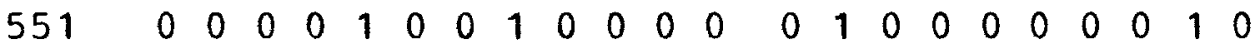

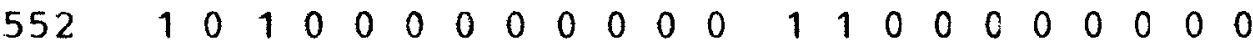

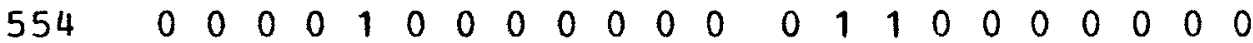

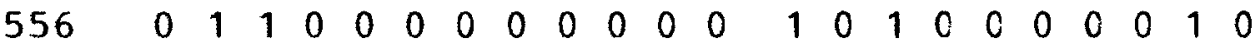

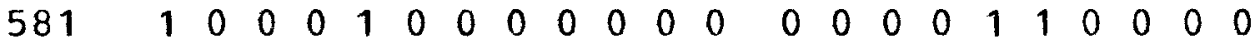

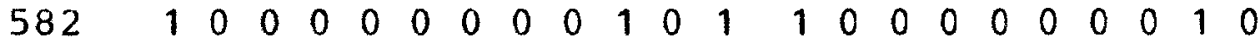

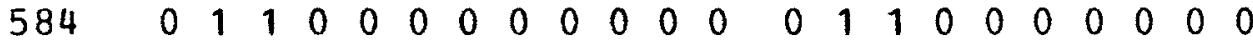

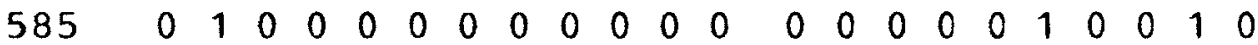
$588 \quad \begin{array}{llllllllllllllllllllll}5 & 0 & 1 & 0 & 1 & 0 & 0 & 0 & 0 & 0 & 0 & 0 & 0 & 1 & 1 & 0 & 0 & 0 & 0 & 0 & 0 & 0\end{array}$

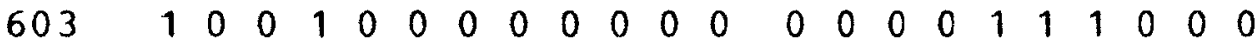

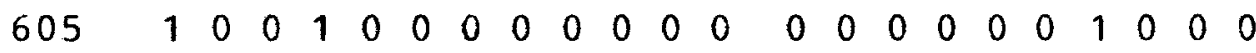

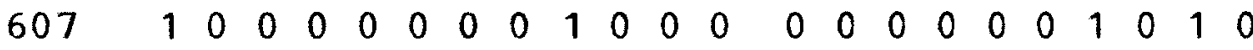

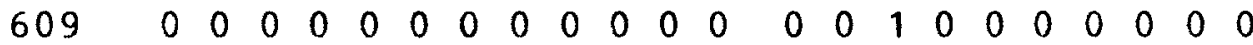

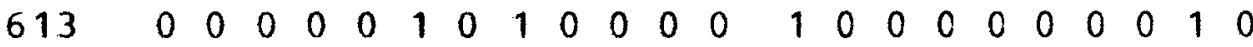

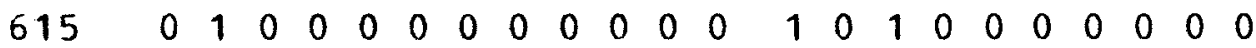

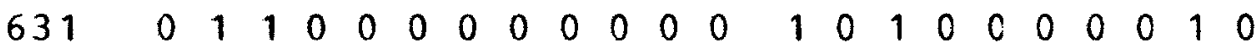

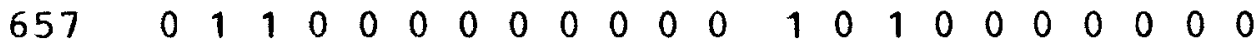
$\begin{array}{lllllllllllllllllllllll}7.01 & 0 & 0 & 0 & 0 & 0 & 0 & 0 & 0 & 0 & 0 & 0 & 1 & 1 & 0 & 1 & 0 & 0 & 0 & 0 & 0 & 1 & 0\end{array}$ $\begin{array}{lllllllllllllllllllllll}702 & 0 & 0 & 0 & 0 & 0 & 0 & 0 & 0 & 1 & 0 & 0 & 1 & 0 & 0 & 0 & 0 & 0 & 0 & 0 & 0 & 1 & 1\end{array}$

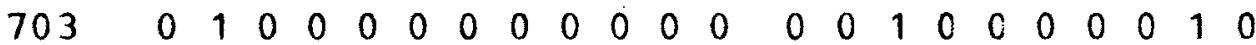

$\begin{array}{lllllllllllllllllllllll}704 & 0 & 1 & 0 & 0 & 0 & 0 & 0 & 0 & 0 & 0 & 0 & 1 & 1 & 0 & 1 & 0 & 0 & 0 & 0 & 0 & 0 & 0\end{array}$ $\begin{array}{lllllllllllllllllllllll}705 & 0 & 0 & 0 & 0 & 0 & 0 & 0 & 0 & 1 & 0 & 1 & 0 & 0 & 0 & 0 & 0 & 0 & 1 & 0 & 0 & 0 & 1\end{array}$ $\begin{array}{lllllllllllllllllllllll}706 & 0 & 1 & 0 & 0 & 0 & 0 & 0 & 0 & 0 & 0 & 0 & 1 & 1 & 0 & 0 & 0 & 0 & 0 & 0 & 0 & 0 & 0\end{array}$

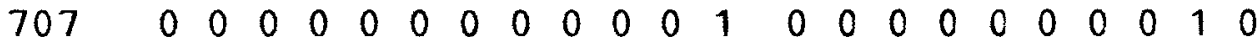
$\begin{array}{lllllllllllllllllllllll}708 & 0 & 1 & 0 & 0 & 0 & 0 & 0 & 0 & 0 & 0 & 0 & 0 & 1 & 0 & 1 & 0 & 0 & 0 & 0 & 0 & 1 & 0\end{array}$

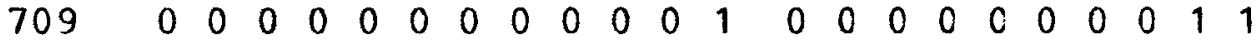

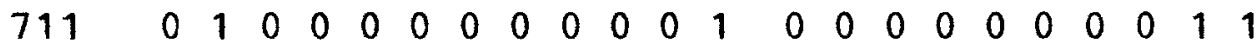

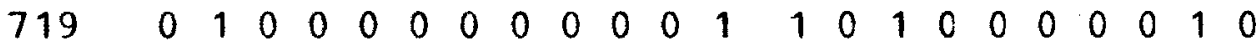
$\begin{array}{lllllllllllllllllllllll}721 & 0 & 1 & 0 & 0 & 0 & 0 & 0 & 0 & 0 & 0 & 0 & 1 & 1 & 0 & 1 & 0 & 0 & 0 & 0 & 0 & 1 & 0\end{array}$ $\begin{array}{lllllllllllllllllllllll}722 & 0 & 1 & 0 & 0 & 0 & 0 & 0 & 0 & 0 & 0 & 0 & 1 & 0 & 0 & 0 & 0 & 0 & 0 & 0 & 0 & 1 & 0\end{array}$

$\begin{array}{lllllllllllllllllllllll}724 & 1 & 1 & 0 & 0 & 0 & 0 & 0 & 0 & 0 & 0 & 0 & 1 & 0 & 0 & 0 & 0 & 0 & 0 & 0 & 0 & 1 & 1\end{array}$

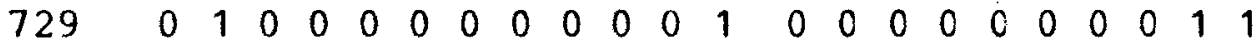
$731 \quad \begin{array}{llllllllllllllllllllll}73 & 1 & 1 & 0 & 0 & 0 & 0 & 0 & 0 & 0 & 0 & 0 & 1 & 0 & 1 & 0 & 0 & 0 & 0 & 0 & 0 & 1\end{array}$ $732 \quad 0 \begin{array}{lllllllllllllllllllll}732 & 0 & 0 & 0 & 0 & 0 & 0 & 0 & 0 & 0 & 1 & 1 & 0 & 1 & 0 & 0 & 0 & 0 & 0 & 0 & 0\end{array}$ $\begin{array}{lllllllllllllllllllllll}733 & 0 & 1 & 0 & 0 & 0 & 0 & 0 & 0 & 0 & 0 & 0 & 1 & 1 & 0 & 1 & 0 & 0 & 0 & 0 & 0 & 0 & 0\end{array}$

$\begin{array}{lllllllllllllllllllllll}734 & 0 & 1 & 0 & 0 & 0 & 0 & 0 & 0 & 0 & 1 & 0 & 1 & 0 & 0 & 0 & 0 & 0 & 0 & 0 & 0 & 1 & 1\end{array}$ $\begin{array}{lllllllllllllllllllllll}735 & 0 & 1 & 0 & 0 & 0 & 0 & 0 & 0 & 0 & 0 & 0 & 1 & 0 & 0 & 1 & 0 & 0 & 0 & 0 & 0 & 1 & 0\end{array}$

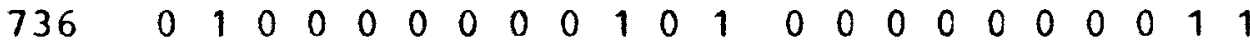

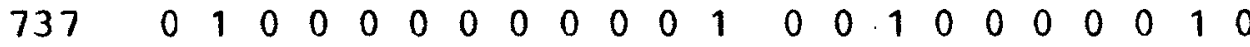
$\begin{array}{lllllllllllllllllllllll}738 & 0 & 1 & 1 & 0 & 0 & 0 & 0 & 0 & 0 & 0 & 0 & 0 & 1 & 0 & 1 & 0 & 0 & 0 & 0 & 0 & 0 & 0\end{array}$ 
OCCU-

PATION $1 \begin{array}{llllllllllllllllllllll} & 2 & 3 & 4 & 5 & 6 & 7 & 8 & 9 & 0 & \mathrm{X} & \mathrm{Y} & 1 & 2 & 3 & 4 & 5 & 6 & 7 & 8 & 9 & 0\end{array}$

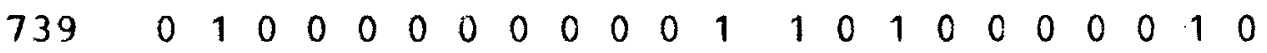

$\begin{array}{lllllllllllllllllllllll}741 & 0 & 1 & 0 & 0 & 0 & 0 & 0 & 0 & 0 & 0 & 1 & 1 & 1 & 0 & 0 & 0 & 0 & 0 & 0 & 1 & 1 & 1\end{array}$

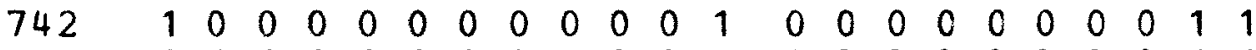

$743 \quad \begin{array}{llllllllllllllllllllll}74 & 0 & 0 & 0 & 0 & 0 & 0 & 0 & 1 & 0 & 0 & 1 & 0 & 0 & 0 & 0 & 0 & 0 & 0 & 0 & 1 & 1\end{array}$

$\begin{array}{lllllllllllllllllllllll}744 & 1 & 0 & 0 & 0 & 0 & 0 & 0 & 0 & 0 & 0 & 1 & 1 & 0 & 0 & 0 & 0 & 0 & 1 & 0 & 1 & 1 & 1\end{array}$

$\begin{array}{lllllllllllllllllllllll}745 & 0 & 1 & 0 & 0 & 0 & 0 & 0 & 0 & 0 & 0 & 0 & 1 & 1 & 0 & 0 & 0 & 0 & 0 & 0 & 0 & 1 & 0\end{array}$

$\begin{array}{lllllllllllllllllllllll}746 & 0 & 1 & 0 & 0 & 0 & 0 & 0 & 0 & 0 & 0 & 0 & 1 & 0 & 0 & 1 & 0 & 0 & 0 & 0 & 0 & 1 & 0\end{array}$

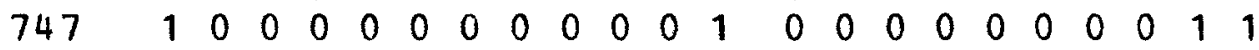

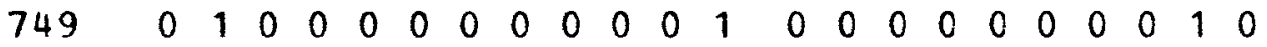

$\begin{array}{lllllllllllllllllllllll}752 & 0 & 0 & 0 & 0 & 0 & 0 & 0 & 0 & 0 & 0 & 0 & 1 & 0 & 0 & 0 & 0 & 0 & 0 & 0 & 0 & 1 & 1\end{array}$

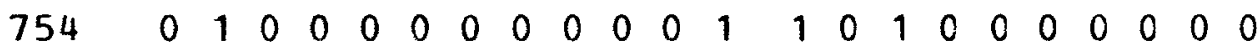

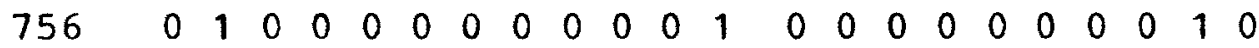

$\begin{array}{lllllllllllllllllllllll}758 & 0 & 1 & 0 & 0 & 0 & 0 & 0 & 0 & 0 & 1 & 0 & 1 & 1 & 0 & 0 & 0 & 0 & 0 & 0 & 0 & 1 & 0\end{array}$

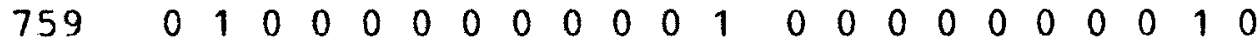

$\begin{array}{lllllllllllllllllllllll}761 & 0 & 0 & 0 & 0 & 0 & 0 & 0 & 0 & 0 & 1 & 0 & 1 & 1 & 0 & 0 & 0 & 0 & 0 & 0 & 0 & 1 & 0\end{array}$

$\begin{array}{lllllllllllllllllllllll}762 & 0 & 1 & 0 & 0 & 0 & 0 & 0 & 0 & 0 & 0 & 0 & 1 & 1 & 0 & 0 & 0 & 0 & 0 & 0 & 0 & 1 & 0\end{array}$

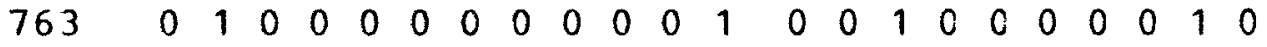

$\begin{array}{lllllllllllllllllllllll}766 & 0 & 1 & 0 & 0 & 0 & 0 & 0 & 0 & 0 & 0 & 0 & 1 & 1 & 0 & 1 & 0 & 0 & 0 & 0 & 0 & 1 & 0\end{array}$

$\begin{array}{lllllllllllllllllllllll}768 & 0 & 1 & 0 & 0 & 0 & 0 & 0 & 0 & 0 & 0 & 0 & 1 & 1 & 0 & 1 & 0 & 0 & 0 & 0 & 0 & 1 & 0\end{array}$

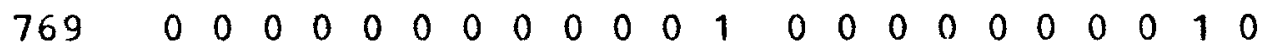

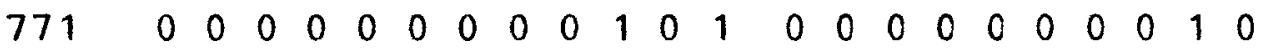

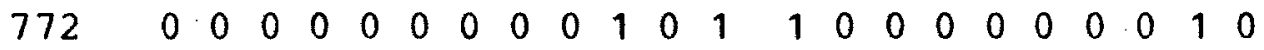

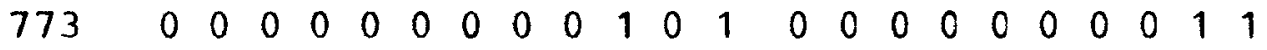

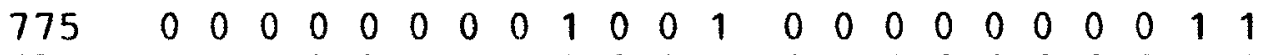
$\begin{array}{lllllllllllllllllllllll}776 & 1 & 0 & 0 & 0 & 0 & 0 & 0 & 0 & 0 & 0 & 0 & 1 & 0 & 0 & 0 & 0 & 0 & 0 & 0 & 0 & 1 & 1\end{array}$

$\begin{array}{lllllllllllllllllllllll}778 & 0 & 1 & 1 & 0 & 0 & 0 & 0 & 0 & 0 & 0 & 0 & 0 & 0 & 0 & 1 & 0 & 0 & 0 & 0 & 0 & 1 & 0\end{array}$ $779 \begin{array}{llllllllllllllllllllll}779 & 0 & 0 & 0 & 0 & 0 & 0 & 0 & 0 & 0 & 0 & 1 & 1 & 0 & 0 & 0 & 0 & 0 & 0 & 0 & 1 & 0\end{array}$ $\begin{array}{lllllllllllllllllllllll}781 & 0 & 0 & 0 & 0 & 0 & 0 & 0 & 0 & 0 & 0 & 0 & 1 & 1 & 0 & 0 & 0 & 0 & 0 & 0 & 0 & 1 & 0\end{array}$ $\begin{array}{lllllllllllllllllllllll}782 & 0 & 0 & 0 & 0 & 0 & 0 & 0 & 0 & 0 & 1 & 0 & 1 & 1 & 0 & 0 & 0 & 0 & 0 & 0 & 0 & 1 & 0\end{array}$ $\begin{array}{lllllllllllllllllllllll}786 & 0 & 0 & 0 & 0 & 0 & 0 & 0 & 0 & 0 & 0 & 0 & 1 & 0 & 0 & 0 & 0 & 0 & 0 & 0 & 0 & 1 & 1\end{array}$

$\begin{array}{lllllllllllllllllllllll}787 & 0 & 1 & 0 & 0 & 0 & 0 & 0 & 0 & 0 & 0 & 0 & 1 & 0 & 0 & 0 & 0 & 0 & 0 & 0 & 0 & 1 & 1\end{array}$ $\begin{array}{lllllllllllllllllllllll}788 & 0 & 1 & 0 & 0 & 0 & 0 & 0 & 0 & 0 & 0 & 0 & 1 & 1 & 0 & 0 & 0 & 0 & 0 & 0 & 0 & 1 & 0\end{array}$

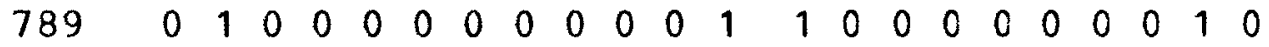

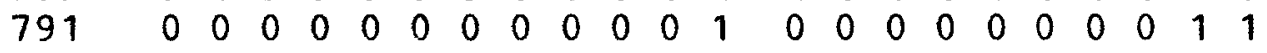

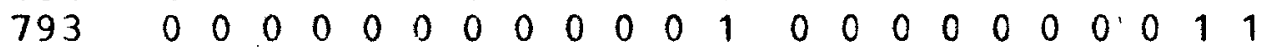

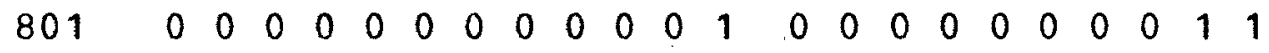

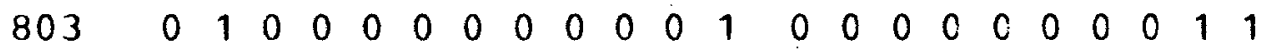

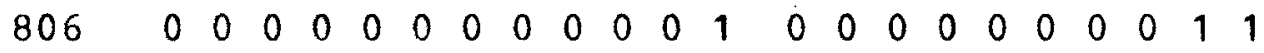

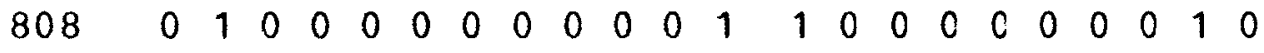

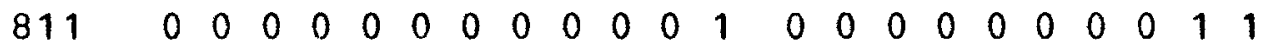


OCCU-

PATION $1 \begin{array}{llllllllllllllllllllll} & 2 & 3 & 4 & 5 & 6 & 7 & 8 & 9 & 0 & \mathrm{X} & \mathrm{Y} & 1 & 2 & 3 & 4 & 5 & 6 & 7 & 8 & 9 & 0\end{array}$

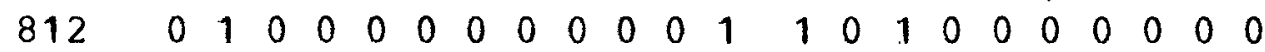

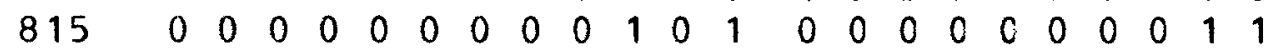

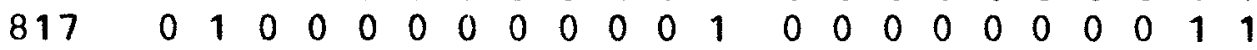

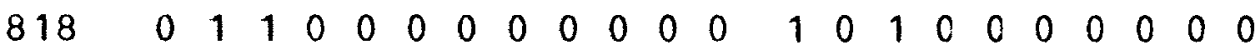

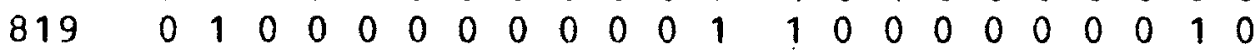

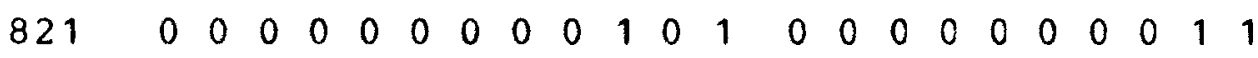

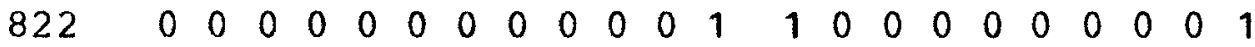

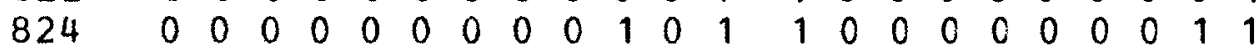

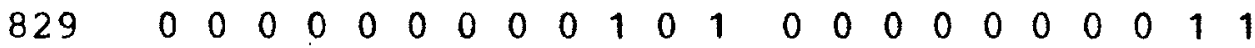

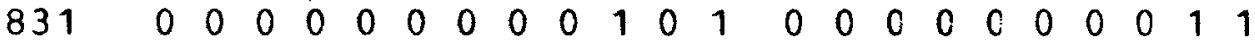

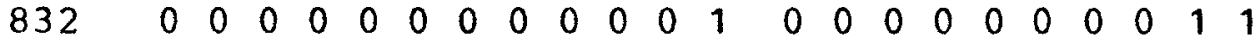

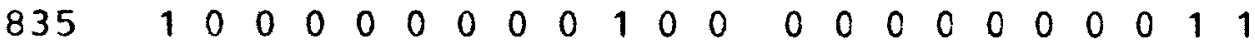

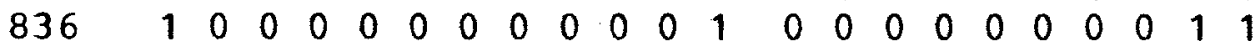

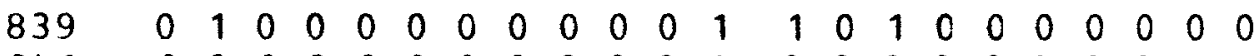

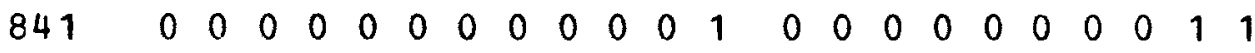

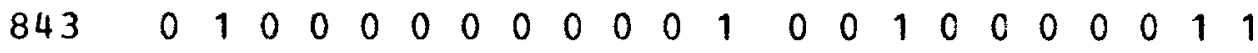

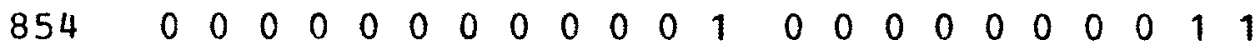

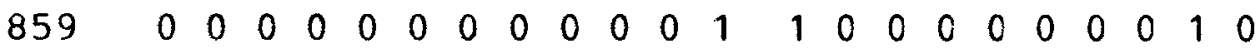

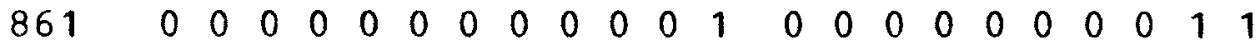

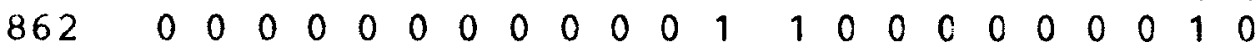

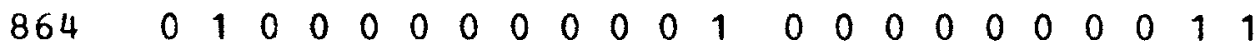

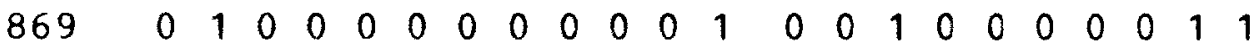

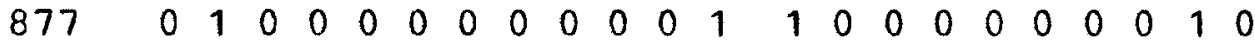

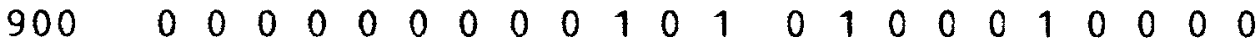
$\begin{array}{lllllllllllllllllllllll}911 & 0 & 1 & 1 & 0 & 0 & 0 & 0 & 0 & 0 & 0 & 0 & 0 & 0 & 0 & 1 & 0 & 0 & 0 & 0 & 0 & 1 & 0\end{array}$

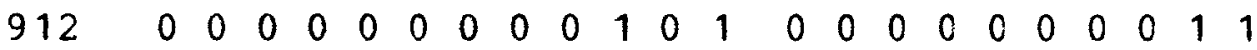

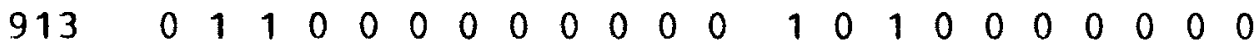
$\begin{array}{lllllllllllllllllllllll}914 & 0 & 1 & 1 & 1 & 1 & 0 & 0 & 0 & 0 & 0 & 0 & 0 & 1 & 1 & 1 & 0 & 0 & 0 & 0 & 0 & 1 & 0\end{array}$ $\begin{array}{lllllllllllllllllllllll}915 & 0 & 0 & 0 & 0 & 0 & 0 & 0 & 0 & 0 & 0 & 0 & 1 & 1 & 0 & 0 & 0 & 0 & 0 & 0 & 0 & 1 & 0\end{array}$ $\begin{array}{lllllllllllllllllllllll}916 & 0 & 0 & 0 & 0 & 0 & 0 & 0 & 0 & 0 & 1 & 0 & 1 & 0 & 0 & 0 & 0 & 0 & 0 & 0 & 0 & 1 & 0\end{array}$

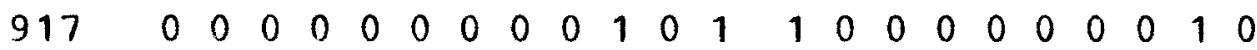

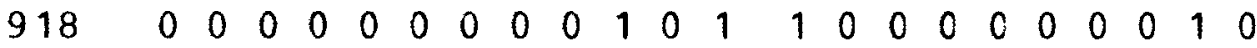

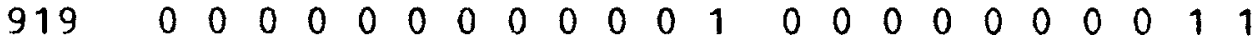

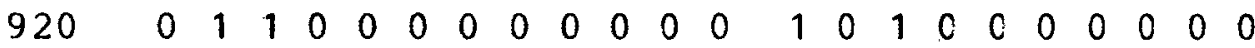


OCCU- PAYSICAL CAPACITIES WORKING CONDITIONS

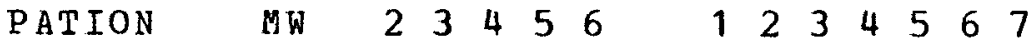

\begin{tabular}{|c|c|c|c|c|c|c|c|c|c|c|c|c|}
\hline 1 & 1.0 & 0 & 0 & 1 & 0 & 1 & 1 & 0 & 0 & 0 & 0 & 0 \\
\hline 4 & 1.0 & 0 & 0 & 0 & 1 & 0 & 1 & 0 & 0 & 0 & 0 & 0 \\
\hline 6 & 1.0 & 0 & 0 & 0 & 1 & 0 & 1 & 0 & 0 & 0 & 0 & 0 \\
\hline 8 & 2.0 & 0 & 0 & 0 & 1 & 1 & 1 & 0 & 0 & 0 & 0 & 0 \\
\hline 10 & 1.6 & 0 & 0 & 0 & 1 & 0 & 1 & 0 & 0 & 0 & 0 & 0 \\
\hline 101 & 1.4 & 0 & 0 & 0 & 1 & 1 & 1 & 0 & 0 & 0 & 0 & 0 \\
\hline 102 & 1.6 & 0 & 0 & 1 & 0 & 1 & 1 & 0 & 0 & 0 & 0 & 0 \\
\hline 105 & 1.8 & 0 & 0 & 1 & 1 & 1 & 1 & 0 & 0 & 0 & 0 & 0 \\
\hline 108 & 1.5 & 0 & 0 & 1 & 0 & 1 & 1 & 0 & 0 & 0 & 0 & 0 \\
\hline 109 & 1.6 & 0 & 0 & 1 & 0 & 1 & 1 & 0 & 0 & 0 & 0 & 0 \\
\hline 111 & 1.8 & 0 & 0 & 1 & 0 & 1 & 1 & 0 & 0 & 0 & 0 & 0 \\
\hline 114 & 1.0 & 0 & 0 & 1 & 1 & 0 & 1 & 0 & 0 & 0 & 0 & 0 \\
\hline 119 & 1.7 & 0 & 0 & 1 & 0 & 1 & 0 & 0 & 0 & 0 & 0 & 0 \\
\hline 121 & 2.0 & 0 & 0 & 1 & 0 & 1 & 1 & 0 & 0 & 0 & 0 & 0 \\
\hline 124 & 3.5 & 0 & 0 & 1 & 0 & 1 & 1 & 0 & 0 & 0 & 0 & 0 \\
\hline 129 & 2.7 & 0 & 0 & 0 & 0 & 0 & 0 & 0 & 0 & 0 & 0 & 0 \\
\hline 131 & 1.5 & 0 & 0 & 0 & 1 & 0 & 1 & 0 & 0 & 0 & 0 & 0 \\
\hline 135 & 1.9 & 0 & 0 & 0 & 1 & 0 & 1 & 0 & 0 & 0 & 0 & 0 \\
\hline 139 & 2.0 & 0 & 0 & 1 & 1 & 1 & 1 & 0 & 0 & 0 & 0 & $c$ \\
\hline 140 & 1.9 & 0 & 0 & 1 & 1 & 1 & 1 & 0 & 0 & 0 & 0 & 0 \\
\hline 141 & 2.0 & 0 & 0 & 1 & 1 & 1 & 1 & 0 & 0 & 0 & 0 & 0 \\
\hline 142 & 2.8 & 0 & 0 & 1 & 1 & 1 & 1 & 0 & 0 & 0 & 0 & 0 \\
\hline 143 & 5.0 & 0 & 0 & 1 & 1 & 1 & 1 & 0 & 0 & 0 & 0 & 0 \\
\hline 144 & 2.8 & 0 & 0 & 1 & 1 & 1 & 1 & 0 & 0 & 0 & 0 & 0 \\
\hline 145 & 1.0 & 0 & 0 & 1 & 1 & 1 & 1 & 0 & 0 & 0 & 0 & 0. \\
\hline 146 & 5.0 & 0 & 0 & 1 & 1 & 1 & 1 & 0 & 0 & 0 & 0 & 0 \\
\hline 147 & 2.0 & 0 & 0 & 1 & 1 & 1 & 1 & 0 & 0 & 0 & 0 & 0 \\
\hline 148 & 2.2 & 0 & 0 & 1 & 0 & 1 & 1 & 0 & 0 & 0 & 0 & 0 \\
\hline 153 & 1.3 & 0 & 0 & 0 & 1 & 0 & 1 & 0 & 0 & 0 & 0 & 0 \\
\hline 171 & 1.4 & 0 & 0 & 1 & 0 & 1 & 1 & 0 & 0 & 0 & 0 & 0 \\
\hline 172 & 2.3 & 0 & 0 & 1 & 0 & 1 & 1 & 0 & 0 & 0 & 0 & 0 \\
\hline 174 & 1.0 & 0 & 0 & 0 & 1 & 1 & 1 & 0 & 0 & 0 & 0 & 0 \\
\hline 176 & 1.4 & 0 & 0 & 1 & 1 & 0 & 1 & 0 & 0 & 0 & 0 & 0 \\
\hline 182 & 1.0 & 0 & 0 & 1 & 0 & 1 & 1 & 0 & 0 & 0 & 0 & 0 \\
\hline 183 & 1.9 & 0 & 0 & 1 & 1 & 1 & 0 & 0 & 0 & 0 & 0 & 0 \\
\hline 186 & 1.0 & 0 & 0 & 0 & 1 & 1 & 1 & 0 & 0 & 0 & 0 & 0 \\
\hline 188 & .0 & 0 & 0 & 1 & 0 & 1 & 1 & 0 & 0 & 0 & C & 0 \\
\hline 191 & 2.0 & 0 & 0 & 0 & 1 & 1 & 1 & 0 & 0 & 0 & 0 & 0 \\
\hline 192 & 1.4 & 0 & 0 & 0 & 1 & 0 & 1 & 0 & 0 & 0 & 0 & 0 \\
\hline 195 & 2.8 & 1 & 1 & 1 & 0 & 1 & 1 & 0 & 0 & 0 & 0 & 0 \\
\hline
\end{tabular}




\begin{tabular}{|c|c|c|c|c|c|c|c|c|c|c|c|c|c|}
\hline OCCU - & PHY SICAL & & AP & $A C$ & IT & IES & & RK & IN & & & & ITIONS \\
\hline PATION & MW & 2 & 3 & 4 & 5 & 6 & 1 & 2 & 2 & 4 & & & \\
\hline 196 & 2.0 & 0 & 0 & 1 & 0 & 1 & 1 & 0 & 0 & 0 & 0 & 0 & 0 \\
\hline 198 & 1.8 & 0 & 0 & 1 & 0 & 1 & 1 & 0 & 0 & 0 & 0 & 0 & 0 \\
\hline 199 & 1.3 & 0 & 0 & 1 & 0 & 1 & 1 & 0 & 0 & 0 & 0 & 0 & 0 \\
\hline 201 & 1.4 & 0 & 0 & 1 & 0 & 1 & 1 & 0 & 0 & 0 & 0 & 0 & 0 \\
\hline 203 & 1.6 & 0 & 0 & 1 & 0 & 1 & 1 & 0 & 0 & 0 & 0 & 0 & 0 \\
\hline 212 & 3.2 & 0 & 0 & 1 & 0 & 0 & 1 & 0 & 0 & 0 & 0 & 0 & 0 \\
\hline 214 & 1.8 & 0 & 0 & 1 & 0 & 1 & 1 & 0 & 0 & 0 & 0 & 0 & 0 \\
\hline 223 & 2.0 & 0 & 0 & 1 & 1 & 1 & 1 & 0 & 0 & 0 & 0 & 0 & 0 \\
\hline 232 & 1.0 & 0 & 0 & 1 & 1 & 1 & 1 & 0 & 0 & 0 & 0 & 0 & 0 \\
\hline 234 & 1.4 & 0 & 0 & 1 & 0 & 1 & 1 & 0 & 0 & 0 & 0 & 0 & 0 \\
\hline 241 & 2.0 & 0 & 0 & 1 & 0 & 1 & 1 & 0 & 0 & 0 & 0 & 0 & 0 \\
\hline 249 & 1.5 & 0 & 0 & 1 & 0 & 1 & 1 & 0 & 0 & 0 & 0 & 0 & 0 \\
\hline 307 & 1.5 & 1 & 0 & 0 & 1 & 0 & 1 & 0 & 0 & 0 & 0 & 0 & 0 \\
\hline 312 & 2.3 & 0 & 0 & 1 & 1 & 0 & 0 & 0 & 0 & 0 & 0 & 0 & 0 \\
\hline 314 & 2.0 & 0 & 0 & 0 & 1 & 0 & 1 & 0 & 0 & 0 & 0 & 0 & 0 \\
\hline 325 & 2.0 & 0 & 0 & 1 & 1 & 0 & 1 & 0 & 0 & 0 & 0 & 0 & 0 \\
\hline 331 & 1.5 & 0 & 0 & 1 & 1 & 1 & 1 & 0 & 0 & 0 & 0 & 0 & 0 \\
\hline 338 & 1.8 & 0 & 0 & 0 & 1 & 0 & 0 & 0 & 0 & 0 & 0 & 0 & 0 \\
\hline 339 & 1.7 & 0 & 0 & 1 & 1 & 0 & 1 & 0 & 0 & 0 & 0 & 0 & 0 \\
\hline 403 & 2.0 & 0 & 0 & 0 & 1 & 1 & 1 & 0 & 0 & 0 & 0 & 0 & 0 \\
\hline 405 & 2.0 & 0 & 0 & 0 & 1 & 0 & 0 & 0 & 0 & 0 & 0 & 0 & 0 \\
\hline 412 & 2.3 & 0 & 0 & 1 & 1 & 0 & 1 & 0 & 0 & 0 & 0 & 0 & 0 \\
\hline 413 & 5.4 & 0 & 0 & 1 & 0 & 0 & 1 & 0 & 1 & 0 & 0 & 0 & 0 \\
\hline 414 & 2.0 & 0. & 0 & 1 & 0 & 0 & 1 & 0 & 0 & 0 & 0 & 0 & 0 \\
\hline 415 & 2.0 & 0 & 0 & 1 & 1 & 0 & 1 & 0 & 0 & 0 & 0 & 0 & 0 \\
\hline 416 & 7.7 & 0 & 0 & 1 & 0 & 1 & 1 & 0 & 0 & 0 & 0 & 0 & 0 \\
\hline 417 & 7.4 & 0 & 0 & 1 & 0 & 0 & 1 & 0 & 0 & 0 & 0 & 0 & 0 \\
\hline 419 & 3.1 & 0 & 0 & 1 & 0 & 0 & 1 & 0 & 0 & 0 & 0 & 0 & 0 \\
\hline 431 & 2.3 & 0 & 0 & 1 & 1 & 1 & 1 & 0 & 0 & 0 & 0 & 0 & 0 \\
\hline 433 & 2.0 & 0 & 0 & 1 & 1 & 0 & 1 & 0 & 0 & 0 & 0 & 0 & 0 \\
\hline 451 & 2.0 & 0 & 0 & 1 & 0 & 1. & 1 & 0 & 0 & 0 & 0 & 0 & 0 \\
\hline 452 & 3.0 & 0 & 0 & 1 & 0 & 1 & 1 & 0 & 1 & 1 & 0 & 0 & 0 \\
\hline 453 & 3.5 & 0 & 0 & 1 & 0 & 0 & 1 & 0 & 0 & 0 & 0 & 0 & 0 \\
\hline 454 & 5.0 & 1 & 1 & 1 & 0 & 0 & 1 & 0 & 0 & 0 & 0 & 1 & 0 \\
\hline 455 & 5.0 & 0 & 0 & 1 & 0 & 1 & 1 & 0 & 0 & 0 & 0 & 1 & 1 \\
\hline 456 & 2.8 & 0 & 0 & 1 & 0 & 0 & 1 & 0 & 0 & 0 & 0 & 0 & 0 \\
\hline 457 & 1.9 & 0 & 0 & 1 & 1 & 0 & 1 & 0 & 0 & 0 & 0 & 0 & 0 \\
\hline 459 & 2.8 & 0 & 0 & 1 & 0 & 0 & 1 & 0 & 0 & 0 & 0 & 0 & 0 \\
\hline 510 & 2.3 & 0 & 0 & 1 & 0 & 1 & 1 & 0 & 0 & 0 & 0 & 0 & 0 \\
\hline 520 & 2.0 & 0 & 0 & 0 & 1 & 1 & 1 & 0 & 0 & 0 & 0 & 0 & 0 \\
\hline
\end{tabular}




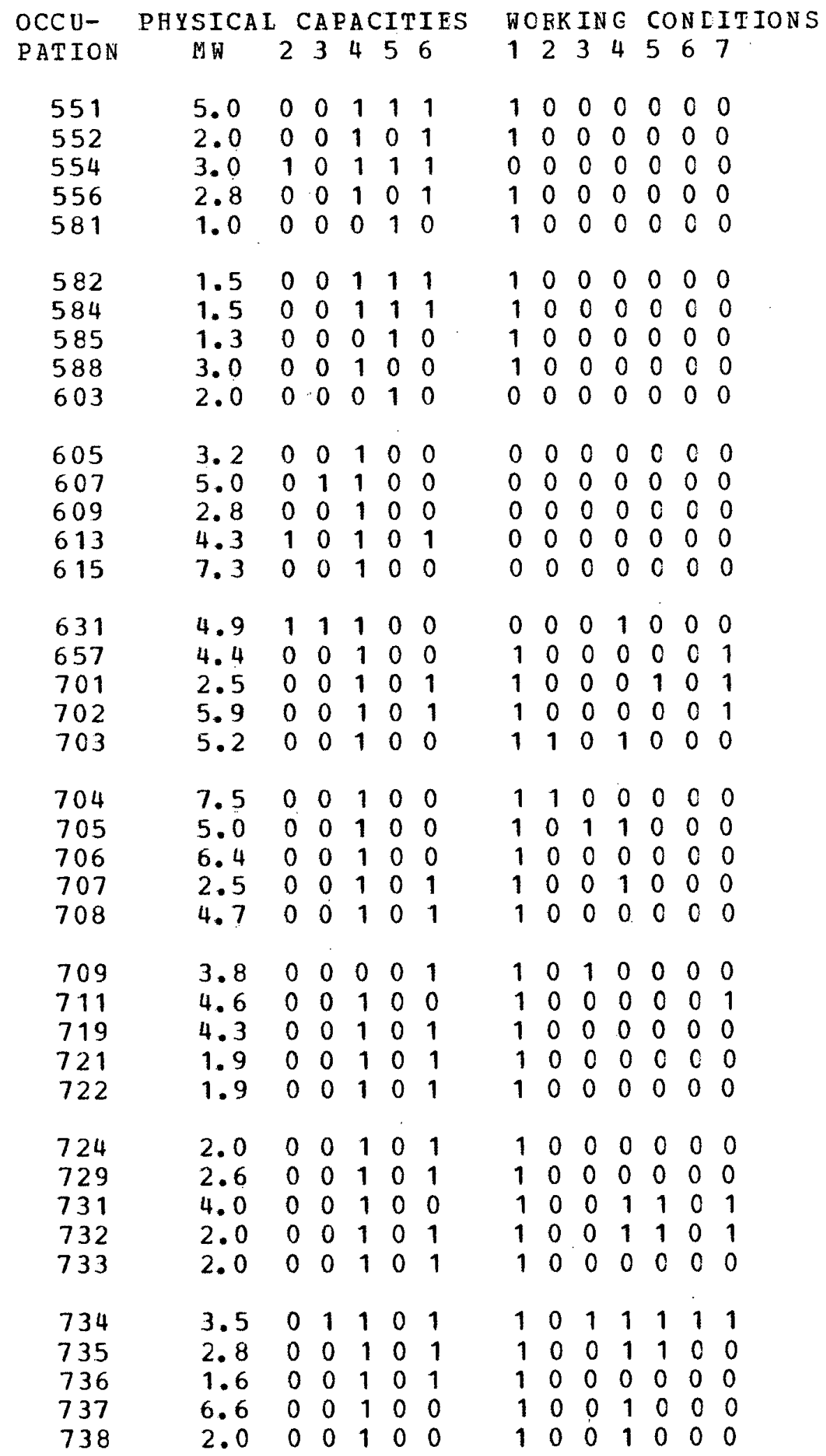




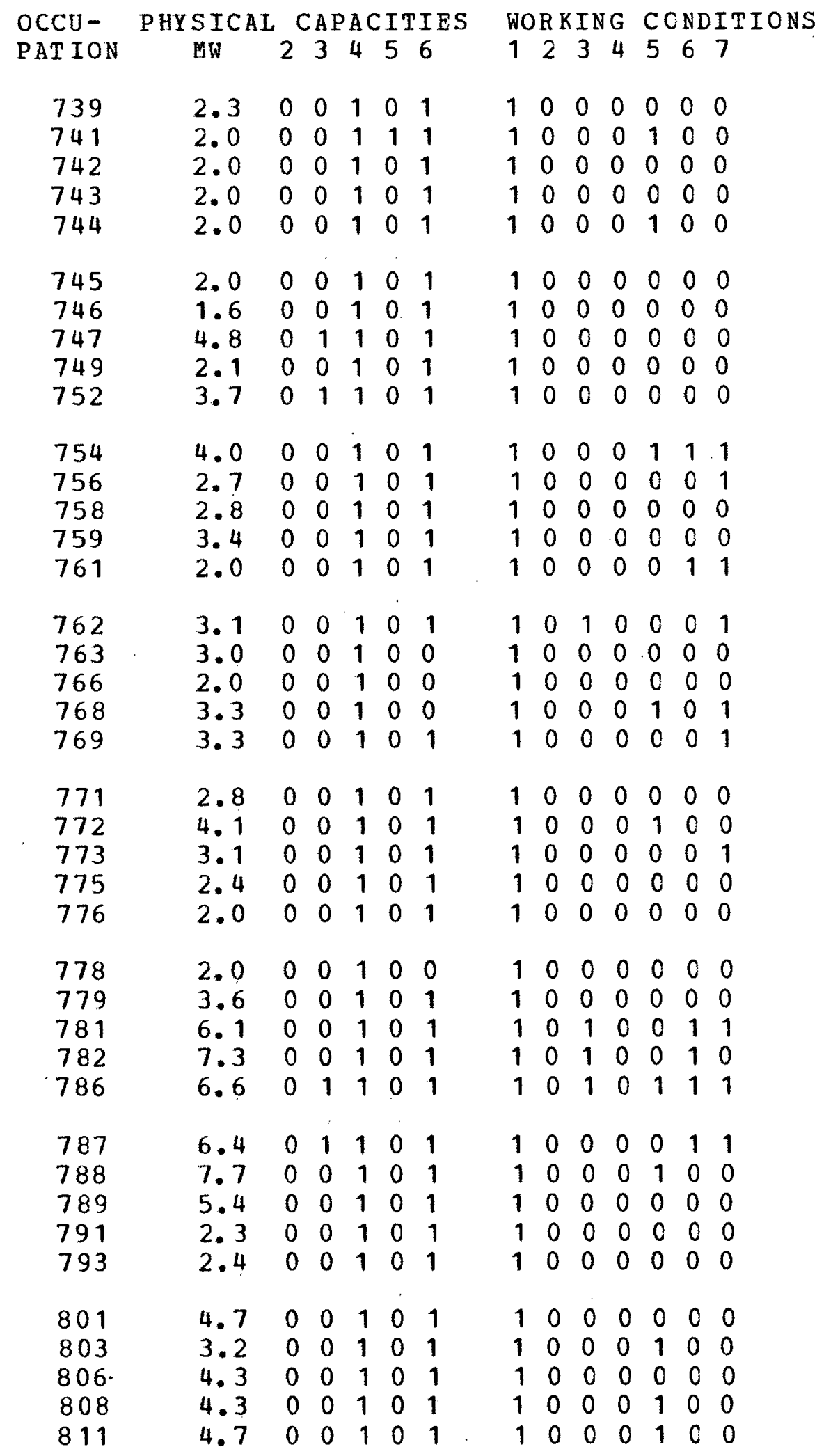




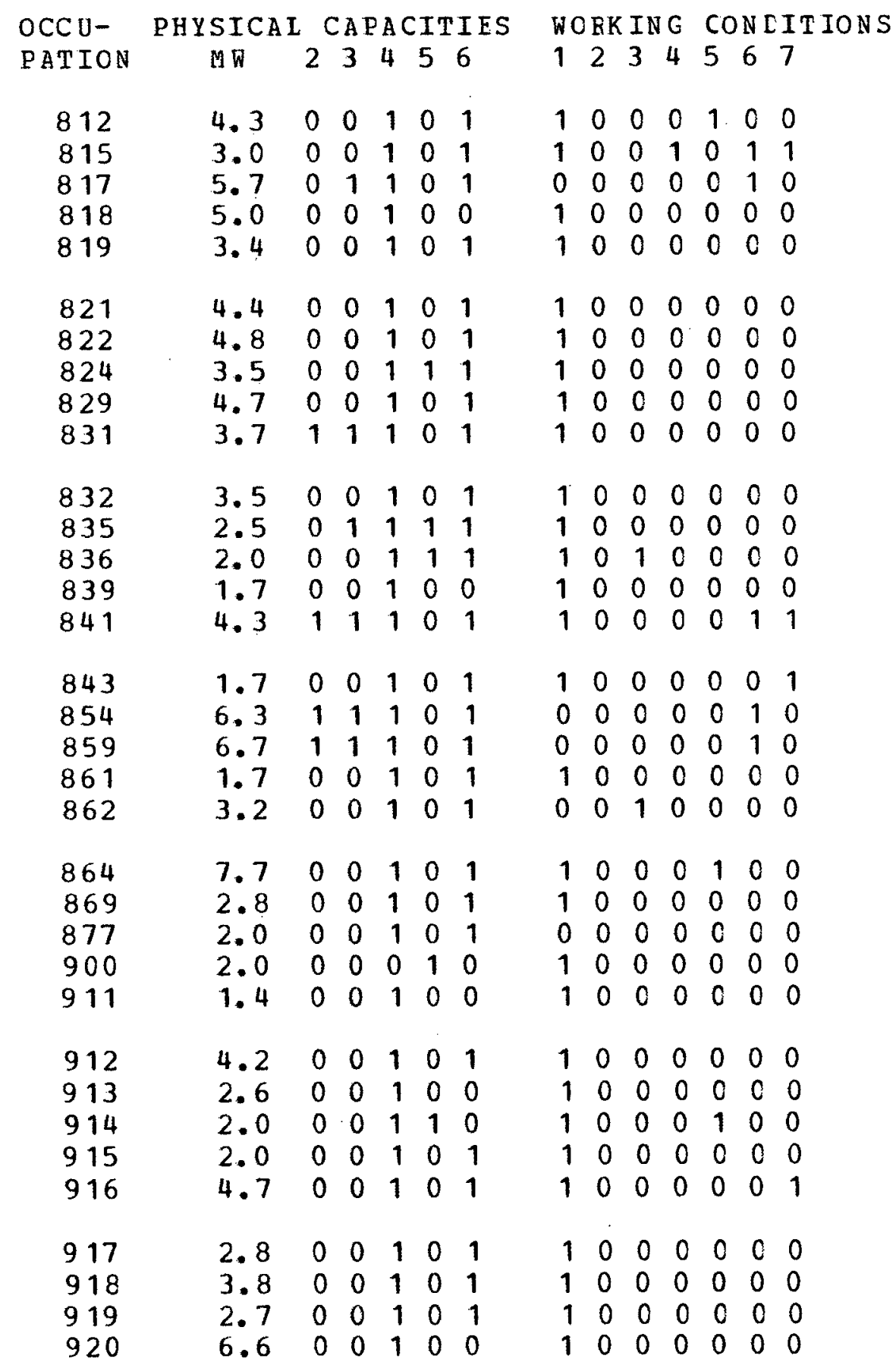


Appendix C: Occupational Code by Occupational Class Title

Occ.

Code Occupational

No. Class Title

Division 1 -- MANAGERIAL OCCUPATIONS

001 Advertising managers

002 Credit managers

004 Sales managers

005 Delivery managers

006 Office managers

$007 \quad$ Postmasters

008 Purchasing agents and buyers

010 Owners and managers, n.e.s.

Division 2 -- PROFESSIONAL AND TECHNICAL OCCUPATIONS

101 Civil engineers

102 Mechanical engineers

104 Industrial engineers

105 Electrical engineers

107 Mining engineers

108 Chemical engineers

109 Professional engineers, n.e.s.

111 Chemists

112 Geologists

114 Physicists

119 Physical scientists, n.e.s.

121 Biological scientists

124 Veterinarians

129 Agricultural professionals, n.e.s.

131 Professors and college principals

135 School teachers

139 Teachers and instructors, n.e.s.

140 Physicians and surgeons

141 Dentists

142 Nurses, graduate

143 Nurses-in-training

144 Physical and occupational therapists

145 Optometrists

146 0steopaths and chiropractors

147 Pharmacists

148 Medical and dental technicians

149 Other health professionals 
Occ.

Code Occupational

No. Class Title

151 Judges and magistrates

153 Lawyers and notaries

161 Clergymen and priests, n.o.r.

163 Nuns and brothers, n.o.r.

169 Religious workers, n.o.r.

17 Artists, commercial

172 Artists (except commercial), art teachers

174 Authors, editors and journalists

176 Musicians and music teachers

181 Architects

182 Draughtsmen

183 Surveyors

184 Actuaries and stisticians

186 Economists

187 Computer programmers

188 Accountants and auditors

191 Dietitians

192 Social welfare workers

194 Librarians

195 Interior decorators and window dressers

196 Photographers

198 Science and engineering technicians, n.e.s.

199 Professional occupations, n.e.s.

Division 3 -- CLERICAL OCCUPATIONS

201 Bookkeepers and cashiers

203 Office appliance operators

212 Stock clerks and storekeepers

214 Shipping and receiving clerks

221 Baggagemen and expressmen, transport

223 Ticket, station and express agents, transport

232 Stenographers

234 Typists and clerk-typists

241 Attendants, doctors' and dentists' offices

249 Clerical occupations, n.e.s. 


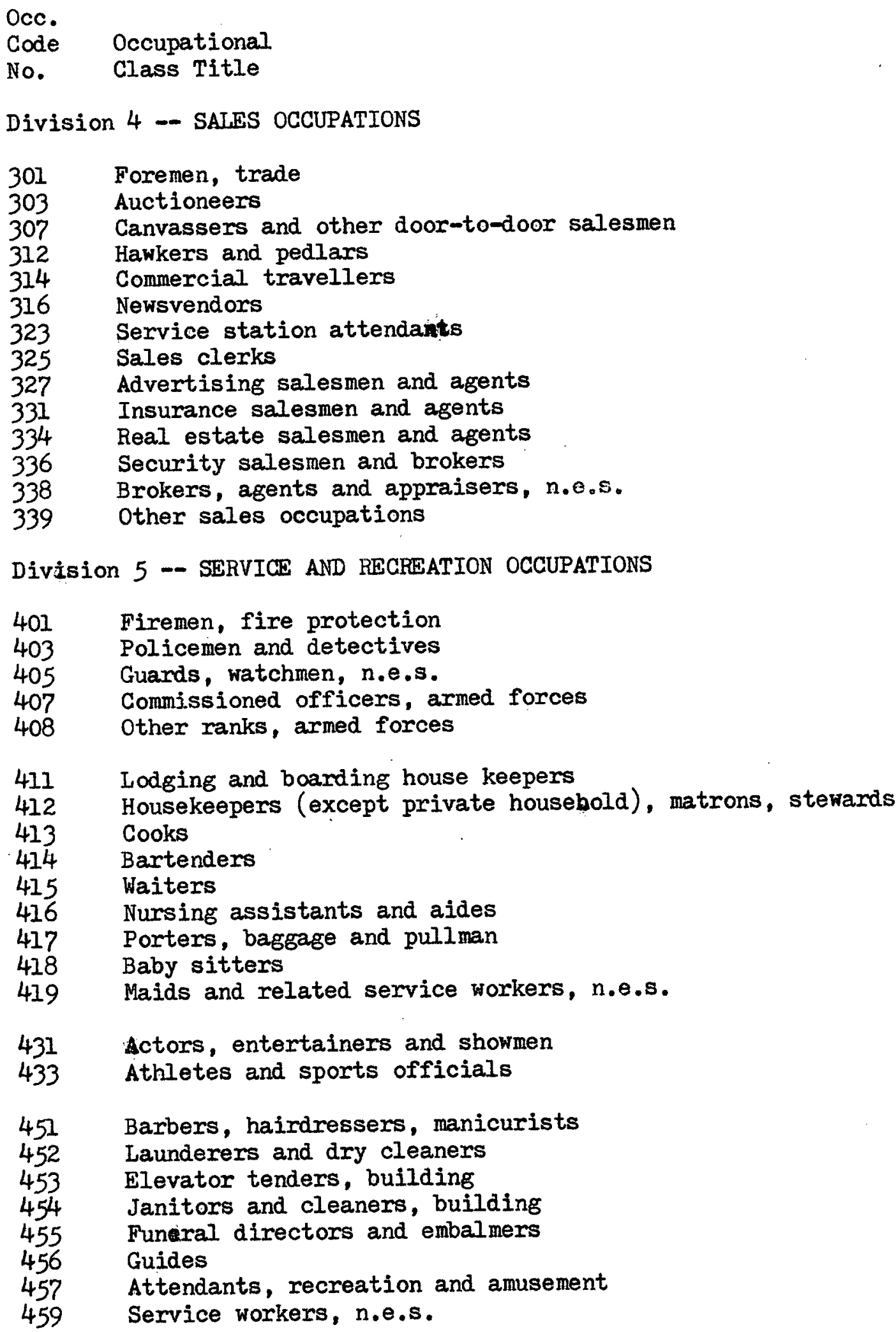


Occ.

Code Occupational

No. Class Title

Division 6 -- TRANSPORT AND COMMUNICATION OCCUPATIONS

510 Inspectors and foremen

520 Air pilots, navigators and flight engineers

531 Locomotive engineers

532 Locomotive firemen

534 Conductors, railroad

535 Brakemen, railroad

537 Switchmen and signalmen

541 Deck officers, ship

543 Engineering officers, ship

545 Deck ratings (ship), barge crews and boatmen

547 Engine-room ratings, firemen and oilers (ship)

551 Bus drivers

552 Taxi drivers and chauffeurs

554 Driver-salesmen

556 Truck drivers

561 Operators, electric street railway

563 Teamsters

569 Transport occupations, n.e.s.

570 Inspectors and foremen, communication

581 Radio and television announcers

582 Radio and television equipment operators

584 Telephone operators

585 Telegraph operators

587 Postmen and mail carriers

588 Messengers

Division 7 - FARMERS AND FARM WORKERS

601 Farmers and stockraisers

603 Farm managers and foremen

605 Farm labourers

607 Gardeners (except farm) and groundskeepers

609 Other agricultural occupations

Division 8 -- LOGGERS AND RELATED WORKERS

611 Logging foremen

613 Forest rangers and cruisers

615 Lumbermen, including labourers in logging 
Occ.

Code Occupational

No. Class Title

Division 9 -- FISHERPEN, TRAPPERS AND HUNTERS

631 Fishermen

633 Trappers and hunters

Division 10 -- MINERS, QUARRYMEN AND RELATED WORKERS

651 Foremen -- mine, quarry, petrol. well

652 Prospectors

653 Timbermen

654 Miners, n.e.s.

655 Millmen

656 Well drillers and related workers

657 Labourers, mine

659 Quarriers and related workers, n.e.s.

Division 11 -- GRAFTSMEN, PRODUCTION PROCESS AND RELATED WORKERS

701 Millers of flour and grain

702 Bakers

703 Butchers and meat cutters

704 Meat canners, curers, packers

705 Fish canners, curers, packers

706 Fruit and vegetable canners and packers

707 Milk processors

708 Other food processing occupations

709 Beverage processors

711 Tire and tube builders

713 Vulcanizers

719 Other rubber workers

721 Leather cutters

722 Shoemakers and repairers -- factory, n.e.s.

724 Shoemakers and repairers -- not in factory

729 Other leather products makers

731 Carders, combers and other fibre preparers

732 Spinners and twisters

733 Winders, reelers

734 Weavers

735 Loom fixers and loom preparers

736 Knitters

737 Bleachers and dyers - textile

738 Finishers and calenderers

739 Other textile occupations 
Occ.

Code Occupational

No. Class Title

741 Tailors and tailoresses

742 Dressmakers and seamstresses -- not in factory

743 Furriers

744 Milliners; hat and cap makers

745 Cutters, markers -- textiles; garment and glove leather

746

747

749

Sewers and sewing machine operators, n.e.s.

Upholsterers

751 Carpenters

752 Cabinet and furniture makers -- wood

754 Sawyers

756 Woodworking machine operators, n.e.s.

758 Inspectors, graders, scalers, 1 og and lumber

759 Woodworking occupations, n.e.s.

761 Batch and continuous still operators

762 Roasters, cookers and other heat treaters, chemical

763 Cellulose pulp preparers, n.e.s.

765 Paper makers

766 Paper making occupations, n.e.s.

768 Crushers, millers, calenderers, n.e.s. -- chemical

769 Chemical and related process workers, n.e.s.

771 Compositors and typesetters

772 Pressmen, printing

773 Lithographic and photo-offset occupations

775 Photoengravers

776 Bookbinders

778 Other occupations in bookbinding

779 Printing workers, n.e.s.

781 Furnacemen and heaters, metal

782 Heat treaters, annealers, temperers

783 Rolling mill operators

784 Blacksmiths, hammermen, forgemen

786 Moulders

787 Coremakers

788 Metal drawers and extruders

789 Metal treating occupations, n.e.s.

791 Jewellers and watchmakers

793 Engravers, except photoengravers 
Occ.

Code Occupational

No. Class Title

801 Toolmakers, diemakers

802 Machinists and machine tool setters

803 Filers, grinders, sharpeners

805 Millwrights

806 Fitters and assemblers, n.e.s. -- metal

808 Metalworking machine operators, n.e.s.

810 Plumbers and pipefitters

811 Sheet metal workers

812 Riveters and rivet heaters

813 Boilermakers, platers and structural metal workers

815 Electroplaters, dip platers and related workers

817 Welders and flame cutters

818 Polishers and buffers -- metal

819 Metalworking occupations, n.e.s.

821 Mechanics and repairmen, aircraft

822 Mechanics and repairmen, motor vehicle

824 Mechanics and repairmen, office machine

825 Mechanics and repairmen, railroad equipment

829 Mechanics and repairmen, n.e.s.

831 Electricians, wiremen and electrical repairmen

832 Fitters and assemblers -- electrical and electronics

833 Power station operators

835 Mechanics and repairmen, radio and television receivers

836 Projectionists, motion picture

838 Linemen and servicemen -- telephone, telegraph and power

839 Electrical and electronics workers, n.e.s.

841 Painters (construction and maintenance), paperhangers and glaziers

843 Painters, except construction and maintenance

851 General foremen -- construction

852 Inspectors -- construction

854 Bricklayers, stonemasons, tilesetters

855 Cement and concrete finishers

856 Plasterers and lathers

857 Insulation appliers

859 Construction workers, n.e.s.

861 Lens grinders and polishers; opticians

862 Furnacemen and kilnmen, ceramics and glass

864 Stone cutters and dressers

869 Clay, glass and stone workers, n.e.s. 
Occ.

Code Occupational

No. Class Title

871 Boiler firemen (except ship)

872 Stationary enginemen

873 Motormen (vehicle), except railway

874 Hoistmen, cranemen, derrickmen

875 Riggers and cable splicers, except telephone, telegraph and power

876 Operators of earth-moving and other construction machinery, n.e.s.

877 Materials-handling equipment operators

878 Oilers and greasers -- machinery and vehicles (except ships)

881 Longshoremen and stevedores

883 Warehousemen and freight handlers, n.e.s.

890 Sectionmen and trackmen

900 Foremen, n.e.s.

911 Tobacco preparers and products makers

912 Patternmakers (except paper)

913 Bottlers, wrappers, labelers

914 Paper products makers

915 Photographic processing occupations

916 Tanners and tannery operatives

917 Inspectors, examiners, gaugers, n.e.s. -- metal

918 Inspectors, graders and samplers, n.e.s.

919. Production process and related workers, n.e.s.

Division 12 -- LABOURERS, n.e.s.

920 Labourers, excluding those engaged in agricultural, fishing, logging or mining operations

Division 13 -- OCCUPATION NOT STATED

980 Occupation not stated 